\title{
Children and Young People's Developing Concept of Perceived Value
}

By

Janine Williams

\begin{abstract}
A thesis
submitted to the Victoria University of Wellington in fulfilment of the requirements for the degree of Doctor of Philosophy in Marketing
\end{abstract}

School of Marketing and International Business

Victoria University of Wellington 



\begin{abstract}
This thesis examines value perception as part of the decision to purchase, from the perspective of the child consumer. To date no academic research has defined the concept of value perception from a child's perspective. On the basis of a two stage qualitative investigation with children aged eight to fourteen years, value for children was found to be an important concept in consumer decisions. Even from the age of eight years, evidence emerged that children were quite 'canny' in their purchasing. While value was found to be comprised of benefits and costs of purchase for children from this young age, the nature of these factors and the way they contributed to value perception varied considerably as they grew older. Six distinct dimensions emerged from diaries and a series of in-depth interviews with children. The benefits which were identified were functional value, emotional value, social value and curiosity/novelty value while the costs included both price and risk related factors. The way in which the dimensions were considered was found to vary with age, changing from separate consideration of benefits and costs to a more adult like tradeoff between the two. The emotional value of products was consistently important for children of all ages, sensory response in particular. Several concepts were found to become increasingly complex. Conceptual understanding of quality emerged as children grew older. Branding was found to be central to children's value perceptions despite limited conceptual understanding for very young consumers and the way price was considered changed markedly with age and experience. A conceptual model defining perceived value from a child's perspective is detailed and a series of propositions relating important conditions to perceived value are advanced. A discussion of the findings as they relate to the extant literature is provided along with directions for future research, building on the results of this work. Finally, a discussion of the implications of this work for the field of Marketing is presented.
\end{abstract}




\section{Acknowledgements}

It is a wonderful feeling to be writing my acknowledgements for this thesis. It has been a long journey and many people have contributed along the way.

First and foremost I want to thank my supervisors Professor Peter Thirkell and Professor Nicholas Ashill. Peter has been a constant source of encouragement, guidance and support throughout the process and believed in me from the beginning when I returned to university and changed direction from my earlier Chemistry degree. Nick has also been an inspiring and supportive mentor remaining as my supervisor even when he left Victoria University of Wellington to join the American University of Sharjah. Both these professors made valuable suggestions and questioned me at each step to help improve my work. They are both inspiring teachers and people. They invest their time and energy unselfishly to share their knowledge and help others succeed. I would also like to acknowledge the assistance of Professor Michel Rod in the development of the research approach.

I would like to thank my fellow $\mathrm{PhD}$ students who I have met along the way and who have made the journey so much fun. I would particularly like to thank Dr Nick Thompson, with whom I shared an office and Dr Aaron Gazley. We shared many lunches and laughs together. Dr Kate Daellenbach has also been a great friend and support throughout the process. My fellow $\mathrm{PhD}$ student and colleague in tutoring Lachlan McLaren has been a wonderful friend in more recent times as have my current office mates Suzana Samsudi and Vu Dang. Vu has also generously shared his technical knowledge.

I would like to thank the staff of the School of Marketing and International Business for teaching me, encouraging me and providing me with a scholarship and employment which allowed me to complete this degree.

Finally, this thesis would not have been possible without the support of my family. My husband, Paul has helped me, supported my decision to return to University and loved me throughout, which has not always been easy. My sister Kathryn has been a second 'mum' to our children as well as encouraging me, listening and making me laugh. Our three children Jessie, Ollie and Tim believed in me and came in to university whenever they got the chance. My parents, Dawn and Alan came to Wellington at times when I had exams or deadlines to meet. I would particularly like 
to thank my mum, Dawn who stepped in to help out whenever I needed her. I would like to thank my brother in-law Carl for proof reading my thesis and for generally providing useful philosophies on life. My parents-in-law Bev and Ian were happy to help out whenever they were in Wellington. I also had the support and encouragement of my brother and sister in-law who also were completing postgraduate study. I am so lucky to have such a wonderful family.

Finally all my friends who have helped me along the way - Adele, Kate, Gabe, Tess, Emma, Jan, Sarah, Susie, Russell, Dave and Mark thank you for your friendship! 


\section{Table of Contents}

Chapter 1. Introduction ...............................................................................................1 1

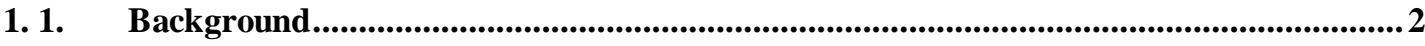

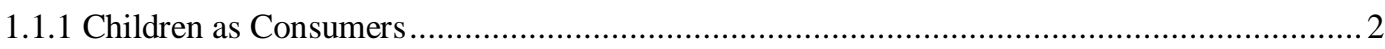

1.1.2 The Perceived Value Concept ........................................................................................... 4

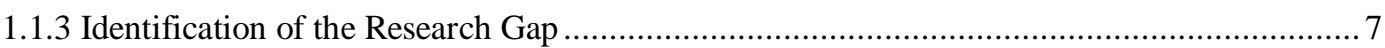

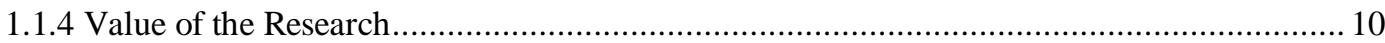

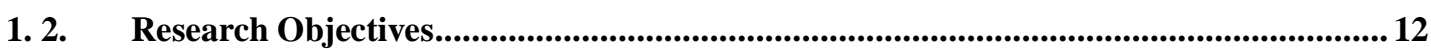

1. 3. Research Overview and Structure of Thesis ...................................................................... 12

Chapter 2. Literature Review ...................................................................... 15

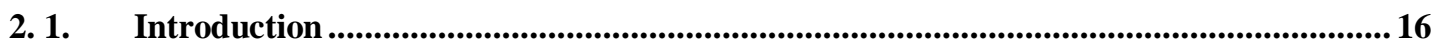

2. 2. Perceived Value ........................................................................................................................ 16

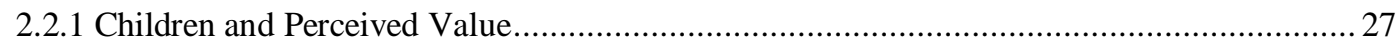

2.2.2 Involvement and Perceived Value................................................................................ 29

2.2.3 Perceived Value, Behavioural Intention and Behaviour ......................................................2 29

2. 3. Perceived Price..........................................................................................................................30

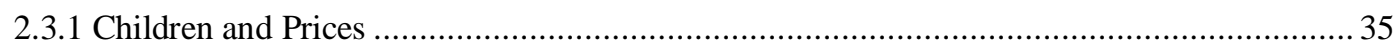

2. 4. Perceived Quality.........................................................................................................39

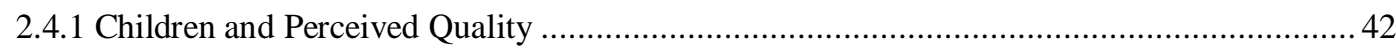

2.5. Children's Use of Product Attributes ....................................................................................44

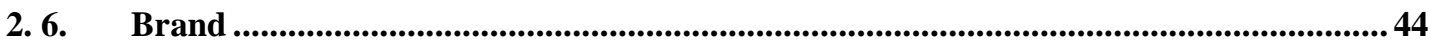

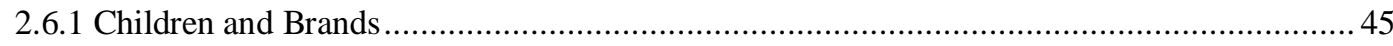

2. 7. Consumer Socialisation Theory ……........................................................................................ 48

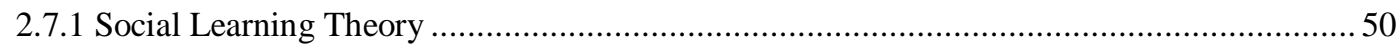

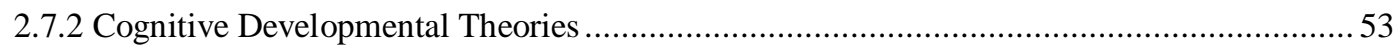

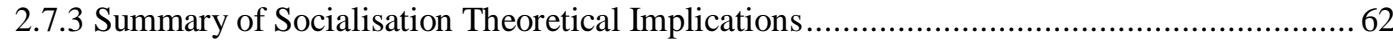

2. 8. Children's Understanding of Economic Concepts ......................................................63 
2.9. Summary of the Literature Review ............................................................................66

Chapter 3. Research Methodology ................................................................69

3. 1. Introduction .........................................................................................................................70

3. 2. Research Question and Objectives.........................................................................................70

3. 3. Research Paradigm ................................................................................................................71

3. 4. Grounded Theory .............................................................................................................73

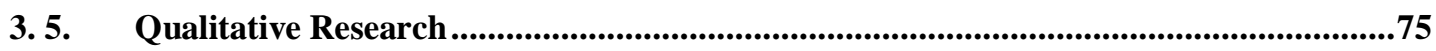

3. 6. Considerations for Researching Children …...................................................................76

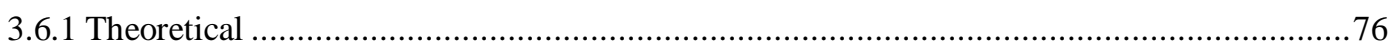

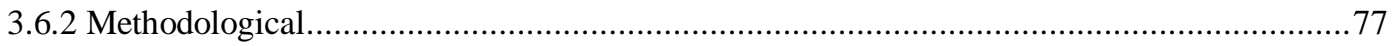

3. 7. Qualitative Research Design .........................................................................................78

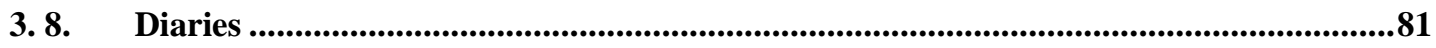

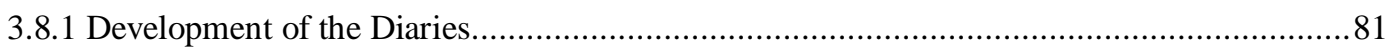

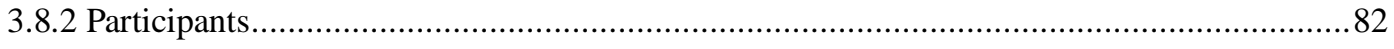

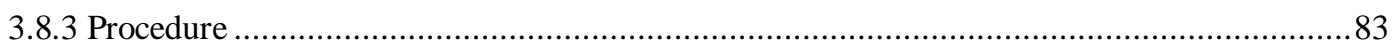

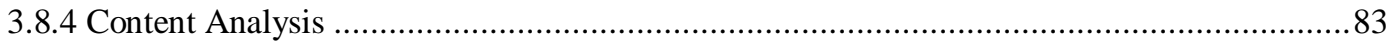

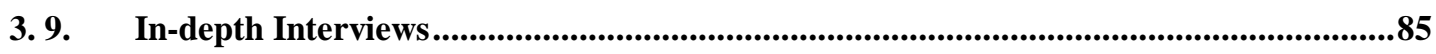

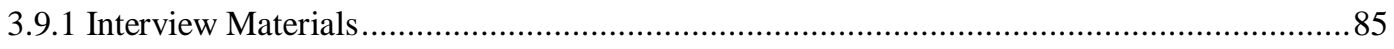

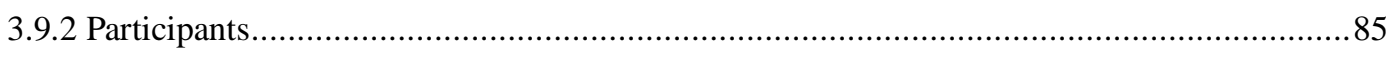

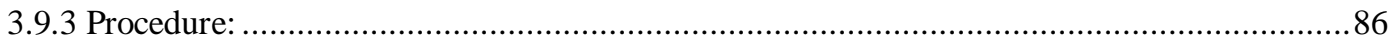

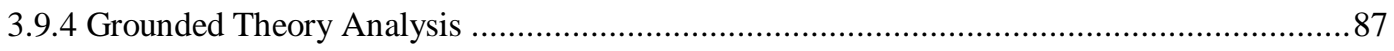

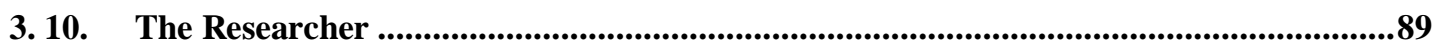

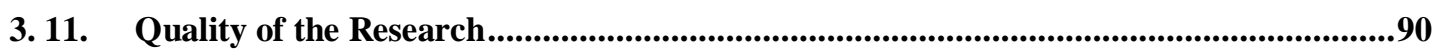

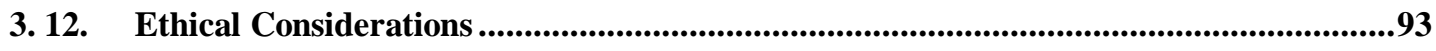

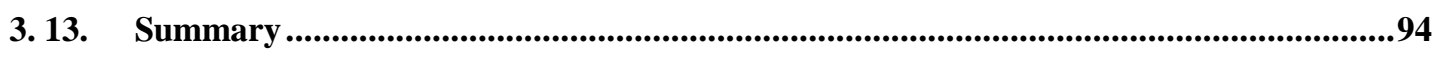

Chapter 4. Stage 1 - Diary Study ................................................................... 95 


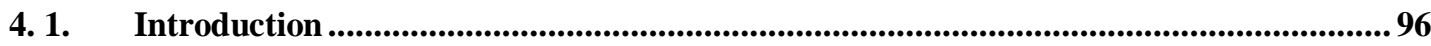

4. 2. Participant Details ...............................................................................................................96

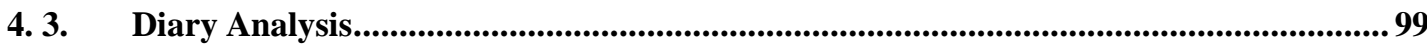

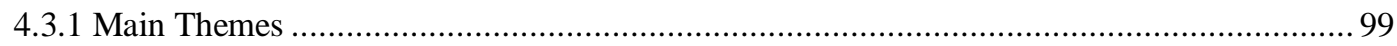

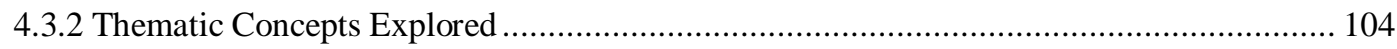

4. 4. Age Related Changes in Purchase Value ................................................................... 116

4. 5. Summary

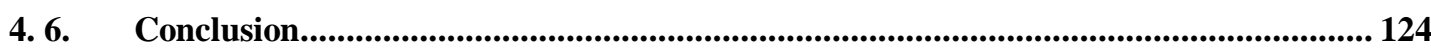

Chapter 5. Stage 2 - In-depth Interviews ................................................... 126

5.1. Introduction ............................................................................................................................ 127

5. 2. Participant Details ...................................................................................................... 128

5.3. Overview of Results ............................................................................................................. 130

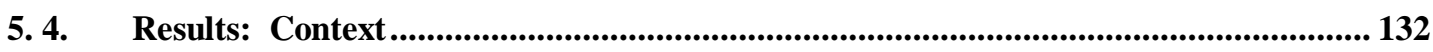

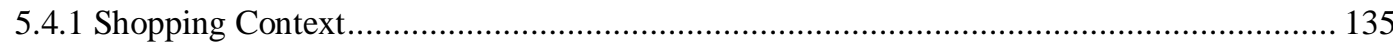

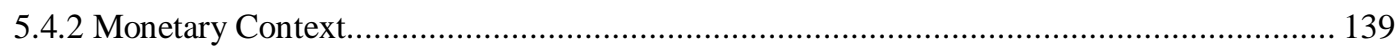

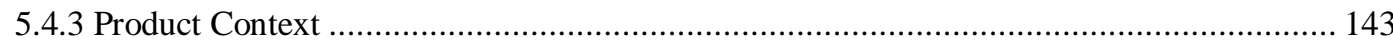

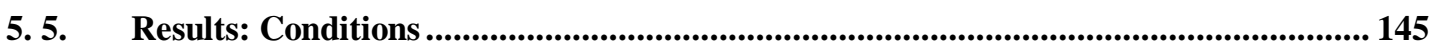

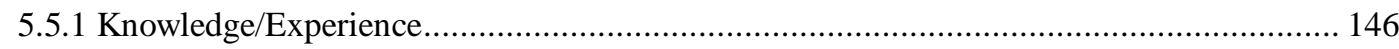

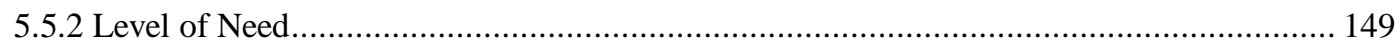

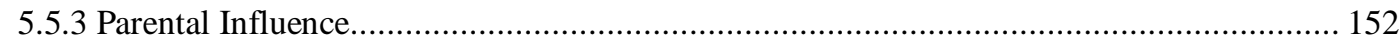

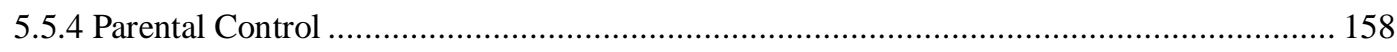

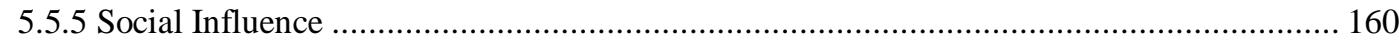

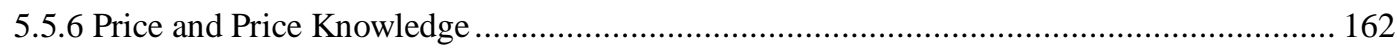

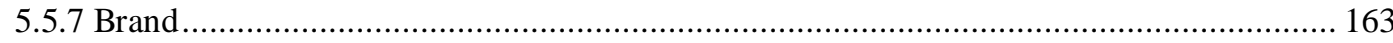

5. 6. Results: Children's Perceived Value .................................................................................. 166

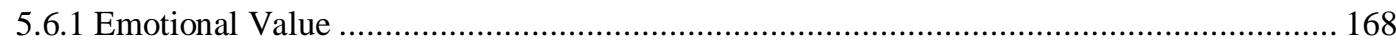

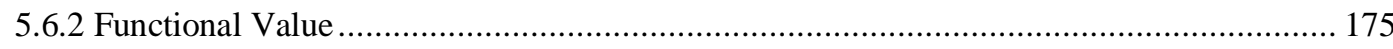


5.6.4 Curiosity/ Novelty Value ........................................................................................... 192

5.6.5 Perceived Price .................................................................................................... 195

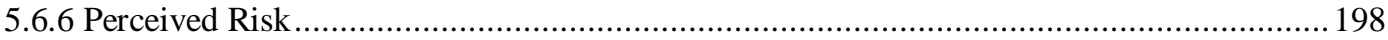

5.6.7 Age Related Changes in Perceived Value ................................................................... 201

5. 7. Results: Consequences .......................................................................................204

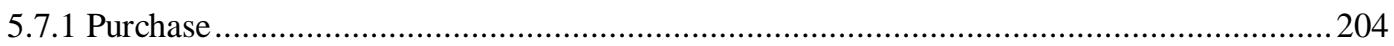

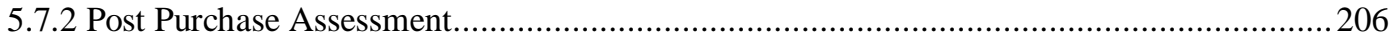

5. 8. Conceptual Framework of Results...............................................................................208

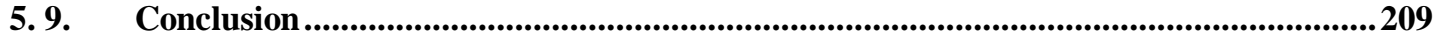

Chapter 6. Discussion and Propositions ......................................................... 211

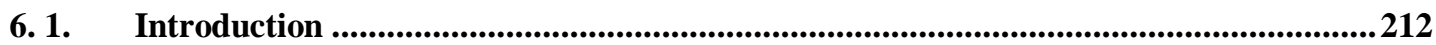

6. 2. The Two Stages of the Research ................................................................................213

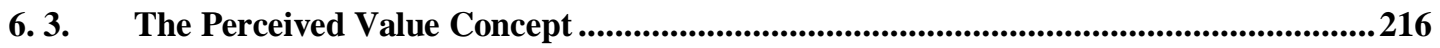

6.3.1 Benefits and Costs ........................................................................................ 217

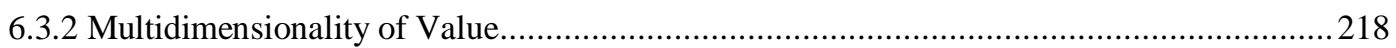

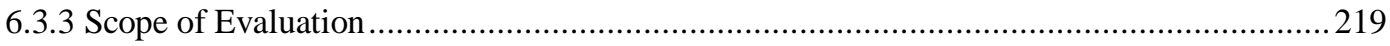

6.3.4 Interrelatedness of Value Dimensions ................................................................. 220

6. 4. Age Related Changes in Value Perception..................................................................221

6. 5. Contexts and Conditions Influencing Perceived Value ...........................................224

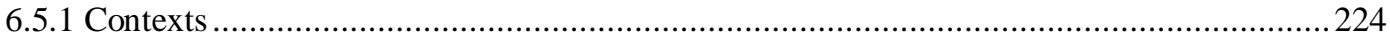

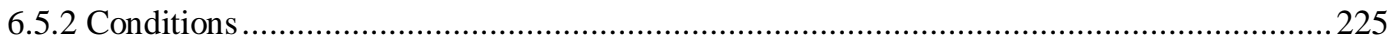

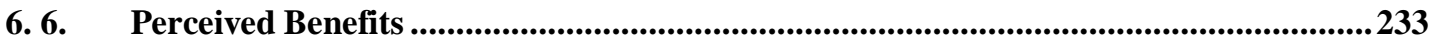

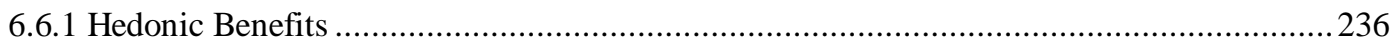

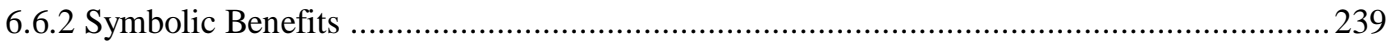

6.6.3 Utilitarian Benefits ........................................................................................... 242

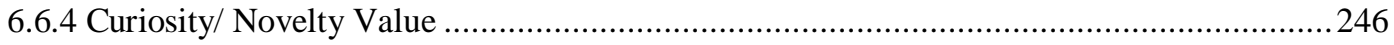




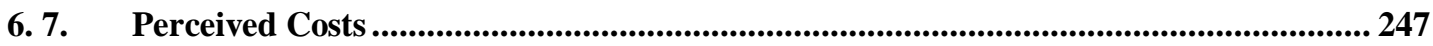

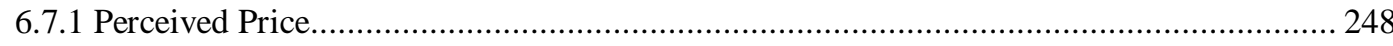

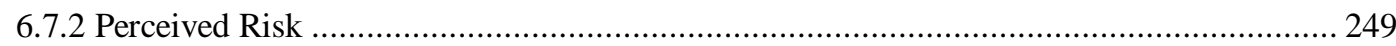

6. 8. Consequences of Perceived Value....................................................................................... 251

6.8.1 Purchase

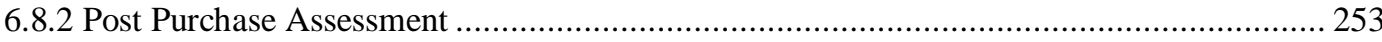

6. 9. Summary

Chapter 7. Implications and Conclusions .....................................................255

$7.1 \quad$ Introduction............................................................................................................................ 256

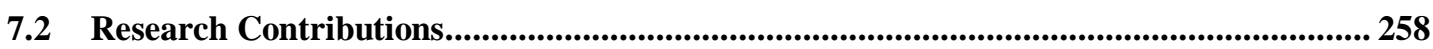

7.3 Implications for Practitioners ................................................................................................ 261

7.4 Implications for Policy ......................................................................................................... 263

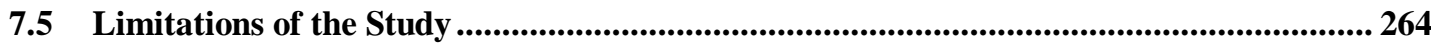

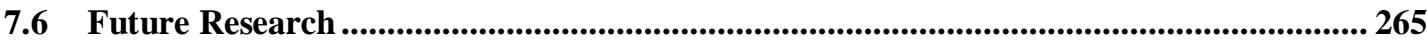

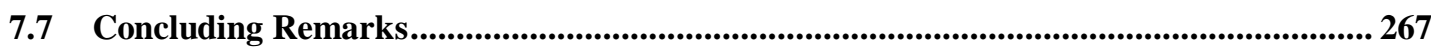

References................................................................................................................................ 268

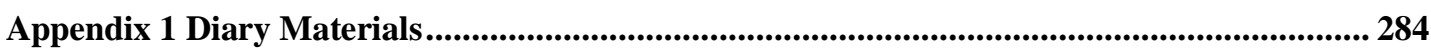

Appendix 2 In-depth Interview Materials........................................................................................ 297

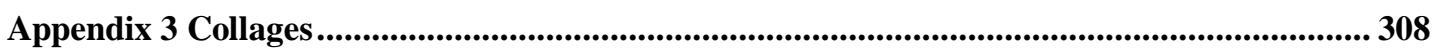

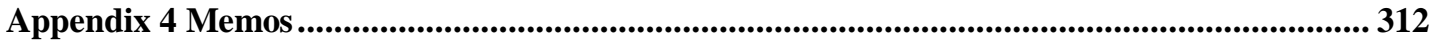




\section{List of Figures}

Figure 2-1 Conceptual Model of Price Effect on Perceived Value (Dodds, et al. 1991).................. 18

Figure 2-2 Consumer Socialisation Model (Ward, et al., 1977, p. 29) ..........................................50

Figure 5-1 Children's Perceptions of Value .............................................................. 208

Figure 6-1 The Grey Benefit Scheme, (Young \& Feigin, 1975)..........................................2220

Figure 6-2 Conditions Influencing Perceived Value ....................................................... 226

Figure 6-3 Conditions Influencing Perceived Value and Perceived Benefits ................................234

Figure 6-4 Conditions Influencing Perceived Value, Perceived Benefits and Costs.....................248

Figure 6-5 Conceptual Model of the Antecedents and Consequences of Perceived Value ..............252 


\section{List of Tables}

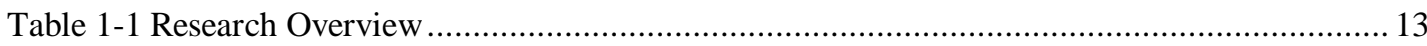

Table 2-1 Studies Using a Single Dimensional Approach to Perceived Value ................................... 19

Table 2-2 Studies Using a Multidimensional Approach to Perceived Value ......................................22

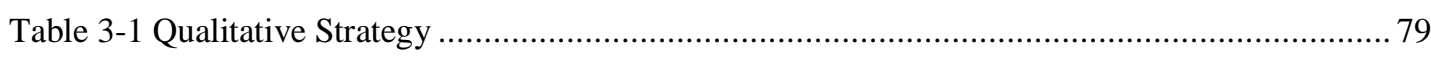

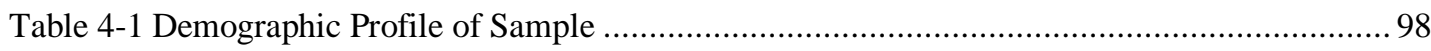

Table 4-2 Meta Matrix for Cross Case Analysis of Themes Identified in Diaries............................. 100

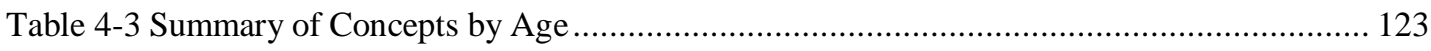

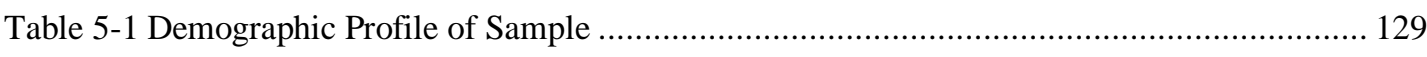

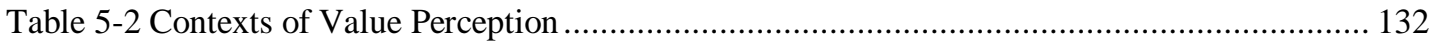

Table 5-3 Two-Variable Case-Ordered Matrix of Age and Context of Value Perception ................. 134

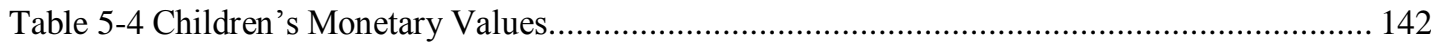

Table 5-5 The Conditions Influencing Perceived Value for Children ........................................... 146

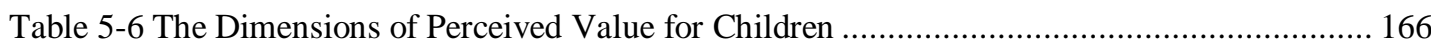

Table 5-7 The Emotional Value of Products for Children ............................................................. 169

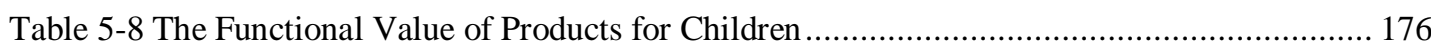

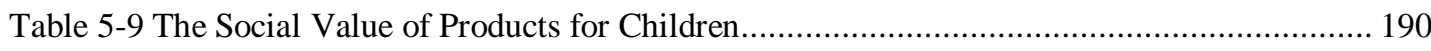

Table 5-10 The Curiosity/ Novelty Value of Products for Children ................................................. 193

Table 5-11 The Perceived Price of Products for Children .............................................................. 195

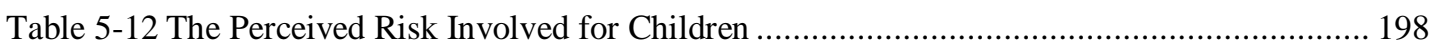

Table 5-13 Frequency of Perceived Risk in In-depth Interviews ..................................................... 199

Table 5-14 A Two Variable Case Ordered Matrix of Perceived Value by Age ............................... 201

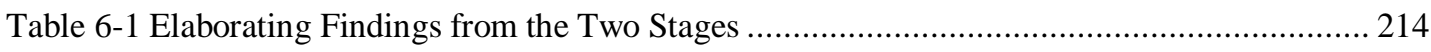

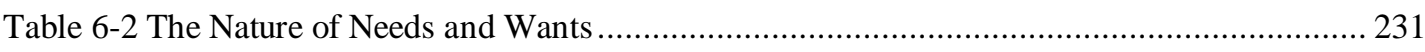


Chapter 1. Introduction 


\section{1. Background}

The concepts of price, quality and perceived value have been widely researched in the field of marketing (e.g. Li \& Green, 2011; Lin, Sher, \& Shih, 2005; Zeithaml, 1988). This is due to the importance of these concepts in determining shopping behaviour and willingness to purchase.

Based on research regarding children's changing conceptualisation of economics and price (Berti \& Bombi, 1988; Fox \& Kehret-Ward, 1985, 1990; Strauss, 1952), the initial motivation for this research came from a desire to investigate the changing influence of price cue on children's perceptions of value. However, it soon became apparent that value is an elusive concept and even with adults the definition and measurement was still being refined (Lin, et al., 2005). No research had been conducted about how children perceived value, which appeared to be a significant gap in our understanding of children as consumers.

In this chapter the concept of perceived value for children is introduced. This is followed by the contributions of the research, the research objectives and finally an overview of the research and thesis structure.

\subsubsection{Children as Consumers}

Investigation of child consumers from a marketing perspective is an important direction for research, and many areas have been highlighted as requiring further study (John, 1999). On the basis of children's increased spending power and increase in actual purchasing (Anonymous, 2005; Dotson \& Hyatt, 2005; Lindstrom, 2003; Martensen \& Tufte, 2002; McNeal, 2007), as well as the rapid changes that are occurring in both households, media exposure and children's consumer behaviour generally (Lindstrom, 2003), current and extensive research is important. Clearly it is necessary to understand children's consumer behaviour in order to facilitate marketing to this intriguing group in a manner which is both ethical and effective. At the outset of the current research, empirical research of this rapidly changing consumer group remained relatively low (Dotson \& Hyatt, 2005).

Consumer socialisation is defined as "the process by which people acquire skills, knowledge, attitudes, and preferences relevant to their own functioning and participation in the marketplace" (Schiffman, et al., 2001, p. 313). However while 
this term has been extended to all consumers it was originally utilised in the seventies to explain the combined developmental and experiential factors which result in changing consumer behaviour in children (Ward, 1974). Research in the area of consumer socialisation of children began in the 1950s (John, 1999). As a result of public concern regarding the effects of television advertising on children, investigation increased extensively in the seventies (McNeal, 1987; Moschis \& Churchill, 1978; Moschis \& Moore, 1979; Ward, 1974; Ward, Wackman, \& Wartella, 1977). However, the main focus of this research stream was advertising.

Given that businesses market products for and to children, it is essential that their ability, knowledge and perception of marketing stimuli be researched and better understood. This study helps to inform those who market to this group and those who legislate to protect them.

Children are recognised as consumers both in terms of their influence in purchase decisions (Caruana \& Vassallo, 2003; John, 1999; McNeal, 1999; Rose, Boush, \& Shoham, 2002) and actual purchase behaviour (John, 1999; McNeal, 1987, 1999). Based on Australian research it has been suggested that by age nine, ninety per cent of children are operating as autonomous shoppers (Schiffman, et al., 2001). Ward (1974) found that some patterns of adult consumer behaviour were influenced by childhood and adolescent experiences. Ward et al. (1977), found that by the time they were eight years old, children were able to recognise bias and deception in advertising. Children of this age have also been found to be able to categorise products on the basis of a combination of perceptual and underlying cues, and their understanding of symbolic meaning and resultant preference for particular brands has been shown to be emerging (John, 1999). By as young as eight years of age they are acting as autonomous shoppers but questions remain as to why they purchase the products they do and what provides value in the eyes of children?

Research regarding children is critical in several regards. Firstly, children themselves are a viable market. The trend towards higher allowances, greater autonomy of spending and more encouragement to spend, mean this is increasingly the case (McNeal, 1992; McNeal \& Ji, 1999; Scally, 1999). This segment is of sufficient size and importance to warrant investigation by both marketing researchers as well as marketers. Children in America, between seven and fourteen years have been estimated to spend around ninety billion (US dollars) per annum in their own right 
(Belch \& Belch, 2004). In New Zealand, at the time of this research, there were two hundred and ninety thousand children aged eight to fourteen years (Light, 2004) and while their spending has not been recorded in census data, it is likely, based on international trends (McNeal, 2007), that they comprise a significant consumer group. Secondly they are a unique consumer group in terms of their purchase behaviour, the context of their purchase behaviour and their cognitive development (Cook, 2009). Thirdly, children are the consumers of the future and consumer behaviour learning now is likely to play a significant role in future consumer behaviour (Lindstrom, 2003; McNeal, 2007). Finally, children have persuasive influence over an extensive range of purchases made by their parents (McNeal, 1999).

\subsubsection{The Perceived Value Concept}

Perceived value is regarded as an extremely important precursor to success in business. Practitioner focused literature advocates the provision of customer value as being paramount. "More and more business owners are recognizing that increased long term profitability is the reward for successful management of customer value." (Dodds, 2003, p. 1). Perceived value refers to the value as it is perceived by the customer (Woodruff, 1997).

Perceived value has been investigated from several perspectives. The first views value as a perceived quality-monetary sacrifice trade off, a value for money conceptualisation (Agarwal \& Teas, 2001, 2002, 2004; Dodds, Monroe, \& Grewal, 1991; Monroe, 2003; Sweeney, Soutar, \& Johnson, 1999; Teas \& Agarwal, 2000). Perceived quality in this conceptualisation is operationalised in terms of dimensions such as reliability, workmanship, durability, dependability and quality in these studies (Dodds, et al., 1991). Exploratory qualitative research which defined quality as superiority or excellence (Zeithaml, 1988), extended the definition of value, to incorporate all salient give and get components of the purchase (Zeithaml, 1988). "An overall assessment of the utility of a product based on assessments of what is received and what is given."(Zeithaml, 1988, p. 14). This research identified four groups of adult consumers based on the differential contributions of each component of value to their overall perceived value. This definition is still utilised by consumer researchers. 
An alternative research stream which attempted to more fully incorporate the distinct contributions to perceived value as identified in this exploratory work evolved. A study utilising broader consumption values was described by Sheth, Newman and Gross (1991a). Sweeney and Soutar (2001) incorporated this work in developing a scale to measure perceived value for a durable product in which they identified four components of perceived value - two functional values of price and quality as well as emotional and social value. Functional value in terms of price referred to the utility derived from the product due to the reduction in its perceived short and long term costs. Functional value in terms of quality referred to the utility derived from the product due to its perceived quality and expected performance. Emotional value referred to the utility derived from the feelings or affective states that a product generates. Finally social value referred to the product's ability to enhance one's social self-concept (Sweeney \& Soutar, 2001). More recent work has also favoured a multidimensional construct, attempting to incorporate all salient components of purchases including what is received and what is given up (Lin, et al., 2005; Petrick, 2002; Pura, 2005; Roig, Garcia, Tena, \& Monzonis, 2006; Tsai, 2005). Consumer researchers have extended the use of this multidimensional scale to consumer non-durables by applying the scale to services (Petrick, 2002) and snack foods (Wang, 2010). The single dimensional measure of the abstract construct 'value for money' is still utilised by some researchers (Agarwal \& Teas, 2001, 2002, 2004; Sweeney, et al., 1999; Teas \& Agarwal, 2000). The multidimensional concept has more recently been modelled as being second order formative rather than reflective (Lin, et al., 2005). The benefit and sacrifice indicators being modelled as causal of the construct rather than effect indicators.

The first conceptualisation (value for money) was largely driven by the desire to empirically validate the dual role of price as both an indicator of what you get in terms of perceived quality and what you are giving up in terms of perceived sacrifice. It has been shown that when consumers know price and quality are positively related and objective information about the product is low, consumers use price as both an indicator of product quality as well as sacrifice (Dodds, et al., 1991; Monroe, 2003; Rao \& Monroe, 1988). Depending on their familiarity with the product, they may rely on other cues both extrinsic (external to the physical product) and/or intrinsic (derived from the actual product) to assess quality and hence, 
perceive value (Monroe, 2003). The second research stream came from consumer values research regarding these as contributors to perceptions of value and the tradeoff consumers make between what they get and what they give up when purchasing. When developing a scale for perceived value for adult consumers, Sweeney and Soutar (2001) found that value for money was a distinct component of perceived value rather than a trade-off between the value dimensions and the price.

Early work only found small increases in willingness to buy with increases in perceived value (Dodds, et al., 1991), however the definition of perceived value used was the one-dimensional, value for money. Empirical evidence to date supports the importance of value in influencing purchase intentions for adult consumers (Chang \& Wildt, 1994; Dodds, et al., 1991; Lin, et al., 2005; Sweeney, et al., 1999; Zeithaml, 1988).

Indications that at least some dimensions of perceived value are important in children's consumer decisions have been provided by several early investigations. Moschis and Moore (1979) studied seven to twelve year olds and found brand name and price were instrumental in their buying decisions. Respondents favoured a product with a well-known brand name that was on special. Only three directly relevant empirical studies had been conducted prior to the current research. The first investigated children's ability to determine a best buy in terms of unit price (Turner \& Brandt, 1978) and the other two focused on price alone and children's theories of the underlying sources of value inherent in the meaning of price (Fox \& KehretWard, 1985, 1990).

Practitioner focused research supports the importance of perceived value in terms of 'value for money' in children's consumer behaviour. It was found by Lindstrom (2003) to be a component of purchase decisions from as young as eight years old.

Every indication from the BRANDchild study is that price has less and less relevance in the tween market. They buy according to customer value - that is, the difference between the benefits a company gives tweens and the price it charges. More precisely, customer value equals customer perceived benefits minus customer-perceived price. So the higher the perceived benefit and/or the lower the price of a product, the higher the customer value and the 
greater the likelihood that tweens will choose that product. (Lindstrom, 2003, p. 266).

This study suggested that for young children price alone was an important determinant of shopping behaviour and that the concept of perceived value as a trade-off, developed with increasing age. This research finding suggested the use of a single indicator measure of value would not be useful with children, and that further research into the meaning of the concept is required.

\subsubsection{Identification of the Research Gap}

Although children's ability to shop according to customer value is regarded as an important and developmentally significant aspect of their consumer socialisation, until now no academic research has specifically defined this concept or related concepts from a child's perspective (John, 1999). It represents a significant and interesting research area in need of further investigation. To date, how children perceive value or the dimensions they consider has received little research attention and developmental progression in understanding has not been investigated.

Self-brand connections have been shown to be emerging by eight years (Chaplin \& John, 2005) indicating that social value as a concept would potentially be incorporated into children's perceptions of value. However, whether children use such heuristics as price/quality or whether these concepts would be incorporated into perceived value judgements is unknown. The research that exists for children regarding price and value is exploratory in nature and focussing only on the meaning of price (Fox \& Kehret-Ward, 1985, 1990) and not on children's perceptions of value when purchasing.

Evidence from qualitative research by McNeal (1999) suggests that price sensitivity is increasing in young consumers. This author discussed two similar qualitative studies in the late eighties and early nineties with children aged seven to eleven years and showed a marked increase in price consciousness (McNeal, 1999). A 1995 study amongst children aged eight to seventeen years found price consciousness for seventy-five per cent of the children (McNeal, 1999). These findings suggest an increase in the importance of price to child consumers and supported the need for more research to investigate the role of price in value perception. Empirical findings 
also support an increase in concern for price with age (Moschis \& Churchill, 1978, 1979; Shim, 1996). Moschis and Churchill (1978, 1979) found younger adolescents had more favourable attitudes to prices than older adolescents. Shim (1996) showed a positive correlation between age and the price conscious/value for money decisionmaking style. These findings indicate that price might influence perceived value and that age related changes in perceptions of value may occur.

Brand reliance has also been identified as an important impact on choice and preference in children (Hite \& Hite, 1995; Lindstrom, 2003; Ward, et al., 1977). Children have been shown to incorporate conceptual brand meanings into product evaluations at twelve and sixteen years in contrast with eight year olds who evaluated identical products, differing only by brand, in the same way (Achenreiner \& John, 2003). Extrinsic marketplace cues such as brand, store and objective price have been shown to influence value perception (value for money) by adult consumers (Dodds, et al., 1991). But, while this area has received considerable research attention with regard to adults, little is known about value perception for young consumers. Whether cues such as brands signal value to child consumers is unknown. McNeal (1999) found that when children were emotionally positive toward brands they were more tolerant of price increases (McNeal, 1999); however this has not been empirically tested.

Understanding of value, from a child's perspective, is an area that has received little research attention. It had been highlighted as an important area for future investigation (John, 1999). Martenson and Tufte (2002, p. 15) noted the importance of answering the question "How do children understand the concept 'value for money'?".

The majority of research on consumer behaviour of children has been based on Piaget's theory of cognitive development. Such age and stage models have been used to interpret children's understanding (Bahn, 1986; John, 1999; Moore \& Lutz, 2000; Turner \& Brandt, 1978; Ward, et al., 1977) with some combining an information processing approach as a mechanism for this development and in doing so, not completely supporting the stage theory but instead utilising stages to describe findings (Fox \& Kehret-Ward, 1990; John, 1999; John \& Sujan, 1990a; Roedder, 1981; Ward, et al., 1977). Piagetian theory details major developmental stages based on differences in ability. Of relevance to the current study are the concrete 
operational (aged seven to eleven) and formal operations (aged eleven to fourteen) groups. This theory suggests that by eleven years the majority of children can consider several dimensions of a stimulus at a time and relate these in a complex way. Research regarding children's understanding of price has indicated that understanding of this concept may be later in developing to adult-like levels than predicted by Piaget's theory (Fox \& Kehret-Ward, 1990). Piagetian approaches have been criticised in terms of the distinct stages proposed (e.g. Miller, 1993; Shaffer, 1999) and more recent studies in psychology have favoured an information processing approach (Shaffer, 1999). By focusing on children aged eight to fourteen years, and looking at conceptual development the current research provides an opportunity to relate findings to developmental models which predict age based changes in understanding. Rather than adhering to any one developmental theory, however, the research findings have been discussed in terms of which developmental theories are most applicable to changes in children's understanding of perceived value.

Clearly, given the lack of research with children regarding this concept and the lack of evidence regarding developmental change it is not ideal to conduct quantitative research. The accuracy and relevance of adult perceived value scales remains largely unknown and there was insufficient evidence on which to base propositions regarding children and perceived value. To conduct the research without this qualitative underpinning would provide misleading results. This research takes a post positivist approach to social life and as such the concept of value can only be probabilistically understood through the study of reality as perceived by the children studied (Cook, 2009).

Hence, things like "the family," "child," "fairness," or any such concept, make sense and have significance through the lived reality of persons; these do not exist outside of or apart from living, interpreting persons. (Cook, 2009, p. 278)

The current research is focussed on the eight to fourteen year age group. This is based on evidence that eight years of age is the median age for children's first shopping experience (McNeal, 1999), and that by eight price has been shown to be clearly understood by children as the amount of money to be paid for a product (Berti \& Bombi, 1988). While children have been shown to recognise brands from a 
very young age (Hite \& Hite, 1995), brand and price have been shown to become instrumental in buying decisions between seven and ten years (Moschis \& Moore, 1979). Additionally by incorporating a wide age range, changes in cognitive development and social learning can be captured.

This research is motivated firstly, by a desire to determine how child consumers understand the concept of value and to identify and define the dimensions they consider. Secondly, it is motivated by a desire to investigate the changes that occur with age and corresponding increases in consumer socialisation.

In light of this overview, the following represents a statement of the problem examined by the research.

"How value is perceived by children aged eight to fourteen years and how this changes with age."

\subsubsection{Value of the Research}

The value of the current research lies in the advancement of understanding of the key marketing concept of value perception by children, who represent an increasingly important consumer group. Such research which explores the concept of perceived value has been advocated in the marketing literature (Woodall, 2003; Woodruff, 1997). Additionally the findings have implications for marketing practitioners working with products targeted at children as well as legislation and policy regarding protection of this consumer group.

Contributions are made to existing understanding of perceived value on theoretical, empirical, and methodological grounds. Conceptually the research provides a rich and in-depth description of children's value perception grounded in empirical enquiry and relates it to the broader theoretical domain in which it exists. Methodologically a definition of perceived value for child consumers is presented and a relatively new method of gathering data from children is detailed.

The findings are compared with current theoretical models of perceived value for adult consumers (Dodds, et al., 1991; Lin, et al., 2005; Sheth, et al., 1991a; Sweeney \& Soutar, 2001; Tsai, 2005; Zeithaml, 1988). On this basis conceptual definitions of perceived value are extended as they are found to be relevant to children specifically. The research defines the dimensions of perceived value at different ages and 
provides the first conceptual account of how perceptions of value change with age. The research delineates what value is for children and the process involved in value perception. This study contributes a preliminary model and proposed theoretical relationships between concepts involved in children's value perception which will be useful to direct future research in the area.

Definition of concepts and constructs is essential in social research; shared meaning forms the basis of both qualitative and quantitative methods and has been advocated in marketing generally and is a requirement for scale development procedures (Churchill, 1979; Rossiter, 2002). Recent criticisms of quantitative methods suggest validity is lost through deletion of conceptually important items in order to obtain high factor loadings (Rossiter, 2002). This can be overcome by having comprehensive definitions of concepts studied, obtained from samples of interest. Such research provides evidence regarding the classification of concepts as formative or reflective in nature, the elements or dimensions contributing to them and the contexts in which they are relevant.

Methods for studying marketing concepts with children are scarce and with regard to perceived value, no measurement tool exists. Adult measures cannot be utilised for children as they may be inappropriate in terms of the conceptual definitions, interpretation, wording utilised or length resulting in low validity. By providing a conceptual definition of perceived value for children correspondence between any potential measures and the concept can be ensured (Rossiter, 2008). A child-centric approach to consumer research with children has been advocated in the marketing literature (Banister \& Booth, 2005) where researchers are urged to obtain as full an understanding of the participants as is possible through the insightful use of methodologies. This study utilised two methods of data collection to determine children's conceptual definition of perceived value and the constituent dimensions of this concept. The two sources of data were progressively combined in order to define and describe this concept, overcome limitations of individual methods and engage respondents across the ages studied. By using a diary study and in-depth interviews, the present study attempted to reduce the influence of the researcher, obtain information in natural settings and allow comparison across methods.

An understanding of value perception in children is important for marketing practitioners determining pricing, branding and product strategy for child oriented 
goods. It is also critical with respect to the communication of this concept to children. The implication of the brand on children's perception of value is a vital consideration for marketing practitioners in the brand image they convey and the prices they can command. The relationship between the brand and value perceptions is important in terms of the use of branding and nature of brand image desirable for child oriented products targeted at differing ages. Given that guidelines for strategic proactive pricing require that marketers set prices so as to reflect customers perceived value (Monroe, 2003), perceived value for all consumer groups needs to be better understood.

A greater understanding of value perception and age related changes is also of interest to legislators as it will assist in their understanding of the protection needs of this group of consumers. Children may be in danger of being sold low 'value for money' products due to an inability to perceive value in an appropriate way. This research also highlights ages at which educational intervention may be required or pricing may need to be regulated for child oriented goods.

\section{2. Research Objectives}

On the basis of the research gaps discussed, this study has three overall objectives: Firstly, to define perceived value from a child's perspective and identify the relevant concepts comprising the perceived value construct in children's consumer decisionmaking, secondly, to examine age related changes in children's perception of value, and thirdly, to advance current theoretical understanding of how children perceive value.

\section{3. Research Overview and Structure of Thesis}

This thesis examines children's perceptions of value when they purchase products.

In order to meet the research objectives two qualitative research methods are used. The research follows a two stage approach (Table 1.1) and this shapes the structure of the thesis.

The thesis is divided into seven chapters. Following this introductory chapter, the relevant literature is reviewed in Chapter 2. The first section of this reviews the concept of perceived value within the marketing literature and identifies the relevant 
dimensions seen in adult research. This is followed by discussion of the concepts previously identified as comprising perceived value. The research which has been carried out regarding cues of price and brand in relation to perceived value is also discussed. Given the importance of the psychological concept of human development in explaining changes in value perception with age, the review includes psychology literature. The literature is reviewed in terms of consumer socialisation theory, the foundations from theories of human development and children's understanding of economic concepts. Given that an inductive approach to the research question was adopted, in accordance with the ideas proposed in grounded theory methodology (Corbin \& Strauss, 2008) the literature was used to identify a gap and to understand current thinking but set these ideas aside as data was coded, going back to it for data analysis.

Table 1-1 Research Overview

\begin{tabular}{|l|l|}
\hline Chapter 2 & Literature Review \\
\hline Chapter 3 & Research Methodology \\
\hline Chapter 4 & Diary Study \\
\hline Chapter 5 & Individual In-depth Interviews \\
\hline Chapter 6 & Discussion of Analysis and Propositions \\
\hline Chapter 7 & Conclusions and Implications \\
\hline
\end{tabular}

Chapter 3 discusses the methodological approach undertaken in order to answer the research question. The discussion begins with the philosophical assumptions underlying the methodology and this is followed by the research strategy which was followed. Specific considerations with regard to research with children and incorporated into the research strategy are included. Finally consideration of the quality of the research is discussed.

Chapter 4 outlines the findings from first stage of the current investigation which adopted a qualitative approach using diaries and was exploratory and descriptive in nature. The aim of this stage was to gain preliminary understanding of children's value perception in their purchase decisions. The research identified some relevant 
concepts comprising the value construct for children and age related changes were also examined. The advantages and limitations associated with this method are described.

Chapter 5 includes details of the findings from the second stage of the research investigation which involved individual qualitative in-depth interviews. These were analysed using grounded theory techniques. Once again the advantages and limitations associated with the method are discussed.

Chapter 6 compares the findings from the two studies and these are related back to the literature. New literature has been incorporated as it was deemed relevant to the research findings. This leads to development of a conceptual framework and theoretical relationships between concepts have been proposed.

The final chapter of the thesis details the implications of the conceptual framework for the developing concept of perceived value for children. The implications are discussed as they relate to research and practice in the field of marketing, education regarding marketing concepts and regulatory considerations. 
Chapter 2. Literature Review 


\section{1. Introduction}

The literature review covers four main areas. Firstly, the research regarding perceived value is discussed. This includes the way in which empirical research, both qualitative and quantitative, has contributed to conceptual understanding over time. The objective of this section is to present existing theory which will be advanced by the current research.

Secondly, research regarding key associated concepts is reviewed in terms of dimensions that have been asserted to contribute to, or form, perceived value as well as conditions which potentially influence the concept. Literature in the context of adults is reviewed initially and is followed by any related evidence regarding the concepts for child consumers.

Thirdly, an examination and discussion of consumer socialisation theory and the foundation developmental theories from the field of psychology relevant to this study, is undertaken. This will allow application of appropriate developmental theory to understanding of children's value perception as they grow older.

Finally special considerations for conducting research with children are identified from the literature in order to select the most appropriate method to conduct such research in the context of this unique consumer group.

\section{2. Perceived Value}

Perceived value, as with other pricing concepts in marketing, emerged from a basis in economic theory (Monroe, 2003) and in the context of this study is used to refer to the reasoning for a child's preference during a single transaction.

Perceived value has its origins in economics but evidence from the field of psychology and marketing has significantly contributed to our understanding of this concept.

In classical economic theory, the monetary value of a product is regarded as dependent on the production costs. However, expected value based on costs is not always observed and early behavioural research in this field led to the development of the neoclassical theory of how price influences buyer behaviour. From this perspective, price is set on the basis of the market forces of supply and demand and 
takes into account differences in utility. This theory of buyer behaviour requires the buyer to decide what products, as well as how much of each product should be purchased. The quantity to be purchased depends on the price of that product, prices of all other products, the income of the buyer and the buyer's tastes and preferences. Buyers are regarded as rational decision makers and who choose among alternatives in order to maximise satisfaction/utility (Monroe, 2003).

Price in such utility models is assumed to exert influence over buyer choice only in terms of sacrifice. On this basis, given perfect information regarding prices and want satisfaction, buyers should choose the lower price alternative if there is a choice between two or more similar products. This theory does not account for the way people acquire and process information before they form preferences or choose what to purchase (Monroe, 2003). In reality, consumers do not have perfect information about the utility of products or prices of all alternatives but they do make purchase decisions.

During the sixties, Gabor and Granger (cited in Monroe \& Lee, 1999), proposed that consumers may use the price as both an indicator of sacrifice as well as of the product's quality. Current research regarding the role of price in consumer decisionmaking has accepted this proposition and moved from the neoclassical model. "Contemporary thinking recognizes that there is asymmetric information about prices and quality between sellers and buyers, and that quality and price are, in many ways, co-dependent" (Monroe \& Lee, 1999, p. 210).

The influence of perceived value on purchase behaviour was incorporated into research inquiry in marketing in the 1970's with perceived value being conceptualised in terms of perceived quality gained and the perceived sacrifice made (Monroe, 1979; Rao \& Monroe, 1989). On this basis, a model was proposed by Monroe (1979); a value for money conceptualisation of perceived value. Monroe and Krishnan (1985), refined this model (Figure 2-1). 


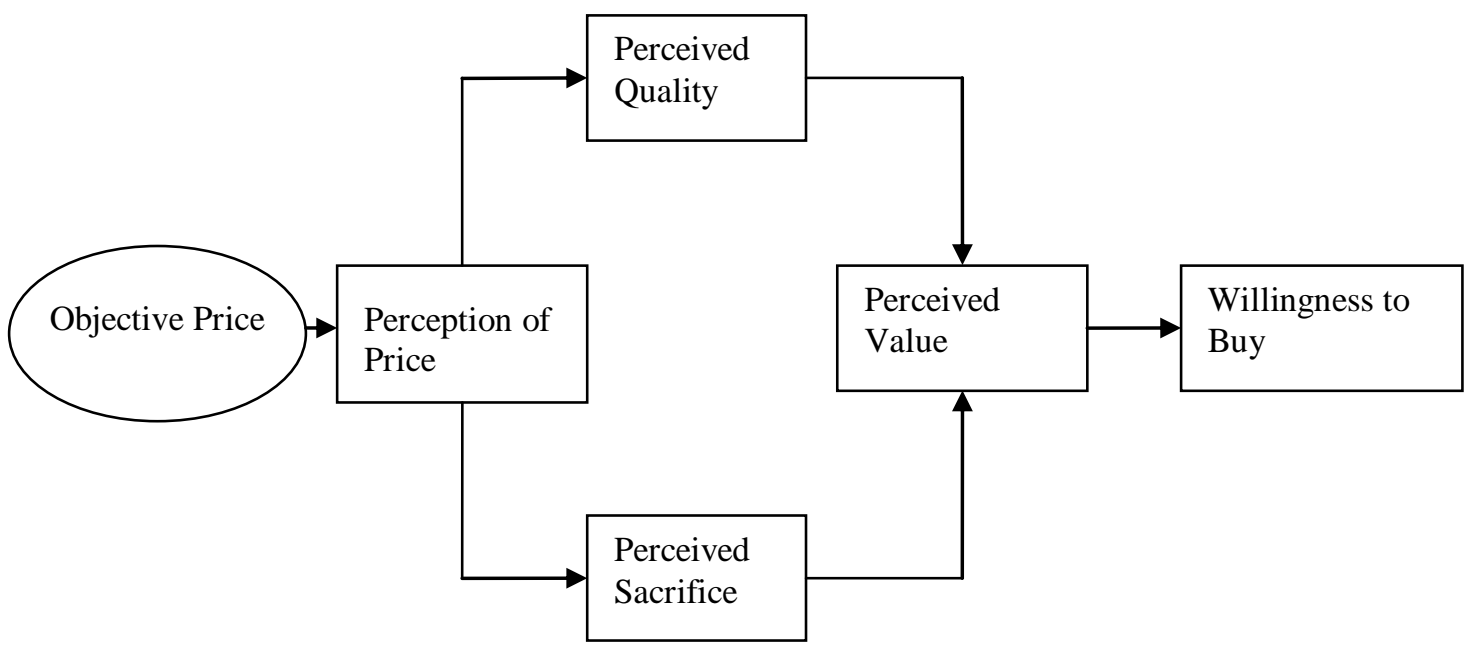

Figure 2-1 Conceptual Model of Price Effect on Perceived Value (Dodds, et al. 1991)

Several conceptual definitions of perceived value have since been used. The most common early definition was "a cognitive trade-off between perceived quality and sacrifice" (Dodds, et al., 1991, p. 316). This conceptualisation of perceived value represents the net gain from the acquisition as a negative function of perceived price and a positive function of perceived quality and perceived quality a positive function of perceived price (Monroe, 1979, 2003).

Early research was criticised in many regards including the inadequacy of conceptual definitions used as well as measurement methods adopted (Monroe \& Krishnan, 1985). Following on from Monroe's (1979) pioneering work, Zeithaml (1988) defined the concepts of price, quality and value from a consumer perspective on the basis of a qualitative investigation and review of existing literature. It was found that each of these two components of perceived value (quality and price) have differing influence for individual consumers (Zeithaml, 1988). Through her qualitative investigation, Zeithaml (1988) found that while perceived value was attributed four different meanings by adult consumers, they could be grouped in one definition: "perceived value is the consumer's overall assessment of the utility of a product based on perceptions of what is received and what is given." (Zeithaml, 1988, p. 14). Some consumers emphasised price, some quality for the price, some benefits received and others what they get for what they give.

A comprehensive model incorporating intrinsic and extrinsic cues as described by Olson and Jacoby (1972, cited in Zeithaml, 1988) in their cue utilisation theory and 
the influence of these cues on perceived quality and perceived value, was proposed by Zeithaml (1988). The theory suggests product-related cues are used as indicators of quality to shoppers, with the greatest weight given to those providing high predictive power regarding quality and those for which the consumer has the greatest confidence in their ability to use and judge (Richardson, Dick, \& Jain, 1994). This model which incorporates the influence of the brand and store on quality and hence value perceptions, has been used in several investigations from a value perspective (e.g. Dodds, et al., 1991; Sweeney, et al., 1999).

Zeithaml's (1988) conceptual definition of value implies a cognitive decisionmaking model of value which has traditionally been applied in consumer research regarding consumption. It also defines value as a trade-off and incorporates perceptions of what is received and what is given. This definition leads to the conclusion that quality alone may not account for what is received. Most research generally agrees that perceived value is the customer's perception of what is given and what is received or a judgement of worth incorporating benefits and sacrifices (for a summary of definitions see Snoj, Korda, \& Mumel, 2004).

Although the definition of perceived value implies a multidimensional concept, many studies use a single dimensional measurement approach to the perceived value concept. These studies measure perceived value in terms of overall indicators such as 'value for money', 'acceptability of the price', 'fairness of the price', 'economy' and 'product appears to be a bargain' (Agarwal \& Teas, 2001, 2002, 2004; Dodds, et al., 1991; Sweeney, et al., 1999; Teas \& Agarwal, 2000). The following Table 2-1 provides a summary of research in which value is measured as unidimensional.

Table 2-1 Studies Using a Single Dimensional Approach to Perceived Value

\begin{tabular}{|c|c|c|c|c|}
\hline Author & Type & Concepts & Definition/Operationalisation & Findings \\
\hline $\begin{array}{l}\text { Dodds, } \\
\text { Monroe and } \\
\text { Grewal (1991) }\end{array}$ & Experiment & $\begin{array}{l}\text { Price, brand, } \\
\text { store } \\
\text { information, } \\
\text { perceived } \\
\text { quality, } \\
\text { perceived value, } \\
\text { willingness to } \\
\text { buy }\end{array}$ & $\begin{array}{l}\text { Quality } \\
\text { Reliability } \\
\text { Workmanship } \\
\text { Quality } \\
\text { Dependability } \\
\text { Durability } \\
\text { Perceived Value } \\
\text { Value for money } \\
\text { Economical } \\
\text { Good buy } \\
\text { Price acceptability } \\
\text { Bargain }\end{array}$ & $\begin{array}{l}\text { Price positively } \\
\text { effects perceived } \\
\text { quality. } \\
\text { Price negatively } \\
\text { effects perceived } \\
\text { value. } \\
\text { Favourable brand } \\
\text { and store } \\
\text { information } \\
\text { positively } \\
\text { influences } \\
\text { perceived quality } \\
\text { and value and } \\
\text { willingness to buy. }\end{array}$ \\
\hline $\begin{array}{l}\text { Chang and } \\
\text { Wildt (1994) }\end{array}$ & Experiment & $\begin{array}{l}\text { Objective price, } \\
\text { information } \\
\text { context, }\end{array}$ & $\begin{array}{l}\text { Perceived Quality } \\
\text { "Product attribute information is an } \\
\text { elemental or disaggregate form of }\end{array}$ & $\begin{array}{l}\text { Supports price } \\
\text { positively effects } \\
\text { perceived quality }\end{array}$ \\
\hline
\end{tabular}




\begin{tabular}{|c|c|c|c|c|}
\hline Author & Type & Concepts & Definition/Operationalisation & Findings \\
\hline & & $\begin{array}{l}\text { perceived price, } \\
\text { perceived } \\
\text { quality, } \\
\text { perceived value, } \\
\text { purchase } \\
\text { intention }\end{array}$ & $\begin{array}{l}\text { information, whereas perceived quality } \\
\text { can be considered a summarisation of this } \\
\text { information." (p. 18) } \\
\text { Measured two overall quality measures } \\
\text { and a measure of comfort (apartments) and } \\
\text { dependability (PCs). } \\
\text { Perceived Price } \\
\text { "The consumer's perceptual representation } \\
\text { or subjective perception of the objective } \\
\text { price." (p. 18) } \\
\text { Measured as high or low. } \\
\text { Perceived Value } \\
\text { "An intervening construct in the } \\
\text { relationship of price and non-price } \\
\text { information with purchase intention" (p. } \\
\text { 18) affected by contextual or situational } \\
\text { factors. A trade-off between the 'get' and } \\
\text { 'give' components of a product. Measured } \\
\text { on a single item 9-point scale. }\end{array}$ & $\begin{array}{l}\text { Price has less } \\
\text { influence on } \\
\text { perceived quality } \\
\text { when high direct } \\
\text { product } \\
\text { information. } \\
\text { Supports negative } \\
\text { effect of price on } \\
\text { perceived value } \\
\text { and positive effect } \\
\text { of perceived } \\
\text { quality on } \\
\text { perceived price. } \\
\text { Perceived value } \\
\text { positive influence } \\
\text { on purchase } \\
\text { intention. }\end{array}$ \\
\hline $\begin{array}{l}\text { Sinha and } \\
\text { Desarbo } \\
(1998)\end{array}$ & Experiment & $\begin{array}{l}\text { Perceived } \\
\text { value }\end{array}$ & $\begin{array}{l}\text { Measured whether value was better, the } \\
\text { same or worse than expected. Information } \\
\text { on brands provided in terms of: } \\
\text { Manufacturer } \\
\text { Reliability } \\
\text { Mileage } \\
\text { Safety features } \\
\text { Depreciation } \\
\text { Performance. }\end{array}$ & $\begin{array}{l}\text { Provide a new } \\
\text { method for } \\
\text { identifying } \\
\text { dimensions } \\
\text { influencing } \\
\text { perceived value } \\
\text { without pre } \\
\text { specification. They } \\
\text { provide an } \\
\text { example where the } \\
\text { relevant } \\
\text { information is } \\
\text { provided and } \\
\text { consumers are } \\
\text { asked to value } \\
\text { judgements. }\end{array}$ \\
\hline $\begin{array}{l}\text { Grewal, } \\
\text { Monroe and } \\
\text { Krishnan } \\
(1998)\end{array}$ & Experiment & $\begin{array}{l}\text { Advertised } \\
\text { selling price, } \\
\text { advertised } \\
\text { reference price, } \\
\text { reference price, } \\
\text { perceived } \\
\text { quality, } \\
\text { perceived } \\
\text { transaction } \\
\text { value, perceived } \\
\text { acquisition } \\
\text { value, } \\
\text { search } \\
\text { intentions, } \\
\text { willingness to } \\
\text { buy }\end{array}$ & $\begin{array}{l}\text { Internal Reference Price } \\
\text { "A price (or price scale) in buyers' } \\
\text { memories that serves as a basis for judging } \\
\text { or comparing actual prices."(p. 47) } \\
\text { Estimate of the average market price } \\
\text { A fair price } \\
\text { Perceived Quality } \\
\text { "Buyer's estimate of a product's } \\
\text { cumulative excellence."(p. 47) } \\
\text { Good quality } \\
\text { Durability } \\
\text { Reliability } \\
\text { Perceived Transaction Value } \\
\text { "The perception of psychological } \\
\text { satisfaction or pleasure obtained from } \\
\text { taking advantage of the financial terms of } \\
\text { the price deal" (p. 48) } \\
\text { Deal makes me feel good } \\
\text { Pleasure from saving money } \\
\text { Deal gives a sense of joy } \\
\text { Perceived Acquisition Value } \\
\text { "The buyers' net gain (or trade off) from } \\
\text { acquiring the product or service" (p. } 48 \text { ) } \\
\text { Getting money's worth } \\
\text { Good quality for a reasonable price } \\
\text { Quality features for selling price } \\
\text { Value for money } \\
\text { Meets high quality and low price } \\
\text { requirements } \\
\text { Comparison to maximum price willing to } \\
\text { pay } \\
\text { Sale price represents good value } \\
\text { Meets needs for a reasonable price } \\
\text { A worthwhile acquisition because it would } \\
\text { help exercise at a reasonable price }\end{array}$ & $\begin{array}{l}\text { The influence of } \\
\text { price comparison } \\
\text { advertising on the } \\
\text { price - perceived } \\
\text { value relationship. } \\
\text { Separates } \\
\text { transaction and } \\
\text { acquisition value. } \\
\text { Found positive } \\
\text { relationships } \\
\text { between perceived } \\
\text { quality, advertised } \\
\text { selling price and } \\
\text { advertised } \\
\text { reference price and } \\
\text { internal reference } \\
\text { price. Transaction } \\
\text { value mediates the } \\
\text { relationship } \\
\text { between advertised } \\
\text { selling price and } \\
\text { acquisition value. } \\
\text { The effect of } \\
\text { perceived } \\
\text { transaction value } \\
\text { on behavioural } \\
\text { intentions } \\
\text { mediated by } \\
\text { acquisition value. }\end{array}$ \\
\hline
\end{tabular}




\begin{tabular}{|c|c|c|c|c|}
\hline Author & Type & Concepts & Definition/Operationalisation & Findings \\
\hline $\begin{array}{l}\text { Sweeney, } \\
\text { Soutar and } \\
\text { Johnson } \\
(1999)\end{array}$ & Survey & $\begin{array}{l}\text { Perceived } \\
\text { quality, relative } \\
\text { price, } \\
\text { performance/ } \\
\text { financial risk, } \\
\text { value for } \\
\text { money, } \\
\text { willingness to } \\
\text { buy }\end{array}$ & $\begin{array}{l}\text { Perceived Value for Money } \\
\text { (Dodds, Monroe \& Grewal, 1991) } \\
\text { Perceived Quality } \\
\text { (Dodds, Monroe \& Grewal, 1991) } \\
\text { Relative Price } \\
\text { Price high/low in comparison to a product } \\
\text { with similar features } \\
\text { Considering (1) the least expensive } \\
\text { product with similar features available and } \\
\text { (7) as the most expensive product with } \\
\text { similar features available, how would you } \\
\text { rate the product you looked at, purchased? } \\
\text { Perceived Risk } \\
\text { "...subjective expectation of loss" } \\
\text { Chance something wrong with product } \\
\text { Chance stand to lose money due to failure } \\
\text { to perform or costs more to maintain than } \\
\text { should } \\
\text { Encounter Specific Functional Service } \\
\text { Quality } \\
\text { Employees courteous } \\
\text { Employees willing to help } \\
\text { Store gave personal attention } \\
\text { Employees gave prompt service } \\
\text { Store gave individual attention } \\
\text { Encounter Specific Technical Service } \\
\text { Quality } \\
\text { Employees knowledgeable enough to } \\
\text { answer questions } \\
\text { Employees knew what they were talking } \\
\text { about }\end{array}$ & $\begin{array}{l}\text { Found that } \\
\text { perceived quality } \\
\text { components } \\
\text { enhance perceived } \\
\text { value and decrease } \\
\text { perceived risk. } \\
\text { Perceived risk } \\
\text { found to mediate } \\
\text { perceived quality- } \\
\text { perceived value for } \\
\text { money } \\
\text { relationship. }\end{array}$ \\
\hline $\begin{array}{l}\text { Agarwal and } \\
\text { Teas (2001) }\end{array}$ & Experiment & $\begin{array}{l}\text { Perceived } \\
\text { quality, } \\
\text { perceived } \\
\text { sacrifice, } \\
\text { performance } \\
\text { risk, financial } \\
\text { risk, perceived } \\
\text { value }\end{array}$ & $\begin{array}{l}\text { Perceived Quality } \\
\text { Reliability } \\
\text { Workmanship } \\
\text { Quality } \\
\text { Dependability } \\
\text { Durability } \\
\text { Perceived Sacrifice } \\
\text { Not be able to purchase other products I } \\
\text { would like to purchase now } \\
\text { Have to reduce the amount of money I } \\
\text { spend on other things for a while } \\
\text { Performance Risk } \\
\text { Confidence product will perform } \\
\text { Certainty the product will work } \\
\text { satisfactorily } \\
\text { Financial Risk } \\
\text { Investment risk } \\
\text { Risk of associated costs } \\
\text { Overall financial risk } \\
\text { Perceived Value } \\
\text { Value for money } \\
\text { Economical } \\
\text { Good buy } \\
\text { Price acceptability } \\
\text { Bargain }\end{array}$ & $\begin{array}{l}\text { High perceived } \\
\text { quality can reduce } \\
\text { the influence of } \\
\text { perceived risk on } \\
\text { perceived value. } \\
\text { Support the role of } \\
\text { perceived quality } \\
\text { and perceived } \\
\text { sacrifice as } \\
\text { mediators between } \\
\text { concrete extrinsic } \\
\text { cues perceived risk } \\
\text { (both financial and } \\
\text { performance) and } \\
\text { perceived risk } \\
\text { mediates the } \\
\text { relationship } \\
\text { between perceived } \\
\text { quality and } \\
\text { perceived sacrifice } \\
\text { and perceived } \\
\text { value. }\end{array}$ \\
\hline
\end{tabular}

Studies utilising unidimensional measurement of value as a trade-off between quality and price only, have been criticised as being over-simplified (Sweeney \& Soutar, 2001). Models measuring value in terms of concepts such as benefits, worth, quality and value for money assume shared meanings which may not be accurate. Consensus on definitions of some of these constructs has also been found to be lacking (Woodruff, 1997). It has been argued that a more useful model of value is a 
multidimensional model incorporating the benefits and costs from which value is derived (Sweeney \& Soutar, 2001).

Sweeney and Soutar (2001) developed a multi-dimensional scale to measure perceived value which incorporates the experiential perspective. Holbrook and Hirschman (1982) advocated the experiential perspective including symbolic, hedonic and aesthetic aspects be incorporated with the traditional information processing view that focuses on utilitarian components of value. They noted that while all products may carry symbolic meaning, for some it is particularly important. This is more likely to be the case when branding is present.

Sheth, Newman and Gross (1991a; Sheth, Newman, \& Gross, 1991b) suggested five dimensions of the consumer value that incorporate both utilitarian and experiential dimensions contributing to choice. They claim their theory applies to the decision to buy a specific product, product type or brand. The dimensions included are functional, social, emotional conditional and epistemic value.

Functional value refers to:

The perceived utility acquired from an alternative's capacity for functional, utilitarian, or physical performance. An alternative acquires functional value through the possession of salient functional, utilitarian or physical attributes. Functional value is measured on a profile of choice attributes.

Social value refers to:

The perceived utility derived from an alternative's association with one or more specific social groups. An alternative acquires social value through association with positively or negatively stereotyped demographic, socioeconomic, and cultural-ethnic groups. Social value is measured on a profile of choice imagery.

Emotional value refers to:

The perceived utility acquired from an alternative's capacity to arouse feelings or affective states. An alternative acquires emotional value when associated with specific feelings or when precipitating or perpetuating those feelings. Emotional value is measured on a profile of feelings associated with the alternative. 
Conditional value refers to:

The perceived utility acquired by an alternative as the result of the specific situation or set of circumstances facing the decision maker. An alternative acquires conditional value in the presence of antecedent physical or social contingencies that enhance its functional or social value. Conditional value is measure on a profile of choice contingencies.

And epistemic value refers to:

The perceived utility acquired from an alternatives capacity to arouse curiosity, provide novelty and/or satisfy a desire for knowledge. An alternative acquires epistemic value by questionnaire items referring to curiosity, novelty and knowledge. (Sheth, et al., 1991b, p. 160-162)

Sweeney and Soutar (2001) developed their scale of perceived value in order to determine "what consumption values drive purchase attitude and behaviour" (Sweeney \& Soutar, 2001, p. 203). The resulting scale builds on the work of Sheth, Newman and Gross (1991a) and includes both utilitarian (quality and price) and hedonic components (emotional and social value). Rather than correlating with an overall value measure, such as the "product offers value for money" the value for money perspective is incorporated in the price dimension. This study provides a robust measure of perceived value in adults for a nondurable product at the brand level and identifies the key dimensions of the construct. The dimensions of perceived value were allowed to be interrelated and the important distinction between value and satisfaction was noted. Value can be evaluated pre-purchase whereas satisfaction is a post-purchase evaluation (Sweeney \& Soutar, 2001). The four resultant dimensions identified are defined as follows:

Emotional value: "The utility derived from the feelings or affective states that a product generates"

Social value: "The utility derived from the product's ability to enhance social self-concept" 
Functional value (price/value for money): "The utility derived from the product due to the reduction of its perceived short term and long term costs"

Functional value (performance/quality): "The utility derived from the perceived quality and expected performance of the product" (Sweeney \& Soutar, 2001, p. 211)

Several other researchers have agreed that perceived value is multidimensional (Lin, et al., 2005; Petrick, 2002; Pura, 2005; Roig, et al., 2006; Tsai, 2005). Different dimensions have been identified for the service industry (Petrick, 2002), e-tail industry (Lin, et al., 2005) and banking (Roig, et al., 2006), with multidimensional models capturing cognitive and affective aspects. Lin (2005) discussed problems regarding the definition of perceived value (Zeithaml, 1988) and its conceptualisation which should be, on the basis of Zeithaml's work, an abstraction, more individualistic and personal than quality and multidimensional. These authors argue that including the dimensionality is important in order to investigate the complex nature of the concept but that current models are incomplete as they do not capture the overall value or trade off of the consumer experience. Instead they propose the dimensions should be modelled as components of an overall perceived value and these authors provide evidence using structural modelling, to investigate three models of perceived value. Findings indicated that perceived value should be defined as a multidimensional, first order reflective, second order formative construct (Lin, et al., 2005). ${ }^{1}$

The following Table 2-2 provides a summary of research discussed in which value is conceptualised as multi-dimensional and definitions of the dimensions used.

\footnotetext{
${ }^{1}$ Reflective or formative describes the relationship between a construct and its indicators, the assumed direction of causality. For a reflective construct the indicators reflect the construct, the direction of causality is from the construct to the indicators. For a formative construct the indicators form the construct. The direction of causality is towards the construct and all are conceptually necessary to accurately measure the construct. (Jarvis, MacKenzie, \& Podsakoff, 2003)
} 
Table 2-2 Studies Using a Multidimensional Approach to Perceived Value

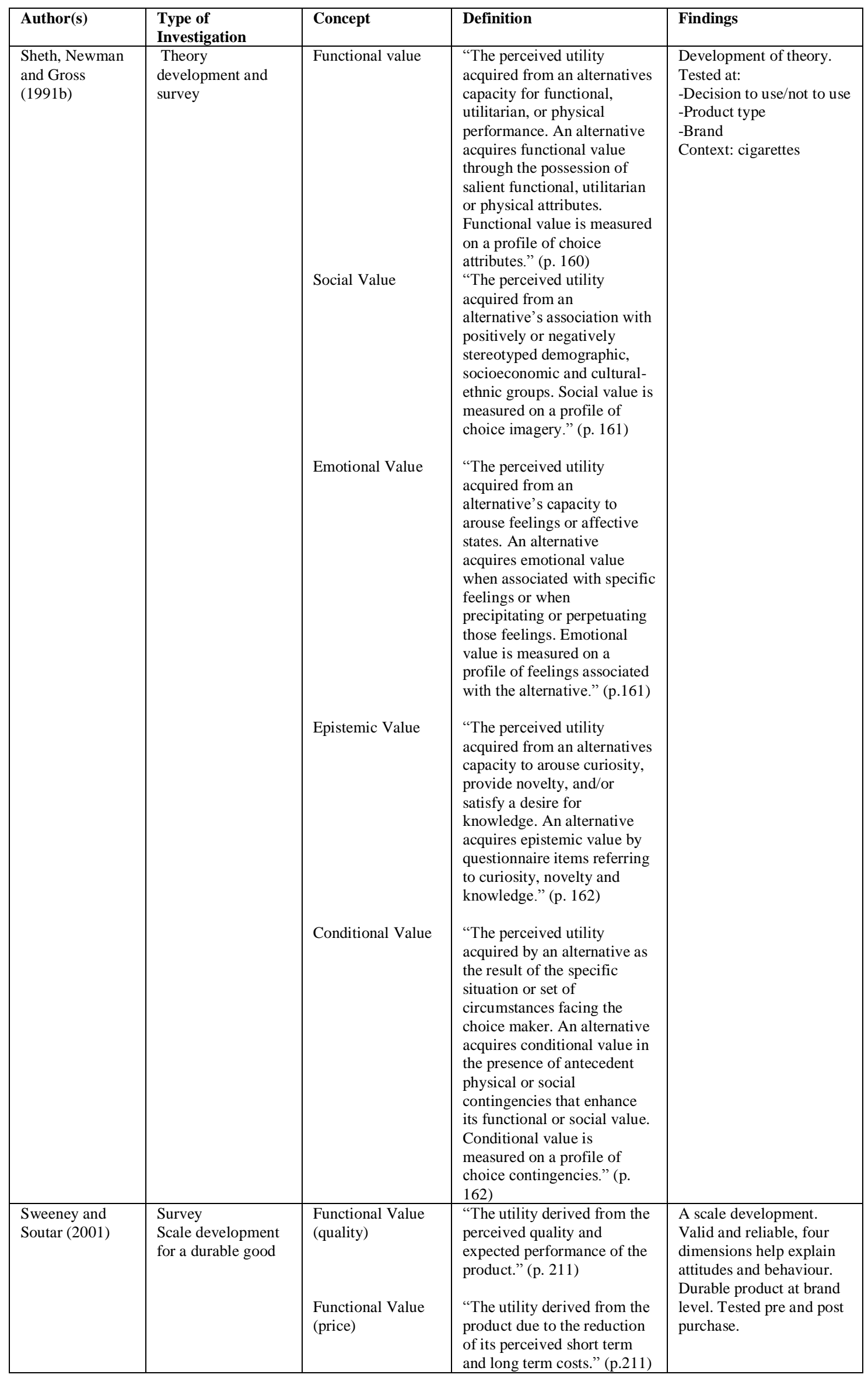




\begin{tabular}{|c|c|c|c|c|}
\hline Author(s) & $\begin{array}{l}\text { Type of } \\
\text { Investigation }\end{array}$ & Concept & Definition & Findings \\
\hline & & $\begin{array}{l}\text { Emotional Value } \\
\text { Social Value }\end{array}$ & $\begin{array}{l}\text { "The utility derived from the } \\
\text { feelings or affective states } \\
\text { that a product generates." (p. } \\
211 \text { ) } \\
\text { "The utility derived from the } \\
\text { product's ability to enhance } \\
\text { social self-concept." (p. 211) }\end{array}$ & \\
\hline Petrick (2002) & $\begin{array}{l}\text { Survey } \\
\text { Scale development } \\
\text { for Tourism } \\
\text { industry }\end{array}$ & $\begin{array}{l}\text { Behavioural Price } \\
\text { Monetary Price } \\
\text { Emotional } \\
\text { Response } \\
\text { Quality } \\
\text { Reputation }\end{array}$ & $\begin{array}{l}\text { "The price (non-monetary) of } \\
\text { obtaining a service, which } \\
\text { included the time and effort, } \\
\text { used to search for the service } \\
\text { (Zeithaml, 1988)." (p.125) } \\
\text { "The price of a service as } \\
\text { encoded by the consumer } \\
\text { (Jacoby and Olsen, 1977)." } \\
\text { (p.125) } \\
\text { "A descriptive judgement } \\
\text { regarding the pleasure that a } \\
\text { product or service gives the } \\
\text { purchaser (Sweeney et al., } \\
\text { 1998)." (p.125) } \\
\text { "A consumer's judgement } \\
\text { about a product or service's } \\
\text { overall excellence or } \\
\text { superiority (Zeithaml, } \\
\text { 1988)." (p.125) } \\
\text { "The prestige or status of a } \\
\text { product or service, as } \\
\text { perceived by the purchaser, } \\
\text { based on the image of the } \\
\text { supplier (Dodds et al., } \\
\text { 1991)." (p. 125) }\end{array}$ & $\begin{array}{l}\text { A scale development. } \\
\text { Five dimensions, reliable } \\
\text { and valid in the context of } \\
\text { a service. }\end{array}$ \\
\hline $\begin{array}{l}\text { Lin, Sher and } \\
\text { Shih (2005) }\end{array}$ & $\begin{array}{l}\text { Survey/ e Tail } \\
\text { service industry } \\
\text { SEM modelling of } \\
\text { the nature of } \\
\text { perceived value }\end{array}$ & $\begin{array}{l}\text { Monetary Sacrifice } \\
\text { Website Design } \\
\text { Fulfilment/Reliabil } \\
\text { ity } \\
\text { Security/Privacy } \\
\text { Customer Service } \\
\text { Perceived Value }\end{array}$ & $\begin{array}{l}\text { "Consumer perceived eTail } \\
\text { service value is composed of } \\
\text { the benefits provided by the } \\
\text { eTailer to facilitate efficient } \\
\text { and effective e-transaction } \\
\text { and the monetary cost the e- } \\
\text { shopper pays for the } \\
\text { product." (p. 327) }\end{array}$ & $\begin{array}{l}\text { Perceived value should be } \\
\text { conceived as a formative } \\
\text { construct. }\end{array}$ \\
\hline Tsai (2005) & $\begin{array}{l}\text { Theory } \\
\text { development/Survey }\end{array}$ & $\begin{array}{l}\text { Symbolic Value } \\
\text { Affective Value } \\
\text { Trade off Value }\end{array}$ & $\begin{array}{l}\text { "Is related to how the } \\
\text { consumer evaluates the } \\
\text { product's brand name in } \\
\text { terms of the valence assigned } \\
\text { to the brand's reputation and } \\
\text { its capability for self- } \\
\text { expression." (p. 281) } \\
\text { "Refers to how the consumer } \\
\text { evaluates the branded } \\
\text { product according to overall } \\
\text { feelings towards it." (p. 282) } \\
\text { "Is related to how the } \\
\text { consumer evaluates the } \\
\text { branded product's value with } \\
\text { economic and monetary } \\
\text { considerations." (p. 282) }\end{array}$ & $\begin{array}{l}\text { Proposed and tested a } \\
\text { model incorporating } \\
\text { symbolic, affective and } \\
\text { monetary value and found } \\
\text { them to be simultaneously } \\
\text { positively related to } \\
\text { purchase intention. }\end{array}$ \\
\hline Pura (2005) & Survey & $\begin{array}{l}\text { Monetary Value } \\
\text { Convenience Value }\end{array}$ & $\begin{array}{l}\text { "Value derived from task } \\
\text { fulfilment. Monetary benefit } \\
\text { or superiority compared with } \\
\text { alternatives." (p. 516) } \\
\text { "Ease and speed of achieving } \\
\text { a task effectively and } \\
\text { conveniently." (p. 516) }\end{array}$ & $\begin{array}{l}\text { Behavioural intentions } \\
\text { were most influenced by } \\
\text { conditional value, } \\
\text { commitment and to some } \\
\text { extent monetary value. } \\
\text { Commitment can be } \\
\text { enhanced by building } \\
\text { emotional value. }\end{array}$ \\
\hline
\end{tabular}




\begin{tabular}{|c|c|c|c|c|}
\hline Author(s) & $\begin{array}{l}\text { Type of } \\
\text { Investigation }\end{array}$ & Concept & Definition & Findings \\
\hline & & $\begin{array}{l}\text { Social Value } \\
\text { Emotional value } \\
\text { Conditional Value } \\
\text { Epistemic Value }\end{array}$ & $\begin{array}{l}\text { "The utility derived from the } \\
\text { products ability to enhance } \\
\text { social self-concept." (p. 516) } \\
\text { "Product/service generates } \\
\text { feelings or affective states." } \\
\text { (Sweeney \& Soutar, 2001, p. } \\
\text { 211) } \\
\text { "Depends on the context, } \\
\text { exists only in a specific } \\
\text { situation. Context includes } \\
\text { any information that } \\
\text { characterises a situation } \\
\text { related to the interaction } \\
\text { between humans, } \\
\text { applications, and the } \\
\text { surrounding environment." } \\
\text { (p. } 516 \text { ) } \\
\text { "Experienced curiosity, } \\
\text { novelty or gained } \\
\text { knowledge." (p. 516) }\end{array}$ & \\
\hline
\end{tabular}

\subsubsection{Children and Perceived Value}

Importantly for the child consumer, in order to function successfully in the consumer environment, an understanding of value in terms of what they are getting and giving up is ideal and this implies a cognitive approach to consumer decisions. While rational perceived value as a trade-off may not always form the basis of choice, an understanding of this concept by children is desirable. It is not known how or when value is understood by children or its impact on consumer choice. From an economic perspective value for money may only be accurately compared when the product is identical and the only difference is the unit price (Capon \& Kuhn, 1982). When the products are different, differing value dimensions may be of greater importance. Even in the situation of comparing unit price the "give" component must be weighed up against the "get" component and in terms of the utility derived from the additional product received, traded off against the price in order to determine value for money.

Limited evidence does exist to indicate possible dimensions considered by children and developmental change in the concept. Burris (1983) conducted a developmental study of economic concepts and found the related concept of economic value reflected by prices developed in three stages, with size being the determinant attribute for young children (4-5 years) and then function or usefulness at age seven to eight and finally production costs for eleven year olds. Murray (1980, cited in Kehret-Ward \& Yalch, 1984) found that adolescents and adults were willing to pay more for a product that varied only by its social scarcity but preadolescents were not. 
Pre-adolescents did not show conscious understanding of the communication value of a distinct product. According to Murray (1980, cited in Kehret-Ward \& Yalch, 1984), by adolescence, children understood how to use products to reveal aspects of the self which is the key to creating symbolic values. This developmental change suggests that social value may be later to develop as it requires an understanding of the communication value of products.

Evidence of the importance of price and brand to adolescents is supported by the work of Moschis and Moore (1979). In their work adolescents indicated that the information most likely to indicate the best product to buy, from five statements, was "one that is on sale" and "one with a well-known brand name". These results indicate that perceived sacrifice is an important aspect of their consumer decisions and that the trade-off between what they are getting and what they are giving up may be assessed in decisions.

Before companies can provide value, an understanding of what constitutes value to the customer must first be understood. Perceived value is regarded as a key determinant in adult consumer decisions, however due to the abstract nature of this concept it has been defined and investigated from several perspectives. By looking at the development of this concept in children this research will contribute to understanding of perceived value.

The Brandchild survey results, while only indicative, suggest that eight to twelve year olds buy according to customer value; defined as the difference between the benefits provided by a company and the price charged. This study also indicates that by twelve years of age children are able to comparison shop (Lindstrom, 2003).

No research has specifically investigated how children perceive value and whether they consider the dimensions of perceived value found for adults. It is not known whether their perceptions change as they develop and whether children develop a rational understanding of value before incorporating emotional and social concepts. John (1999) calls for research as follows "A related topic children's understanding of prices and value, would also be a natural candidate for further research" (John, 1999, p. 204) 


\subsubsection{Involvement and Perceived Value}

According to research on consumption value, for adult consumers the importance and contribution of each dimension of value differs for different people (Zeithaml, 1988) and product type, brand, and decision to buy or not to buy (Sheth, et al., 1991a). The consumer decision-making process is classified as extended, limited, habitual and impulse and is dependent on product involvement (Howard \& Sheth, 1969). Adults have been shown to adopt certain decision-making styles when shopping. "A consumer decision-making style is defined as a mental orientation characterising a consumer's approach to making choices. It has cognitive and affective characteristics..." (Sproles \& Kendall, 1986, p. 268). The decision style adopted has been shown to be influenced by both the product and product involvement (Bauer, Sauer, \& Becker, 2005). Product involvement is “...a person's perceived relevance of the object based on inherent needs, values and interests" (Zaichkowsky, 1985, p. 342, cited in Bauer, et al., 2005). A negative relationship between product involvement and the price-value consciousness decision-making style and the decision-making style of spontaneity was found, while a positive relationship between product involvement and brand/store loyalty was found (Bauer, et al., 2005). At this point, research regarding children's involvement with the products they purchase was not available.

\subsubsection{Perceived Value, Behavioural Intention and Behaviour}

According to the model (Figure 2-1, p. 18) of Dodds, Monroe and Grewal (1991), perceived value should directly and positively affect willingness to buy. Zeithaml (1988) suggests, on the basis of exploratory work, that perceived value influences the relationship between quality and product choice. Favourable value perceptions using a one-dimensional measure of value, resulted in positive, small to moderate increases in willingness to buy (Dodds, et al., 1991). The weak nature of the relationship found may be due to the fact that this conceptualisation of perceived value did not incorporate distinct dimensions of perceived value. Sheth, Newman and Gross (1991a) found functional value "The perceived utility acquired from an alternatives capacity for functional, utilitarian, or physical performance..." (Sheth, et al., 1991b, p. 160), to have the greatest influence on choice dependent on both the product and brand. In the e-Tail environment, using either reflective or formative 
multidimensional models of perceived value, direct effects on behavioural intentions of re-patronage and positive word-of-mouth were found (Lin, et al., 2005). The scale developed by Sweeney and Soutar (2001) was tested in the pre and post purchase situation for a durable good. This relationship between perceived value and behavioural intention and behaviour has not been investigated with children.

Budgetary constraints may influence willingness to buy, particularly for children who have limited available funds. They may obtain more value from a lower quality product, as was found for adult consumers (Zeithaml, 1988), because lower costs compensate for the reduction in quality. Given the influence of involvement on consumer decision-making styles, involvement may influence the relationship between perceived value and willingness to buy.

On the basis of the literature review to this stage there is consensus that perceived value is comprised of at two conceptually distinct parts, perceived benefits and perceived costs.

\section{3. Perceived Price}

Price is a key component of the perceived sacrifices or costs associated with perceived value. Due to the influence of price in adult consumers' value perception, it is useful to discuss consumers' processing of this cue. Prices are perceived differently by different consumers, for different products, in different purchase situations and at different times (Cooper 1969, cited in Dodds, et al., 1991). Perception involves the categorisation of new experience into existing classifications of familiar experience. Price perception is "the process by which consumers translate prices into meaningful cognitions" (Lichtenstein, Bloch, \& Black, 1988, p. 243). Consumers are exposed to the same price cue but individuals assign unique meaning to it based on the actual or objective price and their price knowledge. Objective price has been defined as the "actual price as an objective external characteristic of a product that consumers perceive as a stimulus" (Dodds, et al., 1991, p. 308). The objective price and the perceived price are distinct concepts with the former referring to the actual price of a product and the perceived price referring to the price as it is encoded by the consumer. 
The relationship between an objective price and the individual's price knowledge has its historic foundations in the idea that consumers regard items for purchase as having a just or fair price. Scitovsky (cited in Gabor, 1977; Monroe, 2003; Monroe \& Lee, 1999) noted that two prices are attributed to every product "(1) a traditional past price ("normal" or "fair" price) that denotes it's worth and (2) the products actual price." (Monroe \& Lee, 1999, p. 210). Research from the forties to the seventies supported the existence of a band of acceptable prices rather than a specific price point in the consumer's mind, which would vary by income, price level of the category, previous price paid, price structure of category and buyer uncertainty (Monroe, 2003). Rao and Sieben (1992) found that the width of this band depends on prior knowledge of the product.

When a consumer perceives prices for products, their assessment is based on their price knowledge (Vanhuele \& Dreze, 2002). Price knowledge has been assumed in pricing research to be knowledge formed on the basis of previous experience and as a result "...buyers know the prices of the products and services they consider for purchase" (Monroe \& Lee, 1999, p. 207). On the basis of classical economic theory, consumer decisions are associated with a comparison between a price and a stored reference price (Briesch, Krishnamurthi, Mazumdar, \& Raj, 1997; Lawson \& Bhagat, 2002; Monroe, 1973). Historically, the concept of the existence of an internal reference price has been assumed. Empirical support, through analysis of scanner data for grocery shoppers, indicates a range of acceptable prices surrounding such a reference price (Kalyanaram \& Little, 1994). On this basis price perception is based on a comparison between the objective price and a reference price (Chang \& Wildt, 1994) or range of prices.

Measurement of the ability of buyers to recall prices previously paid (Monroe, 2003; Monroe \& Lee, 1999) has been used to determine price knowledge. While research has attempted to measure price awareness through recall of prices last paid, or used as reference in price evaluations, these studies requiring recall of internal reference prices, have shown memory of previously encountered prices to be low (Dickson \& Sawyer, 1990; Monroe \& Lee, 1999). This finding does not indicate that buyers do not form and use reference prices, only that they may not be remembered as exact prices and that they may not be stored in such a way as to allow for recall (Monroe \& Lee, 1999). Dickson and Sawyer (1990) suggested that the reason for this low result 
is that price knowledge is high at the point of choice but rapidly drops off, and on this basis they tested recall at the time of choice. Results were still surprisingly low and the methodology has subsequently been criticised in terms of the type of memory which is being tapped in such studies (Vanhuele \& Dreze, 2002). It is more likely to be short term rather than long-term memory being measured (Vanhuele \& Dreze, 2002). Other researchers have looked at the difference between actual and recalled prices and expressed it as a percentage of the correct price. These showed that the error in recall was in fact quite low, ranging from six to around nineteen percent, especially in comparison with correct recall which was between eight and sixty one percent (Monroe \& Lee, 1999).

Memory is characterised on the basis of storage and retrieval characteristics. Research with amnesic patients has provided evidence of a capacity limited memory or short term memory, which remains intact amongst these patients and a long lasting memory which is impaired (Squire, 1986) However, the longer lasting memory or long-term memory can be further characterised as evidenced by studies of these patients, which have revealed a distinction between skill learning and priming effects (procedural knowledge) and declarative knowledge. Declarative knowledge is knowledge which can be recalled whereas procedural knowledge occurs without recognition (Squire, 1986). Declarative memory is accessible to conscious awareness and includes both semantic and episodic memory (explicit), whereas procedural knowledge is implicit and is accessed through performance (Squire, 1986).

Recall tests represent only declarative or explicit memory. This type of memory requires conscious recollection of an exposure episode and is directly accessible to verbal recall. Pricing knowledge may be better understood in terms of implicit memory, that is memory characterised by non-conscious retrieval of previously encountered stimuli (Monroe \& Lee, 1999). Implicit memory is evidenced in improved performance in a task after exposure to the stimuli (Monroe \& Lee, 1999).

One study measured implicit memory of price in terms of the inference of price based on where a product fits within a product knowledge frame. Such a frame consists of product specific attributes in combination with universal marketing attributes such as purchase related experience, performance and brands (Lawson, 1998, cited in Lawson \& Bhagat, 2002). Price knowledge using this method is 
viewed as a numerical estimation based on a frame of knowledge rather than from memory of an isolated exposure.

Vanhuele and Dreze (2002) call upon memory research to determine price knowledge of consumers using three measures of price knowledge in order to detect both explicit and implicit forms and to elicit responses on the basis of consumer's long-term memory. The measures employed included recall as a measure of explicit knowledge and use of recognition and deal spotting as measures of implicit price knowledge. These measures are related to three types of memory for numerical data. However, a limitation of the method for eliciting this knowledge was that recognition questions actually provided, as part of the question, the actual price as a central point which was also the case in the deal spotting question. This may have resulted in a carry-over effect and inflation of the price knowledge measurement.

An alternative theoretical perspective on encoding of numerical information suggests that prices may be encoded as fuzzy traces (Shaffer, 1999). They may not be able to be retrieved in an exact form. The results discussed offer support to both theories of implicit knowledge and also fuzzy trace theory; neither of which would predict accurate recall of reference prices.

These findings from investigations of price knowledge using price recall indicate that it is inappropriate to measure price knowledge using solely explicit measures. Researchers should be aware of implicit knowledge with consumers when designing research. In models of perceived value, price knowledge is usually not measured. Perceived price has been measured using high/low scales, relative price and as part of perceived sacrifice (refer Tables 2-1 and 2-2). Another consideration regarding price perception is that in reality reference prices are usually available as a comparison at the point of purchase and consumers do not have to rely on their price knowledge. As long as consumers have a rough idea of how much a product should cost, comparisons can be made at this stage.

In traditional models of perceived value, price as an objective external product characteristic has been shown to influence perceived value in two ways as shown in Figure 2-1, (p. 18). These are positively in terms of perceived quality and negatively in terms of perceived sacrifice (Agarwal \& Teas, 2002; Dodds, et al., 1991; Monroe, 2003; Suri \& Monroe, 2003; Sweeney, et al., 1999; Teas \& Agarwal, 2000). As 
noted, studies of perceived value (e.g. Dodds, et al., 1991) often use a value for money conceptualisation and operationalise perceived value in a similar way to the price dimension of the perceived value scale developed by Sweeney and Soutar (2001).

Dodds et al. (1991) used price as an independent variable in their study and perceived quality, perceived value for money, and willingness to buy were dependent variables. Perceived price was implied in the negative relationship between objective price and perceived value and the positive relationship between objective price and perceived quality but not measured explicitly (Dodds, et al., 1991). In this way the influence of price perception on these other variables was investigated.

Prices are perceived as similar or different to prices the customer believes they have previously paid. Making a price-based choice in favour of a higher priced alternative may occur if the price cue leads to the consumer perceiving product differences. Such a decision is not predicted based on the traditional model of demand. In this case the price may be used as an indicator of quality, the consumer may be trying to impress others or they may be avoiding risk associated with the choice of the cheaper item. Recall of prices has been found to be negatively related to price as it is perceived in its positive role as a signal of quality (Lichtenstein, Ridgway, \& Netemeyer, 1993). Biswas and Sherrell (1993) showed that confidence in price estimates was greater for those with high familiarity or expertise in the category. This is as expected on the basis that a consumer who is familiar with a product category will be more able to recall prices and use these as a comparison to assess value than the novice who may rely on price as a cue to signal quality and hence allow value to be determined.

On the basis of information processing theories of consumer choice, the current knowledge that a decision-maker possesses affects processing of new information on that topic; it is easier and more efficient (Johnson \& Russo, 1984). On this basis, it is probable that prior price knowledge will impact on the perceived value offered. It has been shown for adult consumers that increasing prior knowledge (a combination of product and price knowledge) is accompanied by an increase in the acceptable price range (Rao \& Sieben, 1992). 
The concept of perceived sacrifice has been measured from a budgetary constraint perspective and it was found to negatively impact perceived value (Teas \& Agarwal, 2000). Price was also found to directly influence perceived value (Teas \& Agarwal, 2000). Children are likely to have budgetary constraints. More recently, Hansen (2005) incorporated multiple decision-making perspectives into a model and illustrated that perceived price was positively related to perceived quality and perceived quality was positively related to buying intention but perceived price did not impact directly on buying intention. Perceived price was operationalised in terms being high or low in comparison to average market prices as well as generally.

Perceived sacrifice has been used to describe all the costs associated with a purchase an approach supported by Zeithaml's (1988) findings by incorporating all costs including price, contributing to perceived sacrifice as part of perceived value. Examples are time, effort, search and psychic costs.

\subsubsection{Children and Prices}

Relatively few studies have investigated children's perception and use of prices in their consumer behaviour.

While it is known that children enact shopping script (the sequence of shopping events) from as young as three years (Karsten, 1996, cited in John, 1999), evidence suggests very young children may pay little attention to price (John, 1999) other than knowing that there is a price to pay and that money is exchanged. According to McNeal and McDaniel (1981, cited in John, 1999) by eight to nine years, they know products have prices, where to look for this information, and that variability exists between products and places of purchase.

According to Ward et al. (1977), children are unlikely to include price information when listing what they would want to know about a new product prior to purchase. There is an increasing trend to do so as they get older, with fifteen percent of four to five year olds and thirty one percent of eight to nine year olds including price as an important attribute compared with forty one percent of eleven to twelve year olds. This study related to a television set, which is not a product typically purchased by children. In a study by McNeal (1992), children were required to produce drawings to describe shopping. Only ten percent of the drawings describing shopping included 
price information. According to McNeal (1992), with regard to children and pricing, when other information is available such as brand name and shop image, these cues may be more important to the child in determining the price-quality relationship.

Several studies have measured price knowledge in children using price recall measures (Erickson, 2003; Pliner, Freedman, Abramovitch, \& Darke, 1996; Stephens \& Moore, 1975). A study by Stephens and Moore (1975) measuring price knowledge showed older adolescents were more proficient at estimating prices and specifying brands than younger adolescents but neither group exhibited high proficiency. The most accurately priced items were those most salient to the groups. In this study, the price of the radio was the most accurate. Weekly spending, family communication about consumption, and brand specification were the independent variables positively correlated with price accuracy for older adolescents. For younger respondents, family communication about consumption, media exposure, slogan recall and brand recall were positively correlated. However, this study took no account of product knowledge, experience or salience of products to the target audience. It relied completely on survey methodology and explicit memory of prices, which may not capture the actual pricing knowledge of the child if this memory is recorded implicitly or as a fuzzy trace.

A 2003 doctoral dissertation reinvestigated price knowledge in children using price recall accuracy. This work showed an increase in accuracy with age between first, third and fifth graders with fifth graders exhibiting adult like levels, a significant effect of consumer socialisation was also found (Erickson, 2003). However, the results of the price knowledge measure were again extremely low, with prices averaging two hundred percent different to actual prices for the youngest respondents and the eldest respondents. Fifth graders recalled prices averaging seventy six percent different from actual prices. The measures of price knowledge were explicit in nature. An investigation in the economic field attempted to investigate this concept using a categorisation procedure to code responses (Pliner, et al., 1996). If price estimates fell within a plausible category they were counted as correct (e.g. \$0.01-\$1.00, \$1.00-\$10.00 ...). All children aged eight to ten years were reasonably accurate in their estimates. The number of items correctly categorised by price increased with increasing age. The method used allowed respondents to score correctly even if the memory was not explicit, that is unable to be recalled exactly. 
Consumers generally have poor price recall and on this basis price is often attributed a low level of importance. Market place evidence of changes in price and the associated behaviour of consumers, is contradictory to this conclusion (Monroe \& Lee, 1999). Several studies support the importance of price to child consumers and show an increase in their understanding with age. In two studies Moschis and Churchill $(1978,1979)$ found younger adolescents had more favourable attitudes to prices than older adolescents. They suggest an increase in experience and hence, understanding of pricing techniques, results in a decrease in confidence that price is an indicator of quality and performance.

Investigating adolescent decision-making styles, Shim (1996) found age to be positively correlated to the price conscious/value for money style as well as the habitual/ brand loyal style and negatively associated with the recreational/ hedonistic decision style. This provides further evidence that adolescents do, in fact, regard price as important in their consumer decision-making. When making a decision about which product to buy, they favoured products that were on sale (prices reduced) and that had a well-known brand name ahead of those favoured by peers (Moschis \& Moore, 1979).

The importance of price in product choice was also illustrated by a study in high school cafeterias where prices of fresh fruit and baby carrots were reduced by fifty percent. The price reductions resulted in a four-fold increase in fresh fruit sales and a doubling of baby carrot sales (French, 2003).

Fox and Kehret-Ward (1985) conducted an initial qualitative investigation into theories of price (reasoning for price differences) for children aged five and nine years and adults, in order to determine whether regularities in experience would lead to qualitatively different theories reflected in prices at differing ages. Their research focussed on how retailers justify price differences within a category, given three major influences on the child's developing theory; experience with buying and selling, social perspective taking and moral reasoning. They identified three levels of children's development with the third level having a sub level. They found the majority of five year olds reasoned at level 1 which requires the child to have an operational theory in that they know the properties that make them want to buy something, they believe that prices are fixed, and that they vary with certain properties such as size. At this level, the child can shift perspective to a limited 
extent in that he realises the seller may have different things in mind when setting the price than the buyer does. They cannot articulate the source of the price the seller uses, but it can be inferred from their responses and they understand the numbers on the price are a measure of value. The reasoning regarding payment at this level represents level 1 of the moral reasoning hierarchy in that the child appeals to the consequences of not paying, as a reason to pay.

The majority of nine year olds cited attributes of products and/or costs such as labour or manufacturing inputs as reflected in price. Payment was viewed in terms of a 'value for value' theory of price or reciprocal exchange, stage 2 of Kohlberg's theory of moral reasoning.

In another investigation by the same researchers (Fox \& Kehret-Ward, 1990) into naïve theories of pricing, the levels were refined. In this study, they compared adults with five, ten and thirteen year olds. It was found that in the absence of cueing, all adults gave a source for the price in response to a question regarding the reasoning behind the setting of a price. In the absence of cueing, fifty percent of five year olds had no awareness of price as a fixed amount of money that must be exchanged for a product. Forty percent of five year olds used a price criterion of size and had no theory of why. Eighty four percent of ten year olds and fifty percent of thirteen year olds used size alone as a price criterion and did not mention a source of value. Ten percent of five year olds, sixteen percent of ten year olds and fifty percent of thirteen year olds spontaneously mentioned a source of value. Using cue facilitated sources of value, most nine and ten years olds were found to use a source of value in terms of production inputs when reasoning about prices. Forty three percent of adults and seven percent of thirteen year olds included relative scarcity and demand considerations in their theories, but only when cued (Fox \& Kehret-Ward, 1990). These findings support the consumer socialisation theory of John (1999) and Piagetian cognitive developmental theory in that seven to eleven year old children are cued processors hence required cueing to mention a source of value.

Fox and Kehret-Ward (1990) reasoned that due to the complexity of the task, the requirement for cues extended to older subjects (thirteen years), fifty percent of whom were still requiring cues to determine underlying sources of value reflected in prices. The sample size for this study was small, with only fourteen respondents in each age group. The findings may also be consistent with more recent theories of 
implicit versus explicit knowledge and cued processing of information in that cueing allows retrieval of implicit knowledge.

Turner and Brandt (1978) illustrated an increase in consumer skill and identification of value in terms of ability to compare and compute unit prices with age, home responsibility and money experience. Their study used a simulated market to test four year olds and eight to nine year olds for the selected skills. The three skills were: saving to pay for purchases, comparing packages to find the one containing more product and ability to determine unit price and hence value for money. Results illustrated younger children either exhibited none of the skills (thirty seven percent for test 1 , seventy percent for test 2 ) or only one skill. Which skill, was not detailed. A small percentage (nine percent for test 1, sixteen percent for test 2) of older children exhibited all three levels of skill. It has been shown that a large proportion of adults are unable to compute and compare unit prices (Capon \& Kuhn, 1982).

Clearly the price of a product and the way it is perceived by a consumer is an important contributor to the perceived value of an alternative for adults. Children on the other hand appear to have less regard for price as an important attribute of products particularly under the age of about ten years. Children's knowledge of prices appears to be most accurately represented as an estimate rather than an explicit memory. By nine to ten years of age, most children viewed price in terms of the product offering determined on the basis of size with manufacturing inputs accounting for price differences. Given these findings it remains unclear whether price or paying for an item contributes to the value perceived by children and whether it is perceived differently as children get older.

The next section will focus on the benefits perceived by the consumer beginning with perceived quality as identified by Zeithaml (1988).

\section{4. Perceived Quality}

Models of value perception describe benefits to be gained in terms of quality alone (Dodds, et al., 1991; Monroe, 2003) or in combination with other concepts (Lin, et al., 2005; Petrick, 2002; Roig, et al., 2006; Sheth, et al., 1991a; Sweeney \& Soutar, 2001; Tsai, 2005; Zeithaml, 1988). 
Using a nondurable product, Zeithaml (1988) conducted a qualitative investigation to define price, quality and value concepts from a consumer viewpoint as discussed. Quality was defined as "the consumer's judgement about the superiority or excellence of a product" (Zeithaml, 1988, p. 5). Zeithaml (1988) defines perceived quality for adult consumers using four specific elements: it is different to objective quality, is regarded as a higher level abstraction rather than a specific attribute of a product, it is a global assessment sometimes resembling attitude, and is usually made within a consumer's evoked set. Zeithaml (1988) found that perceived quality led to perceived value.

In Zeithaml's (1988) investigation regarding perceived quality, she found that consumers focussed on purity and freshness to infer of quality for fruit juices. Later, six general quality dimensions for durable goods were identified: ease of use, versatility, durability, serviceability, performance and prestige (Brucks, Zeithaml, \& Naylor, 2000). Dodds, Monroe and Grewal (1991) operationalise perceived quality in terms of reliability, workmanship, quality, dependability and durability.

Historically, the price-quality relationship has been extensively researched, with early studies varying only price information (Monroe, 1973). These single-cue studies found that satisfaction was enhanced for higher priced brands when price was the only differential information available. Choice for higher priced brands was consistent with beliefs regarding quality differences for particular products and was more likely when the price differences were large (Leavitt, 1954). Several other single-cue studies followed including replication of this study, and all supported a positive price-quality relationship (McConnell, 1970; Monroe, 1973).

Single-cue studies have been criticised on the basis that manipulation of only one variable may result in the large effects observed (Monroe \& Krishnan, 1985; Rao \& Monroe, 1989), particularly the work of Leavitt and the replication of this study where price was the only variable manipulated (Monroe, 1973). According to Rao and Monroe (1989), in order to empirically test the relationship, multiple independent variables should be manipulated to provide valid results as, in reality, numerous cues are used to judge quality. These criticisms resulted in a stream of research based on cue utilisation theory which varied multiple cues, both intrinsic and extrinsic to the product (e.g. Richardson, et al., 1994). Intrinsic being internal characteristics of the product itself, for example the nutritional content of the 
product, and extrinsic cues being product related attributes external to the product such as price, brand name, store name and country of origin (Olson and Jacoby, 1972, cited in Monroe \& Krishnan, 1985). Zeithaml's (1988) study indicates that, while the intrinsic attributes signalling quality are product-specific, the dimensions of quality can be generalised to product classes. Findings also support use of extrinsic cues as general indicators of quality. On the basis of an extensive literature review and findings from her exploratory study, Zeithaml (1988) proposed conditions under which consumers would rely on each type of cue. Results supported greater reliance on intrinsic cues at the point of consumption, in pre-purchase situations, when intrinsic attributes are search attributes and when intrinsic cues have high predictive value. Greater reliance on extrinsic attributes in initial purchase situations when intrinsic cues are not available, when evaluation of intrinsic cues requires more time and effort than perceived to be worthwhile and when quality is difficult to evaluate (Zeithaml, 1988).

This investigation focuses on children who may be new to independent purchasing; as such some purchase situations for these young consumers may be initial purchases in terms of specific brands. Their purchases are typically low priced and may be difficult to evaluate intrinsically without prior experience, hence extrinsic cues may be of greater importance than intrinsic cues.

Many investigations have addressed the indicative relationship between extrinsic cues and product quality perceptions for adults. The findings of multicue studies investigating price and quality have been varied (Brucks, et al., 2000). This may be due to the additional sources of variance introduced in multicue studies as a result of manipulation of the independent variables in combination with sensory, memory, and response variability (Monroe \& Krishnan, 1985). Perceived price - quality research findings are variable across individual consumers (Shapiro, 1973) and differ between products (Gardner, 1971). Not all consumers link price to quality and if they do they are likely to use this link under specific conditions such as when the risk of product failure is high (Peterson \& Wilson, 1985).

A meta-analysis of previous work showed positive and statistically significant relationships for brand and price in relation to perceived quality. Store name was found to exert a small influence but this relationship was not statistically significant (Rao \& Monroe, 1989). A model incorporating these extrinsic factors as positive 
influences on perceived quality was described (Dodds, et al., 1991). They found that the price alone effect was larger than any other combined price cue effect. The effect of brand on quality perceptions was found to be large, whether alone or in combination with price and store information. The influence was larger in the combined situation, indicating these cues augmented the brand cue as quality indicators. Store name had a moderate influence and this diminished in the presence of the additional cues.

Miyazaki, Grewal and Goodstein (2005) suggested that the price manipulation used in the Dodds, Monroe and Grewal's (1991) study was not high enough to fit the prestige brand and hence the brand cue overwhelmed the price cue when combined, resulting in a weakening of the price-quality relationship. In accordance with cue consistency theory, they found that when intrinsic cues are scarce, the price-quality relationship is enhanced by pairing with a second cue consistent in strength. They also found that when the cues are inconsistent, the negative cue is more salient and is emphasised in quality evaluations. This finding has been suggested by these authors to be the reason for the equivocal results found in previous multicue, price-perceived quality studies.

A meta-analysis by Rao and Monroe (1989) of previous work showed positive and significant relationships between price and perceived quality, as well as brand name and perceived quality for adults.

Brucks, Zeithaml and Naylor (2000) investigated the influence of price, brand and product attributes on judgements of quality dimensions and found price and brand were searched for most when prestige was being evaluated. They considered prestige to be a dimension of quality, on the basis of their exploratory work.

Studies relating objective quality and price indicate the relationship is, in reality, weak and product specific (Gerstner, 1985). It should be noted that a major limitation of this study is that there is a lack of agreement regarding measurement of objective quality (Zeithaml, 1988).

\subsubsection{Children and Perceived Quality}

Very little work has been carried out regarding children and perceived quality. Pliner et al. (1996), investigated the general rule that items that cost more are of greater 
value in that they are of higher quality or are more desirable. They asserted that to function effectively as a consumer, one must understand this relationship. An experiment was conducted in which three identical boxes were presented containing a gift and marked with a price $(\$ 1, \$ 2$ or $\$ 3)$. The $\$ 3$ gift was chosen by sixty three percent of respondents and ten percent chose the cheapest one. Qualitative investigation supported the use of a price-perceived quality rule. When results were analysed by age, the effect was strongest for the eight to nine year old group in comparison to the five to seven year and the ten to twelve year age groups. Reasoning for choice amongst the oldest group revealed that a social motive was influencing choice of the middle price. Children had chosen the mid-priced item over the more expensive item to avoid being greedy generally, or due to the fact that because it was a gift one shouldn't take the most expensive one.

Moschis and Churchill (1978) found that with increasing age, attitudes to prices are less favourable and hence the older adolescent may have decreased confidence in price as an indicator of product quality and performance. Adult consumers are more likely to infer quality on the basis of price when they know price and quality are positively related for that category (Rao \& Monroe, 1988). Under conditions of high time pressure, relatively high prices have been shown to be associated with higher quality perceptions and lower perceived sacrifice, even when the consumer was motivated to process information. When motivation to process the information was low, consumers processed price information heuristically under conditions of both high and low time pressure (Suri \& Monroe, 2003). Motivation to process might be high in children given their lack of, or low income and limited purchasing opportunity. Time pressure is likely to be lower for children as they have fewer demands on their time compared to adults.

As children become more experienced shoppers, they will be making more repeat purchases, have increased product knowledge, and have greater ability to evaluate intrinsic attributes rather than relying on extrinsic cues. They may also be more aware of the signals of extrinsic cues such as price and brand. Whether they use product attributes to signal quality is not known. 


\section{5. Children's Use of Product Attributes}

There is a change in children's ability to evaluate and compare products with age. Preschool children cannot focus on important, relevant information whereas with school age children there is an increase in their ability to focus on the most important information (John, 1999). Bahn (1986) showed that the number of attributes used in product evaluations increases as children get older and develop cognitively. This difference between preoperational (mainly four to five years) and concrete operational (eight to nine years) children (as defined by Piaget, refer Section 2.7.2.1) was shown for cereals but not beverages. The dimensions used also differed for cereals. One explanation is that cereals may be perceived as more heterogeneous than beverages. These results may also be interpreted from an information processing perspective in terms of a greater amount of information being processed by older children when it was relevant.

In a study of the dimensions considered in overall preference with children it was shown that by late adolescence, preference judgement on two or more dimensions were incorporated into overall preference (Capon \& Kuhn, 1980). This increasing ability to incorporate judgement on more than one dimension and ability to focus only on relevant information might also be evidenced in value perceptions with age.

In their investigation of the information children would use to select a product Ward, Wackman and Wartella (1977) found that while the majority of children across all ages (four to twelve years) mentioned physical attributes, with increasing age there was a significant increase in the mention of price and functional attributes such as quality.

\section{6. Brand}

Consumers use marketplace cues to infer quality, the product's overall superiority or excellence (Zeithaml, 1988). Brand is a marketplace cue which has been shown to significantly impact the way consumers perceive price in terms of the quality it signals (Rao \& Monroe, 1989). According to the American Marketing Association, a brand is "A name, term, design, symbol, or any other feature that identifies one seller's good or service as distinct from those of other sellers. The legal term for brand is trademark. A brand may identify one item, a family of items, or all items of 
that seller. If used for the firm as a whole, the preferred term is trade name."(AMA, 2011). Given that value is the result of a trade-off between quality or benefits and monetary sacrifice, then a positive attitude toward the brand may be an indication that increased value is offered and hence an increase in the upper limits of the acceptable price range would be observed and higher prices would be perceived as more acceptable. Variation in perception of value has been shown to differ by segment and perceived brand value (Sinha \& DeSarbo, 1998).

\subsubsection{Children and Brands}

The importance of brands in children's consumer decision-making and the emphasis on their use compared to adult consumers has been well documented. The 'Brandchild' survey revealed that eight to twelve year olds were brand advocates persisting with requests for brands they want, but were only brand loyal if the brand appealed to their friends (Lindstrom, 2003). According to McNeal (1987), children seem to place emphasis on brands despite the products being seen by parents as very similar and substitutable. Their brand awareness increases with age and begins with child oriented products with awareness of more adult-oriented products developing as these become more salient (Ward, et al., 1977). By ten to eleven years, children have a sense of social meaning and prestige associated with brand names (John, 1999).

Brand recognition has been shown to begin as young as two years old (Hite \& Hite, 1995). They showed in an investigation of two to six year old children, that this group rely on non-functional, perceptual (visual) brand attributes when making choices and determining preference. Hite and Hite (1995) used peanut butter and cereal and a simple comparative method involving comparison of two products; one nationally advertised, the other not, in preference judgements. Haynes, Burts, Dukes and Cloud (1993) used children's clothing and parental response regarding the frequency that their children preferred brand names and/or characters on their clothing as the measure of brand importance. They found that seventy percent of children aged three to six years did not request brands for clothing; however requests for clothing with brand characters occurred at least half of the time for forty one percent of children. Fifty one percent of children's letters to Santa included specific brands in requests (Otnes, Kim, \& Kim, 1994). It is clear that brands are recognised 
and become increasingly important as children grow and that they are particularly important as visual perceptual cues for younger children.

An early investigation of seven to twelve year olds showed that, as children got older, brand became an increasingly important consideration in their consumer decision-making (Moschis \& Moore, 1979). Brand name and price were found to be instrumental in the buying decisions of older children. Trade publications such as Lindstrom's (2003) 'Brandchild' study identified that for the eight to twelve year old age group, brands are extremely important on the basis of what the brand itself means and what it means about them to own it.

Belk, Mayer and Driscoll (1984) found that by nine to twelve years, children associated certain brands with personal characteristics of the owners. The brand based stereotypes were found to be greater for eleven to twelve year olds than nine to ten year olds.

Achenreiner and John (2003) have argued that incorporation of more abstract or symbolic thoughts into consumer judgements requires greater cognitive ability than observable attributes require, hence these skills emerge later between ten and twelve years (Achenreiner \& John, 2003). According to these authors, brands may be perceived as perceptual cues that are recognised as familiar, they may relate to perceptual features of products, or they may have abstract meanings which are not observable. These abstract meanings may be functional (such as quality) or symbolic such as prestige or social status. Their findings regarding the development of brand meaning support this assertion in that brand names serve as simple perceptual cues in product evaluations for eight year olds. This was evidenced by their equivalent evaluation of two products and the owners of the products which differed only in terms of brand popularity. For older children aged twelve and sixteen years, brands were associated with conceptual or symbolic meaning as evidenced by more favourable product evaluations and owner impressions for the more popular brand (Achenreiner \& John, 2003).

Chaplin and John (2005) found that self-brand connections increased in number and sophistication between the ages of eight and eighteen years. Eight to nine year olds mentioned significantly fewer brands than twelve to thirteen year olds in their response to a "who am I?" question both verbally and using a collage technique. 
Twelve to thirteen year olds mentioned fewer brands than the seventeen to eighteen year olds. Younger respondents' self-brand connections were based on concrete associations with brands such as the fact that they owned a particular brand. Older children and adolescents made deeper connections based on similarity between their self-concept and the personality and symbolic nature of the brand.

Attitude toward the brand has been used to measure consumer response to a brand image. Brand attitude has been defined: "Attitude toward the brand is a psychological tendency that is expressed by evaluating a brand with some sort of favour or disfavour." (Eagly \& Chaiken, 1993, cited in Pecheux \& Derbaix, 1999, p. 21). In developing a validated scale for measurement of the brand attitude with children aged eight to twelve (Pecheux \& Derbaix, 1999), two underlying variables associated with the overall brand attitude were identified; a hedonic aspect and a utilitarian aspect. The hedonic aspect is described as consummatory affective gratification, from sensory attributes and the utilitarian aspect as instrumental, from functional and non-sensory attributes. These dimensions may be related to the value children perceive.

Between the ages of eight and twelve years the importance of the brand has been shown to change from a familiar perceptual attribute of a product to incorporate conceptual meaning beyond the concrete. By ten years of age, conceptual meaning of brands beyond the concrete is evidenced in categorisation tasks, however such meaning does not relate to impression formation. By twelve years of age, these conceptual meanings are evident in product evaluations and meaning associated with social status, prestige and group affiliation have been shown to be understood.

Given the evidence to date with regard to adult consumers from qualitative investigation of perceived value (Zeithaml, 1988) and that children's attitudes to brands have been shown to be comprised of utilitarian as well as hedonic dimensions, brand may influence other benefit dimensions of perceived value. On the basis of increasing cognitive development as children get older and the emergence of abstract and symbolic meanings of brands, an increase in perceived value of popular brands may follow. 


\section{7. Consumer Socialisation Theory}

There has been extensive research into aspects of consumer socialisation or the transmission of consumer skills to children with research increasing in the 1970's and continuing over the past thirty-six years (for an extensive review see John (1999)). The initial broad investigation into the consumer socialisation of children by Ward, Wackman and Wartella (1977) provides a theoretical framework on which many subsequent investigations have been based. The definition of consumer socialisation by Ward (1974) as "processes by which young people acquire skills, knowledge and attitudes relevant to their functioning as consumers in the marketplace" (Ward, 1974, p. 3), has led to more narrowly focused research in these specific areas of children's consumer behaviour.

Studies investigating influences on consumer skills, knowledge and attitudes of children provide a theoretical framework based on two theories of human development (Moschis \& Moore, 1979; Ward, et al., 1977). These are theories of cognitive development and social learning. Evidence supports the influence of both cognitive developmental and environmental factors on consumer socialisation of children (Haynes, et al., 1993; John, 1999; John \& Whitney, 1986; Moschis \& Moore, 1979; Ward, et al., 1977). Cognitive factors are explained in terms of Piagetian theory and information processing theory and refer to age related changes in ability. Environmental factors are explained in terms of social learning theory.

In her extensive review of the literature regarding children's socialisation for the previous twenty five years, John (1999) uses an age-based framework to classify the research which is Piagetian in nature, in that it is stage based. Her framework incorporates information processing theory to explain differences in cognitive abilities between age-based stages. She also incorporates social perspective taking as detailed by Selman, (1980, cited in John, 1999) which is also described in terms of stages, characterised by differences in perspective taking. Finally impression formation or changes in ability to make social comparisons (Barenboim, 1981; John, 1999 ) is included. While the role of socialisation agents is acknowledged in many of the studies, these are noted rather than being the focus of the interpretation. The theoretical framework resulting from this review describes three stages of consumer 
socialisation based on these changes in cognitive and social development. The stages are summarised below:

Perceptual Stage (ages 3-7 years) thought is focussed on perceptual features referring to readily observable characteristics of the marketplace. The focus is on single dimensions or attributes represented by concrete details. This stage is characterised by a surface level understanding of stores and brands. The perspective taken is largely egocentric.

Analytical Stage (ages 7-11 years) is characterised by large shifts in cognitive and social development. Thought shifts from a focus on perceptual to more symbolic along with marked increases in information processing abilities. Two or more dimensions are used to analyse products and brands and thought incorporates functional or underlying dimensions. Children can consider both their own and others perspectives.

Reflective Stage (ages 11-16 years) is characterised by more complex, sophisticated knowledge of concepts with multiple dimensions used to analyse products and brands. Thinking and reasoning becomes more reflective. Awareness of others perspectives and their own self-image results in consideration of both their own and others perspectives in a social context.

In summary, John's (1999) review provides support for an age/stage based consumer socialisation conceptual framework based on cognitive developmental progression in combination with changes in social perspective taking and impression formation.

Social learning theory has been deemed relevant by many consumer socialisation researchers to the study of consumer behaviour of children (Bush, Smith, \& Martin, 1999; Moschis \& Churchill, 1978, 1979; Moschis \& Moore, 1979; Ward, et al., 1977). Information processing theory has also been deemed relevant and incorporated into models of consumer socialisation (Capon \& Kuhn, 1980; John, 1999; Roedder, 1981; Ward, et al., 1977). Ward, Wackman and Wartella's (1977) model is depicted in Figure 2-2. Information processing theory of cognitive development has been incorporated with the Piagetian stages on the basis that this theory provides a mechanistic description of changes in cognitive development (Ward, et al., 1977). 
Independent Variables

Cognitive Development

Family Context

- Parents own consumer behaviour

- Parent-child interaction

- Children's independent consumer opportunities

\section{Child's Information Processing}

Initial processing

Central processing

Behaviours

Money use

Information search

Interpretation and

Spending

comprehension

Structuring of

Saving

information

evaluation

Information selection

Use of information

Purchase

requests

\section{Television Advertising}

Figure 2-2 Consumer Socialisation Model (Ward, et al., 1977, p. 29)

Developmental theories differ on the basis of three main issues. The first is whether development is determined by nature or nurture. The second is whether humans are active or passive participants in development while the third is whether the process is continuous or discontinuous--progressing through a series of stages (Shaffer, 1999). Differing theories place emphasis on differing developmental changes and no one theory can completely describe human development.

In order to investigate the development of children's perceptions of value, these relevant theoretical foundations grounded in human development and consumer behaviour were reviewed the details are described in the following sections.

\subsubsection{Social Learning Theory}

Social learning theory views the child as passive in the developmental process. They are moulded by their environment rather than biological influence and development is continuous through addition of learned responses (Shaffer, 1999).

Learning theories generally provide precise and testable hypotheses with an emphasis on the cause of overt behaviour (a behaviouristic perspective) (Miller, 
1993). They assume that learning occurs by performing responses and experiencing their effects (Bandura, 1977). Of particular relevance to development of consumer behaviour in children is social learning theory. This theory incorporates traditional learning theory of classical and operant conditioning with vicarious learning (Bandura, 1977). Classical conditioning refers to an automatic response learnt as a result of repeated exposures to a stimulus that does not invoke a response, paired with a stimulus that does invoke a response. The pairing results in a response being elicited by the stimulus not usually eliciting a response. This type of conditioning is used to explain very simple behaviour. Operant conditioning refers to learning that occurs regarding a stimulus and a response. Learning occurs as a result of the rewards received for the behaviour. This type of learning is useful for explaining more complex behaviour (Schiffman, et al., 2001).

Social learning theory places particular emphasis on the added dimension of vicarious learning through observation of behaviour of others and its consequences (Gilbert, Fiske, \& Lindzey, 1998). It retains the basis of traditional learning theory in that it is the study of how basic learning occurs in response to environmental influences and incorporates the influence of these experiences on development through modelling, instruction and vicarious learning (Bandura, 1977). Bandura builds on traditional learning theory in that he acknowledges that humans are cognitive beings (Miller, 1993) and his emphasis on observational learning permits the explanation of new responses acquired by children, through role models who are not intending to teach them (Shaffer, 1999).

There are several major criticisms in the psychological literature regarding this theory (Miller, 1993; Shaffer, 1999). Firstly, it has been criticised as being an oversimplification of human learning with too little emphasis on cognitive developmental changes. Secondly, individual differences are attributed to differences in environmental influence rather than biological influence. Thirdly, it lacks consideration of the context in which learning occurs (Shaffer, 1999).

The importance of observational learning is without question when it comes to children's consumer socialisation; however it is unlikely, on the basis of the criticisms cited above, to completely explain children's consumer behaviour. As mentioned earlier, consumer socialisation research with children provides evidence of the dual contributions of both the behaviourist approach (social learning theory) as 
well as the cognitive developmental approaches in explaining children's consumer behaviour. Very young children are most likely to experience shopping through observation. As they age and have money of their own they will gain experience with making consumer decisions and evaluating alternatives. Consequences of behaviour will be observed and learning will occur.

While Ward, Wackman and Wartella (1977) do not specify incorporating social learning theory in their conceptual model of consumer behaviour they include the environmental factors of parent's own consumer behaviour, parent-child interaction, children's independent consumer opportunities and television advertising as independent variables. Their findings show that theories of cognitive developmental change explain more variation in consumer skills than do environmental factors. They did show that for consumer skill development, the mother's own consumer behaviour (measured in terms of amount and frequency of information processing in consumer decisions) positively influenced skill development for the older children in the sample (aged six to seven and nine to ten years).

Evidence from the work of Moschis and colleagues supports the influence of parents, peers and mass media (primarily television) on children's consumer behaviour (Moschis \& Churchill, 1978; Moschis \& Moore, 1979). Economic motivations for consumption by adolescents, (defined as a cognitive orientation concerning the importance of functional and economic features of products), has been shown to be encouraged by family communication with parents regarding purchasing (Moschis \& Churchill, 1978). Economic motives are referred to as rational and socially desirable consumer skills. Peers are found to be more influential over irrational values (materialistic values and social motivations i.e. the importance of conspicuous consumption). The same study showed that the amount of mass media viewed was positively related to social motivations for consumption (Moschis \& Churchill, 1978). Generally, the factors influencing more rational motivations for consumption are the opposite of those influencing social and materialistic motivations (John, 1999).

Nguyen (2003) showed that children who rated their parents as high in support/less controlling were less materialistic than those who rated their parents low in support/ more controlling. Those from lower income families were more materialistic than those from higher income families. Those children, who rated their parents high in 
materialism, were also more materialistic themselves than those who rated their parents low in materialism.

Recent work has identified five major influence factors in children's consumer socialisation; irrational social (peer) influence, the importance of television, familial/parental influence, marketplace shopping influence and brand importance (Dotson \& Hyatt, 2005). They measured the relationship between age and these influence factors and found that older children experience more irrational peer influence and less rational parental influence. There was no correlation between age and other socialisation influence factors.

\subsubsection{Cognitive Developmental Theories}

Cognition refers to the activity of knowing and the processes through which knowledge is acquired (Shaffer, 1999). These processes allow us to understand and adapt to our environment and include attending, learning, thinking and remembering (Flavell, Miller, \& Miller, 1993).

Three major theoretical perspectives dominate research on children's cognitive development (Shaffer, 1999). First, Piaget's theory of cognitive development views the person as an active participant in development, constructing new knowledge based on experience. Development is regarded as discontinuous, progressing in a universal stage-like pattern determined by nature and experience. Second, Vygotsky's sociocultural viewpoint emphasises the importance of social transaction and culture on cognitive growth and provides an alternative explanation of learning development that is continuous and where the person is an active participant. The third and more recent theoretical perspective is information processing. This theoretical perspective views the person as an active information processor and proposes continuous change influenced by both maturation as well as social, cultural and educational influences (Shaffer, 1999). There are many information processing theorists. Each of these three major theoretical perspectives is discussed in the following sections.

\subsubsection{Piagetian Theory}

Piaget describes cognitive development in terms of broad sequences of development. His work has provided the foundation of the discipline of cognitive development 
and, until recently, largely guided research in this area. While limitations have been shown to exist with his theory, his findings and ideas have had a major influence on the field of psychology (Crain, 2000; Schaffer, 2000; Shaffer, 1999). Piaget's theory of cognitive development has also been influential in the field of children's consumer behaviour (John, 1999; Moschis \& Churchill, 1979; Ward, et al., 1977) and economic socialisation (Berti \& Bombi, 1988; Strauss, 1952).

Piaget proposes that children pass through an invariant sequence of developmental stages and at different stages think in qualitatively distinct ways. This discontinuous stage like development is one basis on which this theory can be differentiated from alternate theories (Miller, 1993; Schaffer, 2000; Shaffer, 1999).

One important assumption underlying Piaget's theory is that if children are to know something they must construct the knowledge themselves. He uses schemas to describe mental structures which children use to represent, organise and interpret their experiences. Piaget uses three types of schemas, behavioural, symbolic and operational and these are used to describe the stages through which children develop (Shaffer, 1999).

Piaget proposes four stages of cognitive development that determine the child's skill and competence. He proposes that all children progress through all the stages in the same order and that each stage is a requirement for progression to the next stage. $\mathrm{He}$ recognises that individual differences exist between children in the age at which they progress and that cultural and other environmental influences may accelerate or slow the rate of intellectual progression. These stages are thought to be universal across cultures and to a large extent biologically based. Once general principles are acquired, Piaget's theory assumes they will transform all psychological domains (Keller, 2000).

The four general stages proposed by Piaget are characterised by the schemas he described. These are sensorimotor (ages birth to two years) where behavioural schemas develop. Symbolic schemes emerge in his second stage, described as preoperational (two to seven years) whereby children can solve problems and think about objects and events without having acted upon them and where they can represent experiences mentally as symbols such as words and images. However, their thinking is unsystematic and illogical. The third stage, described as concrete 
operational (seven to eleven years), is where children acquire the ability to operate cognitively on tangible, concrete objects and events, that can be represented symbolically, to reach a logical conclusion, for example the ability to solve conservation problems. This systematic thinking requires reference to concrete (observable) objects and activities. Formal operations (eleven to fourteen years) is characterised by similar mental actions but these can now be performed on ideas and propositions. They can now think systematically about abstract and hypothetical objects and activities and they can also think inductively (Crain, 2000; Miller, 1993; Morris \& Maisto, 2002; Shaffer, 1999; Ward, et al., 1977).

Of interest in this study are the concrete operational and formal operational phases. The concrete operational phase is characterised by the ability to consider two aspects of a problem simultaneously including perceptual characteristics (readily observable aspects of their environment) but without acceptance of them as the only reality. Children are aware of others' perspectives and have a better appreciation of causal principles with the limitation that they refer to real tangible objects. They are able to co-ordinate two perspectives in their social and scientific thinking (Crain, 2000). Formal operations is characterised by more adult-like evaluation of stimuli, children become capable of thinking hypothetically about an activity without actually performing it and considering all possible outcomes systematically (Crain, 2000; John, 1999).

Piaget's theory of cognitive development has been shown to be flawed in several regards (Bjorklund, 1995; Flavell, et al., 1993; Gelman \& Baillargeon, 1983; Miller, 1993; Schaffer, 2000; Shaffer, 1999). His research has been shown to have underestimated the ability of developing minds in terms of when individuals can be expected to enter a stage of development or master a concept (Bjorklund, 1995). When researchers reduced Piaget's tasks to only the essentials, younger children were able to master them (Bjorklund, 1995; Schaffer, 2000). Piaget also assumed that failure to solve his problems by a child was due to a lack of the underlying concepts or thought structures necessary to do so but later research revealed that in some cases it may have been due to an inability to articulate a response rather than a lack of understanding (Shaffer, 1999).

The holistic stage approach has also been criticised (Bjorklund, 1995; Flavell, et al., 1993; Gelman \& Baillargeon, 1983; Miller, 1993; Schaffer, 2000; Shaffer, 1999). 
Firstly, there is little consistency in terms of a task performance within stages. Different problems are mastered in different orders by different children, despite the fact that they may require the same underlying principle. Examples of this are conservation problems of volume, mass and number (Miller, 1993). While evidence suggests that within a specific area competency may be acquired in small orderly steps, this is not consistent across different domains (Donaldson,1978, cited in Graue \& Walsh, 1998).

Piaget has also been criticised on the basis that his theory does not actually explain cognitive development. He does not detail what determines the child's transition between stages in terms of the maturational changes or experiences necessary to progress (Shaffer, 1999), and hence it has been asserted to have limited explanatory power (Gelman \& Baillargeon, 1983). It has also been criticised due to the lack of consideration of cultural factors. While Piaget acknowledged that cultural factors may influence the rate of development it has been shown that culture also affects how children think. Piaget's emphasis on the self-directed nature of cognitive growth may also underestimate the influence of others (Smith, 1992).

Despite these criticisms, Piaget's theory captures essential elements of children's cognitive development and provides a comparison for new ideas (Crain, 2000). It has also been shown, with some modification in terms of overlap between stages, to provide a useful framework for describing developmental changes in children's consumer socialisation (John, 1999).

\subsubsection{Vygotskian Contextualist Theory}

The contribution of social interaction to cognitive development is the basis of the sociocultural theory of Vygotsky (1978). While this theory was developed at the same time as that of Piaget it was incomplete due to the fact that Vygotsky died before the completion of his work (Crain, 2000; Shaffer, 1999). While only the theoretical framework was sketched, this view is popular in the educational area (Smith, 1992). This view proposes a continuous, socially-mediated, developmental process (Shaffer, 1999; Smith, 1992).

Vygotsky's (1978) view is essentially that learning advances development. Children can be advanced through the guidance and help of others. The help can then be gradually withdrawn resulting in the child being able to perform the skill on their 
own (Smith, 1992). "Every function in the child's cultural development appears twice, first on the social level and later on the individual level, first between people (inter psychological) and then inside the child (intra psychological)" (Vygotsky, 1978, p. 57)

Vygotsky proposed that learning creates a zone of proximal development. When the child is interacting with people in their environment and interacting co-operatively with peers they can problem solve at a higher level than they can independently. This difference is what he termed the zone of proximal development. Once the processes being shared are internalised, they become part of the child's actual development and can be utilised in independent problem solving. The child takes an active role reconstructing the task through his own understanding (Smith, 1992). In contrast with Piaget, Vygotsky emphasises social interaction to facilitate cognitive growth whereas Piaget regards children's ability to learn as limited by their stage of cognitive development.

The concept of 'scaffolding' is a term described by Bruner (1985) (cited in Smith, 1992) that comes from Vygotsky's theory and refers to the guidance and support given to the child within the zone of proximal development. Essentially the teacher allows the child to do as much as he can by himself, filling in what he cannot do. The child then takes over himself once the task has been mastered.

This theory is particularly popular in educational settings and as a mechanistic explanation of cognitive development but is a complementary theoretical perspective rather than a complete explanatory theory of cognitive development in that it describes only the facilitation of advances in cognitive development.

Reservations regarding this theory from the developmental perspective are that by pushing children forward they cannot fully develop at their current stage and that by assisting the child they are not allowed to be independent and to think for themselves (Crain, 2000).

\subsubsection{Information Processing Theories}

The information processing perspective is currently the dominant approach to the study of children's intellectual development in the field of psychology (Miller, 1993). This is due to the more detailed description it provides of how cognitive processes change gradually and continuously with age in contrast with the 
discontinuous stage perspective provided by Piagetian theory (Shaffer, 1999). This theory divides Piaget's explanatory stages into detailed processes.

Information processing approaches are not based on a single theory but rather a theoretical framework, a mind - computer analogy (Miller, 1993; Shaffer, 1999). This framework details age related changes in children's ability to gather, store and use information to construct knowledge and problem solve. It is based on several major assumptions: that people process information; they register, store, retrieve and operate on input; that there is a capacity limit to these processes in terms of amount, time to hold and process information; and that it is based on a flow and store model. In this model information flows through three processing units or stores. These are the sensory store holding sensory input, the short term store, holding a limited amount of information for a short time, and the long term store, a large and relatively permanent store. This theory also assumes humans control cognitive processes, channelling the input, planning and monitoring what they attend to and how they deal with the input (Shaffer, 1999).

In contrast to Piaget's theory, most information processing theorists do not acknowledge a qualitative difference between thought of varying ages. They view cognitive development as gradual, characterised by small increases in processing capacity, speed and types of strategies used and by an increase in the amount of general knowledge acquired. The changes described can be applied to the problems encountered (Shaffer, 1999).

Some information processing theorists do support a stage based theory (Case, 1992). Case (1992) focuses on age related changes in information processing but includes environmental influence and motivational factors to account for inconsistencies within stages. This is the view adopted by both John (1999) and Ward, Wackman and Wartella (1977) in their conceptual frameworks for consumer socialisation. However, John (1999) notes overlapping rather than discontinuous stages.

Information processing theorists are in agreement with Piaget in that the child plays an active role in their cognitive development. They also look for schemes and strategies on which children rely to generate solutions to problems.

Support for information processing theory comes from research which reveals that age-based differences in the physical capacity of the short term memory store appear 
to be small (Bjorklund, 1995) whereas speed of processing of information appears to be enhanced by past experience and increases with age (Kail, 1992, 1997 cited in Shaffer, 1999). Children's capacity for sustained attention improves throughout childhood and adolescence. Memory and processing strategies also increase and develop over this period. Strategies are defined as "deliberately implemented, goal directed operations used to aid task performance" (Shaffer, 1999, p. 281). Simpler strategies that younger children prefer are replaced by more sophisticated strategies in older children and adults, however at any age there are several possible strategies available to the child. The development is shown to be wave-like and not to progress in a stage like manner (Siegler, 1996). The work of Siegler and colleagues (Shaffer, 1999; Siegler, 1991) suggests that strategies compete and more efficient strategies are selected and used more often as the child ages.

While it is acknowledged that a simple information processing model may underestimate the complexity of human problem solving, by identifying the information processing skills that underlie competent performance in a particular area and how these skills change with age, richer and more detailed findings will emerge than alternative cognitive developmental models and these can be used to teach and inform children, to enhance their skills in a particular area as well as to understand their thinking.

Of interest in the present investigation is the development of consumer skills. "Consumer skills are defined as cognitions held with respect to basic rational aspects of consumption such as budgeting, product evaluation, and the selection of purchase criteria" (Wilkie, 1994, cited in Viswanathan, Childers, \& Moore, 2000, p. 409). Ward et al. (1977) distinguish between skill and non-skill consumer activities. In their definition, consumer skills have a "cognitive basis in that they involve information-processing or other 'thinking' capabilities which might follow the course of general cognitive growth" (Ward, et al., 1977, p. 48). Consumer information processing skills can be further defined as high or low level skills. Low level skills refer to the use of concrete perceptual attributes whereas higher level skills refer to the use of more abstract concepts and functions in information processing (Ward, et al., 1977). This research will investigate the consumer skill of value perception, a construct which may incorporate the use of both concrete 
perceptual product attributes and more abstract concepts and functions (Zeithaml, 1988).

John and Sujan (1990a) showed that age differences in product categorisation between children aged from four to ten years could be explained in terms of information processing theory. They illustrated a shift with age from the use of perceptual characteristics (e.g. shape, size, colour) at four to five years, to underlying attributes that convey the true meaning of a category (e.g. taste, flavour), as a basis for product categorisation by six to ten years. Perceptual cues are defined as "concrete attributes and the presence (or absence) of perceptual cues can be assessed based on direct, visual observation." Underlying cues are defined as "more abstract attributes which convey a deeper understanding of the category or product. These attributes generally cannot be assessed through visual inspection and need to be learned through either direct experiences or socialisation" (John \& Sujan, 1990a, p. 459). They also showed that prompting the use of underlying attributes eliminated differences between six to seven and nine to ten year olds but not between four to five year olds and six to ten year olds. These results are predicted based on the emergence of this processing strategy. Processing deficits characteristic of these ages predict the influence of prompting observed for six to seven year olds but not four to five year olds. These processing deficits are termed production deficits and mediational deficits. Mediational deficits are evidenced by the lack of skills required for use of a particular information processing strategy. Prompting cannot facilitate the use of such a strategy in children exhibiting mediational deficits. Children with production deficits do not spontaneously produce the most appropriate strategy to be used in a situation but are able to do so if prompted. According to Fox and KehretWard (1990, p. 318) "abstractness and complexity are likely to create production deficits as well as mediational deficits".

Information processing theory characterises knowledge acquisition as constructed, in that people are active processors of information. As knowledge increases, cognitive restructuring or reorganising occurs in order to form a new concept which may be completely different to the previous one or may be an expansion or change in causal relationships (Hatano \& Inagaki, 2000b). As children develop a concept of perceived value, prerequisite concepts must first develop which can be incorporated by cognitively restructuring the original concept. In categorisation tasks, John and Sujan 
(1990b) argue that children's reliance on perceptual cues results from naïve theories relating these perceptual cues to the meaning of categories. Their findings support this assertion with both four to five year old and six to seven year old groups using perceptual cues diagnostically (referring to the underlying meaning of the category) to categorise products. The diagnostic use of perceptual cues improved with age.

Fox and Kehret-Ward (1990) describe their findings regarding children's reasoning to account for variation in price in terms of naïve theories. A number of researchers investigating conceptual development describe the knowledge children have within a domain, in terms of a naïve theory (Hatano \& Inagaki, 2000b). According to these authors a naïve theory must have ontological distinctions, coherent organisations among pieces of knowledge and causal devices or explanations. Fox and KehretWard (1990) found age related differences in terms of the criterion the child believes is/should be used in a decision and the source of that criterion.

Criticisms of the information processing approach note the lack of attention paid to social and cultural influences by this theoretical view. This theory is seen as fragmented by some (Miller, 1993; Shaffer, 1999). The existence of a single limited capacity memory store has also been challenged (Brainerd and Kingma, 1985, cited in Shaffer, 1999).

An alternative information processing approach is "fuzzy trace theory" (Shaffer, 1999, p. 275). This theory views memory representations as a continuum from literal verbatim representations to vague fuzzy representations which lack the precise details (Shaffer, 1999). Generally people find it easier and preferable to reason with fuzzy traces but there is variation with age. Young children, younger than six or seven years, rely on verbatim information and older children prefer to use gist-like information (Marx \& Henderson, 1996). Gist-like or fuzzy-trace information is easier to retrieve and just as effective for solving a large number of problems. Price has been cited as an example of a memory which may be recorded as a fuzzy trace (Schaffer, 2000; Shaffer, 1999) such as high or low rather than the verbatim price information and this is supported by poor recall of exact prices in pricing research, as discussed previously.

Consumer socialisation research has utilised information processing theory to provide explanation of observed differences in cognitive ability and strategies used 
for storing, processing and retrieving information (Capon \& Kuhn, 1980; John, 1999; Roedder, 1981; Ward, et al., 1977). All of these studies adopted an information processing theoretical model to interpret Piagetian-like stages. Roedder's (1981) consumer behaviour model characterises these stages in several ways including the information processing strategies characteristic of each stage. As such, several processing levels are described. These are: limited processors (aged two to seven) whose processing skills are not fully developed; cued processors (aged seven to eleven years), who use many strategies for storing and retrieving information, such as verbal labelling and rehearsal, but need to be aided by cues for retrieval; and strategic processors (twelve and over), who use similar strategies but do not need to be prompted. Review of empirical consumer socialisation research (John, 1999) supports this model.

\subsubsection{Summary of Socialisation Theoretical Implications}

According to Miller (1993), knowledge of developmental theories can prevent narrow vision in researchers investigating children and that an egocentric and rigid perspective can be avoided by shifting from theory to theory as appropriate for the concept being investigated. In agreement with this perspective, the evidence to date regarding consumer socialisation of children supports the position that an integrated theoretical framework is appropriate for investigating children's consumer development (John, 1999).

With regard to the current investigation of perceived value by children, the theories provide information which can be used to understand, interpret and compare changes with increasing consumer socialisation. On the basis of Piagetian theory, a child in the concrete operational phase will be able to consider two aspects of a problem simultaneously but will require tangible objects or characteristics to do so. Formal operations should be evidenced by simultaneous consideration of many aspects of a problem and the inclusion of more abstract aspects in their evaluation of perceived value their evaluations are more adult-like in nature. On the basis of information processing theory, exact ages at which changes occur may differ by domain. Information processing theory allows understanding, interpretation and prediction of changes in the amount of information children attend to, remember, and are able to retrieve and the strategies they use in their consumer evaluations. Evidence from 
consumer socialisation research and developmental psychology regarding categorisation and conceptual development, find that children possess "coherent bodies of knowledge about important aspects of the world" (Hatano \& Inagaki, 2000b, p. 173), they develop concepts, and incorporate these into naïve theories.

Both Piagetian and Information Processing theories predict an increase in ability with increasing age. "Age, however, is a shorthand variable, used with the understanding that it implies a shift in some underlying state: in the capacity to make sense of events, in the degree of experience, or in the kinds of demands that are being faced and the goals that are likely to be salient" (Gilbert, et al., 1998, p. 746). There is general agreement amongst theoretical stances that an age-based improvement in cognitive ability occurs.

\section{8. Children's Understanding of Economic Concepts}

In order to understand value, children must understand basic economic concepts. At this point it is appropriate to review the research pertaining to children's understanding of economic exchange at varying ages as it will be useful both in designing the present study and ultimately interpreting the findings. How children of varying age understand work, income and consumption and the pricing system have been investigated. A relevant aspect to the current investigation is children's understanding of value as an economic concept.

Early research regarding children's understanding of economic concepts was undertaken in the 1950 's by Strauss $(1952,1954)$. Strauss investigated children's understanding of money and economic roles of shopkeepers, customers and factory owners. Results are interpreted in terms of Piagetian stages of development and detail changes in understanding. Strauss identifies ten stages between the ages of three and eleven years through which children pass in their progressive development of understanding. It is important to note that significant overlap in terms of age was noted between stages. Before most children are seven there is an understanding of the function of money and its role in buying, selling and for the payment for services. This work provides a useful background in terms of the broad concepts studied and provides guidance, on the basis of children's economic understanding, for the current study. 
The most extensive contribution with regard to children's understanding of economic concepts is the work of Berti and Bombi (1988). Using Piaget's theory of cognitive development to explain findings, various developmental stages and the characteristics of children's knowledge at each of these stages are detailed. Concepts investigated include work, where money comes from, source of goods and value of money. In addition the concepts of ownership and production were investigated. The research was conducted using qualitative methods. Italian children between the ages of four to thirteen years were included in the studies and independent variables of social class and educational exposure were also investigated.

Of particular relevance to the current investigation are findings related to the buying and selling of goods, children's understanding of the reasons for differences in prices between goods and their views of how prices are formulated. The findings, while similar to those of Strauss, are more finely detailed and extensive, allowing the time order of emergence of understanding to be detailed as well as clarification of distinct concepts from the child's perspective. Findings relevant to the current investigation are as follows:

\section{Preoperatory Period (three to six years)}

The majority of children recognise money, and that it is used for paying. Shops are recognised as places where you can obtain things and children know that adults work. By four to five years, the sequence of economic exchanges, particularly in a retail environment, become established. Their knowledge is restricted to the things to which they are exposed. Things, with which they have no experience, such as land, are not recognised as goods. The link between work and pay is not understood, it is simply accepted. Children believe that there are no restrictions on the availability of money and products. Economic exchanges are understood as sequences without any understanding of value. Change given in a shop is regarded as a source of money.

\section{Intuitive Level (six to seven years)}

At this stage, children construct rules allowing correspondence between prices of objects and the amounts paid to buy them and between work and remuneration. Children can now discriminate the values of money types such as coins and notes. They can relate prices to the most obvious characteristics of products and order 
products in terms of expensiveness. Children are still unable to interpret the function of change.

\section{Concrete Operatory Level (seven to ten years)}

Buying and selling is now understood more broadly than simply the exchange of money and products in shops, to include other goods such as houses and land. The shopkeeper is distinguished from the producer. Prices are not well understood, children do not attribute costs of production including labour to price. Price is regarded as a characteristic of the products themselves and is seen as invariant through the course of commercial transactions. Children in the educational investigation also regarded price as arbitrarily set, based on the guidelines of authorities or on the basis of quality of the goods with no account for profit. Children of this age generally understand the link between the price of an object and the money paid to buy it. They now understand the concept of change. This has been described by the authors as a concrete problem and this supports Piaget's theory of cognitive development. Wealth and poverty are understood. Work and remuneration are understood in terms of the amount or intensity of work being correlated with the pay. This is better understood by middle than lower class children and is also considered as more acceptable by this group.

\section{Formal Operatory Level (eleven to fourteen years)}

At this level, children understand that the owner pays the workers with money from the sale of the factory's products. They understand that the price of products is comprised of the costs of materials, labour, commercial intermediaries and includes a profit margin. Children relate different pay rates to the amount and intensity of the work as well as the prestige of the occupation.

A review of cross cultural research has revealed that children's ideas follow the same developmental sequence, however, the rate of development differs between cultures (Berti \& Bombi, 1988).

Educational intervention research of a longitudinal nature (Berti \& Bombi, 1988) provides evidence that some children pass directly from primitive economic ideas to correct ones after teaching, while others maintain beliefs despite instruction. Due to the absence of a control group, conclusions were limited in respect to child development. However, these findings would be predicted by Vygotskian theory, in 
terms of teaching facilitating progression, for those in the zone of proximal development. This observation also supports information processing theory. Regarding conceptual change, information processing theorists show "later changes in naïve theories which occur by incorporating scientific concepts and correcting 'misconceptions' are difficult to induce" (Hatano \& Inagaki, 2000b, p. 174). Overall, the research of Berti and Bombi (1988) is descriptive in nature and reveals that even those children reaching the highest levels of understanding of various economic concepts and sequences still do not fully understand the function of the economy.

The most relevant findings from this research are the evidence of the use of obvious product characteristics related to prices for children aged six to seven years and the emergence of the quality concept somewhere between seven and ten years. These findings are consistent with those from the marketing field as have been discussed in relation to the concepts of price and quality.

\section{9. Summary of the Literature Review}

On the basis of this literature review, it is apparent that while a lot is known about age related changes in consumer behaviour (John, 1999), how children of different ages perceive value, and how their understanding changes with age is not known. There is evidence that perceived value is important to children (Lindstrom, 2003; Moschis \& Moore, 1979; Ward, et al., 1977) and that they have an understanding of concepts of quality and value (Berti \& Bombi, 1988; Fox \& Kehret-Ward, 1985, 1990; Lunt \& Furnham, 1996).

Cognitive development has been shown to be most closely associated with development of consumer skills or rational aspects of consumer decision-making (John, 1999; Ward, et al., 1977). Social learning models of development highlight changes with age in the influence of others; particularly parents and peers with

parents becoming less influential and peers becoming more influential with increasing age (Dotson \& Hyatt, 2005). This is particularly relevant as parental communication about consumer behavioural matters is positively associated with economic consumption motives (Moschis \& Churchill, 1978) and peer influence with the more irrational materialism (Nguyen, 2003). 
Research has led to models of positive and negative roles of price in perceptions of value for adult consumers (Monroe, 1979; Monroe \& Krishnan, 1985). A trade-off between these in terms of the perceived sacrifice and the perceived quality gained is used to determine value and hence willingness to buy (Dodds, et al., 1991). These concepts have been defined from an adult perspective (Zeithaml, 1988) to include all the give and get components of purchase. The applicability of such models to children is unknown.

While it is known that brands are extremely important to children in their consumer decision-making (Lindstrom, 2003; Moschis \& Moore, 1979), children's value perception at purchase is an area which has not been investigated. Before companies can provide value, an understanding of what constitutes value to the customer must first be understood. Perceived value is regarded as a key determinant in adult consumer decisions, however, due to the abstract nature of this concept; it has been defined and investigated from several perspectives with theoretical definitions not always matched by the operationalisation of this construct. There is continued discussion and use of the concept as both a single dimensional (Agarwal \& Teas, 2001, 2002, 2004; Dodds, et al., 1991; Sweeney, et al., 1999; Teas \& Agarwal, 2000) and a multidimensional construct (Lin, et al., 2005; Petrick, 2002; Roig, et al., 2006; Tsai, 2005) and value has been modelled using both reflective and formative indicators (Lin, et al., 2005).

By looking at the development of perceived value in children, it is hoped that further understanding of this concept will result. The concept will be defined from a child's perspective and the theoretical dimensions and linkages relevant at differing ages will be described. As such, this research will result in the first conceptual description of children's perceptions of value.

The literature review confirms that the concepts of interest cannot be fully operationalised based on current research. A conceptual framework cannot be advanced due to the fact that description and definition is incomplete. Additional important concepts may not have been discovered due to a lack of research in the area. The meaning of value to children remains largely unknown and benefits contributing to value have not been explored. The relevance and meaning of abstract concepts known to comprise value for adults are not known for children. On this 
basis exploratory research is deemed appropriate to uncover the benefits and costs associated with purchases for children. 
Chapter 3. Research Methodology 


\section{1. Introduction}

A qualitative approach was required in order to understand the ideas and concepts children hold regarding value and purchasing. Key to qualitative inquiry is integration of the research question with data collection and analysis (Richards \& Morse, 2007) and there are many methodologies available. In this section the paradigm which underlies the research and the rationale behind the methodology and methods chosen to investigate children's perceptions of purchase value are provided.

The chapter begins with a discussion of the research question and the research paradigm guiding the research investigation. This is followed by a discussion of grounded theory methodology. Next the specific issues associated with researching children are discussed. The current study is introduced and strategies for data collection and analysis of the data are detailed. Finally the issues of validity are considered.

\section{2. Research Question and Objectives}

At the outset of this investigation, the literature regarding children's perceived value was virtually non-existent as discussed in Chapter 2 and there had been a call for research regarding children's understanding of the value concept (John, 1999). It was also noted that, while operationalisation and measurement of the construct exists in the adult marketing literature, that it is inappropriate to simply adopt adult meaning when conducting research with children. Based on what is known about child consumers, although limited, it was likely that the concept would be markedly different for children and could vary with age.

Bannister and Booth (2005) reiterate the importance of giving children a 'voice', allowing them to generate data rather than simply confining their responses in terms of adult meanings and predefined categories. As noted by Graue and Walsh (1998, p.112) "Children know more than they know they know. They surely know more about what they know than the researcher does." Generally, current researchers in this area call for 'child centric' research and a reconceptualisation of childhood (Banister \& Booth, 2005; Veale, 2005). 
Clearly exploratory research was required with children central to the research process, in order to determine the meaning of value to them and developmental progression in their understanding.

On this basis, the study seeks to determine how value is perceived by children aged eight to fourteen years and how this changes with increasing age? The objectives of the research are as follows:

- To define value from a child's perspective and to identify the relevant concepts comprising the value construct in children's consumer decisionmaking.

- To examine age related changes in children's perception of value.

- To develop a theory to describe how children perceive value and to propose theoretical relationships between concepts.

\section{3. Research Paradigm}

The research paradigm is the term used to describe differing world views. It is a set of philosophical assumptions about what knowledge is and how we know it, referred to as ontology and epistemology (Creswell, 2003).

Research paradigms can be represented as a continuum with a positivist perspective at one extreme and a constructivist perspective at the other. A positivist perspective views reality as being able to be studied and understood, in the search for a universal truth (Denzin \& Lincoln, 2005a; Guba \& Lincoln, 2005) while the constructivist perspective views knowledge as locally and specifically constructed and coconstructed with findings created. The researcher and what can be learned cannot be separated and this perspective advocates the use of naturalistic methods of inquiry (Denzin \& Lincoln, 1998; Guba \& Lincoln, 2005). The research paradigm is governed by the researcher's view about how they will learn about the problem and the ultimate aim of the inquiry (Guba \& Lincoln, 2005).

Scientific research to advance theory may be quantitative or qualitative. Quantitative research uses either experimental or survey methods to test theory based hypotheses. Operational definitions of variables allow measurement under varying conditions. Theories are usually borrowed from social or psychological sciences. The research is 
deductive and explanatory, seeking to objectively test propositions and hypotheses based on this theory and therefore advance or modify the theory as a result. These studies have traditionally formed the basis of knowledge in the field of marketing (Deshpande, 1983). Quantitative research fits the assumptions of a positivist view point. Qualitative research is exploratory or inductive in nature with the aim of generating or discovering theory (Creswell, 2003; Deshpande, 1983). It has been defined in many ways: "Qualitative research is multi-method in focus, involving an interpretive, naturalistic approach to its subject matter" (Denzin \& Lincoln, 1998, p. 3). Qualitative methods can be situated at varying points along this continuum. Interpretivism is used to refer to all non-positivistic research approaches (Carson, Gilmore, Perry, \& Gronhaug, 2001).

The current inquiry lies within the post positivist inquiry paradigm (Patton, 2002). A post positivist perspective implies critical realist ontology, the belief that reality exists but that it can only be probabilistically and imperfectly understood. The epistemology of this view relates to the fit of findings to this reality and acknowledges that replicated research findings are probably true rather than definitely true as in the positivist view. The current research uses constant comparison and multiple perspectives to develop theory and acknowledges that a verification study using quantitative methods may be carried out. A post positivist perspective also acknowledges the influence of the researcher but attempts to minimise this and to be as objective as possible (Guba \& Lincoln, 2005). The postpositivist approach attempts to address issues with positivistic methodology. These relate to a lack of consideration of situational influences and individual meanings.

It should be noted here that where grounded theory methodology is situated within an interpretivist paradigm is open for discussion in the literature. Guba and Lincoln (2005) assert the grounded theory method to be situated in the post-positivist camp. Annells (1996) regards classical grounded theory (Glaser \& Strauss, 1967) to be post positivist and more recent forms such as the style detailed by Corbin and Strauss (2008; 1998) to be moving toward a constructivist world view. She bases her argument on differences in ontological view, Glaser's critical realist view of reality and Corbin and Strauss's consideration of the conditions and consequences of interactions in the contexts they occur. She also notes the objectivist epistemology advocated in classical grounded theory and the subjectivist view of the researcher by 
Corbin and Strauss in their modified version of grounded theory. Corbin and Strauss (2008) acknowledge the foundations of the methods to be from Symbolic Interactionism and Pragmatism and in the latest edition of their methodology. Symbolic Interactionism assumes the view that humans respond to others actions based on their perception or interpretation of the action and Pragmatism assumes knowledge is created out of action and interaction (Corbin \& Strauss, 2008). These philosophies have elements which reflect qualities of each, post-positivism and constructivism.

\section{4. Grounded Theory}

Critically for all good research, "the research question should dictate the methodological approach that is used to conduct the research."(Corbin \& Strauss, 2008, p. 12)

Grounded theory methodology was developed by Glaser and Strauss (1967) for the purpose of "building theory from data" (Corbin \& Strauss, 2008, p. 1). Where "theory denotes a set of well-developed categories (e.g., themes, concepts) that are systematically interrelated through statements of relationship to form a theoretical framework that explains some relevant social, psychological, educational, nursing or other phenomenon" (Corbin \& Strauss, 2008, p. 22). As such grounded theory is useful for answering questions related to process and changes over time (Richards \& Morse, 2007).

Three divergent approaches to this methodology have been detailed, however the current work follows the systematic data analysis method described by Corbin and Strauss (2008).

The methodology attempts to capture the complexity of experience situated in place and time and in doing so, to further our understanding. It also seeks to reveal processes involved. The intention of this methodology is that analysis occurs without a preconceived framework or hypotheses and that the researcher remains open to new ideas and concepts as they emerge from the data. It is recognised that complete objectivity, which was traditionally proposed in this methodology, is in reality not possible. It is also acknowledged that initial concepts may guide questions or be used 
comparatively during the analysis. This method stresses remaining open and allowing theory to be grounded in the data.

Data can be gathered in the same way as other forms of qualitative research, through interviews and observations as well as from secondary data. The difference between this and other qualitative methods is that it leads to the development of theory. Through comparison, developing hypotheses are verified and theory can be proposed on this basis.

The main analytic strategies which Corbin and Strauss (2008) suggest are identification of concepts, asking questions, looking for relationships between concepts and making comparisons between data. In this way the researcher can extract enough information from the data on which to theorise.

Data are analysed line by line into concepts and dimensions and then concepts are grouped and ordered by theme or category. Corbin and Strauss (2008) provide a paradigm for linking contextual factors with process which involves examining the actions and interactions involved in the situation, including the conditions leading to them and the consequences of them.

The ideas of theoretical sampling and theoretical saturation are fundamental to grounded theory methodology described by Corbin and Strauss (2008). Sampling is based on concepts rather than being numerical. Analysis is carried out as data are collected and continues until no new concepts, dimensions or properties are emerging. Corbin and Strauss (2008) acknowledge that full theoretical saturation is probably never achieved and recommend that data collection should continue until sufficient depth and breadth of the concept is attained and the phenomena is understood.

Grounded theory was chosen for this study on the basis that very little was known about children's purchase decisions and their perceptions of value. As discussed in the literature review section much of the information about children and purchase value is anecdotal. Also the findings have been largely descriptive in nature when academic research has been undertaken such as studies of the meaning of price and its relation to value represented in products (Fox \& Kehret-Ward, 1985, 1990; Strauss, 1952) but not as part of a child's purchase decision and results are not incorporated with recent developmental theory. Grounded theory also provides a 
systematic way of investigating age related changes in meaning (Andronikidis \& Lambrianidou, 2010).

There is no theory regarding the way value is perceived by children to underpin quantitative research and no measurement tools have been developed. Given the complexity of the concept in combination with evidence regarding children's conceptual development, it would have been misleading to simply adapt adult theory and measurement tools for use with children. Children may be able to answer the questions but it would not be known whether the concepts were related to perceived value. Grounded theory provides a way of generating such theory and relating it to existing frameworks through a series of inductive and deductive comparisons. The current work is focussed on what is in the data and existing literature is used comparatively (Corbin \& Strauss, 2008).

\section{5. Qualitative Research}

In order to answer the research questions and meet the research objectives, a qualitative approach was adopted. In this section the justification for this approach is provided.

Shank (2006, p. 4) offers a definition "Qualitative research is a form of systematic empirical inquiry into meaning." According to Shank's definition it is systematic in that it is planned, ordered and public. It is empirical in that it depends on the world of experience. It looks for meaning in terms of complexity, deep, textured, thick, insightful and illuminative of the phenomenon or situation. Qualitative methods are interactive and aim to involve participants with the researcher, aiming to build rapport and establish credibility (Creswell, 2003). As such, it was necessary to gain a detailed insight into the social process of value perception, through the experiences of children. The only way to do this was by utilising a qualitative methodological approach in the first instance. As noted by Creswell (2003, p. 22), "if a concept or phenomenon needs to be understood because little research has been done on it, then it merits a qualitative approach." Qualitative research allows exploration of conceptual meaning and ensures that children's words, views and ideas are included.

Qualitative research attempts to understand human behaviour from the person's point of view and is grounded in the data that is collected (Deshpande, 1983). Qualitative 
research is particularly useful for when the researcher is looking to uncover the way people think about their experiences, the meanings they understand and to discover the concepts relevant to the phenomenon of interest.

In the current study, qualitative methods were used to shape value related concepts and ideas (Brannen, 2005) which were then used to develop theory regarding perceived value for children of differing ages. When little is known about a phenomenon, an inductive approach is called upon to understand, interpret and generate theory. This may be the goal or the findings may be used to direct quantitative, deductive research in the future (Poggenpoel, Myburgh, \& Van Der Linde, 2001). This view is also in accordance with that of Graue and Walsh (1998, p. 28) "Theory should be empirically grounded, but the strength of that grounding should depend on where one's inquiry lies on the theory building/theory testing continuum.”.

\section{6. Considerations for Researching Children}

When researching children, there are many additional considerations which must be taken into account. These cover the spectrum of the research process beginning with the conceptualisation of childhood including the developmental process and implications of this impact on all aspects of the study. In this section these factors are discussed.

\subsubsection{Theoretical}

How childhood is conceived influences the way children are studied in terms of whether the research focus is 'on children' or 'with children' (Bartholomew \& O'Donohue, 2003; Cook, 2009; Darbyshire, MacDougall, \& Schiller, 2005). Recent trends in academic research in the field of marketing have slowly moved to a conceptualisation of the child as knowing and acting persons in their own right, a view which is accepted as the new paradigm for childhood studies (Cook, 2009). This view means that research must incorporate the contexts of children's lives, their views and voices. Qualitative interpretive research provides the most effective way of entering children's worlds. Researching children directly also enhances the validity of the research as parents or others may not fully know children's thoughts attitudes or feelings (Mahon, Glendinning, Clarke, \& Craig, 1996). 


\subsubsection{Methodological}

Children are potentially open to suggestion and are more likely to answer what they feel is expected by the researcher (Mahon, et al., 1996). This is a concern for both quantitative and qualitative methods. Children are likely to provide answers to questions they may not actually know the answers to, or may answer in the way they think is correct. The advantage of conducting a qualitative investigation with children lies in the ability of the researcher to be in tune with non-verbal responses and to reassure the respondent that there are no correct or incorrect answers. In addition the researcher can pick up on confusion, clarify wording and put the respondent at ease. This was particularly important when measurement tools specifically designed to measure the concept of interest with children, were not available. In addition very young children may not be able to complete a structured questionnaire (Andronikidis \& Lambrianidou, 2010). Developmental theory posits changes in children's thinking as they age and hence quantitative measures may need to be adapted based on changing conceptual understanding and abilities.

The role of the researcher and the way they are perceived by the children is an important consideration when designing qualitative research with children. As noted by Graue and Walsh (1998) the differences that exist physically, socially, cognitively and politically between the adult and the child make this relationship very different to an adult to adult relationship. There are several ways to address these concerns. It is important that children can relate to the researcher. This can be achieved by using a child researcher (Alderson, 2001) or, as was the case in the present study, the researcher can establish a rapport with the children. Experience with speaking to children is helpful (Mahon, et al., 1996). If the researcher gets to know the children before an interview this facilitates the process (Kortesluoma, Hentinen, \& Nikkonen, 2003). Graue and Walsh (1998) suggest beginning with factual questions as a way of putting children at ease. Alternatively methods in which children are considered active participants or where the researcher does not play as bigger part may be considered (Hunleth, 2011).

The children's competencies should also be considered in terms of the format and questions included. Can they provide written responses or answer verbal questions? Questions should be clear for children to understand and this can be achieved 
through piloting with the age groups studied to ensure appropriate vocabulary. Researchers should also begin with open ended questions so they do not lead children's responses. However, very open questions can be difficult for young children so some direction may be needed (Gollop, 2000).

Another consideration relates to children's or indeed anyone's ability to articulate what they are thinking or feeling. Using more than one method of data collection helps overcome limitations associated with a single method study (Graue \& Walsh, 1998). The use of concrete stimuli or props can also help children to articulate a response (Graue \& Walsh, 1998).

Motivation for children to answer the questions can be assisted through a small reward. It has been suggested that a small material reward, such as a picture, scrap or balloon, will encourage children to concentrate on questions (Kortesluoma, et al., 2003). In the current study children received a small pen which clipped onto their bags, as a reward for participating in the research.

In developing the research design to answer the research questions these factors specific to researching children were considered and a child-centred, meaning-based approach was adopted.

\section{7. Qualitative Research Design}

The qualitative approach to be undertaken is dependent on the focus of the inquiry (Marshall \& Rossman, 2006). Graue and Walsh (1998) note three forms for generating qualitative data. These are observational methods, interviews and artefact collection. Observational or artefact collection methods alone were unlikely to uncover children's thoughts about value. As such interviews were deemed most appropriate.

Given the objectives of the current study which were to define perceived value from a child's perspective and identify the relevant concepts comprising the perceived value construct in children's consumer decision-making, to examine age related changes in children's perception of value, and to develop a theory to describe how children perceive value and to propose theoretical relationships between concepts, a two stage approach was adopted. Bannister and Booth (2005, p. 157) emphasise the use of methods that locate children as "active generators of data". 
The qualitative strategy employed included two data collection techniques, diaries and in-depth interviews in a two stage approach to address the research objectives and to inform the methods that followed. Table 3-1 details the data collection methods which were used.

Table 3-1 Qualitative Strategy

\begin{tabular}{|l|l|}
\hline Stage 1 & $\begin{array}{l}\text { Pilot test shopping diary method } \\
\text { Sample: one child of each age ( } \mathrm{n}=7) \\
\text { Analyse data, finalise or refine methods for shopping diaries }\end{array}$ \\
\cline { 2 - 3 } & $\begin{array}{l}\text { Shopping diaries } \\
\text { Sample: Around ten children in each age group (n=63) } \\
\text { Analyse data, use to refine semi-structured interview guide for stage } 2\end{array}$ \\
\hline Stage 2 & $\begin{array}{l}\text { Individual in-depth interviews } \\
\text { Sample: A new sample of around ten children in each age group }(\mathrm{n}=51) \\
\text { Analyse data and compare emerging categories }\end{array}$ \\
\hline Stage 3 & Final comparative data analysis \\
\hline
\end{tabular}

Firstly, data were collected using diaries to gain an insight into the concepts which children considered to contribute to the value of products they purchased while at the same time attempting to "bridge the power inequalities" (Hunleth, 2011, p. 82) between the adult researcher and child research participants. Secondly in-depth interviews were used to seek deep information in order to enhance conceptual definition, expand on findings, and provide more information on contexts, interactions and consequences surrounding value perceptions.

By using a two stage approach to this research question the research findings could build on the previous stage. The concepts, identified in stage one were elaborated upon and categories filled in as the research proceeded. Using two different qualitative methods adds to understanding of children's perceptions of value. According to Denzin and Lincoln (2005b, p. 5) "the use of multiple methods, or triangulation, reflects an attempt to secure an in-depth understanding of the 
phenomenon in question." This is also supported by Richards, (2005, p. 35) "A researcher seeking to learn from the data, rather than to test theory already arrived at, will usually be helped by having more than one way of looking at what is being studied." This approach corresponds to that described as bricolage by Denzin and Lincoln, (2005b, p. 4) "a pieced together set of representations that is fitted to the specifics of a complex situation".

Use of more than one means of obtaining the data reduces the limitations of each the methods in isolation and increases the validity of the research as discussed for each of the methods (Chapters 4 and 5) and quality of the research, Section 3.11. "Looking from many different angles and in many different ways provides a more complete description of the part of the social world being investigated." (Graue \& Walsh, 1998, p.102). This strategy is termed triangulation "finding the multiple perspectives for knowing the social world" (Marshall \& Rossman, 2006, p. 204).

The first stage of the research involved children writing a diary. "Diaries, self-report instruments used repeatedly to examine on-going experiences, offer the opportunity to investigate social, psychological, and physiological processes within everyday situations" (Bolger, Davis, \& Rafaeli, 2003, p. 580). Diaries were chosen for three reasons. Firstly, diaries are a useful starting point in a qualitative investigation intending to develop a 'grounded theory'. "Several analysts start their field work with initial strategies...Another way to begin is to ask a few knowledgeable participants to write a diary or a case history for an event, such as an AA meeting. Then the researcher can begin analysing this material" (Glaser, 1978, p. 45).

Such accounts allow the researcher to establish 'local concepts' with as little researcher intervention as possible. Firstly, reducing researcher intervention is an important consideration when researching children as their responses may be influenced by the researcher due to the differences in power which occur in society between adults and children (Graue \& Walsh, 1998; Grover, 2004) as discussed in Section 3.6.2. Secondly, concepts can then be elaborated on theoretically and emergent fit with new data, from subsequent research, established. The identification concepts should not however, restrict the researcher's openness to additional new concepts. The process in practice is iterative. Thirdly, by identifying the initial concepts in this manner the validity (or credibility and dependability) of the study was enhanced. In temporal terms a diary provides data at or soon after the purchase 
decision. "Diary data can be used to generate summary accounts without biases introduced by retrospection over relatively long periods" (Bolger, et al., 2003, p. 581). Also given the natural situation in which questions are completed, diaries "offer the opportunity to investigate social, psychological, and physiological processes within everyday situations"(Bolger, et al., 2003, p. 579). This method is designed to capture the experiences of everyday life with the goal of "achieving reliable person-level information" (Bolger, et al., 2003, p. 581).

The interview method complements the diary method in that the purpose of the interview method is to get participants to talk about what they know (Graue \& Walsh, 1998). In combining these methods, age related changes in understanding can be examined, the construct defined, and dimensions identified.

To date, open-ended interviews have been shown to be the most effective way to find out about experiences of childhood because the flexible face-toface format of this method allows the researcher to follow up on vague, confusing, even contradictory information, sensitively and systematically. (Rogers, 2005, p.159).

Sections 3.8 and 3.9 provide a detailed description of the methods used.

\section{8. Diaries}

Research diaries were developed and piloted, schools and participants were recruited for the investigation, and diaries were distributed for completion by children aged 814 years and subsequently collected and analysed. The research process is discussed in the following sections.

\subsubsection{Development of the Diaries}

The research instrument was a diary containing a series of questions related to children's purchase decisions. Respondents were requested to complete the series of questions for each product they purchased over a two week period, termed event based diaries (Bolger, et al., 2003; Zarantonello \& Luomala, 2011). Children were not constrained to specific products or categories when completing the diary, to maintain external validity and to allow for comparisons across categories. Space was allowed for up to four products with respondents instructed to add additional 
products if required (extra pages were provided to the teachers). Questions were designed to capture the information required to meet research objectives but were sufficiently general to allow a broad spectrum of insights into children's perceptions and experiences. Questions were largely 'how' questions as recommended by Patton (2002), on the basis that 'why' questions assume the respondent can make 'deductive inferences' about what has been experienced which is often not possible for them. It was important to keep the questions general and not to limit the questions to concepts known from existing perceived value theory. In this way the research attempted to ensure children's responses were not influenced by the researcher, or led or confined by the questions. Both the questions and the design of the diary were piloted by a year seven/eight teacher with six students both male and female to ensure that children understood all the questions and that the cover was appealing (see Appendix 1).

\subsubsection{Participants}

Given the exploratory nature of the study it was decided to contain the sample to schools in Wellington with a high decile rating reflecting a high socioeconomic catchment area. In this way variance attributable to other factors was minimised and the validity of any age related differences enhanced. Researchers have shown a relationship between high socioeconomic status and high levels of cognitive development (Bradley \& Corwyn, 2002). While the sequence of development should be consistent there is likely to be a spectrum at which ability is acquired and this could be researched at a later stage with other socioeconomic groups.

Participants selected for this study were aged eight to fourteen years and the study used a purposeful sampling strategy in order to examine age based variation. The youngest age was based on eight years of age being the average for independent consumption, although children have been found to purchase independently from as young as four (McNeal, 1998). Also, based on Australian research it has been suggested that by age nine, ninety percent of children are operating as autonomous shoppers (Schiffman, et al., 2001). This is also the age at which previous research has indicated relevant concepts such as price and brand are understood (John, 1999; Lindstrom, 2003). Fourteen was the oldest age group studied in accordance with theories of cognitive development and experience in the domain of consumer 
behaviour which would suggest adult like dimensions beginning to emerge by this age. In accordance with theoretical sampling, this was flexible with an openness to gathering additional data from respondents should new concepts be still emerging.

\subsubsection{Procedure}

Schools in central Wellington were identified through the Ministry of Education website and School Principals were contacted to determine their interest in participating in the study. An introductory meeting was held and permission to conduct the research in their schools sought. Principals then identified the appropriate classes and teachers. The researcher then visited the classes to explain the research and to distribute the parental consent forms. Contact was maintained with the class teachers and once the consents were returned to school the researcher scheduled a time to collect the parental consents, gain the student's consent and distribute the diaries. The students were given an opportunity to look over the questions and clarify any issues with the researcher.

Response to the proposed research was largely positive with most students keen to participate. The main hurdle was gaining parental consent, some children were however, unsure about participating and others simply did not purchase things.

It was hoped to have seventy children complete the diary, ten of each age from eight to fourteen years. Two hundred and fifty consent letters were distributed, parental consent was obtained from ninety parents and sixty two diaries were returned. Classes approached covered years four through to nine. Recruitment was done by class and about ten diaries were returned per year group. Several follow-up visits were required to collect diaries as children found it difficult to remember to bring them back to school. Girls were more likely to participate in this stage of the study and discussion with class teachers indicated girls were more likely to enjoy written response formats than males. Analysis of the diaries also supported this in that it was more likely that girls provided more detailed responses to the questions.

\subsubsection{Content Analysis}

Diaries were completed by respondents in the absence of the researcher and over a two week period. As such questions were broad and were not modified as the research progressed. On this basis the process of data analysis deemed most 
appropriate was content analysis and followed the guidelines of Miles and Huberman (1994) and Patton (2002). Content analysis is described by Patton, (2002) as a strategy to identify, code, categorise and label the primary patterns in data. This involves the identification of themes and is usually done with reference to textual data such as interview transcripts, diaries or documents. Pattern analysis relates to descriptive findings and thematic analysis involves identification of categories and meanings (Patton, 2002). This type of analysis is also detailed by Miles and Huberman (1994) as representing one method of data analysis from a social anthropology background. The process involves searching the data for recurring themes in order to simplify and make sense of the situation. This then involves searching for regularities and what fits together, as well as what is different and finally recognising processes and linkages in the data. Category descriptions are compared with the extant literature to determine if the description applies to a concept described previously and if it does this is applied to the category or theme (Morse, 2004).

Miles and Huberman (1994) similarly describe three processes of data reduction, data display and conclusion drawing. Data reduction involves reducing the raw data to simplified, more abstract concepts without using pre-set standardised codes. Data display involves the use of diagrams to display the findings and further understanding which leads to conclusions regarding the concepts and their relationships. All three processes are interlinking and occur before, during and after data collection.

Patton on the other hand suggests a sequential process with interpretation and hypothesizing as the final step. According to Patton (2002),

once case studies have been written and descriptive typologies have been developed and supported, the tasks of organisation and description are largely complete and it is appropriate, if desired, to move on to making comparisons and considering causes, consequences, and relationships (p. 479).

In the current study the process was necessarily completed after data collection as described by Patton, due to the data gathering technique used. 


\section{9. In-depth Interviews}

The second stage of the study involved in-depth interviews. In order to conduct the in-depth interviews, new participants were recruited, a semi-structured interview guide developed and interviews conducted. These were simultaneously transcribed and analysed. The research process is discussed in the following sections.

\subsubsection{Interview Materials}

An interview guide was developed to help the researcher to ensure all relevant areas had been discussed (Appendix 2) and to ensure ethics approval.

The guide was based on themes identified from the diaries. When it is necessary to have an interview guide Corbin and Strauss (2008) advocate basing such a guide on preliminary fieldwork.

The interview guide was used only as a guide, as the researcher did not want to limit the potential of the interview method in allowing spontaneity, flexibility in following conceptual leads and probing.

Gollop (2000) recommends that the interview begins with non-threatening topics and as such this research study began with factual questions about the child, the contexts of their purchases as well as their pocket money, which they could answer easily.

Props were used when necessary to assist the children in their descriptions these included plastic copies of New Zealand currency and photographs of product displays in shops. (Appendix 3)

\subsubsection{Participants}

Schools in Wellington with a high decile rating reflecting a high socioeconomic catchment area were used.

Participants selected for this study were again aged eight to fourteen years. Sampling was carried out with a view to where to get information to answer the research questions and to find out information about categories (Corbin \& Strauss, 2008). This involved purposeful sampling to begin based on age. The nature of the analysis allowed the researcher to sample theoretically within the cases. The main requirements were that the respondents had money and purchased independently 
with it. While it would have been ideal to follow the guidelines of theoretical sampling completely, this was not possible due to consent and access issues. Corbin and Strauss (2008) acknowledge that research may be subject to practical limitations. "As with all research there is the 'ideal way' of doing things and there is the 'practical way'. Sometimes a researcher has to settle for the latter." (Corbin \& Strauss, 2008, p. 153).

\subsubsection{Procedure:}

Careful consideration of the interview procedure was made, as advocated by other child researchers (Gollop, 2000).

It is therefore not only the interview content that can influence a child's responses. The entire context and process of an interview can have a huge impact on the outcome and careful thought needs to be given to such issues. (Gollop, 2000, p. 19)

For all primary school aged respondents, the researcher visited on three occasions in order to develop a rapport with them. This is particularly important when working with younger children to ensure they are comfortable with the interviewer and it is useful for overcoming their view of the researcher as a teacher. The researcher accompanied classes doing unstructured work such as PE and art and participated in the activities with them. As discussed in section 3.6.2, developing a rapport increases the likelihood that children are open and honest in their answers and realise there are no correct or incorrect responses. Children were also encouraged to use the first name of the researcher.

Only one prior visit was possible for the high school aged participants, however developing a rapport at this age was not found to be difficult and the difference between the researcher and respondents in terms of both age and physical size was less.

Interviews were conducted in schools as it has been suggested that the best place to interview children is somewhere that they feel comfortable (Gollop, 2000).

"An advantage of conducting an interview at school is that it can be a neutral setting for children..." (Gollop, 2000, p. 20) 
This stage of research involved children being interviewed individually. They were asked to bring an item to the interview which they themselves had bought. This provided a concrete reference point for children and helped them to feel at ease with talking about their experience. Given that children's purchasing is sometimes limited to one or more categories it was appropriate to leave the options open initially before focussing on specific categories. In this way contexts could be explored as different concepts emerged comprising children's perceived value.

Children were first asked about money in terms of how much they got and how often they got it. They were then asked about their independent shopping experience and how they had chosen the item they had bought. Any concepts mentioned were discussed and answers were probed for meaning. If concepts from the literature were not mentioned spontaneously the researcher asked specifically about them, later in the interview. Children were asked about food, toys and clothes specifically. In this way the influence of contextual factors on perceived value dimensions could be determined and comparisons made between children.

The interview method allowed recording and transcription of responses and these transcripts were analysed using grounded theory methods.

\subsubsection{Grounded Theory Analysis}

The process of analysis followed the guidelines of grounded theory methodology as detailed by Corbin and Strauss (2008). Analysis began as soon as the early data were collected and findings guided subsequent data collection. Sometimes two or three interviews were scheduled in a day and in this case notes were made following each interview in order to allow ideas to be followed up in subsequent interviews. Often there were several weeks between groups of interviews and this allowed complete transcription of these interviews and analysis. In this way new concepts were followed up and questions answered with subsequent respondents.

Analysis began at a micro level. Microanalysis is defined as "Detailed coding around a concept. A form of open coding used to break the data apart and to look for varied meanings of a word or phrase" (Corbin \& Strauss, 2008, p. 46). This form of analysis was used at the beginning of the project as well as at the beginning of each age group in order to focus on new meanings as they were emerging and gain new 
insights into what children were saying. The process involves identifying concepts then discovering the dimensions and properties of those concepts. A paragraph could be coded at one or many meaning units.

Techniques were applied, as advocated in this methodology, such as questioning, making comparisons, looking for the meaning of words and emotions and timing. Negative cases were sought and understanding of the contextual factors leading to the process identified. Memos were recorded throughout data analysis regarding cases, codes or at a theoretical level (Appendix 4). Finally the analysis led to integration of concepts into theory.

The techniques used in analysis are briefly described as follows: Questioning involved asking questions regarding what respondents said, such as "what do you mean by...?" and these questions were used to look for answers in the case or to explore the answers in future cases.

The various meanings of words were considered and subsequent respondents were questioned further to try and determine shared meaning. Only meanings that would further analysis were followed up on.

The researcher was aware of expressed emotions in addition to verbal responses if they added to the meanings of respondents. Finally comparison of an occurrence in a case with subsequent cases was made in order to identify similarities and differences. The analysis involved identification of contexts of events and emotions and consequences arising from them.

The grounded theory method of analysis suited the purpose of the research which was to build theory that is "faithful to and illuminates the area under study". (Richards \& Morse, 2007, p. 24)

In the present study the data was gathered in batches due to constraints in collecting data with children. Restrictions are further discussed in Section 3.11, Quality of the Research. However, theoretical sampling can still be achieved by remaining concept driven and filling in gaps and answering questions about concepts as analysis proceeds. In the present study concepts were followed up and expanded in the next batch of data collected. Corbin and Strauss (2008) also discuss going back to data previously collected to follow up on new ideas that have emerged as analysis proceeds. Despite restrictions of access when researching children, as noted by 
Corbin and Strauss (2008, p.150) "A researcher can do a high level analysis on whatever data he or she has."

Grounded theory suggests helpful ways of moving from description to theory and as part of this process the researcher is advised to delineate contexts, causes, actions/interactions and consequences. It is useful to define these terms before moving on to the actual data.

Context doesn't determine experience or set the course of action, but it does identify the sets of conditions in which problems and/or situations arise and to which persons respond through some form of action/interaction and emotion (process), and in doing so bring about consequences that in turn might go back to impact upon conditions. (Corbin \& Strauss, 2008, p. 22).

To summarise the data can be classified as conditions, actions and interactions, and consequences. Conditions describe the conditions leading to the response the person has and may be the context or other causal factors. The actions or interactions are the responses to the situation or problem. The consequences refer to the outcomes of people's responses to the situation. Clearly this simplifies what often occurs in real life. A social process may have many conditions leading to action/ interaction. This is also the case for the consequences. An action may lead to one or many consequences which may have further consequences. What is important is to remain open to these possibilities and to use the paradigm to assist analysis (Corbin \& Strauss, 2008). The data in this study was considered using these ideas and in this way the process of value perception by children was considered.

\section{10. The Researcher}

In considering the quality of such research within a post positivist paradigm, the researcher should acknowledge and be aware of who they are coming into the study and in this way be explicit about any potential influence of themselves which could influence replication of the study (Miles \& Huberman, 1994). In this study the researcher is a white female, aged thirty-nine years at the time of the interviews, completing a doctorate in Marketing. She is a mother of three and as such, has significant experience in communicating with children. She has worked in market 
research and has some experience in qualitative interviewing. She also has a Master's degree in Chemistry and a Graduate Diploma in Marketing.

\section{11. Quality of the Research}

Consideration of the quality of research is usually made with regard to issues of validity and reliability. These terms have traditionally been used with quantitative research methods and refer to objective truthfulness and the generalisability of the findings. Science values objectivity in research and hence quantitative methods, as concepts are more assessable using statistical methods and large samples. Patton (2002, p. 574) notes that "All statistical data are based on someone's definition of what to measure and how to measure it." Different considerations are certainly required for qualitative research. According to Patton (2002, p. 575), "Qualitative rigor has to do with the quality of the observations made by an evaluator." While Guba and Lincoln assess the quality of qualitative research on the basis of the following question "Are these findings sufficiently authentic (isomorphic to some reality, trustworthy, related to the way others construct their social worlds) that I may trust myself in acting on their implications?” (Guba \& Lincoln, 2005, p.205).

Qualitative methods within a post positivist paradigm refer to the same concerns as other scientific research in terms of the striving for the study of objective reality and the truthfulness of the research (Richards, 2006). Corbin and Strauss (2008) offer a list of criteria for evaluating grounded theory research and these include fit, applicability, concepts, contextualisation of concepts, logic, depth, variation, creativity and sensitivity. Yin (2009) suggests the use of four tests common to social science methods of construct validity, internal validity, external validity and reliability. It is the researcher's view that the most appropriate criteria for evaluating the quality of such research is that of Mile's and Huberman (1994). Miles and Huberman (1994) pair the traditional terms from quantitative sciences with the qualitatively focussed descriptions which are regarded as more appropriate within a post positivist paradigm for assessing the quality of qualitative research. The current research is now discussed with reference to each of these.

Objectivity/confirmability - This refers to the external reliability of the study, could the study be carried out by others and consistent results obtained? 
In the current study a two stage design in which a diary was used to identify key concepts and then in-depth interviews were used to elaborate the findings in this way the design of the study ensured the research questions were answered.

A detailed description of the procedures followed for data collection and analysis is provided. Conclusions are linked to codes and specific quotes from the respondents.

By using the grounded theory method the data was coded word by word and line by line using the respondent's own words to generate initial codes prior to comparison with the literature. In this way the researcher attempted to reduce the influence of prior experience with the perceived value concept and other relevant marketing concepts resulting from academic study in this area.

In the discussion section, Chapter 6, possible conclusions and propositions are considered.

Reliability/ dependability/auditability - this refers to the consistency of the research process over time, across researchers and methods.

Awareness of the researchers skills and experience is discussed in Section 3.10. In this study two methods were used, one where the researcher was not present (diaries) and one where they were present (in-depth interviews). Using these two methods of data collection convergent findings provided a quality check on the findings.

Questions were also asked in different ways in the interviews to ensure the quality of responses (i.e. to avoid deceit and bias).

Developing categories were constantly reviewed with the main supervisor as analysis proceeded and compared back to the literature.

The study is positioned from a post positivist perspective and used grounded theory analysis techniques of constant comparison (refer Section 3.9.4), across multiple sources of data to ensure reliability.

Internal validity/ credibility/ authenticity - this refers to truth value of the research. To what extent are the explanations true?

The use of more than one method to inform the current research enhanced the internal validity. As the research used both the diaries where the researcher was absent and in-depth interviews with the researcher present. Diaries reduce the bias due to the effects of delay on recall by allowing the respondents to complete their 
response at or around when the event occurs. There was convergence of findings across methods. The use of more than one method can help to overcome limitations associated with one method.

When theory is generated using grounded theory the categories that emerge must fit the data. This method ensures that the concepts discussed by participants and the categories used to describe them are valid. They are refitted as new data is gathered so they provide a true representation of all the data for a category. Children's actual words and views were used to develop initial codes.

Informants were drawn from high decile schools reflecting high socioeconomic status for families at the schools. This allowed the research to focus on differences due to age related factors rather than socioeconomic factors.

Negative cases, or different patterns or ideas to those emerging, were identified and compared with other instances of the phenomenon to determine conditions under which the developing theory did not hold. Contingencies to account for this variation were then incorporated.

While some theorists suggest checking back with respondents to ensure the interpretations are valid and reflect what they expressed in their responses this was not appropriate in the current study due to the potential inability of children to analyse their thoughts, a lack of awareness of more abstract meanings. In addition access to the children was difficult post hoc due to requirements for parental consent. The identification of patterns that emerged across multiple accounts increased the credibility of findings.

External Validity/ transferability/ fittingness - this refers to the extent that the findings can be transferred to other settings and contexts?

The samples used in the current study have been described in detail and contain enough theoretical variation to be applicable to other settings. The findings are also sufficiently detailed including verbatim comments for others to apply them to other settings. The sample size was relatively large for a qualitative study.

Thick descriptions were used to allow future readers to apply the research to other settings.

Rules used in developing propositions from the research were explicitly detailed. 
Findings were related back to existing theory in value perception from the marketing literature as well as age related developmental theory from the field of psychology.

The resulting theory is transferrable due to the nature of theoretical sampling. This method ensures fully explored categories and concepts through the use of constant comparison and consideration of context. It can also be tested in other contexts and be modified if necessary to incorporate variation noted.

Researcher bias may occur where the researcher looks for what they want to find in the data due to preconceived ideas of what they expect to find. Findings are verified through review with colleagues and comparison with other data sets from the other methods. Supervisors were asked to review the findings and ask questions about the study. In this way the quality of the research was ensured.

\section{12. Ethical Considerations}

The study was approved by the Victoria University of Wellington Ethics committee. Consent was obtained at a school and parental level as required by university protocol and the consents covered ethical issues with regard to research with children. A police check on the researcher was available to all schools and parents.

In addition the researcher entered the field with a view that children are "smart, sensible and desire a good life" and are the "knowledge holders, the permission granters and the rule setters" as advocated by Graue and Walsh (1998, p 57). Permission was sought from the children themselves and their right to participate or not, clearly stated.

Once again the research was reviewed by the Victoria University of Wellington Ethics Committee and the consent and assent forms were approved prior to the research being conducted. These covered ethical issues with regards to research with children and copies of these forms can be found in Appendix 1 and 2. Consent was initially obtained at school level from the Principal or Deputy Principal as well as at parental level. Children also provided assent for their inclusion in the research and the option to withdraw from the study at any stage was clearly stated.

As Graue and Walsh (1998, p. 56-57) point out, the ethics of research with children goes beyond consent and assent forms. It involves permission to enter another's life and when researching children requires the researcher to be 'taught by children'. The 
opposite of what occurs naturally in our society. Finally, the benefits and dangers of the research should be considered, to humanity, the discipline and oneself, when designing ethical research. The results of this research are intended to be used to understand, educate and protect children as consumers.

\section{13. Summary}

In summary, the present study opted for a grounded theory approach as most suited to defining perceived value from a child's perspective, examining age related changes in this concept and developing theory to describe how children perceive value.

A two stage approach allows the findings from the first stage to be built on in the second stage and by using two methods the limitations associated with each could be largely overcome.

The first stage was a diary study of children's purchase decisions in which they recorded their thoughts and feelings associated with their purchase decisions. The findings from this stage of the research follow in Chapter 4.

The second stage involved in-depth interviews with children about products they purchased and value dimensions they considered in the contexts in which they shopped. The findings from this stage of the research can be found in Chapter 5 . 
Chapter 4. Stage 1-Diary Study 


\section{1. Introduction}

As discussed in Chapter 3 this study used grounded theory methodology in order to meet the research objectives below:

- To define value from a child's perspective and to identify the relevant concepts comprising the value construct in children's consumer decisionmaking.

- To examine age related changes in children's perception of value.

- To develop a theory to describe how children perceive value and to propose theoretical relationships between concepts.

While there is ample literature available defining perceived value and detailing conceptual relationships and measurement of the construct for adults, children's perceptions of value remain insufficiently detailed. The literature is anecdotal in terms of defining what value means for children in the context of their purchase decisions (see Chapter 2). On this basis it was necessary to conduct exploratory research in order to detail the construct for children and generate theory relating age and the meaning of the construct to purchase decisions. Diaries are a good way to begin a study where very little research has been previously carried out and provide a starting point for developing a grounded theory (Corbin \& Strauss, 2008).

This chapter provides details of research participants and analysis of the diaries. The main themes from the diaries are summarised and then specifically discussed. Age related changes, if they emerged, are examined in this detailed exploration of the themes and then summarised at the end of this section.

\section{2. Participant Details}

Due to the nature of year groups in the New Zealand school system two seven year olds completed the diary. In total between eight and fourteen children of each year group from year four to nine participated in the study.

The sample consisted of females and males with more females consenting to participate in the research and to a greater extent completing the diaries. There were 23 males who completed the diary and 39 females. 
Participants were drawn from large suburban schools in the Wellington city area and included two primary schools, one intermediate and one high school. All schools were of a high decile rating reflecting a high socioeconomic catchment area, for the schools. This is confirmed by the data on family income with over half the families having income levels over NZ\$100 000 per annum. It should also be noted that in fact seventy percent of the sample had between NZ\$0 and $\$ 5$ of their own, in pocket money per week, despite the socioeconomic status of the family. This is still quite low. Table 4-1 details the demographic profile of the final sample drawn from year $4,5,6,7,8$ and 9 classes. 
Table 4-1 Demographic Profile of Sample

\begin{tabular}{|l|l|}
\hline Age & Totals \\
\hline $7-8$ & 13 \\
\hline $9-10$ & 16 \\
\hline $11-12$ & 21 \\
\hline $13-14$ & 12 \\
\hline Gender & \\
\hline Male & 23 \\
\hline Female & 39 \\
\hline Child's Income Per Week & \\
\hline None & 21 \\
\hline$\$ 0.10-5.00$ & 23 \\
\hline$\$ 5.10-10.00$ & 11 \\
\hline$\$ 10.10-30.00$ & 7 \\
\hline Child's Position in Family & \\
\hline First & 27 \\
\hline Second & 19 \\
\hline Third & 11 \\
\hline Fourth or more & 5 \\
\hline Family Income (Gross) & \\
\hline \$30 000-50 000 & 4 \\
\hline$\$ 50$ 001-70 000 & 8 \\
\hline$\$ 70001-100000$ & 13 \\
\hline$\$ 100001-150000$ & 10 \\
\hline$\$ 150001+$ & 22 \\
\hline Unassigned/ not applicable & 5 \\
\hline & \\
\hline
\end{tabular}




\section{3. Diary Analysis}

The diaries were transcribed by the researcher then re-read and analysed. NVivo 8 software was used to assist analysis. Concepts were identified and coded and then grouped into larger more abstract meaning units as described by Miles and Huberman (1994) and Patton (Patton, 2002). Using NVivo software and advanced and grouped find options the data was analysed by product, age and gender.

Analysis of the diaries revealed the concepts underlying children's perceptions of value when purchasing products. As with adults, children typically evaluate the product prior to purchase and their evaluation is often based on previous experience. All themes, including influencing factors which relate to children's value perception are discussed. Children described both specific product attributes and more abstract evaluative themes. Age related patterns were evident and will be discussed briefly for each theme in Section 4.4. Children's overall value perceptions varied from limited product evaluations through to complex trade-offs between the product and the price. Both 'give' and 'get' components (Sweeney \& Soutar, 2001; Zeithaml, 1988) were found in children's value perceptions. Some children traded the give against the get and others simply focussed on one or the other.

More than sixty concepts were identified in the analysis and these have been grouped into themes at a higher level of abstraction. The relative importance of each theme is then estimated based on the number of children mentioning the theme in their diary. Patterns in responses are discussed and summarised.

\subsubsection{Main Themes}

On the basis of children's responses to the diary questions, children's reasoning for purchasing products or services was largely based on overall affect and/or liking of the product at a sensory level. Concepts have been grouped into nine main themes that emerged and these are summarised in Table 4-2. A definition of each theme is provided and some examples from the diaries provided to illustrate. 
Table 4-2 Meta Matrix for Cross Case Analysis of Themes Identified in Diaries

\begin{tabular}{|c|c|c|c|c|}
\hline $\begin{array}{l}\text { Theme } \\
\text { (net diaries) }\end{array}$ & $\begin{array}{l}\text { Description } \\
\text { of theme }\end{array}$ & $\begin{array}{l}\text { Second } \\
\text { order } \\
\text { concepts }\end{array}$ & $\begin{array}{l}\text { First order } \\
\text { concepts }\end{array}$ & $\begin{array}{l}\text { Example of } \\
\text { theme }\end{array}$ \\
\hline $\begin{array}{l}\text { Previous } \\
\text { experience } \\
(\mathrm{n}=31)\end{array}$ & $\begin{array}{l}\text { Assessment } \\
\text { of intrinsic } \\
\text { attributes of } \\
\text { the product } \\
\text { known } \\
\text { through } \\
\text { direct } \\
\text { experience } \\
\text { with the } \\
\text { product }\end{array}$ & $\begin{array}{l}\text { Enjoyed } \\
\text { before } \\
\text { Had before }\end{array}$ & $\begin{array}{l}\text { - A favourite (8) } \\
\text { - Knew liked/ } \\
\text { loved (19) } \\
\text { - Had tried } \\
\text { before (11) } \\
\text { - Hadn't had for } \\
\text { a while (2) }\end{array}$ & $\begin{array}{l}\text { "Because I tried } \\
\text { this one before } \\
\text { and I liked it" } \\
\text { (Female, } 11 \\
\text { years) } \\
\text { "I knew I liked } \\
\text { it" } \\
\text { (Male, age 13) }\end{array}$ \\
\hline $\begin{array}{l}\text { Prior } \\
\text { knowledge } \\
(\mathrm{n}=13)\end{array}$ & $\begin{array}{l}\text { Prior } \\
\text { knowledge of } \\
\text { the product } \\
\text { but not direct } \\
\text { experience }\end{array}$ & $\begin{array}{l}\text { Had } \\
\text { information } \\
\text { about product }\end{array}$ & $\begin{array}{l}\text { - Knew about } \\
\text { product (seen or } \\
\text { used similar } \\
\text { products)(9) } \\
\text { - Had been } \\
\text { given } \\
\text { information } \\
\text { about product } \\
\text { (2) } \\
\text { - Had sought } \\
\text { information } \\
\text { about product } \\
\text { (3) }\end{array}$ & $\begin{array}{l}\text { "I chose this } \\
\text { book because I } \\
\text { like reading } \\
\text { about Pokemon" } \\
\text { (Male, age 8) } \\
\text { "I'd seen other } \\
\text { people wear them } \\
\text { and they looked } \\
\text { pretty cool" } \\
\text { (Female, age 11) } \\
\text { "Me and my } \\
\text { sister wanted the } \\
\text { full version } \\
\text { instead of the } \\
\text { demo" } \\
\text { (Male, age 11) }\end{array}$ \\
\hline $\begin{array}{l}\text { Affective } \\
\text { attitude } \\
(n=38)\end{array}$ & $\begin{array}{l}\text { Positive } \\
\text { feelings } \\
\text { about the } \\
\text { product }\end{array}$ & $\begin{array}{l}\text { Positive } \\
\text { feelings } \\
\text { about } \\
\text { product/ }\end{array}$ & $\begin{array}{l}\text { - Liked/ loved } \\
\text { the product (33) } \\
\text { - Liked the taste } \\
\text { (25) }\end{array}$ & $\begin{array}{l}\text { "Because I like } \\
\text { quiche soooo } \\
\text { much" } \\
\text { (Female, age 8) }\end{array}$ \\
\hline
\end{tabular}




\begin{tabular}{|c|c|c|c|c|}
\hline & & $\begin{array}{l}\text { service } \\
\text { Positive } \\
\text { sensory } \\
\text { response to } \\
\text { product }\end{array}$ & $\begin{array}{l}\text { - Liked the look } \\
\text { (23) }\end{array}$ & $\begin{array}{l}\text { "I liked it a lot } \\
\text { and it's a Lebron } \\
\text { James and I like } \\
\text { Lebron James (a } \\
\text { basketball)" } \\
\text { (Male, age 13) }\end{array}$ \\
\hline $\begin{array}{l}\text { Perceived } \\
\text { emotional } \\
\text { value }(n=26)\end{array}$ & $\begin{array}{l}\text { Utility } \\
\text { derived from } \\
\text { the feelings } \\
\text { or affective } \\
\text { states that a } \\
\text { product } \\
\text { generates }\end{array}$ & $\begin{array}{l}\text { Feelings } \\
\text { about } \\
\text { consuming/ } \\
\text { owning } \\
\text { product }\end{array}$ & $\begin{array}{l}\text { - Felt excited } \\
\text { about } \\
\text { consuming } \\
\text { (8) } \\
\text { - Would make } \\
\text { me happy (7) } \\
\text { - Would enjoy } \\
\text { consuming } \\
\text { (4) } \\
\text { - Would make } \\
\text { me feel good (3) } \\
\text { - Couldn't wait } \\
\text { to consume (3) }\end{array}$ & $\begin{array}{l}\text { "I was feeling } \\
\text { sad so I bought a } \\
\text { chocolate bar to } \\
\text { cheer myself up" } \\
\text { (Male, age 10) } \\
\text { "Because I love } \\
\text { chocolate and it } \\
\text { makes me happy, } \\
\text { my taste buds go } \\
\text { wild" (Female, } \\
\text { age 11) }\end{array}$ \\
\hline $\begin{array}{l}\text { Perceived } \\
\text { Functional } \\
\text { Value - } \\
\text { performance } \\
(\mathrm{n}=34)\end{array}$ & $\begin{array}{l}\text { Utility } \\
\text { derived from } \\
\text { the capacity } \\
\text { of the } \\
\text { product to } \\
\text { meet } \\
\text { functional } \\
\text { needs, } \\
\text { perform } \\
\text { functions or } \\
\text { have } \\
\text { functional } \\
\text { attributes }\end{array}$ & $\begin{array}{l}\text { Utility } \\
\text { derived from } \\
\text { the capacity } \\
\text { of the } \\
\text { product to } \\
\text { meet rational } \\
\text { needs } \\
\text { Utility } \\
\text { derived from } \\
\text { rational } \\
\text { consideration } \\
\text { of product } \\
\text { attributes }\end{array}$ & $\begin{array}{l}\text {-Needs/ } \\
\text { requirements } \\
\text { contributed to } \\
\text { value of an } \\
\text { alternative. (e.g. } \\
\text { needed product, } \\
\text { hunger, thirst) } \\
\text { (11) } \\
\text {-Physical } \\
\text { attributes of the } \\
\text { product } \\
\text { contributed to } \\
\text { the value } \\
\text { offered. (e.g. }\end{array}$ & $\begin{array}{l}\text { "I chose lemon } \\
\text { flavour because } \\
\text { it was a hot day } \\
\text { and lemons are } \\
\text { refreshing and } \\
\text { healthy" } \\
\text { (Male, age 11) } \\
\text { "It was the right } \\
\text { size and it suited } \\
\text { me" } \\
\text { (Female, age 12) } \\
\text { "I chose Dairy } \\
\text { Milk over } \\
\text { Caramello }\end{array}$ \\
\hline
\end{tabular}




\begin{tabular}{|c|c|c|c|c|}
\hline & & $\begin{array}{l}\text { relating to } \\
\text { function of } \\
\text { product } \\
\text { Utility } \\
\text { derived from } \\
\text { use }\end{array}$ & $\begin{array}{l}\text { fit, size, colour, } \\
\text { suited, matched, } \\
\text { cool, warm, } \\
\text { pumped up, } \\
\text { sugar free, } \\
\text { vegetarian, } \\
\text { refreshing) } \\
\text { (21) } \\
\text { - Amount or } \\
\text { duration of use } \\
\text { (4) } \\
\text { - Quantity (8) }\end{array}$ & $\begin{array}{l}\text { because Dairy } \\
\text { Milk has more } \\
\text { eggs and I like } \\
\text { plain chocolate" } \\
\text { (Female, age 11) }\end{array}$ \\
\hline $\begin{array}{l}\text { Perceived } \\
\text { Functional } \\
\text { Value - } \\
\text { quality } \\
(n=13)\end{array}$ & $\begin{array}{l}\text { Utility } \\
\text { derived from } \\
\text { the perceived } \\
\text { quality or } \\
\text { superiority of } \\
\text { the product } \\
\text { as an } \\
\text { abstraction } \\
\text { from lower } \\
\text { level } \\
\text { attributes }\end{array}$ & $\begin{array}{l}\text { Superior } \\
\text { performance } \\
\text { Superior } \\
\text { product }\end{array}$ & $\begin{array}{l}\text { - Quality } \\
\text { (5) } \\
\text { - Durability } \\
\text { (3) } \\
\text { - Superiority/ } \\
\text { excellence } \\
\text { (5) } \\
\text { - No defects } \\
\text { (1) } \\
\text { - Healthier } \\
\text { (2) }\end{array}$ & $\begin{array}{l}\text { "Because it was } \\
\text { better quality" } \\
\text { (Female, age 11) } \\
\text { "I knew they } \\
\text { were comfy and } \\
\text { wear and that } \\
\text { they would last a } \\
\text { long time" } \\
\text { (Female, age 11) }\end{array}$ \\
\hline $\begin{array}{l}\text { Perceived } \\
\text { price }(\mathrm{n}=36)\end{array}$ & $\begin{array}{l}\text { Utility } \\
\text { derived from } \\
\text { price as } \\
\text { encoded by } \\
\text { the consumer }\end{array}$ & $\begin{array}{l}\text { Low price } \\
\text { Acceptability } \\
\text { of price }\end{array}$ & $\begin{array}{l}\text { - Cheap price/ } \\
\text { low price (25) } \\
\text { - Low price for } \\
\text { product (17) } \\
\text { - Bargain price } \\
\text { (1) } \\
\text { - Price (11) } \\
\text { - Acceptable } \\
\text { price } \\
(5)\end{array}$ & $\begin{array}{l}\text { "It was the best } \\
\text { thing in the shop } \\
\text { that was under } \\
\text { my limit of } \$ 20 " \\
\text { (Male, age } 8 \text { ) } \\
\text { "I did not want } \\
\text { to spend too } \\
\text { much" } \\
\text { (Female, age 11) } \\
\text { "We chose the }\end{array}$ \\
\hline
\end{tabular}




\begin{tabular}{|c|c|c|c|c|}
\hline & & $\begin{array}{l}\text { Affordability } \\
\text { of price }\end{array}$ & $\begin{array}{l}\text { - Afford to buy } \\
\text { (15) }\end{array}$ & $\begin{array}{l}\text { movie and the } \\
\text { cinema on the } \\
\text { price of the } \\
\text { tickets" } \\
\text { (Female, age 14) } \\
\text { "It was the } \\
\text { cheapest" (Male, } \\
\text { age 14) }\end{array}$ \\
\hline $\begin{array}{l}\text { Curiosity/ } \\
\text { novelty value } \\
(n=18)\end{array}$ & $\begin{array}{l}\text { Utility } \\
\text { derived from } \\
\text { an } \\
\text { alternative's } \\
\text { capacity to } \\
\text { provide } \\
\text { novelty or } \\
\text { satisfy a } \\
\text { desire for } \\
\text { knowledge. }\end{array}$ & $\begin{array}{l}\text { Curiosity } \\
\\
\text { Novelty/ } \\
\text { variety } \\
\text { Interesting }\end{array}$ & $\begin{array}{l}\text { - Wanted to try } \\
\text { something new/ } \\
\text { different } \\
\text { (9) } \\
\text { - New issue/ } \\
\text { version (7) } \\
\text { - Interesting } \\
\text { product (2) }\end{array}$ & $\begin{array}{l}\text { "I always get } \\
\text { strawberry so I } \\
\text { thought it would } \\
\text { be nice to get a } \\
\text { different one, I } \\
\text { did not like the } \\
\text { others" (Female, } \\
\text { age 11) } \\
\text { "First time I } \\
\text { have tried it" } \\
\text { (Male, age 11) }\end{array}$ \\
\hline $\begin{array}{l}\text { Social } \\
\text { Influence } \\
(n=13)\end{array}$ & $\begin{array}{l}\text { The influence } \\
\text { of social } \\
\text { groups on the } \\
\text { utility } \\
\text { derived from } \\
\text { an } \\
\text { alternative. }\end{array}$ & $\begin{array}{l} \\
\text { Sibling } \\
\text { influence }\end{array}$ & $\begin{array}{l}\text { - Friends } \\
\text { recommend/ } \\
\text { have/like } \\
\text { (7) } \\
\text { - Would tell } \\
\text { friends about } \\
\text { product } \\
\text { (7) } \\
\text { - Symbol of } \\
\text { friendship } \\
\text { (1) } \\
\text { Siblings have/ } \\
\text { like } \\
\text { (2) }\end{array}$ & $\begin{array}{l}\text { "Well, all my } \\
\text { friends have } \\
\text { recommended } \\
\text { this book" } \\
\text { (Female, age 9) } \\
\text { "I paid half the } \\
\text { money with my } \\
\text { brother and it } \\
\text { had to be a game } \\
\text { we both liked. I } \\
\text { also knew it } \\
\text { would be a good } \\
\text { game because }\end{array}$ \\
\hline
\end{tabular}




\begin{tabular}{|l|l|l|l|}
\hline & & & $\begin{array}{l}\text { people had } \\
\text { recommended } \\
\text { it. " (Male, age } \\
13)\end{array}$ \\
\hline
\end{tabular}

\subsubsection{Thematic Concepts Explored}

Diaries included between one and six entries. Younger children typically purchased fewer products than older children. Themes were often repeated by children so in order to accurately reflect their importance for children of differing ages the number of diaries for which a certain theme was mentioned is also recorded.

\subsubsection{Previous Experience}

Previous experience was mentioned by children across all age groups as a highly influential factor in product choice. It was mentioned in half of the sixty two diaries. It reflects and relates to the ability to evaluate intrinsic attributes of products and hence facilitates decision making. Children often chose products on the basis that they know they will like them. This concept includes 'have not done something for a while' which implies previous experience with the product. While children across all ages mentioned this direct previous experience the younger children in the study were more likely to mention it. It was largely associated with food and beverage purchases for this group.

“That's why I chose chewing gum because I haven't had it in ages." (Female, age 8)

"Because I have had them before and I liked them and because it was the weekend and normally I go to the dairy on the weekend." (Female, age 8)

“Because I have had this item before and I like the taste." (Female, age 9)

"I had had that ice cream before and I liked it." (Female, 9)

"Because I wanted it to be similar to my old ones and they were the closest." (Female, age 10)

“Because I hadn't had Reese's in a while." (Female, age 10)

“They are my favourite ones, they are really yummy." (Female, age 11)

“Sushi is one of my favourite foods. It's nice I was hungry." (Female, age 12) 
"I knew I liked it and it was cheap." (Male, age 13)

"I picked my favourites." (Male, age 13)

Even if the product was new, children often chose the colour or flavour they knew they liked through previous experience.

"It was cheap and I like that flavour." (Female, age 11)

"I felt like orange." (Female, age 11)

"It's yummy and coz it's my favourite flavour of ice-cream." (Male, age 12)

For children of all ages this direct experience with either products or product attributes was a critical influence on children's value perceptions.

\subsubsection{Prior Knowledge}

Prior knowledge of the purchased product or service was mentioned in thirteen of the sixty two diaries. In cases of new products being purchased by the children they had sometimes heard about or seen the product, had used similar products or had sought information about the product which in turn positively influenced their perceived value of the purchase. Prior knowledge was mentioned consistently by children across the ages studied.

"I chose Miley Mania because I like Hannah Montana and Miley Cyrus to watch on TV."'(Female, 8 years)

"I had been really wanting to get it for a long time and all the other Lego on the shelves was not interesting to me or I had already gotten it." (Male, age 10)

"For the past few weeks I had been wanting to get one. So I went shopping to buy one." (Female, age 12)

"I also knew it would be a good game because people had recommended it." (Male, age 13)

"I had been saving for it I had also checked it out on the internet." (Male, age 13)

When children had not had direct experience with products they often referred to knowing about the product as contributing to their perceived value. 


\subsubsection{Affective Attitude}

Product liking was the most commonly discussed theme of purchase value across ages and product categories. Affective attitude can be defined as a positively valenced reaction to a product. It was mentioned in thirty eight of the sixty two diaries generally with some incorporating what specific feature was liked. The concept of liking is an abstract concept which may contribute emotional value in terms of pleasure or enjoyment to the alternative. Whether this was the case was often not apparent from the written responses. There was insufficient evidence to make such a judgement. Children often spoke of simply 'liking' the products they chose to purchase.

“Nothing else was similar and I love nerds." (Male, age 8)

"Because it was the cheapest, I like pebbles." (Female, age 8)

"I chose 101 excuses not to go to bed because it was a joke book and I like joke books because they are funny." (Female, age 8)

"I really like the skin on the chicken and they were all the same price." (Female, age 11)

“...I got a new jacket and I really liked it.” (Female, age 12)

"I chose this T-shirt because it was on special and I liked it more than the others." (Female, age 12)

“They were the HOTTEST.” (Female, age 12)

"Sushi is one of my favourite foods. It's nice I was hungry." (Female, age 12)

"It was the only one that had the correct colours, even though it was a bit too big, I really liked it." (Female, age 13)

"I paid half the money with my brother and it had to be a game we both liked." (Male, age 13)

"How I liked it, how much it was, how much I had." (Male, age 13)

Sometimes liking was more specific and referred to sensory responses to products. Sub-themes were: liking of the look (twenty three diaries mentioned this concept for at least one item purchased) or liking of the taste of products (twenty five diaries mentioned this concept for at least one item purchased). 
Children referred to liking the look of clothing, accessories and other visually experienced products and the taste of foods/beverages.

Items coded into liking of the look are illustrated by the following examples:

"I liked the colours best." (Female, age 9)

"I like red I got a red shirt it had a cricket player on it." (Male, age 10)

"I chose Reese's because it's very colourful and scrumptious." (Female, age 10)

"She looked good." (Female, age 10)

"They looked the coolest." (Male, age 11)

"It had a cool pattern. The colour would go with other things I got." (Female, age 11)

"I don't know I just saw it and liked it, it was a cool bag." (Female, age 11)

"They were in fashion and they looked awesome." (Female, age 11)

"Because they had a cool pattern on it and it made me feel like summer had arrived." (Female, age 11)

"Did it look good, did it fit well, was it too expensive?"(Female, age 11)

"I liked the look and I needed a new one." (Female, age 12)

"The colour of the jean top was the same as my jeans." (Female, age 12)

"I've wanted a heart pendant for a while, it looked good and it was cheap." (Female, age 13)

"It looked really good and was a good price." (Male, age 13)

While taste has been included as a dimension of quality in adult consumer research, it has been included in the concept of affective evaluation as children referred to liking the taste in affective terms and no reference to the superiority of the taste or other quality references such as freshness of the taste or naturalness of the flavour, as in adult focussed research. Children focussed on pleasantness of the taste.

“...because I like the flavour.” (Male, age 8)

"I know what it tasted like and I like that flavour. And I hadn't one for a long time." (Female, age 8) 
"Because the item I chose is eatable, chewy and very tasty." (Female, age 9)

"Because I like the flavour of the caramel chocolate bar." (Female, age 9)

“Well I've tasted all the other types but this one I liked better." (Female, age 9)

"It was a good price, it tastes good, it came with two in the pack so you could save one for later. " (Female, age 11)

“They are my favourite ones they are really yummy." (Female, age 11)

"Because it would be delicious" (Male, age 11)

"It's yummy and coz it's my favourite flavour of ice-cream." (Male, age 12)

"It had a lot more product for the same price and tasted better." (Male, age 13)

Further research to uncover reasoning and payoff regarding affective attitude was required. This was carried out in Stage 2 of the research.

\subsubsection{Emotional Value}

The concept of emotional value emerged in the diaries which was congruent with the definition of Sweeney and Soutar (2001, p. 211) of "the utility derived from the feelings or affective states that a product generates." It refers to the utility associated with feelings aroused by the product. Many children referred to the feelings a product generates as a reason for purchase. Emotional value was mentioned in twenty seven of the sixty two diaries. Children's enjoyment of the consumption experience was paramount in their choice and the value this enjoyment.

Children's comments reflecting the emotional value of the purchase were reflected in response to the choice question but more so in response to the feelings question.

"I thought about having a yummy, yummy quiche tonight." (Female, age 8)

"Because nothing is better than reading and new books are great." (Female, age 9)

"I was feeling sad so I bought a chocolate bar to cheer myself up." (Male, age 10)

“...because it's lollies I was really tempted to get some all weekend and the taste made me happy because lollies are so nice." (Female, age 11)

“...because they had a cool pattern on it and it made me feel like summer had arrived." (Female, age 11) 
“Because I love chocolate it makes me happy and my taste buds go wild." (Female, age 11)

“...because I was excited to wear my new jacket." (Female, age 11)

“...because it was going to be refreshing." (Male, age 11)

"Because I really liked it and needed it. So I was excited when I bought it." (Female, age 13)

"I knew I would enjoy the product, it was cheap." (Male, age 13)

Emotional value was important for many of the children and contributed to the value children of all ages perceived in their purchases. It was relevant across the categories of products purchased by children. These included books, toys, snacks/drinks and clothes.

\subsubsection{Functional Value - Performance}

The reasoning for purchase is based on functional, utilitarian and physical product performance attributes which meet consumer needs. Many children mentioned functional performance related attributes as being of importance to them. Thirty three diaries included at least one reference to this dimension of value. Examples are detailed below:

"There was only one kind of rugby ball and I chose the most pumped up ball." (Male, age 7)

“It was sugar free so I'm cutting down on sugar." (Female, age 9)

"I was hot so I felt like an ice-cream." (Female, age 10)

"To play with it." (Female, age 10)

"I chose lemon flavour because it was a hot day and lemons are refreshing and healthy." (Male, age 11)

“Did it look good, did it fit well, was it too expensive?" (Female, age 11)

“The size was good." (Female, age 11)

"It was the best deal and mints are healthier than sweets." (Male, age 11)

"It was the right size and it suited me." (Female, age 12)

“...I was happy I got the food plus I was hungry.” (Female, age 12) 
They looked yummy, I was hungry so to satisfy my cravings I bought them." (Male, age 13)

"Well I needed new cricket shoes and the ones I bought were really good. They were full sprigged and had good stability." (Male, age 13)

Children referred to valuing products due to functional attributes which made them suitable for meeting their needs.

\subsubsection{Functional value - Quality}

The superiority or excellence of product attributes was mentioned in twelve diaries. This concept includes dimensions of quality such as reliability, durability and quality of materials or workmanship. The concept of quality was not mentioned by children under eleven years of age, by intermediate age the concept is emerging as the superiority of one product over another as defined by Zeithaml (1988) in her study of adult perceptions of price, quality and value. Sometimes the children did not elaborate on their meaning of quality. It was usually associated with durable goods such as clothing and shoes.

“Because it was better quality." (Female, age 11)

"I knew they were comfy and wear and that they would last a reasonable time." (Female, age 11)

"They had good material and I knew these shorts were going to last me." (Female, age 11)

"Would it be the colour I wanted and would it break a day after I used it." (Female, age 11)

"It is fresher and healthier and more delicious than normal coke." (Male, age 11)

"Best quality for the money." (Male, age 13)

"I liked the design on this particular one more than the others and it also looked like it was a lot thicker/warmer than the others." (Female, age 13)

"Cause it is top of the line." (Male, age 14)

Children referred to the excellence of products in comparative terms and this was different to simply having attributes they needed. Sometimes reasoning in terms of manufacturing inputs was referred to. 


\subsubsection{Perceived Price}

Price refers to the money given up or sacrificed in order to obtain a product and was commonly mentioned by children as a factor in their purchase decision. Price was part of most children's perceptions of value in some form from age ten or year seven. Less than a quarter of the diaries from primary school children, aged seven to nine years included the concept of price whereas it was included in more than two thirds of the older children's diaries. Price was the second most commonly cited theme overall being mentioned in thirty six diaries. Price was sometimes mentioned in isolation from any other factor as the basis of choice but usually in combination with the product evaluation. Price was evaluated in several ways which have been grouped into three meaning units. These are: price mentioned generally with no further elaboration, a low price, the affordability of the price and whether it was an acceptable price.

A general mention of price includes in most instances other value dimensions but price is mentioned with no elaboration beyond this. It is simply mentioned as a consideration. Examples are listed below:

"The flavour, the price, the size, the look." (Female, age 11)

"The price if I could get the other thing and this for five dollars." (Female, age 11)

"I just chose my favourites but not too many because I didn't want to spend too much." (Female, age 11)

"How much would it cost? If I really wanted it? How much would it cost in other shops..." (Female, age 11)

"I thought about the colour, style and price." (Female, age 13)

"We choose the movie and the cinema on the price of the tickets." (Female, age 14)

Children also thought about the price in terms of whether it was low or the lowest available:

"Well because it's the cheapest one there and it's also one of my favourites." (Female, age 9)

"It was cheap and refreshing." (Female, age 11)

"It was cheap and I like that flavour." (Female, age 11) 
"I like KFC better than McDonalds and I wanted to get some cheap food." (Female, age 11)

“Hungry, cheap for what it is, had a budget of \$2." (Male, age 13)

"I knew I would enjoy the product it was cheap." (Male, age 13)

"We went to the cheaper theatre out of the ones of our choice." (Female, age 13)

"Because they weren't too bulky and they were cheap." (Female, age 14)

As is apparent from these quotes, value based solely on price was uncommon in children's decisions. They usually chose products they liked that were cheap or low priced rather than products that were the cheapest. Isolated exceptions were the diary of a fourteen year old girl who purchased the lowest priced movie tickets and the diary from an eight year old boy who purchased yoghurt and apples because they were "the cheapest" but he also indicated that he liked the yoghurt flavour and that it was a variety of apples he enjoyed.

The ten year old girl quoted below chose the cheapest product from a reduced choice set of shoes liked.

"It was out of three shoes Reeboks, Nikes and these ones. They were the cheapest." (Female, age 10)

Price was also considered in terms of whether children could 'afford' it:

"I thought should I really buy this? Do I need it? Which book shall I choose - I want so many. If I buy all the ones I want it will cost $\$ 50$ and I don't have that much money." (Female, age 8)

"If it wasn't too big it wasn't too small and it's not a rip off and I could afford it in my 5 dollars. "(Female, age 11)

"If my sister would be allowed it and if she would enjoy eating them, and if I have enough money." (Female, age 11)

"I felt like some lollies at the pool and that was one of the few foods I could afford." (Female, age 11)

"Would I be wasting my money? But this would taste good. It is a bargain. Will it last long. Am I spending too much money. Will I still have lots of money. Is it Ok for me to buy one block of chocolate." (Female, age 11) 
"It was in the budget of how much money I had." (Female, age 12)

"Because we could afford it and it was recommended." (Male, age 13)

"Would she like it? Was it a good price? Could I find a similar item anywhere else?

Could I afford it?" (Female, age 14)

Or whether it was 'an acceptable price' which was mentioned in five diaries.

"Because it's exactly what I wanted and the price was not too much so I am happy with what I got." (Female, age 11)

"Was it a reasonable price?" (Female, age 14)

\subsubsection{Curiosity/Novelty value}

Novelty value refers to the value of trying something new or different, a drive for variety of experience, knowledge or interest. It is the utility derived from an alternative's capacity to provide novelty or satisfy a desire for knowledge.

This concept was mentioned in eighteen of the sixty two diaries and it was related to the product category. In most instances the diaries referred to products for which 'newness' or 'difference' is an essential choice criterion. These items mentioned in the diaries were books, movies, magazines, Play Station, toys and games and jewellery. These items are usually purchased once and have no or low value a second time due to their no longer being new. Some examples are detailed:

"The movie was on at the time I was there and I hadn't seen it yet." (Male, age 12

Referring to a magazine:

"It was the new one out for the month." (Female, age 14)

Only one diary referred to a food item and two diaries referred to beverages.

"I always get strawberry so I thought it would be nice to get a different one, I did not like the others." (Female, age 11)

Referring to Cherry Coke:

"That it is a really interesting item."

"First time I have tried it." (Male, age 11)

Referring to Vanilla Coke: 
“Never tried it before." (Male, age 8)

The novelty value of food and beverage products best reflected the concept and was only mentioned by three children indicating it was not a significant contributor to perceived value and supporting the influence of previous experience or knowledge on the value children perceive.

\subsubsection{Social Influence}

Social influence was spontaneously mentioned by only thirteen of the sixty two children. Social influence has been defined as the influence of social groups on the utility derived from an alternative. Children did not refer to their self-concept or association with reference groups but rather the utility that was derived from recommendation from peers or siblings or consideration of what others would think. Positive social influence enhanced value perceptions. Examples below illustrate children's comments regarding social influence. Social influence was only mentioned by children aged nine and older.

"I thought: should I buy it because maybe people wouldn't like it?" (Female, age 10)

"I saw other people wearing them and I liked them." (Female, age 12)

A specific question regarding whether they would tell friends about the product they had bought, was included in the diary in order to indicate whether products had social value at all. Of the one hundred and fifty nine products for which diary entries were completed, children would tell their friends about eighty of them and not discuss eighty seven. Some products were regarded as well-known by friends and as such, children felt they did not need to be discussed. Others felt their friends wouldn't need to know about their purchase. This was particularly the case for food items with older children. Overall two thirds of the items children would not discuss with friends were food or drink items. Of the products which children would discuss with their friends, they would discuss the product, price or place of purchase often recommending their friends also purchase or purchasing products their friends had recommended or told them about (included in the prior knowledge concept). The quotes below illustrate some of the things they would tell their friends. 
"That I bought an awesome bag that was black and looked awesome." (Female, age 11)

"How it worked and what features it had on it." (Female, age 14)

In total forty four children would talk to their friends about at least one item in their diary. This indicates that products did have some kind of social value associated with them. The importance of reference groups as sources of information in terms of recommendation and approval also supports this. Children mentioned feeling excited about their purchases for social reasons.

“Because I had a sign expressing our friendship.” (Female, age 12)

“Because I couldn't wait to show my friends." (Female, age 12)

Social value was a consideration that children did not spontaneously mention as paramount in their decision. However, when prompted with a specific question, around half the products purchased had some type of social value and would be discussed with friends.

Influence of family on the perceived value of the purchase was evident in a few of the diaries.

Two eight year olds (one girl, one boy) mentioned their siblings as influential

"I wanted lollies because of my brother." (Female, age 8)

"My brother was buying. I wanted more cards. My Mum wouldn't buy it for me." (Male, age 8)

\subsubsection{Additional Concepts of Interest}

Seven diaries mentioned parental influence, no respondents over the age of twelve years mentioned being influenced by their parents.

"I asked my mum she looked at the price then she let me have it." (Female, age 8)

"I would tell mum because they are sour. She likes sour things." (Female, age 9)

“Because my Dad didn't want me to get junk food. Sushi is one of my fav foods. It's nice. I was hungry." (Female, age 12)

Parental influence on value perception is an area which was investigated further in Stage 2 of the research. 


\section{4. Age Related Changes in Purchase Value}

Changes were found to be gradual across age groups. Pairing the ages provided the most meaningful description of the patterns observed in the data. The ages were grouped on the basis of similarity. Additionally grouping meant the numbers in each group were larger making emerging patterns clearer.

\section{7-8 Years}

Young children aged seven to eight made purchase decisions largely on the basis of direct previous experience (ten of the thirteen children) relating to a positive affective product evaluation for nine cases. In five of the nine cases they referred to liking sensory aspects of the product. Looking at the instances where they did not mention a positive affective evaluation at all, parents controlled the child's choice in two instances, in one instance the child chose a product with a premium included and the other bought on functional performance value, he wanted sugar for energy in combination with the cheapest price.

"I was feeling tired and I thought it would give the boost to get up the stairs and into bed."

"It was the cheapest." (Male, age 8)

Four children included functional performance reasons for purchase. Three children included a mention of novelty value. Two eight year olds included value offered by a premium included with purchase.

There were two seven year olds in the sample, neither of whom mentioned price as important in their purchase decisions, irrespective of whether the items were paid for by themselves or their parent. Of the eleven eight year olds in the sample only four mentioned price as a factor in their purchase decisions. Three of these four were using their own money for the purchase while the other was purchasing for his mother.

Two of the children were purchasing for themselves with their own money and were purchasing sweets. Both of these children referred to buying the cheapest product.

“Because it was the cheapest I like pebbles." (Female, age 8)

Referring to a lollipop: "It was the cheapest." (Male, age 8) 
One of these children referred to parental approval of the price:

"I asked Mum, she looked at the price then she let me have it."

One child discussing her book club purchase spoke of the price relative to other items and whether she needed them. She also spoke about limiting the number of books she chose in order to afford to buy them. This level of complexity in thinking about price and value was not reflected in any other eight year-old child's diary.

"The other things were too expensive and I didn't need them."

"If I buy all the ones I want it will cost $\$ 50$ and I don't have that much money."(Female, age 8)

Generally these seven and eight year old children did not appear to link price to product evaluation in any way. They evaluated the product in largely sensory terms or simply in affective terms and if the price was evaluated at all it was in absolute terms relative to the money they had.

Apart from sensory liking or liking of taste there is no evidence of young consumers aged seven and eight considering the quality of products in adult terms.

Young people in this group mainly purchased from two categories, these were food/beverages (16 purchases) or books (5 purchases).

This group bought products they liked without weighing this up against the price, value did not appear to be a trade-off but rather products they liked. The 'get' component of value was the main consideration for most children of this age group. For those who did consider the price it was in terms of whether it was low and if they could afford it and this was only in a few cases as was consideration of functional value.

Value at the ages of seven and eight can be characterised in terms of a simplified rebuy and assessment of value. Product evaluation was to a large degree sensed and liking played an important role but it was also thoughtful. Children had a naïve perception of value rather than weighing benefits and costs and price was perceived simply in terms of affordability if considered at all. 


\section{9-10 Years}

There were nine, nine year olds in the sample and seven, ten year olds. Ten of the diaries mentioned previous experience as an influence on their purchase value. Particularly for food products (nine items were food) with children either relying on products they had previously tried or at least flavours that they knew they liked.

"I had had that ice cream before and I liked it." (Female, age 9)

They also based their choice for more durable products (two items) on previous experience with or knowledge of products prior to shopping.

"Because I wanted it to be similar to my old ones and they were the closest." (Female, age 10)

"Because I like books and reading and I got another book by the same author called Henrietta, There's No-one Better from the library and I heard it's a good one." (Female, age 9)

"I had been really wanting to get it for a long time and all the Lego on the shelves was not interesting to me or I had already gotten it." (Male, age 10)

Once again children chose products they liked generally. If more detail was provided it was sensory in focus with children choosing food they liked the taste of and clothes they liked the look of.

The emotional value of the purchase was discussed by six children aged nine or ten, in terms of how happy they felt or in terms of why they felt excited about the purchase.

"I love chocolate bars so Ifelt happy." (Male, age 10)

“...because it was for my friend and I will be really happy if she likes it." (Female, age 9)

Nine and ten year olds were more likely to consider the price as part of their decision than the younger respondents. Four nine year old and three ten year olds (about half the children in each age group) mentioned the price. Usually their decision was based on the price being low, but in one case it was due to the amount of money they had relative to the price of the item. One nine year old mentioned wanting to get 
change. One ten year old indicated that it was a "cool" product for not too higher price.

Functional performance was mentioned by eight of the sixteen in terms of the product performing a function.

"Because it is another shirt I can wear." (Male, age 10)

"This pack had good variety." (Male, age 10)

No nine or ten year olds mentioned or inferred the concept of quality in functional terms.

Curiosity or novelty was not mentioned other than for items for which being different is important to the overall value. Five nine year olds mentioned this for books, jewellery and toys.

"Because it is the first wooden crocodile that's hand carved that I have ever had." (Female, age 9)

Value at ages nine and ten was again based on knowledge which was increasing with children's increased experience. The influence of peers was emerging. Children liked the products they purchased and valued the happiness they would feel. Value was more likely to be comprised of benefits and price but was still a naïve conception. Price was considered in terms of being low and affordability was also considered.

\section{1-12 Years}

There were fourteen diaries from eleven year olds and seven from twelve year olds. Previous experience and prior knowledge of products are still mentioned as key influencing factors for some children. Four eleven year olds and three twelve year olds mentioned having direct experience with the products they purchased and one twelve year old knew about the product prior to purchase.

All diaries of eleven year olds and six out of seven of the twelve year olds' diaries mentioned affective evaluation of the product either generally or relating to the taste of food products or the look of durable products like clothes.

"Because I was really hungry I love sushi." (Female, age 12)

"It had a cool pattern. The colour would go with other things I got." (Female, age 11) 
“They are my favourite ones they are really yummy." (Female, age 11)

Ten of the diaries of eleven year olds and two twelve year olds' diaries mention emotional values associated with their purchases.

Functional value plays a role for most children by the age of eleven with eight diaries indicating this and more than half $(n=4)$ of the twelve year olds indicating such values.

At eleven years several new concepts emerged in the shopping diaries. Both were functional values related to the product and the price.

Children began to mention the quantity of product they were getting. Seven diaries from eleven and twelve year old children mentioned this concept.

"I chose dairy milk over Caramello because dairy milk has more eggs and I like plain chocolate better." (Female, age 11)

"It was the biggest." (Male, age 11)

"It wasn't too big it wasn't too small and it's not a rip off and I could afford it in my 5 dollars." (Female, age 11)

Critically at this age children's perceived value changed to incorporate the trade-off between the product benefits and being worth the price. This was in addition to considering the concept of price generally in terms of a low price, and affording to buy which are mentioned across all ages.

Social influence and telling friends about purchases was important for these ages with children mentioning talking to their friends about their purchase in all but four diaries.

There was also evidence of benevolence or unselfish values influencing purchase decisions for some children with one eleven year old, two twelve year olds incorporating such value in their purchase decision.

Overall value perception by eleven and twelve year olds could be described as more nuanced in terms of the benefits considered. The emergence of quality as a relevant aspect emerged and social considerations became more sophisticated with this age group. Value was characterised by many as the trade off as identified in adult conceptualisations. 


\section{3-14 Years}

The diaries of the thirteen and fourteen year old children were more detailed and included more concepts than the diaries of younger children. Children also purchased across a much broader range of categories including appliances, books, stationery, games, clothing, accessories, home ware, entertainment and communication as well as food and beverages.

Half the diaries mentioned prior experience as an influence on product choice and prior knowledge was mentioned in four diaries. It was mentioned in a lot more detail in terms of specific product attributes and in some instances comparisons with alternatives were made.

"I compared the cell phone I bought with all the other cell phones on the market." (Female, age 14)

Affective evaluation was mentioned in all diaries of thirteen and fourteen year olds. Liking of the look was mentioned in five diaries and liking of the taste was mentioned in only one.

"I thought about getting one I liked it had to match the colours of my room (pink, blue, green) and it also had to be the right size." (Female, age 13)

Functional value in terms of perceived price was mentioned in all diaries except one and as illustrated in the quote above was often combined with affective evaluation of the product.

The emotional value of the product was included in five of the diaries referring to the enjoyment of using or consuming the product.

"I knew I would enjoy the product it was cheap." (Male, age 13)

"Because the thought of eating them excited me." (Female, age 13)

Again the price incorporated all concepts regarding the price alone, low relative to other products and in terms of affordability. Value in terms of the trade-off between the product and the price was generally considered.

In terms of social factors certain products would be talked about with friends and were usually higher priced items such as Play Station games, clothing and other products likely to be high involvement purchases. Food/beverages were not really 
associated with having social value unless friends were with the purchaser or were going to share the items. Regarding the purchase of a Moro bar one thirteen year old indicated he would not tell his friends "because it is not worth the effort". Another student indicated he "did not want to brag." (Male, age 13.)

In one case where the respondent indicated they would tell their friends about a food product, it was at a fair where the quality was likely to be uncertain.

Older children were likely to recommend products they had purchased or simply inform their friends that they had purchased them. There was only one diary in which none of the items purchased would be discussed with friends and these were all snack foods. Gifts were not discussed with friends for obvious reasons in that they were a surprise.

None of the diaries from children in this age group mentioned parental influence in their value perception.

By thirteen to fourteen years of age there was evidence of independence in purchase decisions, maturing social awareness and the capacity to project in terms of considered recommendation based on the benefits perceived. 


\section{5. Summary}

There was a progression both in the number of concepts and the complexity of the concepts considered in purchase with age. The research has shown that the youngest children (7-8 years old) considered the benefits and costs associated with their purchases and as such they had a concept of value. Young children purchased from the categories of books and toys or food and made consumer decisions about them independently. Overall children considered up to nine main themes in their decisions and further subcategories were identified within these. Table 4-3 summarises the main concepts of importance in value perception found for children by age.

Table 4-3 Summary of Concepts by Age

\begin{tabular}{|c|c|c|c|c|}
\hline \multicolumn{5}{|c|}{ AGE } \\
\hline \multirow{8}{*}{ 先 } & $7-8$ years & $9-10$ years & 11-12 years & 13-14 years \\
\hline & & Emotional value & Emotional value & Emotional value \\
\hline & $\begin{array}{l}\text { Functional value } \\
\text { - Performance }\end{array}$ & $\begin{array}{l}\text { Functional value } \\
\text { - Performance }\end{array}$ & $\begin{array}{l}\text { Functional value } \\
\text { - Performance } \\
\text { - Quality }\end{array}$ & $\begin{array}{l}\text { Functional value } \\
\text { - Performance } \\
\text { - Quality }\end{array}$ \\
\hline & $\begin{array}{l}\text { Price } \\
\text { - Afford } \\
\text { - Low }\end{array}$ & $\begin{array}{l}\text { Price } \\
\text { - Afford } \\
\text { - Low }\end{array}$ & $\begin{array}{l}\text { Price } \\
\text { - Afford } \\
\text { - Low } \\
\text { - Low } \\
\text { comparatively }\end{array}$ & $\begin{array}{l}\text { Price } \\
\text { - Afford } \\
\text { - Low } \\
\text { - Low } \\
\text { comparatively }\end{array}$ \\
\hline & $\begin{array}{l}\text { Social influence } \\
\text { - Parents } \\
\text { - Siblings }\end{array}$ & $\begin{array}{l}\text { Social influence } \\
\text { - Parents } \\
\text { - Peers }\end{array}$ & $\begin{array}{l}\text { Social influence } \\
\text { - Parents } \\
\text { - Peers }\end{array}$ & $\begin{array}{l}\text { Social influence } \\
\text { - Peers }\end{array}$ \\
\hline & $\begin{array}{l}\text { Affective } \\
\text { evaluation }\end{array}$ & $\begin{array}{l}\text { Affective } \\
\text { evaluation }\end{array}$ & $\begin{array}{l}\text { Affective } \\
\text { evaluation }\end{array}$ & $\begin{array}{l}\text { Affective } \\
\text { evaluation }\end{array}$ \\
\hline & $\begin{array}{l}\text { Previous } \\
\text { knowledge }\end{array}$ & $\begin{array}{l}\text { Previous } \\
\text { knowledge }\end{array}$ & $\begin{array}{l}\text { Previous } \\
\text { knowledge }\end{array}$ & $\begin{array}{l}\text { Previous } \\
\text { knowledge }\end{array}$ \\
\hline & $\begin{array}{l}\text { Previous } \\
\text { experience }\end{array}$ & $\begin{array}{l}\text { Previous } \\
\text { experience }\end{array}$ & $\begin{array}{l}\text { Previous } \\
\text { experience }\end{array}$ & $\begin{array}{l}\text { Previous } \\
\text { experience }\end{array}$ \\
\hline
\end{tabular}

Age related changes in both the use of main themes as well as the specific dimensions have been noted with most relating to conceptual complexity. Children across all ages in the study consistently relied on prior knowledge and experience about alternatives as well as their affective evaluation of products. Knowing about the products and liking them, led to products being seen as having value.

Parental influence was found to impact on children's perceived value particularly at the youngest age and to gradually decline as children got older and gained both 
independence and experience with shopping. Social influence and benevolence only emerged in older children's diaries and then these factors were rarely mentioned as important. There was evidence of social value for all ages as a result of a question relating to communication about the purchase to friends.

The way children described the price became increasingly complex as they got older. The young children (seven years) didn't consider it, four of the eight year olds mentioned price in terms of it being a low price and one they could afford. By fourteen years children discussed the price in terms of the products worth and in comparison with similar products. They also mentioned affordability, and whether prices were low or cheap.

Functional value in terms of product performance was mentioned from eight years and functional value in terms of quality was discussed in diaries from eleven years.

The meaning of value changed to generally incorporate what you get as well as what you give up, as a trade-off, by eleven to twelve years. Children's perceptions of value became increasingly complex and they relied less on parents.

\section{6. Conclusion}

The diary method provided an effective tool for gathering information regarding children's value perceptions. The first general question ("How did you choose what to buy?") elicited a detailed response. And by including a comparative question ("How did you choose this exact one rather than other similar items?") further elaboration was provided by respondents. Overall these two questions provided the most information on children's value perceptions.

This method did however, carry with it some limitations. The question relating to emotional value in the diary which used the word 'excited' may have influenced responses and could have been more openly worded to capture emotional value. Other than this limitations were primarily compliance and communication preference issues. Some children did not complete and return their diary despite the researcher having gained parental consent for their participation. Children's responses to the questions in the diary became increasingly complex with age. By combining two methods with different response formats it was hoped to overcome this limitation and ensure that observed differences were not due to changes in ability to 
communicate in a written format. The other disadvantage of this written format was that it tended to appeal to girls more than boys. The result was a skewed sample with regard to gender. While the sample was gender balanced at the consent stage, fewer diaries were returned by males. Males also tended to provide less information in this written format than females although the general progression in thinking was still in evidence.

The results showed that even the youngest children in this study had a concept of purchase value. The meaning of the concept changed as respondents got older particularly along the dimensions of price and the functional value of quality.

In order to further investigate children's value perception and the process of age related change, a second study was conducted. The goals of this second study were to examine the process of change in value perception including conditions contributing to consequences of perceived value as children grow older and gain increasing experience as consumers in their own right. The diary study provided insight into the concepts providing value to children, however generally they did not spontaneously provide the level of conceptual detail regarding concepts such as 'liking' as necessary to fully understand the construct or the causal conditions which led to it. In order to achieve this conceptual detail the next stage of the research needed more flexibility in terms of questions and ability to probe for depth and understanding of meaning. Findings from Stage 2 of the research is detailed in Chapter 5. 
Chapter 5. Stage 2 - In-depth Interviews 


\section{1. Introduction}

The findings from the analysis of the diaries as detailed in Chapter 4 revealed key concepts important in children's perceptions of value when purchasing products. Nine main themes were identified across the sample. It was found that the number of concepts increased with age and more abstract concepts emerged as the children got older. Concepts also became increasingly complex as children developed cognitively and gained both experience with shopping and money as well as independence from their parents.

The use of diaries was shown to be a useful tool for gathering information from children which is recent, and has high external validity as it refers to real life purchases. In addition there is no direct influence of the researcher with this method, a commonly cited limitation when conducting research with children as they can sometimes feel as if they are being tested (refer Section 3.6.2 for details). However, the fact that the researcher was not present did not allow an opportunity to probe for more detail or for better understanding of the concepts from respondents and relied solely on explicit knowledge. More evidence was required to generate theory regarding children's value perception. As such it was necessary to build on the findings by conducting further qualitative research and in-depth interviews were chosen. Verbal methods with probing would also provide a comparison with the written response format which may be particularly relevant for young children. Given that value perception is a process in which consumers evaluate products resulting in choice and that this research was looking at age related change, a different method of data collection was required to supplement the preliminary findings.

In-depth interviews and grounded theory methods of data analysis were used in order to uncover both the relationships and details necessary to propose theoretical relationships regarding the way children construct value. This allowed the researcher to look at contextual factors and the differing contributing factors and conditions as experienced by children, to the construct. It also allowed relationships between concepts to be examined as well as consequences of interactions and emotions. 


\section{2. Participant Details}

Participants selected for this study were again in the eight to fourteen year age bracket. The diary study confirmed that by eight years children had begun to purchase independently. And many concepts used by those in the upper age group of fourteen years were consistent with concepts used by adults. In order to find out the views of children one must go to where children are easily accessible, so schools were approached. The sample was drawn by year group in order to sample children of differing ages and to facilitate the recruitment of participants from the school's perspective. Classes from the schools involved were composites of two years. High schools were approached to obtain the thirteen and fourteen year olds from year nine students. Once again the sampling was flexible with openness to gathering additional data from older respondents should new concepts be emerging.

The final sample consisted of 22 females and 29 males.

Given that the research was with children, there were ethical requirements surrounding parental consent as well as the child's assent, hence sampling was limited to those who had parental consent. The anticipated variation by age could be pursued via stratified, purposive sampling but other variation was left open to be followed up should it emerge. Due to the nature of the study research sites were also purposively chosen. Participants were again drawn from large suburban schools in the Wellington city area and included one primary school and two high schools. All schools were of a high decile rating reflecting a high socioeconomic catchment area for the schools.

The majority of children had between $\$ 0$ and $\$ 5$ of their own in pocket money per week which is relatively low. Only five children received more than $\$ 10$ per week. Should any differences have emerged in value perception by children from lower income families, this contextual factor would have been pursued. Table 5-1 details the demographic profile of the sample. 
Table 5-1 Demographic Profile of Sample

\begin{tabular}{|c|c|}
\hline Age & Totals \\
\hline $7-8$ & 9 \\
\hline $9-10$ & 15 \\
\hline $11-12$ & 12 \\
\hline $13-14$ & 15 \\
\hline \multicolumn{2}{|l|}{ Year } \\
\hline Year 3 and 4 & 12 \\
\hline Year 5 and 6 & 12 \\
\hline Year 7 and 8 & 13 \\
\hline Year 9 & 14 \\
\hline \multicolumn{2}{|l|}{ Gender } \\
\hline Male & 29 \\
\hline Female & 22 \\
\hline \multicolumn{2}{|l|}{ Child's Income Per Week } \\
\hline None & 14 \\
\hline$\$ 0.10-5.00$ & 21 \\
\hline$\$ 5.10-10.00$ & 11 \\
\hline$\$ 10.10-30.00$ & 5 \\
\hline \multicolumn{2}{|l|}{$\begin{array}{l}\text { Child's Approximate } \\
\text { Annual Income }\end{array}$} \\
\hline$\$ 0-50$ & 7 \\
\hline$\$ 51-150$ & 11 \\
\hline$\$ 151-250$ & 7 \\
\hline$\$ 251-500$ & 14 \\
\hline$\$ 501-750$ & 3 \\
\hline$\$ 751-1000$ & 5 \\
\hline$\$ 1001-2000$ & 3 \\
\hline$\$ 2001+$ & 1 \\
\hline \multicolumn{2}{|l|}{ Child's Position in Family } \\
\hline First & 31 \\
\hline Second & 11 \\
\hline Third & 8 \\
\hline Fourth or more & 1 \\
\hline \multicolumn{2}{|l|}{ Family Income (Gross) } \\
\hline$\$ 30000-50000$ & 1 \\
\hline$\$ 50001-70000$ & 1 \\
\hline$\$ 70001-100000$ & 5 \\
\hline$\$ 100001-150000$ & 20 \\
\hline$\$ 150001+$ & 22 \\
\hline Unassigned/ not applicable & 2 \\
\hline
\end{tabular}




\section{3. Overview of Results}

The following sections detail the results of the in-depth interviews and grounded theory analysis of the findings.

Analysis of the interview transcripts using the grounded theory method through coding procedures described above resulted in a detailed understanding of the phenomenon of purchase value for the children in the study. The research provided further evidence of change in understanding as children grew older. Some concepts were utilized more often than others and the meanings of some concepts changed with age while others were consistently applied.

Children elaborated upon the contexts surrounding their purchase decisions, the factors influencing their decisions and the resulting value perceived in the alternatives which they purchased. What emerged from the research was confirmation of a progression in children's thinking about purchases as found from the diary study. Children changed with age in terms of the contexts in which they were purchasing, the number of concepts considered as part of the value purchases provided and the complexity of their understanding of some of these concepts.

The context of children's purchasing changed considerably from that of a seven or eight year old in year three of their schooling to that of a thirteen or fourteen year old in year nine of the school system. The children had increasing power over their decisions as they grew and gained confidence to have control over their own worlds. There was a gradual withdrawal of parental control as children gained competence as consumers. They had increasing income and were given the independence with regard to their purchases and places of purchase. While their purchases remained as mainly discretionary items, children had broader interests and more money to spend which allowed a greater variety of categories to be purchased from.

Prior 'knowledge' or 'experience' remained a constant factor positively influencing children's perceived value through reducing perceived risk and enhancing children's ability to accurately assess benefits. Feelings, in terms of wants and needs, influenced the value of alternatives as has been shown in motivation research for shopping (Arnold \& Reynolds, 2003) and research regarding consumer decisions (Belk, Ger, \& Askegaard, 2003). 
The product class influenced value perception in terms of specific product attributes for children of all ages. However, the influence of the concepts of 'brand' and 'price' on value perception changed with age due to changes in the meaning of these concepts and contextual effects which were found to shape them.

Family and social influence factors changed considerably from 'family influence' to 'peer influence' as a result of changing contexts of purchase and increasing independence of the children. The role of the parents in terms of 'control' and 'influence' was gradually withdrawn as they facilitated the child's ability to make decisions for themselves.

The following sections provide detailed results. The details of contextual factors, conditions directly influencing value perceptions and value perceptions are discussed as well as consequences.

Contextual factors are used to describe the circumstances surrounding children's purchase decisions, conditions are used to describe those factors which directly influenced their value perception. Contexts and conditions are considered using the tool described by Corbin and Strauss (2008), the conditional consequential matrix. This helps the researcher to view their results at the differing, macro/micro levels at which they occur. In this study they are viewed at the personal level (micro) as well as at the group or collective level (friends/peers, family, culture) (macro). The value perception is the core concept referred to as 'action or interaction' in this paradigm and the consequences are the outcomes related to the actions/interactions or emotional responses identified as comprising the core concept.

Findings are now presented in terms of the contexts (macro level) influencing the phenomenon of 'value perception', conditions (micro level) that lead to 'value perception' and the action/ interaction characterising this central concept. Finally the consequences are discussed. 


\section{4. Results: Context}

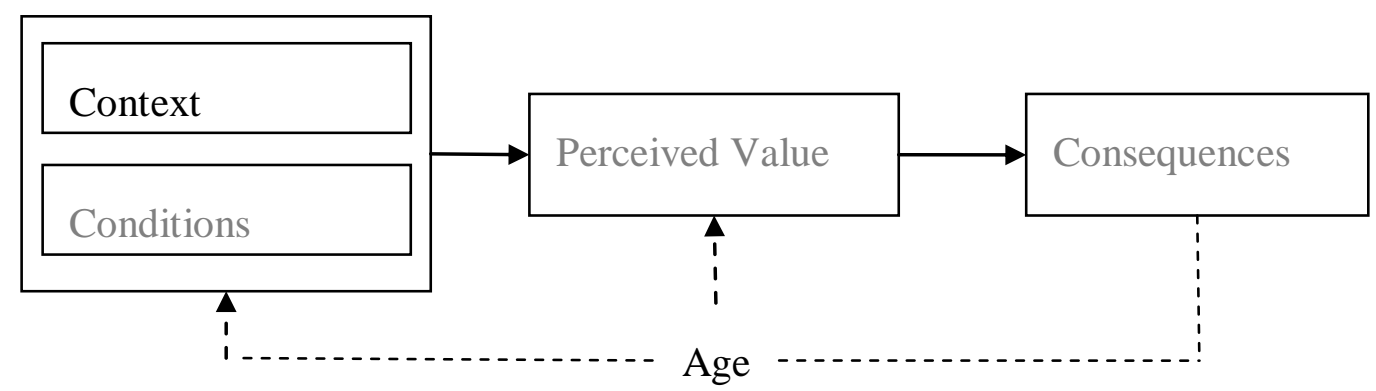

The context describes the conditions in which people respond. Context does not give rise to the response itself but influences the way they respond. Context is used to describe the conditions influencing children's value perception at a macro level. Context may impact upon conditions giving rise to action and emotion involved but it doesn't determine the action. This section identifies the contexts in which children's purchases took place and how these contexts influenced their value perceptions when purchasing. In addition to age and the implications for cognitive development, other age related contextual factors were found to impact children's consumption experience and hence value perception. Table 5-2 illustrates the contexts identified in the study.

Table 5-2 Contexts of Value Perception

\begin{tabular}{|l|l|l|}
\hline Category & Second Order Concepts & First Order Concepts \\
\hline $\begin{array}{l}\text { Contexts } \\
\text { of value } \\
\text { perception }\end{array}$ & Shopping Context & - Who shopped with \\
& Monetary Context & - Where shopped \\
& & - How much money they have \\
& & - How they get money \\
& Product Context & - Monetary values \\
& & - Food/ drink \\
& & - Clothes \\
& & - Coys \\
& & - Electronics/phones \\
& & - Books \\
\hline
\end{tabular}


The contexts in which children shopped were found to change as they grew older, in terms of shopping behaviour, how much money they had, how they got it and values held and products shopped for.

A two-variable case-ordered matrix is a matrix relating two main variables in the row and columns. The cases are ordered by age and these are related to contexts. The matrix is detailed in Table 5-3 overleaf. 
Table 5-3 Two-Variable Case-Ordered Matrix of Age and Context of Value Perception

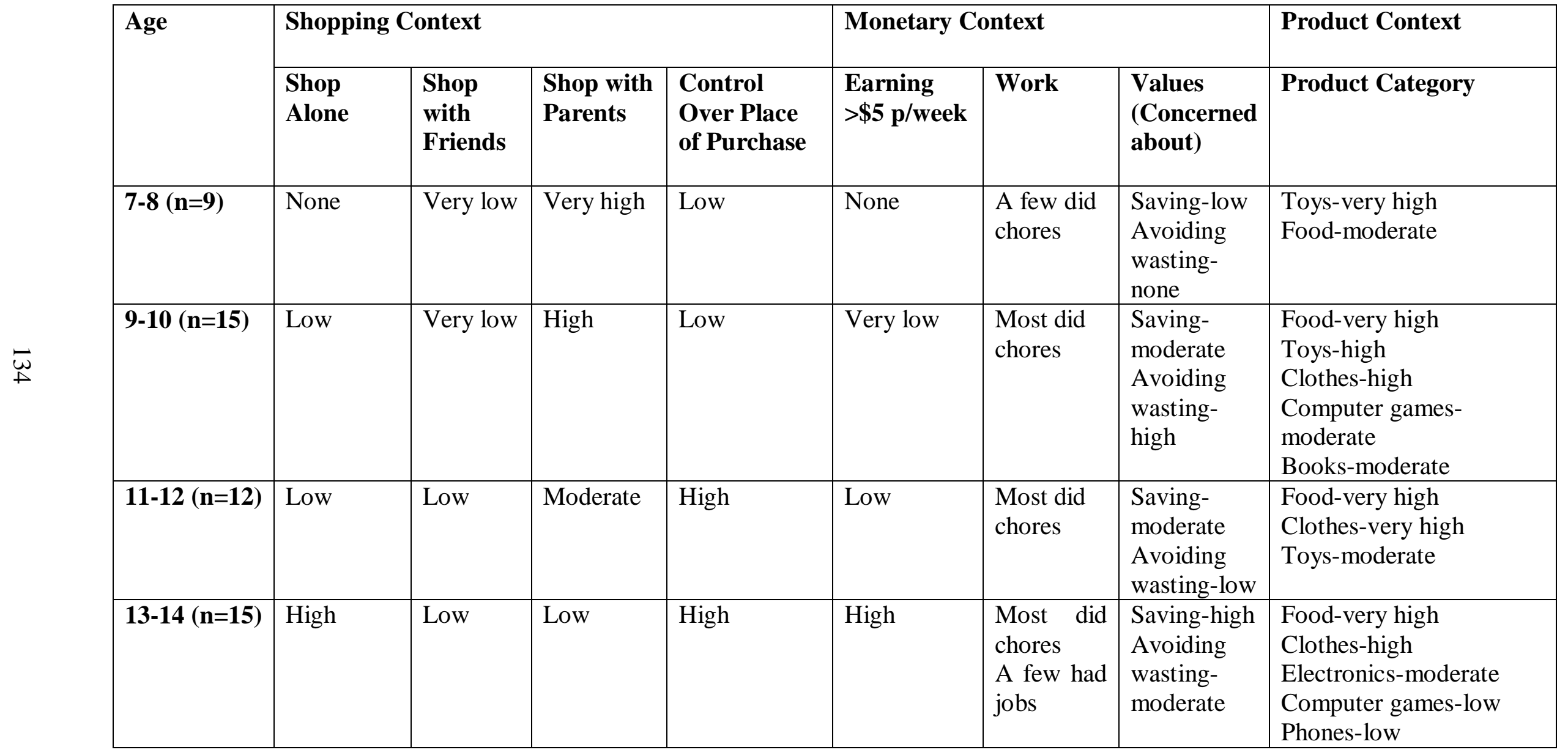

Key: Number of cases mentioning (Very low, Low, Moderate, High, Very high) 


\subsubsection{Shopping Context}

As children grew there was a change in shopping context in terms of "who they shopped with' as well as 'where they shopped'. They were given increasing freedom from their parents as they got older, gaining power to choose who they shopped with and where they could shop.

\section{Who They Shopped With}

The children mentioned who they went shopping with and multiple responses were possible.

The youngest children (school years 3 and 4) were new to purchasing independently and usually shopped with an adult family member typically their parents. Seven of the nine youngest children ( 7 and 8 years) mentioned going to the shops with their parents.

"I go with my Mum and Dad and my sister." (Samantha, age 7)

"Well my parents come with me and then I buy it with my own money." (David, age 8)

“My parents come with me but I decide what I want myself."(Miles, age 8)

Only one year three and four child, Melanie, is allowed to go to the shop alone but she is older being nine years of age.

"Kind of so I guess like sometimes I shop in the mall. Sometimes I go down with my scooter down to the dairy." (Melanie, 9 years)

This contextual factor of parents or adults accompanying children of this age when shopping led to parents being involved in one of two ways in the actual purchase decision. They either influenced the child's perceptions of value as discussed under 'parental influence' or controlled certain aspects of the purchase decision described under 'parental control'.

Many nine and ten year olds were given slightly more scope for independent shopping than their younger counterparts despite the fact that most were still accompanied by their parents. Increasing independence is evidenced by the extra freedom children were given to look in different shops or shop sections from their parents as well as more children being allowed to shop with friends or alone. The 
following quotes illustrate the increasing freedom the nine and ten year olds had even when shopping accompanied by parents.

"No me and my sister went browsing and I saw it and I wanted to get it so I went back to my Mum and asked her because I don't normally carry my money I just, she pays for it and then I give her how much it was. "(Mike, age 10)

"Well my Mum well we like going sometimes we go out where I like to shop for myself. Like sometimes we go to the Warehouse and I go like to the toy section and look for toys to buy and when we like go to the supermarket I usually look for some like magazines or something." (John, age 10)

Almost a third of the nine and ten year olds were allowed to shop with their friends and two out of the fifteen were allowed to shop alone at times but they usually shopped with parents at times as well.

"Sometimes food because I normally go to the dairy with my friends sometimes and sometimes something new at the computer shop or something to put my iPod in like a cover or something like that." (Bella, age 9)

\section{"Right and do you shop for things yourself?"}

"Sometimes I do but I have to get my parents' permission for that." (Sally, age 10)

Eight of the twelve, eleven and twelve year olds discussed the context of their shopping. They shopped increasingly with friends, five mentioned doing this and three mentioned shopping alone. They were often taken shopping by their parents as well.

"I do shopping for just things in general, like I go shopping with my parents but if I'm, sometimes I'll go shopping with my friends and maybe not even get anything but look, yep." (Ruby, age 11)

"Sometimes when my best friend, Ruby who just lives by Marsden we go down to the area every Wednesday and we'd spend at least like \$5 on food." (Gina, age 12)

Most of the oldest children (thirteen and fourteen years) were allowed to shop independently at least for some products. They often spent time away from their parents and this may have been with friends or alone. For example children in this age group discussed travelling to school, sports events or going to the movies. 
Parents still accompanied them on some shopping trips particularly for the more expensive items, but they did not make the purchase decisions.

"Ah generally it would be like the family would be there and I would just go in by myself. "(Richard, age 13)

"Yeah and for things like because I live out in Whitby I use the money to come into town like to see my mates and to go to the movies and stuff and then also to buy things like my phone, IPod, IPod music and stuff."(Joe, age 14)

"It depends what I'm buying. If I'm buying something relatively expensive I'd probably go with my parents just, oh I'd probably go with my Dad because my Dad's sort of taught me lots of stuff about buying things."

\section{“What kinds of products would you buy yourself?”}

"I generally would buy food or clothes or oh just general stuff like things for the computer or something, yep."(Luke, age 13)

The following quote from a thirteen year old boy referred to buying snack food from the dairy.

"Just on my own actually oh sometimes with my friends but never with my parents." (Max, age 13)

Across these ages there was marked change in the context of who children shopped with.

\section{Where They Shopped}

Children shopped at convenient locations near to their homes or schools, such as local dairies or the local toyshop or travelled to stores with parents. As children got older and were more likely to shop alone or with friends they were also more likely to shop at convenient locations they could readily get to. Younger children usually accompanied by parents shopped at a variety of shops which the parents determined to a large extent. This reliance on parents for getting to shops lead to limitations in terms of where children shopped which resulted in further limitation in choice, in terms of products, brands and prices.

"...we went to the supermarket, with purse, in case there is something I would like to buy." (Sarah, age 8) 
"Sometimes I go to the dairy with next door neighbour and we use their money or my money." (Samantha, 7 years)

"I have parental guidance but normally, normally I just go to the shops which are nearby but sometimes I go out to places like Moore Wilsons. Yep and normally I just go to Hopscotch." (Stephen, 8 years)

"Yeah I probably could. I could probably choose a Lego thing like the clone walker battle pack and I could choose a pack of these because that would be about $\$ 30$ and sometimes when we go into Farmers to get Julia some clothes or me some clothes I would have a look at the toys at the toys to see if there's anything I want and if there is and I have my money and I have enough to buy it then I would choose it." (Mark, 9 years)

As a result of children's lack of control over where they shop at this young age (Year three and four) it was difficult for children to shop around and to compare value or to seek improved value offerings. They had to buy at accessible locations or simply not purchase at that time.

As children got older they were still restricted in terms of where they could shop but because they were increasingly able to shop alone they could go to convenient shops such as dairies or look around in shops such as supermarkets. Four of the nine and ten year olds talked about shopping at convenient locations such as the local dairy or shops while eight, eleven and twelve year olds talked about shopping at such locations and all the thirteen and fourteen year olds had the freedom to shop at places near where they were going for school, sport or other activities.

"Usually in the week I buy stuff at Four Square, the Marsden Four Square which is down the road." (Henry, age 12)

“Well generally I just go to the dairy after school." (Luke, age 13)

"Only whenever, like, it's convenient to other people. Like whenever I'm close by to a store I'll go in and look at something. " (Richard, age 13)

“Well usually I don't, like go out to go shopping I just go out to hang with friends but like if we're walking past Foodtown and stuff whenever I see something in a window or I've heard about it, heard about it from a friend that's in there then I'll definitely go and have a look at it then I'll see the price range." (Jamie, age 14) 
There was an age related change in the context of children's shopping in terms of who they shopped with as well as where they shopped as they grew older largely characterised by being given increasing independence from their parents.

\subsubsection{Monetary Context}

Children changed over time in terms of the amount of money they had to spend and the means of getting or earning money. This limited income impacted upon their perceptions of the price of the goods that were considered for purchase

\section{How Much Money They Had and How They Got It}

The majority of the youngest children in the study got between $\$ 2$ and $\$ 5$ per week plus additional one off sums for occasions such as birthdays and Christmas. This amounted to an annual income of between $\$ 100-500$ per year. Four children in the study only received money for random occasions and these children received less than $\$ 50$ per year.

Children usually got pocket money and if they did chores then they received extra. Seven children did chores or had to behave to earn their pocket money or to get extra pocket money from their parents. These children got paid regularly. The remaining children got money to spend but they were not required to do anything for it. The following examples highlight the types of work required for the children to receive pocket money

"Pegging out the washing and bringing it in, folding it, unloading the dishwasher." (Samantha, age 7)

"Like put your plate in the dishwasher or remember to do the jobs." (Toby, 7 years)

"I do dishes but each Saturday we've always got a chore that we have to do and we have to do it and if we don't do it we don't get money and this Saturday my chore is to do the dishes." (Sarah, age 8)

“Well if I get, if I give Dad breakfast in bed he usually and it's not Father's Day or his birthday or anything he would usually give me 50c or sometimes 20c. And if I get Mummy a massage for five minutes she will give me \$1, ten minutes $\$ 2,15$ minutes $\$ 2.50$ and then its $\$ 3$ ”. (Sarah, age 8)

"Not very much but I do have to help sometimes." 
"Like putting my plate away at dinner time and tidying my room and stuff." (Miles, age 8)

"I think it's usually every week when I do my jobs." (Melanie, age 9)

"Yes I have to do jobs like take out the compost, do the dishes, fold my pyjamas and make my bed and stuff like that." (Oscar, age 9)

"Like for doing jobs." (Mark, age 9)

For seven, eight and some nine year olds, the monetary context influenced children's perceptions of value only in terms of what they could afford to buy. Children had small amounts of money and their choice was limited within this. Only three of these children discussed saving for larger items. Parents of these younger children encouraged 'monetary values' such as saving and sometimes put money into a separate savings account. These youngest consumers had relatively small amounts of money and while some had worked to earn it they didn't consider worth in a monetary sense.

With increasing age the context of how they obtained their money changed as well as the amount they obtained. As children got older they had more specific work they did for pay and although the work was still largely for the parents there was a closer correlation between work and pay. They were also given larger amounts of money and more freedom with their 'monetary values'.

"I get pocket money for chores."

\section{"Right. And what kind of amounts would you get for that?"}

“I get how much I am like if I'm 9 then I get \$9." (Bella, age 9)

"Well half an hour if I do something for half an hour or something that takes half an hour it would be \$5." (Mike, age 10)

Eleven of the fifteen, nine and ten year olds and ten of the eleven and twelve year olds mentioned chores as a requirement for being paid. It became more like remuneration for work as they got older and families tended to be more organized with the older children.

The oldest children (thirteen and fourteen years) sometimes had jobs that were external to the family such as babysitting and as such had higher incomes. All 
children in the thirteen to fourteen year age bracket got more than $\$ 250$ per annum income.

"I have to cook and clean up and like take the rubbish out, bring the washing in, do the dishwasher, empty the rubbish, like make my bed. I think that's all. Yeah a couple of times a week." (Belinda, age 14)

"I do like the dishes every night and I have to clean the bathroom once every two weeks for like the extra \$10." (Susie, age 14)

"Yes I do have quite a bit because I have like actually have a job. I play netball every Friday or most Fridays and get paid \$7 a game, so that's like $\$ 50$ every Friday so I save up quite a bit." (Jane, age 13)

“There's no set dates, but usually once a fortnight I babysit for people." (Donald, age 14)

There was a clear age related change in children's monetary situation and this was related to the values they held regarding money.

\section{Monetary Values}

Children mentioned four enduring monetary values which influenced their approach to shopping. These were price consciousness, saving, spending, and avoidance of wasting money. These values were sometimes the child's own or derived from parents views. Table 5-4 details children's monetary values. 
Table 5-4 Children's Monetary Values

\begin{tabular}{|c|c|c|c|}
\hline $\begin{array}{l}\text { Second Order } \\
\text { Concept }\end{array}$ & $\begin{array}{l}\text { Description of } \\
\text { Concept }\end{array}$ & $\begin{array}{l}\text { First Order } \\
\text { concepts }\end{array}$ & Example \\
\hline \multirow[t]{4}{*}{$\begin{array}{l}\text { Monetary } \\
\text { Values }\end{array}$} & $\begin{array}{l}\text { Values the } \\
\text { child holds } \\
\text { regarding } \\
\text { money }\end{array}$ & $\begin{array}{l}\text { Price } \\
\text { consciousness } \\
\text { (7) }\end{array}$ & $\begin{array}{l}\text { "Oh I can go to lots of shops } \\
\text { because my parents just want } \\
\text { the best deal pretty much, yeah } \\
\text { and I went to like four shops to } \\
\text { see the best price and but I } \\
\text { saved about } \$ 5 \text { so yep." (Male, } \\
\text { age 12) }\end{array}$ \\
\hline & & Saving (27) & $\begin{array}{l}\text { "I get about } \$ 17.50 \text { every two } \\
\text { weeks and yeah and } \$ 7.50 \text { goes } \\
\text { in my EFTPOS and } \$ 10 \text { goes } \\
\text { into my savings. And my } \\
\text { savings, my Mum has to sign off } \\
\text { on it so I can't just grab heaps } \\
\text { of money out." (Male, age 14) }\end{array}$ \\
\hline & & Spending (17) & $\begin{array}{l}\text { "Sometimes cause sometimes I } \\
\text { spend stuff that I don't have } \\
\text { enough money for so my Mum } \\
\text { or Dad take away pocket money } \\
\text { so that I can't buy it and use up } \\
\text { the money." (Male, age 9) }\end{array}$ \\
\hline & & $\begin{array}{l}\text { Avoidance of } \\
\text { wasting money } \\
\text { (19) }\end{array}$ & $\begin{array}{l}\text { "Sometimes I have to be careful } \\
\text { what I buy because I don't want } \\
\text { to waste my money." (Girl, age } \\
\text { 9) }\end{array}$ \\
\hline
\end{tabular}

Around half of the children interviewed mentioned saving their money. There was a marked increase in the incidence of saving amongst the oldest children with most of 
the thirteen and fourteen year olds discussing saving generally or saving for a high priced item.

“I've got a PSP but I don't have a console so sometimes I might buy a game for my birthday or whatever if I've got money from that but I suppose I should also mentioned last year I became sort of obsessed with lots of sort of various products because I was saving a long time last year and I ended up buying my iPod and a dock for that, both really good quality ones and I saved up in the end about $\$ 1200$ for it like for about eight or nine months and in that time I didn't buy anything else. Like I wasn't going to the dairy or anything like that for that whole time." (Donald, age 14)

Spending was mentioned by all ages of children as something they like to do, while the values associated with 'not spending' increased markedly with age. The increasing income and responsibility for jobs and chores was accompanied by changes in values held regarding money.

\subsubsection{Product Context}

Overall the six main categories which children mentioned purchasing from were; food/drink (45/51), clothes (35/51), toys (25/51), computer games (19/51), electronics/ phones (17/51), and books (13/51).

Seven and eight year olds in particular mentioned purchasing toys (seven of the nine children). There was a change from toys to food as the main purchase item mentioned as children grew older.

There was an increase in clothing purchase by children as they got older particularly amongst girls. All the girls in the thirteen to fourteen year age group mentioned clothing purchases and the extent of their clothing purchases is also greater than the younger children in the sample. The older children purchased clothing regularly whereas for younger ones it was only from time to time or they may have chosen the clothing but not have to pay.

As children got older they purchased a broader range of products. The oldest children in the sample purchased from a very wide variety of product categories including phones and electronic equipment. As children began to purchase these more highly priced products the concept of product involvement began to emerge, 
while younger children were highly involved with all their purchases, a few older children regarded lower priced food items to be less personally relevant than these higher priced items. For these products some value dimensions were less relevant. The following quote illustrates this distinction.

"Not, not that much really when you're just going to the dairy to buy like something that costs two bucks or something, it's not really expensive, you're not sort of looking for top quality stuff but if you're going yeah to a movie or something and you're paying like fifteen bucks yeah then you sort of like want to know you're going to sit on a quite nice seat yeah or not like have to sit somewhere like right at the front or right to the side. So that's the sort of thing we think about if we're going to a movie and it's completely full and you get a ticket right to the side in the front or something then I'd rather not go I'd just wait till another time." (Max, age 13)

This differentiation was also consistent with changes in monetary context and values held regarding money.

In summary, children in this study aged eight to fourteen years were influenced by contextual factors and these contexts varied with age. Younger children almost always shopped with parents and shopped where their parents took them. They had little control over where they went. They had small amounts of money which they obtained as pocket money, gifts or as payment for chores. Generally they did not exhibit concern about their money. Values associated with saving or obtaining low prices were not usually evident. On this basis the context of their purchase behaviour was highly restricted. As children got older they were gradually given increasing freedom to shop with friends or siblings and go to local shops. By thirteen to fourteen years most children were allowed to shop independently at least some of the time and had greater power over where they shopped. They still required assistance to travel beyond their local area but could shop en route to school or sport without parental influence. Children had a lot more money and there was a greater correlation between work and pay. By this age money was more highly valued as reflected by an increasing concern about saving, getting good prices and avoiding wasting money. Change was also reflected in the range of categories they purchased from which increased in number and type, and higher priced products were incorporated. 


\section{5. Results: Conditions}

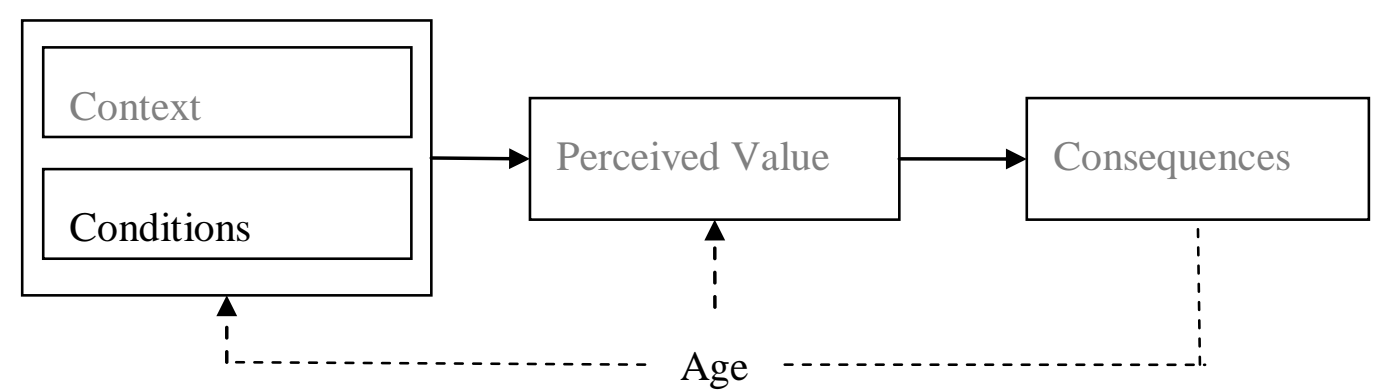

Conditions answer the 'why, how, where and what happens' questions, the conditions directly influencing the response (Andronikidis \& Lambrianidou, 2010; Corbin \& Strauss, 2008) in this case children's value perception. Table 5-5 details the conditions which both influenced children's value perception and changed as children grew older. 
Table 5-5 The Conditions Influencing Perceived Value for Children

\begin{tabular}{|c|c|c|}
\hline Category & Second Order Concepts & First Order Concepts \\
\hline $\begin{array}{l}\text { Conditions } \\
\text { influencing } \\
\text { value } \\
\text { perception }\end{array}$ & $\begin{array}{l}\text { Knowledge/Experience } \\
\text { Level of need } \\
\text { Parental Influence } \\
\text { Social Influence } \\
\text { Brand } \\
\text { Price }\end{array}$ & $\begin{array}{l}\text { - Prior knowledge } \\
\text { - Previous experience } \\
\text { - Product wanted } \\
\text { - Product needed } \\
\text { - Approval of product } \\
\text { - Influence on purchase } \\
\text { - Teaching consumer skills } \\
\text { - Approval of price } \\
\text { - Friends have product } \\
\text { - Friends like product } \\
\text { - Friends recommended product } \\
\text { - Popular } \\
\text { - Price knowledge/reference price } \\
\text { - Price importance } \\
\text { - Brand importance } \\
\text { - Brand meaning }\end{array}$ \\
\hline
\end{tabular}

\subsubsection{Knowledge/Experience}

'Prior knowledge' and 'previous experience' with products were regarded as important influences on the perceived value of an alternative. This was consistently mentioned across all ages in the sample and was consistent with the diary findings.

All the children in the youngest age group used their 'prior knowledge' or 'experience' to buy things. Products they knew about or had tried were purchased. Prior knowledge or experience facilitated decision making and as such resulted in purchase. The benefits of the product and its performance were guaranteed. 
Knowledge was mainly gained through friends, family and the media (such as television programs or advertising).

\section{Prior knowledge $(n=38)$}

Prior knowledge was described in terms of having prior information about the product that led to choice but excluded actually having bought the product previously. Children discussed having heard about or seen products, having used similar products or seeking information about products. Prior knowledge contributed to the value of products. If children possessed knowledge of products they felt the products would provide functional value in terms of performance and that they would be more likely to enjoy the product.

"Like I wouldn't want a brand that I have never heard of."(Fred, age 12)

They got knowledge from peers, parents or from television, often programs with the characters or product involved or sometimes advertisements.

"From my friends and from looking in the shop windows." (Toby, age 7)

“And I didn't know what Pokémon cards were for at first and then I figured out what they were for because me and my friend tried to figure out what they were for because he had some as well. And then we found out and we decided wow that's really cool let's do it. And we partly learned off the TV because they have TV show, TV shows of Pokémon cards." (Mark, age 9)

"I'm not sure really. I just felt like, I didn't feel, like I just really wanted it. But I think I saw a movie or something and got it off that. I thought they were quite cool." (Max, age 13)

"If it looks, like, good enough. Usually if I'd seen other people eating it or it was by a company that already like some of their other products then I'd buy it but apart from that probably I wouldn't try a new product or a new brand that I hadn't tried their other products before." (Donald, age 14)

Clearly as illustrated by the following negative example, when this child didn't know much about the purchase they indicated that they would get help.

“No. I don't buy clothes. I would have to have Mum because I don't know anything about measurements of clothes." (Mark, age 9) 


\section{Previous Experience $(n=39)$}

Previous experience was also identified in the children's diaries and was found to relate to children's ability to evaluate intrinsic attributes of products and facilitate decision making. Children had often tried the products they bought and this could be via a friend, a parent or a sibling either owning the product or giving it to the child. This provided concrete information about the intrinsic product attributes or those that are part of the product itself and hence the functional performance, to the child. This provided value to children in terms of product performance. It was similar to brand loyalty but at the product level for younger children with the older children using brand to identify products they had prior experience with. Five children mentioned advertisements reminding them of products they had prior experience with.

"Because they could taste wrong to me, because even though I don't have allergies I just like the same ones."

\section{"Right and how do you get to know about them in the beginning?"}

"First my Mum and Dad take me to the dairy I go with them and I looked at the lollies and I tried some and then I can come back to the dairy myself." (Samantha, age 7)

"Yeah because last time I had a cold and I got these and my Mum knows I had a cold and I got them. The first time I sucked on them I started coughing but the second time if I didn't and it just worked out perfectly."

"Yeah there were two other flavours. Spearmint and Mint and I tried them before but I don't think I will... because I don't want, because they're quite minty but I've tried mint before and they were okay they helped a bit more."

"That it starts off tasting like the white bit tastes like vanilla ice-cream when you start off and then once you've bitten it the orange stuff, the orange starts to appear but on the mint ones on the mint ones it starts off mint and then gets mintier." (Sarah, age 8)

“Because I've tried it before and there's this one that's got sorbet in the middle and I quite like that one, yeah. And for the drinks I normally choose L \& P or Lift, I quite like those two." (Bella, age, 9) 
Oscar had purchased a Play Station 2 game called Midnight Club 3 which he had tried at his friends place prior to purchase.

"Because when I was doing guitar lessons with my friend Hamish that was before we got a new guitar teacher, I used to always go round to his place because that's where we did our guitar lessons and then we'd play on his Play Station 2."

\section{“Has he got this game?"}

"Yes he had Midnight 3; yeah he has Midnight Club 3." (Oscar, age 9)

"I'd read the other ones and I thought they were really good yeah so I thought I would get this one and it looks awesome." (Mike, age 10)

Children mentioned favourites and trying products out first to maximise the chance of obtaining good value in terms of known product performance.

"Well on a hot day, probably shout my brother and ice-cream and we have favourite ice creams and we stick to those."

\section{“What are they?"}

“We like Magnums, Tiptop ice creams.” (Kate, age 12)

In the following example the boy discusses how he has come to learn that by trying products first he is more certain of the benefits the product offers.

"Yeah I used to do that more than I do now but obviously as I've got older and stuff I've learned to be more careful with things like that and like sometimes my mates will have things before me, like I will use their stuff before I buy it myself to check if I actually am going to use it and stuff." (George, age 13)

Positive prior knowledge and/or experience with products enhanced the perceived value of alternatives and were mentioned by most children. Children could be sure that products they had tried before would perform as they expected and they would not be disappointed. When they had heard of the product they valued it more than one that was unknown.

\subsubsection{Level of Need}

"Motivation can be described as the driving force within individuals which impels them to action" (Schiffman, Bednall, O'Cass, Paladino, \& Kanuk, 2005, p. 70) and 
can be positive or negative. Needs may be physiologically (innate) or psychologically (acquired) based. Unfulfilled needs lead to goals to satisfy tension. "Goals are defined as internal representations of desired states." (Schiffman, et al., 2005, p.72). Wants are a reflection of the goals selected by individuals to satisfy a particular need. Goals are much easier to identify than the need underlying them.

Wants (40) were the main feelings children discussed as drivers of purchase.

"I buy the ones what my parents think I don't really need and my parents will get the ones what I might urgently need so yeah."(Angus, age 9)

'I don't buy the things if I, unless I really want them or I need them but a lot of things if I really need them my parents would buy and that's just the sort of gear that I don't need that I buy myself." (Nick, age 11)

“Well, my parents don't really buy me clothes unless I need them, so if I want something it's, I don't really want to, want to waste it all in one go in case I see something else that I really want or, something like that. "(Susie, age 14)

Sometimes wants lead directly to the purchase or sometimes looking resulted in wanting. Most often they just knew they wanted certain products. Products purchased were not usually 'needed' physiologically as their basic needs were met by parents. Emotional wants typically reflected children's shopping goals and those needs which were more utilitarian in nature such as hunger were met by products which were liked or loved, emotionally satisfying.

"Yes and I had more than $\$ 7$ and I started telling her about why I wanted to be enrolled in Club Penguin we could buy lots of stuff and you can't usually buy a lot of stuff If you're not a member. You can only buy up to two puffels, a red one or a blue one." (Olive, age 8)

"Yeah I thought it was like a good value because my Mum pointed out two like little sets and I didn't really want to get it because I really wanted the big set because I like Lego Star Wars the big sets." (Tim, age 8)

"Because I had always wanted it from Pumpkin Patch and it was in this K Mart shopper's mall and it was \$24 but I could have gotten it with my \$100.” (Sarah, age 8) 
"Yeah. Like if I want something then I have to buy it with my money, yeah." (Oscar, age 9)

"And I saw a book that went clink in my mind and I really wanted to get it which was a Miley Cyrus book and it was because Miley is, how would you say this I'm not sure how you would say it, you look up to her like. And it was all about her story life."

"Oh yeah and I thought I would really enjoy it and it was like it went click into my mind I want to get it. If you know what I mean like you get this tingle in your head that you like a knock in your head that you really need it and you really want to read it desperately." (Melanie, age 9)

Four of these children mentioned a collection or completing a set as the motivation leading to purchase. Collections tend to appeal to children and represent a unique type of motivation. The added value of having more, or a complete set.

"Because I already have a collection." (David, age 8)

"Like if it's Lego if it comes with some really real Lego people or yeah, or if it's Pokémon cards if I like yeah if it's like Donphan and Tyrogue because I don't have very many of them in my cards I think." (Miles, age 8)

"Well it was, just probably the one that I really wanted the most because some of the other ones I already had." (Stephen, age 8)

"And you can get them and I like collecting them and having battles with my friends." (Mark, age 9)

As children got older they provided more detail about why they would want something, they also describe emotional reasons for wanting products (discussed in more depth in Section 5.6.1).

"Well if it's like a toy it would be fun to play with and they would like, they would think that they would want that to play with at home. And yep like sort of a trampoline maybe because we've got a trampoline. And if you went on a trampoline to someone's house and you liked it you'd probably go you know you'd say oh can I get a trampoline for my birthday or something like that." (Annie, age 10)

"You sort of think like how you feel. Like if you're feeling like really thirsty you'd probably choose like a fruity flavour and if you want just something nice you would probably choose a more savoury sort of flavour, less creamy or an ice block that 
would cool you down more. So it depends on what you feel like you want." (Kate, age 12)

While the older children also bought mainly products they 'wanted', for some children, parents had shifted some of the responsibility for needed products to them.

\section{"And when you said you buy clothes, do you buy all your clothes?"}

"Um, pretty much all of them. Sometimes my Mum shouts me something, but, most of the time it's me." (Clare, age 14)

Young children were found to be largely motivated by psychologically based wants rather than physiologically based basic needs. With increasing age some of the responsibility for products which were needed was being shifted to the children by parents.

\subsubsection{Parental Influence}

Parental influence was mentioned in forty two of the fifty one interviews and while it varied in terms of the extent of the influence and the nature of what the parents were influencing with regard to the value children perceived, they were clearly an important factor for many children of all ages.

For young children in the sample, parents were a major influence on their purchases and value perceptions. Parent's attempts to teach children consumer skills often impacted their children's purchase decisions. Parents influenced the value dimensions considered by children in terms of "teaching their children consumer skills', 'approving products', 'approving prices' and 'introducing products'. As children got older the changing context of their shopping experience meant they were often not with parents when shopping. However, the influence of parents was still important for many children, their approval or disapproval increased either the perceived benefits or the perceived costs associated with choice.

Within the 'parental influence' construct specific influences over certain value dimensions were identified. In the following sections the type of influence the parents had, has been more specifically detailed. 


\section{Teaching Children Consumer Skills $(n=15)$}

Children described the influence of their parents over their consumer decisions in terms of the consumer skills they taught them. For young children parents attempted to assist their children's ability to make purchase decisions and to consider dimensions of value that they themselves considered important. This 'teaching of consumer skills' was sometimes followed and sometimes ignored. It was probably the main reason for parents exerting influence over children's purchases in terms of all aspects of value perception as well as 'control' of the final choice, however qualitative investigation with parents would be required to determine whether this was the case from their perspective.

“My Mum told me I didn't have enough money." (Samantha, age 7)

"Yes because yeah my Mum thought it was not worth it but she still bought it for me because she knows that 'one toy every month'."(Vincent, age 8)

"Yeah I thought it was like a good value because my Mum pointed out two like little sets and I didn't really want to get it because I really wanted the big set because I like Lego Star Wars the big sets.” (Tim, age 8)

"Sometimes cause sometimes I spend stuff that I don't have enough money for so my Mum or Dad take away pocket money so that I can't buy it and use up the money." (Oscar, age 9)

As children got older they still mentioned their parents teaching them consumer skills but the teaching was less explicit. Rather than pointing out specific issues, they influenced through earlier teachings or by questioning the child to ensure certain aspects were considered.

'I don't really think they influence me massively like they'll always get me to, they've always taught me not to go like stupid with money and stuff. Like once you've spent it, you've spent it and you can't like get it back and unless you like earn it back or something. But they've always, yeah they've always taught me to look around and see what's cheaper and what actually is different in quality and stuff for something at a lower price compared with something for a higher price. So in that sense I guess they do influence me with the money and stuff and just the type of item 
it is just to make sure that like it is suitable without being ridiculously expensive." (George, age 13)

"Well we were quite close because my Mum and Dad split up since I was three so we've got a great bond and it's, she does know when I'm being a bit stupid when I'm just wasting money and it's taught me like the fact that if I don't need to buy it then I won't generally now buy it and it's like she is, she often stops me and says do you really want this." (Joe, age 14)

\section{Approving Products $(n=29)$}

Children's decisions were influenced by whether their parents would approve of their product choice. If parents were there at the point of purchase, children sometimes asked for this approval of the product.

"Like he said that he really liked it when ... and also my Nana was there and she said that it was really cool, so yeah."(Oscar, age 9)

By parents approving or disapproving purchases they attempted to shape children's value perceptions by influencing children's values and hence the benefits perceived in a choice. Factors such as healthiness may not be considered without parental input but by prompting this consideration children's future value perceptions became increasingly complex.

"Yes but my Mum might come with me and whenever I need, we went to the supermarket and with my purse just in case there was something that I would like to buy and if it was something like maybe something that's to do if it was something like lollies, if it was Tic Tac it wouldn't count because you've got a cold but if it was something like lollies and I've already had heaps of lollies. Like heaps of lollies or heaps of days then I won't be able to buy them because it's too much sugar."(Sarah, age 8)

Even when the parent was not present this child took their view into consideration noting that they had to be 'sensible'. This comment clearly represented the incorporation of parental influence into the decision even when the parents had pulled back allowing the child to go shopping alone.

"No because we go up by ourselves we have to be sensible though." (Samantha, age 7) 
Sometimes they moved away from needing this approval when they felt strongly about the product but unless this was allowed by the parents they had to purchase approved products.

“Actually Mum didn't actually want me to, Mum was thinking about me being a membership on Club Penguin and by then I had its \$7 and I had more than \$7 so I probably could buy it and I started telling her." (Olivia, age 8)

Parent's approval of products was a consistent consideration for children of all ages, while the older children did not always incorporate this approval into their decisions. Six of the seven, thirteen and fourteen year old girls mentioned the importance of their parent's approval for certain products most commonly clothes but also DVDs, food and texting.

"Yes slightly because I, there were two I was originally going to pick from, these ones and another pair that were lower down and my Mum was in the room and she was like Clare that is too low down, you are not getting those. And I was like oh well I suppose I love these ones even more, so I just got them." (Clare, age 14)

\section{Influencing Product Choices (n=29)}

They were often introduced to products and brands by their parents. If they knew their parents had bought the product for them on a previous occasion this would lead to their approval of the purchase. Parental introduction to a product or product concept also lead to 'prior knowledge' which children indicated enhances the value offered by the alternative.

"Probably actually from my friends because they were talking about it and then Dad said do you want to look, watch this movie and stuff." (Toby, age 7)

"Well the first thing before I saw it is my Dad pulled out a movie and it said Star Wars on it and it had episode four and I watched the episode and it looked really cool. Then I went, then my Dad said look onto Lego and then I saw Lego Star Wars."(Tim, age 8)

"Okay. Well I had a lot of choices like my Dad got me shorts to try on, rap tops, jerseys and t-shirts and yeah I had to choose stuff carefully. Like I got a pair of sports shorts, one top and two jerseys and a rap top." (Oscar, age 9) 
For the young children (seven and eight years) parents sometimes helped with the purchase decision.

"I have to agree with my Mum and Dad when I buy it." (Samantha, age 7)

"I would but if I couldn't choose he would probably choose something for me." (Toby, age 7)

\section{"And what would make you try something different?"}

“When my Mum tells me to and I see whether I like it as well." (Vincent, age 8)

Parents influenced children's purchase decisions at all ages but they changed from directly influencing children to having a more subtle influence.

"Well I suppose things that are really bad for you I don't really just get them every day but I still get them. You know whereas when I was a little kid they wouldn't let me get it and now yeah I sort of probably get things that aren't as good for you but taste nicer but not all the time, yep." (Max, age 13)

“And if I'm eating too much junk she will probably steer me away because I don't really need it and it's just helping me know I don't need it." (Joe, age 14)

There were seven children who specifically discussed the fact that their parents did not influence them, five were aged thirteen or fourteen and for the other two children it was simply due to the circumstances. This gradual withdrawal of influence corresponds with the increasing power the children were given to make purchase decisions independently.

“No. I'm lucky though with my parents so they don't really influence what I buy at all really." (Jamie, age 14)

\section{Approving Prices $(n=14)$}

Parents discussed prices with their children and this seemed to be particularly likely when the price of the item was relatively high. They commented on the price itself as well as the value for money offered.

"Well kind of. My Mum and Dad sometimes say oh that's too expensive. You have to pay it with your own money." (Tim, age 8) 
"Sometimes she just thinks the price is too, it's just like not worth it for it. Like a big Ben Ten toy I think it's worth it. Its $\$ 79$, its $\$ 80$ but my Mum doesn't think so. It's that huge, it's so, it's so worth it but my Mum doesn't think so." (Vincent, age 8)

Sometimes they shifted the decision to the child when they felt the value was low or the price too high. They also advised these youngest respondents about the affordability of the products they chose.

“They don't really mind unless it's heaps, unless it's not very good but it cost heaps of money then they say oh I don't think you should get this because it's heaps of money but it doesn't really do much, so yeah. " (Oscar, age 9)

They certainly encouraged children to think more deeply about prices and it is likely that this instruction would encourage incorporation of a deeper consideration of the price in relation to the value offered.

"Oh I can go to lots of shops because my parents just want the best deal pretty much, yeah and I went to like four shops to see the best price and but I saved about $\$ 5$ so yep." (Josh, age 12)

"I asked my brothers if they thought it would be worth it as well and talked to my Dad about it too." (Luke, age 13)

"When I think like value I normally, I do look at how much it is especially when one of my parents is with me and because you know I look oh my gosh that's really cool and then I look at the label and it's like oh ninety bucks mm Mum what do you think. And then yeah but if she likes it or something like that then she'll buy it for me because she's a clothes person as well so you know we go on our little shopping trips together." (Jane, age 13)

Parental influence on children's value perception was both instructional and protective. They influenced their children through specifically attempting to teach consumer skills through pointing out deals, discussing worth and advising on affordability. They also let children know when they approved or disapproved of choices based on both price and product. They also influenced children by introducing them to products they like or liked as a child. 


\subsubsection{Parental Control}

In this analysis it was found that in some cases the parents had direct influence over the purchase decision despite the children perceiving value in an alternative.

'Parental control' refers to parents exerting control over the child's purchases and this was mentioned by thirty three children. This directly impacted the categories they purchased from or the final purchase decision their children could make.

Children may have perceived an alternative to offer value but due to parental control the purchase may have been delayed or not made at all. Parents controlled the money given to allow some decisions and/or determined the prices the child paid. This was the case across all ages but the parents were less controlling of the older children. For older children they were selective as to what products they controlled. If they were to exert influence, they usually limited this to higher priced items. Sometimes they restricted the money they gave the children.

\section{Purchases (n=27)}

Eight of the youngest children mentioned their parents controlling the overall decision or decisions for certain categories of products such as food (see the examples below).

Parents sometimes had the overall control of purchase decisions of children. Parents controlled purchases decisions by intervening at the stage of the purchase decision.

"Mum and Dad had to decide for about two days and I was a bit, I was a bit impatient." (Olive, age 8)

"Yes I thought about choosing some Mentos as well but then Mum said I wasn't allowed to, just one a day." (Sarah, age 8)

Sometimes this was temporary; this child did make the purchase once he had saved up. His parents didn't purchase it for him for his birthday as requested.

"Well I saw it in the catalogue, I saw it for about a month in the catalogue and then it looked, just looked really cool. So then I said to Mum can I please buy it for my birthday or something and she didn't let me so then I had, so then I saved up for $\$ 100$ and then what I did is I went to the shop and bought it." (Tim, age 8) 
Parents also controlled purchasing from certain categories. This control was reduced for older children, as illustrated in the following examples

“Yes as long as it's not food. I'm not allowed to buy food, yeah." (Grace, age 10)

“...sometimes when I'm at school Mum goes shopping with someone else and she sometimes buys me tops and stuff." (Molly, age 11)

"My parents normally buy clothes. I pick them out and they normally buy them because what they do is they normally buy it like one or two sizes too big so I can just grow into it, saves them shopping for a couple of months or something." (Kate, age 12)

By the time the children were thirteen and fourteen they were less likely to mention parental control of certain purchases and for most even when they did mention parental control it was less extreme and not necessarily the usual case.

“How important is your parent's approval in terms of what you buy?"

"Oh pretty high because they'll take it back to the store if they don't approve of it." (Richard, age 13)

"But food Mum and Dad generally pay for unless I'm out I'll pay for lunch." (George, 13)

\section{Prices and Money $(n=11)$}

Eleven children mentioned parents controlling the amount of money they spent. This was in absolute terms or in terms of value for money.

"So I usually go to the lotto store or The Warehouse to get them 'cause I'm only allowed to spend a limited amount of money." (Mark, age 9)

In this second example the reasoning the mother gave for not allowing the purchase was based on the value for money or what the child was getting for the price. Clearly the child felt differently to the parent.

"Because like sometimes she, she just doesn't want to buy it for me."

“Right. Does she tell you what to buy?"

"Yes she does."

“And can you think of any reasons why she might not, that she's told you?" 
"Sometimes she just thinks the price is too, it's just like not worth it for it. Like a big Ben Ten toy I think it's worth it. Its $\$ 79$, its $\$ 80$ but my Mum doesn't think so. It's that huge, it's so, it's so worth it but my Mum doesn't think so." (Vincent, age 8)

Parents were much less controlling of money with the older children aged thirteen and fourteen and clearly allowed their children to independently determine value and make the purchase decision. There were however, limited controls over spending large amounts as illustrated in the following example.

"I get about $\$ 17.50$ every two weeks and yeah and $\$ 7.50$ goes in my EFTPOS and $\$ 10$ goes into my savings. And my savings, my Mum has to sign off on it so I can't just grab heaps of money out." (Joe, age 14)

It is critical that parental control is considered as in addition to the value the child perceives, it may directly influence the purchase decision for children in some cases.

\subsubsection{Social Influence}

Social influence is defined as the influence of social groups on the utility derived from an alternative. Children indicated that social influence was a major influence on perceptions of value. Fifty of the fifty one children indicated they were 'influenced by their friends' in their purchases. They were influenced by what their 'friends like', what their 'friends have', what their 'friends recommend' and what is 'popular'. For young children aged seven and eight, their friends liked, had or simply talked about the products and this in turn influenced their value perceptions as they attempted to conform to social norms.

"Probably actually from my friends because they were talking about it and then Dad said do you want to look, watch this movie and stuff." (Toby, age 7)

"Sort of. Yeah because lots of my other friends have this." (Toby, age 7)

"My friends encouraged me to like it." (David, age 8)

\section{"Right and how did you know about Star Wars in the beginning?"}

"My friend knew quite a bit about it and yeah I liked it too." (Miles, age 8)

"I just thought, from looking at the ones that my friends had I thought it looked quite cool because its legs can move." (Stephen, age 8) 
"Well I am quite into Star Wars like quite a few of them are, other people in our class, well I think there's more than seven people that like Lego Star Wars and they all like Star Wars the movies because they are quite nice, or they're interesting as well as adventurous except you can get, I think you can get Lego." (Mark age 9)

By nine years of age they incorporated more about the influence of friends than just their friends having, liking or talking about products. Explanations included a joint interest in products, playing together, as well as general popularity among peers and reference groups and more of a concern for what others liked.

"Yes. I bring them over to my friend's place and we have battles and I trade them like, I think I traded that one for something. " (Mark, age 9)

"Well a lot of people like them. I know about seven people who like them.” (Mark, age 9)

"I think that they might think it was quite cool. But then I thought that they might not like it but yeah and then I got to the point where I thought they would like it, so yep." (Oscar, age 9)

Younger children discussed social influence on toy purchases as this was the category they mainly purchased from. As children got older they were influenced by friends in the categories of food, clothing and computer games, in fact all products that they bought. What other children had, liked or recommended, enhanced the value to the children in terms of functional performance and liking as well as (for certain products) social value and reduced the risk (both functional and social) associated with purchasing products.

The following example illustrates the influence of friends in terms of providing information.

"Well we were in Whitcoulls and all my friends read these series and so I thought I'd try it and just you know asked Mum if I could buy it and she said yes." (Brendon, age 11)

The following example illustrates the influence of social approval or friends liking the product

“...I think so because I don't like it when I choose something that's really gross and they all kind of act weird when I'm wearing it because it's like Oh okay you didn't 
like it then but I think it's a tiny thing that matters, but I think it's more that I like them but my friends do like them, yep." (Siobhan, age 13)

The youngest children were highly influenced by what toys their friends liked or had and on this basis felt they also would like them. Older children considered their friends approval to confer additional value to products in terms of social implications as well as functional and emotional ones.

\subsubsection{Price and Price Knowledge}

Children of all ages knew the prices of the products they purchased. Given that children had limited money they were restricted in terms of the prices they could pay for items they wanted.

For seven and eight year olds, prices were seen in absolute terms and comparisons were made relative to what was available for spending. The younger children regarded price as 'unimportant'. Most knew prices of the products they had purchased, although one child who quoted a reference price was highly inaccurate, four eight year olds and two seven year olds knew the prices of the things they had purchased. These young children remembered prices of products that were relevant to them and that they had purchased.

"Well I only got it for a month, yep. I think it should have been more because a month you should, you should have had (to pay) \$10 but they just, they just chose \$7.

“Right. Why do you think it should be \$10?”

"Because a month is quite, is quite a long time if you, if you're, if you think about it." (Olivia age 8)

“Well no I didn't know how much because I had already $\$ 100$ and then I saw it and it was like $\$ 99$ so then I paid \$100.” (Tim, age 8)

"I think it's ten cards for $\$ 3$ at the lotto store but you can get a set of 40 for $\$ 10$ at Toyworld and The Warehouse I think you can get the same sort of pack but the same 40 pack but for less which is you can get it for about half the price and Woolworths you get them for \$13. So I usually go to the Lotto Store or The Warehouse to get them cause I'm only allowed to spend a limited amount of money." (Miles, age 8) 
Five of the seven and eight year olds indicated that price was not important to them and this was also reflected in their value perceptions as discussed in Section 5.6.5 Five of the nine and ten year olds and three, eleven and twelve year olds and five thirteen and fourteen year olds regarded the price as not particularly important however this was qualified by the thirteen and fourteen year olds as to why in the particular instances. It was only when little variability existed or when it was a low priced item.

"Not really because it's sort of like if you want to go to this movie like it's sort of, you know there's probably one set price or it's usually like within a dollar at different theatres it doesn't change that much." (Max, age 13)

“A little bit but not as much when it's only around \$2 it's my one week's spot, because if it's that cheap then I think oh it doesn't really matter if I'm spending that much because I can just get it back.” (Joe, age 14)

Young children had good knowledge of the prices of products which they would purchase although they did not consider the price to be particularly important. As children got older they attributed more importance to the price particularly in the case of higher priced products.

\subsubsection{Brand}

The brand refers to the concept of a brand. "A name, term, design, symbol, or any other feature that identifies one seller's good or service as distinct from those of other sellers. The legal term for brand is trademark. A brand may identify one item, a family of items, or all items of that seller. If used for the firm as a whole, the preferred term is trade name." (AMA, 2011)

Children mentioned how important they felt the brand was in their perceptions of value and also the meaning of the brand to them.

\section{Brand Importance $(n=29)$}

'Brand Importance' refers to the perception that brand is important and influences perceived value. Children were influenced by brand in certain contexts and not in others. 
For young children the concept of brand was not well understood. The brand of the product was not a factor considered by this age group however they referred to products by brand in most instances for products other than clothes. All the seven and eight year olds used brands to identify products such as 'Lego' and 'Grainwaves' but did not attach meaning to these names and when asked, regarded the brand as unimportant (two children aged seven and eight years old).

"No I don't care about the brand." (Tim, age 8)

Only two year of the nine and ten year old children referred to brands carrying meaning beyond identification.

“Mm yeah except I think he'd like Lego more. Because Lego has a very, very big thing well it's really popular because Lego has been going for 50 years but there's different types of Lego. You can't, you can get normal Lego but you can get like Lego City, Lego Power Miners, Lego Star Wars. Lego Star Wars though is the most popular." (Mark, age 9)

"There is Lego that isn't really actually Lego, yes because it is sort of like Lego because my friend I think he got something for his sixth birthday which was Star Wars but it wasn't actual Lego."

\section{"Right"}

"It was some sort of other Lego. I think it's made by the same brand." (Mark, age 9)

Eleven of the eleven and twelve year old children indicated they thought brand was important for some products. Five of these children mentioned that it is not important for clothes.

“Cadbury's and Whittaker's because they are like the main brand. I like Cadbury's dairy milk more as say snack food. But if it was something like after dinner I go more towards Whittaker's chocolate because that's just got a better taste." (Henry, age 12)

"Well I don't really know too many clothing brands so not with clothes." (Josh, age 12)

\section{Brand Meaning $(n=15)$}

For the older children from the age of eleven, the brand carried deeper meaning. The 
meanings associated with brand by children of this age and older were: trusted $(n=4)$, quality $(n=12)$, reputation $(n=13)$, and tried and tested $(n=4)$. By fourteen children had a sophisticated understanding of the brand and its influence on value.

"Well with a brand comes a sort of a knowledge that it sort of has that brand seal of approval. You know if it's good enough for them then surely it's good enough for me and if you trust that brand then you think that brand will be fine. If you don't trust that brand or it doesn't look like it's you know very credible then probably you won't buy its products." (Donald, age 14)

Only two nine and ten year olds mentioned brand meaning where as five of the eleven and twelve year olds and eight of the thirteen and fourteen year olds mentioned it.

The conditions directly influencing value perception by children were knowledge and experience, the extent to which they wanted or needed the product, the influence of others, both friends and parents, and also the product related factors of price and brand. As children grew older they had more experience and knowledge of products, however children used what they did know when perceiving value at all ages. The motivation for purchases was found to be largely psychologically based with an increase in the purchase of needed products with increasing age. Older children were also increasingly influenced by friends ahead of parents although the influence of parents was still important, particularly for high priced items. Price and brand were also found to impact perceived value and the meaning associated with these concepts to become more complex with age. 


\section{6. Results: Children's Perceived Value}

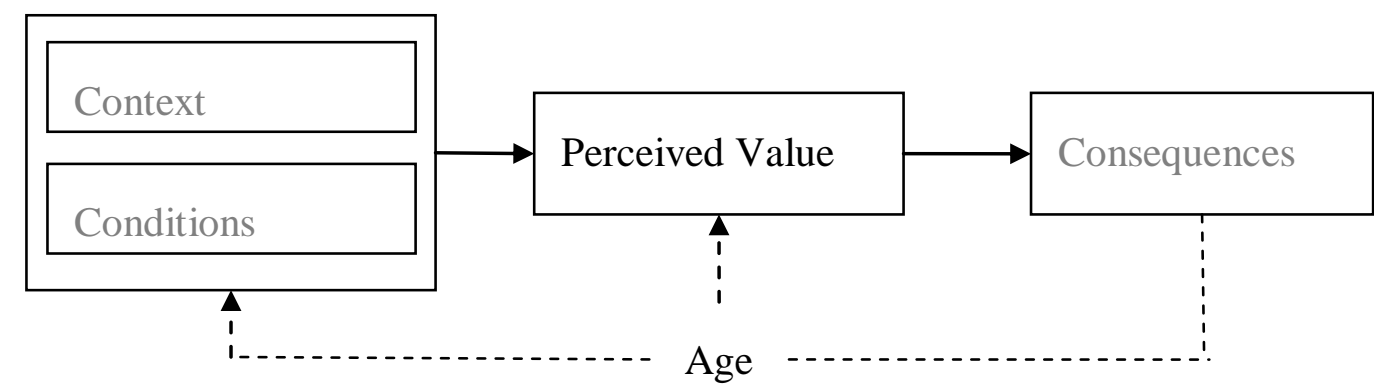

Action or interaction is term used to describe the response that the individual has. The action/interaction or core concept which changes as children grow older is, in this study, the value they perceive in an alternative. They evaluate the product they consider for purchase, the dimensions they consider shape the value concept. Through abstraction, generalisable considerations were identified in children's responses and these are now discussed in detail. They have developed from the data using the constant comparative method with earlier findings and existing theory in order to provide detailed conceptual meaning. Table 5-6 details the dimensions identified in children's value perception.

Table 5-6 The Dimensions of Perceived Value for Children

\begin{tabular}{|l|l|l|}
\hline Core Concept & Description of Concept & Dimension \\
\hline Value & $\begin{array}{l}\text { "Perceived value is the } \\
\text { consumer's overall } \\
\text { assessment of the utility of }\end{array}$ & - Emotional Value \\
& $\begin{array}{l}\text { a product based on } \\
\text { perceptions of what is } \\
\text { received and what is }\end{array}$ & - Curiosity \\
& given." (Zeithaml, 1988, & - Perceived Risk \\
& p. 14) & \\
\hline
\end{tabular}

Children mainly evaluated the benefits they got from purchasing products in terms of positive emotional responses and functional benefits. Social value, the way children 
perceived price and the detailed functional benefits perceived changed with age. Curiosity or novelty value was useful for explaining some product choices and was relevant in certain contexts.

For the newest consumers, their emotional response to products was the most commonly mentioned factor for choice. It was the main benefit perceived. As children grew older the overall concept of value changed from a focus on the benefits of a purchase to a trade-off between what you get and what you give up. The concept changed in terms of complexity and nature of some of the dimensions, with functional value shifting from a short term focus to a combination of short and long term factors.

Dimensions were interrelated. Functional and social aspects impacted emotional dimensions. Pleasure was gained from products that provided sensory stimulation but also performed well and that others approved.

This is illustrated in the following example: "Well I suppose, well the Telecom network everyone has it and like it's just better to be on Telecom because if you have a friend who can only text that one then they can't text you if you're on Vodafone. So if they text you on Telecom they can actually like reply. So that was a plus. And yeah I think pink phones are in and I don't know I think probably it's just what your friends have and what you think is cool personally and what is easy to use. Because you don't want something that's hard or what's cheap because you don't want some really high tech phone that's going to take to school and you're just going to lose it. So that wouldn't really be very much point and also yeah I think you don't want anything that's too expensive because you know you can scratch it or damage it and you don't want to take it to school if it's too expensive. But yeah, yeah." (Girl, 13 years)

\section{Codes Functional value, Social value, Emotional value, Perceived price}

In the following sections each dimension is discussed in detail and analysed in terms of context where relevant. Qualitative differences in concepts by age group are then discussed. At the end of this section a variable based matrix is provided summarising these age based changes. 


\subsubsection{Emotional Value}

Children's affective responses to products and owning or consuming them, contributed to children valuing these items. Such responses have been grouped under the title of emotional value. The most appropriate definition of emotional value which applied in this study was the 'utility derived from the feelings associated with the choice', which is similar to that used in other studies of (Sheth et al., 1991). Affective reactions to products themselves as well as the consumption or use of products are included within this definition. It was found through the interview procedure that emotional value derived from both affective reactions to products as well as use of them. This could not be determined from the diaries but through interviewing was found to contribute to the construct. Affect, feelings and emotions are grouped in this analysis although there is some debate in psychology as to the definition of feelings and emotions and the separateness of the two concepts, feelings being seen as a mental state and emotions as a physical state (Zambardino \& Goodfellow, 2007). While the definition of emotion adopted could be regarded as 'feelings' it was regarded as the most appropriate for understanding children's consumer behaviour. It is also unlikely that children would be able to separate the two.

Richins (1997) offers a definition of emotion used in marketing as follows:

...an emotion is a valenced affective reaction to perceptions of situations. They exclude from the domain of emotion those descriptors that refer to (1) non valenced cognitions such as interest and surprise; (2) bodily states such as sleepy and droopy; and (3) subjective evaluations of people such as selfconfident or 'feeling abandoned'. (pp. 127-128)

All children of all ages described such valenced affective reactions to the products they chose for purchase as well as the situation of owning the products. Such emotions were associated with all types of products that children purchase including toys, food and clothing. Children mentioned liking the products they purchased and this was a consistent contributor to value. Table 5-7 details the concept of emotional value. 
Table 5-7 The Emotional Value of Products for Children

\begin{tabular}{|l|l|l|l|}
\hline $\begin{array}{l}\text { Third Order } \\
\text { Concept }\end{array}$ & $\begin{array}{l}\text { Description of } \\
\text { Concept }\end{array}$ & $\begin{array}{l}\text { Second Order } \\
\text { Concepts }\end{array}$ & First Order Concepts \\
\hline Emotional & $\begin{array}{l}\text { The utility } \\
\text { derived from } \\
\text { the feelings } \text { or } \\
\text { affective states } \\
\text { that a product } \\
\text { generates }\end{array}$ & $\begin{array}{l}\text { Emotional response } \\
\text { to use }\end{array}$ & $\begin{array}{l}\text { - Would make feel happy/ } \\
\text { good/ pleasure } \\
\text { - Would arouse } \\
\text { excitement }\end{array}$ \\
& $\begin{array}{l}\text { Affective response } \\
\text { to product }\end{array}$ & $\begin{array}{l}\text { - Like/ love product } \\
\text { - Cool product } \\
\text { - Fun product }\end{array}$ \\
& $\begin{array}{l}\text { Sensory response to } \\
\text { product }\end{array}$ & - Like look \\
\hline
\end{tabular}

The emotional benefits that result from the purchase of certain products were also described by children. Children purchased products which made them 'feel good' or experience 'pleasure'. Seven out of the nine, seven and eight year olds described feelings of pleasure usually in terms of happiness. Thirteen of the fifteen, nine and ten year olds, four eleven and twelve year olds and ten out of fourteen, thirteen and fourteen year olds mentioned feelings associated with their purchase.

"And what sort of feelings did you have when you were thinking about buying it?" "Quite happy ones because this was the main set that was what I was wanting." (Toby, age 7)

"Yeah. When I buy them I usually just feel quite happy." (Stephen, age 8)

“Quite happy that I was going to buy it.” (Miles, age 8)

"I thought that I might feel quite happy and yeah." (Oscar, age 9)

While the younger children provided more simple descriptions of feelings, some of the older children discussed pleasure. The older children from ten years of age discussed the pleasure in more detail. 
"Oh well sometimes I get it and I have like a chocolate bar and it makes me feel good which is cool and makes me feel really good." (Sally, age 10)

"I felt quite good because it was my first phone and I never had a phone before." (Charlie, age 12)

“Happy that I had something new to wear." (Karen, age 13)

"I like the feeling of having something new to wear and going home and trying them on and seeing what they feel like and what they look good with." (Siobhan, age 13)

"I thought, well I felt that I would be quite happy if I bought it and hopefully I wouldn't get bored with it later on." (Luke, age 13)

"It, as long as it goes out the door, I mean I'll look at the price as long as it's not like over $\$ 5$ and it's around like \$2, \$1.50 then I'll generally buy it because it's what I feel like and I know it will make me happy, know it's what I want, so yeah." (Joe, age 14)

Sometimes they didn't articulate the emotional benefits but usually they mentioned positive feelings about their purchases or affective responses to products. Children value products they 'like', feel are 'cool', and regard as 'fun'. They express feelings about products such as love or liking. All of the youngest children mention liking the products they purchase. Fourteen out of fifteen, aged nine and ten, nine of the twelve, aged eleven and twelve, and thirteen out of fourteen thirteen and fourteen year olds mentioned liking as important.

"I didn't like the other ones but I liked this one because it sparkles. And it looked better in my blue bedroom." (Samantha, age 7)

"I felt, I felt good because I really like Club Penguin." (Olive, age 8)

"I just find yeah if I really like it and I have enough money I quite often buy it." (Miles, age 8)

"The food that I really like."

\section{“And what makes you like a certain food?"}

"Just when I, if it smells yummy, normally and then I just try it and if it smells nice and it's nice." (Tim, age 8) 
'Liking' was often considered in isolation from other factors by eight and nine year olds.

"Like whether I will like it or not. Like when I go to Subway I choose tuna because I know I like tuna." (Vincent, age 8)

"Yeah so I had to choose quite carefully cause I didn't want stuff to be too big or too small. And I had to choose if I really liked them or if other people just liked them." (Oscar, age 9)

“Well I just have a look at what's there and if there's something I like and it's maybe $\$ 3$ or $\$ 5$ I might buy it if I have enough money for it. So I just see what's there because I mean if something's there that's like \$200 and all I've got is \$5 I can't buy that." (Mark, age 9)

"I like it because they've got cool comics, cool comics at the back like this and it's like it's parents have gone into something and this is pretty funny he goes through the secret door at the back of a wardrobe and it leads it to his Mum's room." (John, age 10)

"Well I really like to look at what it is and it depends whether I like it." (Sally, age 10)

"I don't know. I just like them, the other ones I think just look a bit weird." (Ruby, age 11)

"I often lookfor things that I like, like cheap." (Lee, age 13)

"Sort of actually. I thought it would be really nice to get like have a brand new phone and it can be all new and shiny and white and nice but actually no it was more after I bought it that I was sitting in the car because I'd been and bought it with my Dad, I was going back home I was like oh my gosh it's so cool and unpack it and was like fiddling around with it and yeah it was really cool. Yes it's sort of like a happy time when you buy something new." (Jane, age 13)

"Style? They're my favourite and they look really good."

\section{Why is that?}

"I don't know it's just the fashion. I just like it. It's good.” (Clare, age 14)

"Yeah it was probably, it was probably a bit of both. Like I definitely looked at all the...like I compared them to other sticks." 
"Yes"

"And like they were the lightest ones by far and, yeah and so I was going to get them but, but alright so if his drumsticks were like, like heavier than someone else's I still would have got his because like I like him so much, so it was probably a lot to do with the feeling I reckon. "(Jamie, age 14)

The emotional value of products was an important consideration for products purchased by children, which were largely selected on the basis of wants rather than needs. Children often anticipated emotional value in their purchases and then experienced it in actuality reinforcing the anticipated pleasure

Feelings about products were also related to other benefit dimensions of perceived value.

\section{Sensory Response (51)}

Sensory response has been included with emotional value after the in-depth interviews. The concept was found to be highly relevant for children and was based on emotions relating to maximising affective response and or pleasure. The sensory performance was often the differentiating factor beyond function which resulted in an offering being considered as superior.

Sensation is the entry of a sensory message into consciousness. As pointed out by Young (1959), a sensation can have two dimensions: discriminative and affective. The discriminative aspect is a function of the nature and intensity of the stimulus. The affective part of a sensation is the amount of pleasure or displeasure aroused by the stimulus. (Cabanac, 1979, p. 2)

For children the sensory performance of the products they purchased was an important consideration in valuing a product and it was associated with pleasure and therefore the emotion of happiness. Children valued products based on their sensory appeal often without considering other aspects of the purchase. It should be noted that many of the youngest children in the study were not allowed to purchase food (4 purchased foods).

For all children in the study sensory responses were mentioned when determining which products children value. In terms of taste they valued products which would taste good and provide sensory pleasure. In terms of looks, products which they liked 
the look of provided superior value to children. The sensory aspect of products is both functional in that we rationally consider how a product looks, tastes or performs and these attributes form the basis of the function for many products while at the same time the pleasure aroused cannot always be rationalised and is associated with the affective response as described above. It was at this level that the sensory performance enhanced the perceptions of value by the children in the study.

\section{7-8 years}

For food products they chose alternatives based on taste. Three eight year olds mentioned taste. It was related to the emotional response of pleasure rather than the quality of the taste that was discussed by these youngest children.

"I did make a mistake when I bought the, when I bought the mint Tic Tacs, I mean the Shapes it was a flavour I didn't like but I forgot that I didn't like it and I thought I wanted to change it but we had already opened the box so I gave that box to Lydia and my solution was I gave that box to Lydia and Mum got me a new box. But I kept the box so I could make stuff." (Sarah, age 8)

“Because it's, my favourite fruit is orange and these taste like oranges once you suck them for a while." (Sarah, age 8)

"Like whether I will like it or not. Like when I go to Subway I choose tuna because I know I like tuna." (Vincent, age 8)

Liking the look was mentioned by six eight year olds and one seven year old. Categories where the 'look' was important were mainly toys and clothes but even food was mentioned by a seven year old girl.

"I didn't like the other ones but I liked this one because it sparkles. And it looked better in my blue bedroom." (Samantha, age 7)

"The name. Yep. If it looks yummy."

\section{"Right."}

“That's it, look, yeah" (Samantha, age 7)

\section{“And how did you decide what to save up for?”}

"Because I thought it looked cool” (David, age 8)

"Because it just looks really, it just looks really cool when it does that." (Tim, age 8) 
"Just the fact of looking at it just makes me get a glimpse of it. It looks really cool." (Tim, age 8)

"I just thought, from looking at the ones that my friends had I thought it looked quite cool because its legs can move." (Stephen, age 8)

"Because my favourite colour is purple, grey and blue and turquoise and stuff. And I've got lots of those clothes that would match it." (Sarah, age 8)

Liking the smell was mentioned by one eight year old child.

\section{"And what makes you like a certain food?"}

"Just when I, if it smells yummy normally and then I just try it and if it smells nice and it's nice." (Tim, age 8)

\section{9-10 Years}

Thirteen of the fifteen children mentioned the taste of the products they purchased providing value for food. Children who did not mention taste did not discuss food purchases. Sensory performance is key for food purchase.

“Or I would think about some yummiest thing." (Melanie, age 9)

"Yes because I do like some, I do like the taste of some things because like I like Subway and chips and coke so does my sister." (Mark, age 9)

It tastes good, it's sweet and it's sugary and it's really nice and well I savour my lollies a lot and taste them and there's quite a lot of them in one packet. (Anna, age 10)

Fourteen children mentioned the look of the products they purchase the only child who doesn't is focussed on price. Look is relevant across product categories with children generally purchasing products they find visually attractive.

"Just looking at it. It sort of tells them the answer because if it's got a lot of patterns and stuff like that we think it's quite good and cool." (Oscar, age 9)

I choose what to buy by well I just see how it looks then I say I think how much it is and then I usually say yes this is a good then I go tell my Mum I've found something and then I usually buy it. (Angus, age 9) 
"Yeah, yeah I just saw them and I thought I'm might get because I always wanted because I really wanted to try it because it looked really tasty because of the flavour and stuff." (John, age 10)

"So if it just had a picture of a man then I would just go oh boring. If it had something cool on it like big tough man and stuff like that and like interesting things that you may go wow." (Doug, age 10)

\section{1-12 years}

All twelve, eleven and twelve year olds consider sensory performance of products. Taste was mentioned by eight and look by nine children.

\section{3-14 years}

All the oldest children in the sample mentioned sensory performance as a critical contribution to perceived value across product categories purchased. For food 'taste' and 'look' for other products such as clothes and phones.

"Well I usually get, I think it's called ice-cream and soda it's kind of like the spider and it looks, it looks like the most unappealing one, but I like the taste, so yep." (Jamie, age 14)

"I liked the dresses because the look of them. It's kind of a high waisted skirt with a singlet underneath but they made it into one dress and the one I got was like faded jeans at the bottom and it was like cream and blue stripy on top and it's just like a singlet but goes right there." (Susie, age 14)

\subsubsection{Functional Value}

Functional value refers to the utility derived from the consumers' evaluation of product attributes and expected practical, functional or physical product performance. Children often focused on specific product attributes as providing value to them and sometimes mentioned the associated functional benefits and practical benefits leading to enhanced performance. Functional value represents a rational evaluation of whether a product fulfils certain functions or requirements. Functional values which children referred to as providing utility to them were the specific attributes of the product, essentially the presence or absence of these features leading to enhanced performance, the quality of the attributes or the overall 
product, the use value of the product and the quantity. Table 5-8 details the functional values identified for children.

Table 5-8 The Functional Value of Products for Children

\begin{tabular}{|c|c|c|c|}
\hline $\begin{array}{l}\text { Third Order } \\
\text { Concept }\end{array}$ & $\begin{array}{l}\text { Description of } \\
\text { Concept }\end{array}$ & $\begin{array}{l}\text { Second Order } \\
\text { Concepts }\end{array}$ & First Order Concepts \\
\hline $\begin{array}{l}\text { Perceived } \\
\text { Functional } \\
\text { Value - } \\
\text { Performance }\end{array}$ & $\begin{array}{l}\text { Reasoning for } \\
\text { purchase based } \\
\text { on the utility } \\
\text { derived from the } \\
\text { product } \\
\text { attributes and } \\
\text { expected } \\
\text { practical, } \\
\text { functional or } \\
\text { physical } \\
\text { performance }\end{array}$ & $\begin{array}{l}\text { Quality } \\
\text { Use value } \\
\text { Quantity }\end{array}$ & $\begin{array}{l}\text { - Product specific } \\
\text { attributes } \\
\text { - Complexity } \\
\text { - Realistic } \\
\text { - Collectable } \\
\text { - Will last } \\
\text { - Quality (unspecified) } \\
\text { - Durability } \\
\text { - Fit(clothes) } \\
\text {-Well-made/ hand made } \\
\text { - Amount of use } \\
\text { - Duration of use } \\
\text { - Time to consume } \\
\text { - Size } \\
\text { - Number }\end{array}$ \\
\hline
\end{tabular}

\section{Product Attributes}

Children of all ages considered the presence or absence of features or attributes of products to contribute to their perceived value. Forty two children mentioned such rational consideration. The relevant attributes varied by product category and age (related also to product category) but there was clear evidence that most purchases included some utilitarian considerations with reference to attributes.

All the seven and eight year old children attributed at least some of the value they found in the products they purchased, to specific product attributes. The majority of 
children of this age spoke about toys they had purchased. The attributes associated with toys were largely very practical. Young children discussed how they bought products due to the specific attributes such as product complexity such as number of parts. They referred to how real toys looked, how detailed they were, and one child mentioned considering whether the Lego set comes with men or not. The value was due to products having the attributes and the practical or functional benefits offered by having the attributes.

"Yes. And also how long it took and did it come with, because it was on the front of it but some sets it doesn't have guys on it and some sets it doesn't have any guy." (Toby, age 7)

"If it's got like something that's interesting about it. Like something that goes in and then pull it out and then it's kind of like something that, that something comes in like that."

\section{“Right so there's two parts to it?"}

"Yep."

\section{“And what does that, why does that make it more interesting?"}

"Because then it's kind of like it's escaping instead of just staying inside the hole and getting destroyed, escaping."

\section{"Right so why is that important to you?"}

"Because it just looks really, it just looks really cool when it does that." (Tim, age 8)

"They're kind of realistic, more realistic to the ones in the movies than Lego is." (David, age 8)

Often product attributes were related to how the product performed. In terms of performance for cards they were valued because they were collectable for one of the boys whether the toy was good for battling was considered. One child bought a watch because it was waterproof and for clothing 'matching' was mentioned. The usefulness of stickers for decorating cards was another example of functional value. These product attributes provided value to the children.

"Well you get to play games.”

“And you can buy stuff, not like other games you can't buy much stuff. And they have pets, I really like animals. So and not much games have animals in it so I think Puffles are really good animal to make up." 
"I think I'll play with them really good." (Olive, age 8)

“That you can take it apart and build it again." (David, age 8)

"Like if it's Lego if it comes with some really real Lego people or yeah, or if it's Pokémon cards if I like yeah if it's like Diamond and Tyrell because I don't have very many of them in my cards I think." (Matthew, age 8)

And it's I really like the levers with it and it looks really cool. They go up and down like, they can go up and down like, shoot out and go up and down. And then you can open up things that can like go to secret passes. (Tim. age 8)

"I thought it was quite a good price for something like that".

"Why do you say that?”

"Well it was quite hard to build and it was really cool when it was done. Yeah and it's mainly why." (Stephen, age 8)

"Because it is to help my cough when you just suck on them until they get really small. Yeah because last time I had a cold and I got these and my Mum knows I had a cold and I got them."

"Yes"

"The first time I sucked on them I started coughing but the second time if I didn't and it just worked out perfectly." (Sarah, age 8)

"Because my favourite colour is purple, grey and blue and turquoise and stuff. And I've got lots of those clothes that would match it." (Sarah, age 8)

“Because sometimes people's birthdays and I didn't really feel like making the cards so I bought one and sometimes I buy stickers and stuff but usually I buy stickers to put on people's cards so when I make them I've got stickers to put on them." (Sarah, age 8)

“It's huge and you can like open it. It doesn't only stay like this, you can open it and close it and to open it again you just pull this button so it opens up and this thing can pull up and its legs can open up as well." (Vincent, age 8)

Nine and ten year old children referred to product attributes as well but for some the attributes provided many value dimensions. In the following example the cup was both useful and also provided social value in terms of proof that the child had been to the holiday destination. 
"Something to prove that I'd been to Tiger Island and Dream World and something to show to other people and also something to use."(Melanie, age 9)

For this child the fact the product was collectable and tradable related to use it was not a one- off, but a series of products.

"Well these I think I got well some of these I got when I was about six and I started really getting into them and so did my friend. So we started collecting them and trading them and having battles with them." (Mark, age 9)

They described the utility associated with what you can do with the product. This was an important concept for products such as toys and games that are used for entertainment.

"Well partly because I already had the other set of this and that didn't make that much stuff so I needed a bit more to make something bigger." (Cameron, age 10)

“Well I always get this type because well it's just really cool these ones because they've got like stuff to do and lots of stuff to read." (John, age 10)

"Well sometimes graphics and controls and yeah and how many players there is because I like getting two players games.” (Mike, age 10)

"See usually I'd buy like if I was buying gum I'd usually buy like the really chewy stuff." (Sally, age 10)

As children got older they purchased from a wider variety of product classes and their wants were different. As such the attributes they considered were more diverse. For most children product attributes were considered in functional terms.

“They were \$45 I think. And they're comfortable and they've got quite a bit of protection for if you get hit on your hand." (Nick, age 11)

"Some jeans can be very expensive but I often, I mostly buy kid's jeans cause I don't fit other ones and also Just Jeans because they've got adjustable waists and I have like no hips. And some colours I don't like because you can get, like I don't really like black jeans, they don't suit me very much. And so I think about the colour and like the shade of blue because they're mostly blue and then I'll think about the size because often there's not the right size in them and I'll try them on, yep. " (Ruby, age 11) 
"Because they're comfortable and much more nicer than jeans because I've tried jeans before and I don't really like them that much." (Henry, age 12)

"I'd think about size and what fits me and I'd also think about what looks good on me and what's within a reasonable price again." (Bridget, age 12)

"And I thought the other ones were a bit of a rip off because they only had a few colours and they didn't really look that you know fun to play with. So I thought this was the best one." (Kate, age 12)

"Well I look for a decent size keypad because otherwise it gets really hard and sometimes you press two numbers at once." (Charlie, age 12)

"Well just ones that I like the look of and they're really good."

\section{“Right and how do you know if they're good."}

“Well the one I'm getting it needs an I-Pod dock to plug it in and then it's pretty much all I need. "'(Fred, age 12)

“Well if there's pockets because I don't really like things with no pockets because then if I've got a piece of rubbish and there's no bin and I'm like oh where can I put it. Hey I've got no pockets and sometimes I think about the design on it and if it's like really thin I just won't buy it because I will get cold." (Josh, age 12)

"Because then I can put like different colour tops underneath it and they can look good." (Karen, age 13)

In the following example George discusses what he wanted in terms of attributes in a phone in order to meet his needs.

"I was looking at phones and it was like a month before the next Telecom XT came out and I was looking round and I was talking to the guy in the shop about how this new system was going to be much better than the old ones and stuff and how he thought I should wait for things. So I just had a browse at all the stuff and decided to leave it and check out with the new stuff that came out. And when the new stuff came out I didn't go like for the real expensive phone or anything but I picked what I needed. So I only really used my phone for calling and texting. I mean games and put music and stuff on it, I've sort of got my IPod for that." (George, age 13)

"The style kind and they're just the normal jean colour blue so I can just chuck them on whenever and so they're really useful." (Siobhan, age 13) 
"Mainly that it's filling instead of just like something that I want food later. Or the price is reasonable, yes that's all probably." (Susie, age 14)

"Length because I've got pretty big hands, so I need bigger drumsticks, compared the tip of the drumsticks because I don't want a plastic tip because it makes like more of a jazzy sound and the, the type of wood because some are made out of like charcoal and stuff like that. So I just wanted a wood one, yep.” (Jamie, age 14)

"I don't know I went, I used to go to the Regent one a little bit on Manners Mall, yeah Manners Mall but that place just isn't as nice and the Reading one also is really sort of pretty central and it's got food around it as well you can go to afterwards and the prices are going up a bit but there's not really much you can do about it really except for change cinemas and I'm fairly reluctant to do that. If a movie is showing on at the Embassy I will go there because that's a really good place and that's a really nice cinema and that's about the same price but usually it's not." (Donald, age 14)

Only two of the oldest children did not mention considering the attributes of the product they purchased. One was a thirteen year old boy who purchased a fountain pen largely based on emotional value and sensory performance. The other was a fourteen year old girl who had bought sports shoes on the basis of brand, quality, social value and price. While she felt that quality was important its meaning for her was related to popularity rather than any other product attributes.

Overall product attributes were central to children's value perception. They were often specific to the products purchased by the children. While they were not always attributes adults would consider they were never the less considered in a rational manner by children and contributed to the value they perceived. The attributes considered increased in complexity and scope with age. In the rare exceptions where product attributes were not specifically mentioned the children had used more abstract concepts related to attributes of products.

\section{Quality}

Adults use the term quality to describe the more abstract representation of a group of functional attributes that lead to an alternative offering superior value. Zeithaml (1988) defines quality as a products overall 'superiority or excellence'. In order to capture the abstract nature of the concept she extends this definition as follows: 
"perceived quality is (1) different from objective or actual quality, (2) a higher level abstraction rather than a specific attribute of a product, (3) a global assessment that in some cases resembles attitude, and (4) a judgment usually made within a consumers evoked set.” (Zeithaml, 1988, pp. 3-4)

Consumers use quality to compare similar offerings and while it can be category specific it goes deeper than physical attributes, yet physical attributes may be used to infer quality. For durable products it has been measured in terms of such dimensions as durability, reliability, consistency of performance and how well made the product is (Agarwal \& Teas, 2002; Sweeney \& Soutar, 2001). While for food products dimensions such as well made, standard of quality as well as consistency of quality and consistency of performance have been used (Wang, 2010). Intrinsic cues such as freshness, taste and nutrition have been shown to impact perceived value for foods (Chung, Yu, \& Pysarchik, 2006).

Quality was a value dimension which contributed to value perceptions differently across age groups.

The younger children in the study mainly thought about possession of specific attributes relevant to the function of the product rather than quality. For games and toys attributes related to entertainment were important. For food products they might consider on how filling it would be. They focussed on short term performance and meeting needs as well as the emotional value of enjoyment rather than long term performance. Quality was not as relevant for this consumer group particularly for the youngest consumers in the study.

\section{7-8 years $(0)$}

There was no evidence of the concept of quality amongst the seven and eight year olds. Vincent who is eight years old did not consider how long products would last.

\section{"And do you think about how long they will last?"}

“No. I don't think so, but yep." (Vincent, age 8)

\section{9-10 years $(10)$}

Most 9-10 year olds were in years 5 and 6 of their schooling however three 9 year olds were in year 4 . The quality of the product was mentioned by two of these year 
four children. Both referred to the durability of products and purchases were from the categories of clothing and toys.

“I, I, I think about if they're going to last long."

\section{"Like what?"}

"Like, like plastic toys to go in the bath say if it's going to last long or if it's going to get ruined like a watch." (Melanie, age 9)

"Yeah I sort of do think that maybe its thin material and it might rip easily and I might not have it for so long."

\section{"Right and what did you think about this one?"}

"Well I thought it was quite nice and thick so it wouldn't rip easily."

\section{"Right"}

"And so yeah I thought oh I could probably get this one instead of this really cool top but it was still thin as, really thin."

\section{“Right."}

"So yeah I thought, out of the two I thought I'd get this one." (Oscar, age 9)

Amongst the 9-10 year olds from years 5 and 6 there was an increasing consideration of the quality of products (7). Children aged nine and ten used the concept for durable products such as toys, games and clothes (6) more frequently than for food (1). Quality was largely inferred on the basis of intrinsic product factors but two ten year olds mentioned the extrinsic cue of price influencing their quality perceptions. Acceptable standards of quality and the relation of price to quality and performance are illustrated in the following quote

“Yes $\$ 4.50$ but like if it was 50cents I wouldn't have bought it because apparently like cheap stuff, like cheap earrings will get your ears infected and like cheap lip balm I don't know what it could do to your lips, yeah especially if it was secondhand." (Grace, age 10)

Children mentioned performance alone:

"Well their rubbers are pretty really good for rubbing out." (Anthea, age 9) 
They discussed not purchasing products which were too cheap because the product may be inferior.

“... like it hasn't been, it's been lying around and it's really old so that it isn't new and on the screen it just looks all fuzzy and old and yeah." (Doug, 10)

And in the following instance freshness was included for a food product:

"Because it might be cracked and stuff."

\section{"Right"}

"And it might, and it might be all soggy and off the due date maybe." (Angus, age 9)

Children did not consider many dimensions of quality usually focussing on only one or two. It was not at the same level of abstraction found for adults with children largely focussed on short term performance.

\section{1-12 years (11)}

By ages eleven and twelve there was more widespread consideration of quality. Children usually considered more than one dimensions at a time using both intrinsic and extrinsic cues as quality indicators. They still mainly discussed short term benefits/ performance based on physical product attributes rather than more abstract considerations.

"Some of the drinks that you can get that are, not all of them but some of the drinks that you get that are cheap are kind of, they taste all kind of preservative and yucky." (Ruby, age 11)

"If I'd heard of it and heard people had tried it and liked it then I would but sometimes if they're too cheap it can mean they're not good quality. They're not just a fair price. They're, well you're not getting good chocolate or whatever you're buying for your money." (Nick, age 11)

"Yes. Like there's other like cheap counterfeit brands but normally the bricks are cheap and they break and stuff. They don't fit in with other Lego which is why I tend to not really go there." (Charlie age 12)

“My Mum doesn't usually like to spend money a lot. And so I always have to think how much they were and what the quality of them were and stuff like that." (Gina, age 12) 
"Well I'd probably assume it was a budget one because they kind of like branded or something so I probably wouldn't buy it because the ones I buy that you chew them and you get flavour and then the flavour's just gone and it feels like you're chewing just yuk stuff." (Josh, age 12)

"If it won't break after a few months, the sound won't stop working". (Fred, age 12)

\section{3-14 years $(13)$}

Almost all the oldest children considered the quality of the products they purchased. They weighed up many dimensions as deemed relevant and also considered the price. Both extrinsic and intrinsic cues were related to quality perception.

"It means it tastes good, the potato chips are crispy, it won't suddenly like in the middle of the packet it will go suddenly tasteless or something." (Lin, age 13)

“Probably I would go for what I know. Like, I wouldn't buy some strange brand just off the shelves. I would normally go for Cadbury just because it's well known and there's heaps of different like choices and it's yum and it's just probably the most convenient as well. Like if you go into a shop and I think I'm going to buy this sort of brand chocolate but then like it's either not there or it's really expensive or if it doesn't look very nice in the package yep then I would definitely go for Cadbury's just because I know it. And yeah or I would go for Lindt. Actually I've become a bit of a fan of that lately. I got some for Easter and it's amazing it's like so smooth, it's probably nicer quality than Cadbury's." (Jane, age 13)

\section{“...you said quality, what does that mean?"}

"Oh if it's good, like the brand and how it looks, if it appeals." (Luke, age 13)

"Probably, because they are going to last like a long time, because they're the right size and because the material seems nicer. Like the ones that you get at Jay-Jays they kind of, they are really thin and they, you get holes in the knees real quick. Yeah." (Clare, age 14)

“They're Nike I know the brand. I know they'll last longer when I'm looking for clothes I want things that will last a long time because I am growing and I don't want shoes that fit me right now but hey in a couple of months they won 't. "(Joe, age 14) 
"Oh no because if they were crappy drum sticks, oh ten bucks probably under that I would probably think there's something wrong with them." (Jamie, age 14)

“Taste, being fresh, yeah that's probably the two main ones." (Donald, age 14)

Across all ages studied what children did not consider was nutritional quality for food products and they only considered manufacturing inputs to a limited extent. The concept of reliability was not mentioned and how well-made products were was seldom considered (2). Children focussed on short term dimensions of quality related to the product performance at the time.

\section{Use value}

Another functional value mentioned refers to consideration of usage. This refers to the utility derived from the use of the product in terms of amount, duration of use, duration of consumption and quantity. The amount of use the product would get was considered as well as how long children would use the product for durable products. Children also considered time to consume particularly with food as well as the related concept of quantity or size of the product.

\section{Amount of Use (18)}

Eighteen children mentioned considering the amount of use a product would get as contributing to perceived value for durable products. The youngest consumers considered this with reference to toys and the older consumers in the context of clothes for girls or games and electronic devices for boys. It was mainly mentioned by older children with twelve of the 12,13 and 14 year olds discussing amount of use.

Three eight year old children refer to considering the amount of use the product would get. They considered how many times they would use products for or how much they would use them.

"Yeah I do, yeah I might get something, I like them so I use them every day" (Vincent, age 8)

"Well when I think about it I think how often would I use it." (Kate, age12)

"If it doesn't feel right I'll often put it off for a couple of days or something because it's like, I make sure that I do want it because I don't want to waste any money on a game that I'll only play a few times." (Joe, age 14) 


\section{Duration of Utility (7)}

This refers to how long the consumer perceives the product will be useful for. This was usually for durable products. Seven children mentioned this concept regarding use and they considered whether products would be used or liked for a long time. Four thirteen and fourteen year olds considered this type of utility and it was dependent on product. Children mainly mentioned utility duration for durable products such as toys, games or clothes.

"Because well I really liked it but every now and then I thought oh maybe I won't, maybe I won't end up liking it after a couple of days, so yeah. And then I eventually chose it because I thought oh it's quite cool so I might take it. (Oscar, age 9)

"Yes because like sometimes with clothes and stuff I will buy them so they're bigger on me so you can still grow into them and wear them for longer and stuff." (George, age 13)

\section{Time to Consume (15)}

This refers to any discussion regarding how long the product will take to consume it is usually used in reference to non-durable products such as food but can apply to toys which are made or completed or stationery. Children compared value between different products in terms of how long they took to complete or consume. This was mainly children new to purchasing food (nine children in the nine to ten year age bracket) but was mentioned by two seven year olds.

"Little packets with lollies in them what could last"

\section{“What do you mean when you say 'last'?"}

"Like they could last a month."(Samantha, age 7)

"I usually think of things maybe like chewing gum sometimes. That you can last it longer." (Angus, age 9)

One fourteen year olds also mentioned the idea in relation to additional quantity and price.

“And if it's on sale I'm more likely to buy it and a lot of it's how long it will last as it, will it last a couple of days? Will it last two minutes? That's general what I think about and like how, yeah, how much is in it. Like I bought this big one a couple of 
days ago purely because it's bigger than the other one and it was like fifty cents more but if it's fifty cents more you're going to get a lot more value” (Joe, age 14)

\section{Quantity (22)}

Number or size was mentioned as an important dimension of value by twenty two children. Eight, seven and eight year old children discuss number or size. When the value of their purchase was discussed they often mentioned size as a factor contributing to value. However, they often purchased items that they considered were not priced appropriately for their size.

"How many and how long they will last." (Samantha, age 7)

"And sometimes they're a bit bigger. And they come with better guys." (Toby, age 7)

"It was one of the sets I had you know how I talked before how I was saying like look at the big pieces I'm not sure whether that was one of the big sets I thought." (Toby, age 7)

\section{"What did you think about the price?"}

"Kind of high for something that's small." (Miles, age 8)

"Yeah I thought it was like a good value because my Mum pointed out two like little sets and I didn't really want to get it because I really wanted the big set because I like Lego Star Wars the big sets." (Tim, age 8)

"Yeah I thought it was because it's so huge." (Vincent, age 8)

For older children 9-10 they discuss size and number for sweets mainly.

"Well it's very new, and it said it had 30 of that, I didn't know how big they were but I thought they might be pretty big because of the size of them."(John, age 10)

The size or number of product/s remained a consideration for older children but by eleven it was not always the biggest pack or number of sweets that was considered it was about what size and price which best met their requirements. The quantity and price were considered together.

"Price and how big the bottle was. Sometimes you can't get small bottles." (Ruby, age 11) 
"Yes you can use different plans but like you can't have, you can't have like the lowest text plan and the highest caller plan at the same time. You have to have both about the same amount so it was either like spend more for a higher and a flashier phone and then have like limited text and stuff or go for one that was lower down and have more texts and stuff. So I went for the one with the lower down and more texts because it was better value than the other phone." (George, age 13)

Some children still preferred the bigger product at this age if it met their requirements, particularly for food.

"That's generally what I think about and like how, yeah how much is in it. Like I bought this big one a couple of days ago purely because it's bigger than the other one and it was like 50cents more but if it's 50cents more you're going to get a lot more value." (Joe, age 14)

\subsubsection{Social Value}

As discussed under conditions, children's purchasing was highly influenced by social factors, as a result social value represented an important dimension of value for children. Social value was expressed by the majority of children in all age groups as part of their value perception. Forty children discussed social value as important. It was consistently discussed by children across all ages in the study. Table 5-9 details the social value of products for children. 
Table 5-9 The Social Value of Products for Children

\begin{tabular}{|c|c|c|c|}
\hline $\begin{array}{l}\text { Third Order } \\
\text { Concept }\end{array}$ & $\begin{array}{l}\text { Description of } \\
\text { Concept }\end{array}$ & $\begin{array}{l}\text { Second Order } \\
\text { Concept }\end{array}$ & First Order Concepts \\
\hline Social Value & $\begin{array}{l}\text { The utility derived } \\
\text { from the social } \\
\text { meaning of a } \\
\text { product and a } \\
\text { product's ability } \\
\text { to enhance social } \\
\text { self-concept }\end{array}$ & $\begin{array}{l}\text { Social meaning } \\
\text { Social } \\
\text { acceptance } \\
\text { Social self- } \\
\text { concept }\end{array}$ & $\begin{array}{l}\text { - Recommend to friends } \\
\text { - Show to friends } \\
\text { - Tell friends } \\
\text { - Share or use with friends } \\
\text { - Fit in } \\
\text { - Enhance social self - } \\
\text { concept } \\
\text { - Impress friends }\end{array}$ \\
\hline
\end{tabular}

Children indicated they would 'recommend' products they valued, 'share them with friends' or 'show them to their friends'. This was relevant for products such as toys, games, phones and stationery which are used with or around others.

Children valued products which had social significance, they valued products their friends had or recommended as discussed under social influence. Children believed that having these products helped them to 'fit in'. By owning products their friends like they discussed being able to 'impress friends' and 'enhance their self-image'. Social value may be situated in the context of friends/ peers or family. Peers were most influential for children in terms of social value while parents simply controlled or influenced choices directly. The influence of friends was usually through the child's own choice.

Products did have symbolic value for children but not in terms of adult values. They allowed entry into games and acceptance with peers. For some children they symbolised age, gender or class, group membership.

Children valued products they could use, share or recommend to others. Often toys which could be played with together, traded or collected had high social value. Games which children could play with friends or that they could share an interest in with friends were highly valued. 
Items which could be used or shared with friends children attributed social value to "Yes. I bring them over to my friend's place and we have battles and I trade them like, I think I traded that one for something." (Mark, age 9)

Like, I know that if I buy a game then my best friends going to want it. Like she, because she's pretty rich and she loves to have what I have. So, yeah. That's always good and then we can, like, swap games. That's fun. (Clare, age 14)

Fitting in or social acceptance by friends was the social value dimension most often mentioned with twenty three children discussing this as important. It was most commonly mentioned by children nine years old and over, however three eight year olds mentioned this concept and observation of products brought to the interviews indicated that certain products were regarded as valuable by large numbers of boys in the class such as Star Wars Lego for the year three and four boys. The following comment by an eight year old boy illustrates the importance of normative influence.

"And what makes you into something? You know you said you buy what you're into?”

“Well like my friend doing it, or into it too, a bit. Yeah.” (Miles, age 8)

By thirteen and fourteen years of age children are much more aware of the subtleties of conforming to group norms and fitting in.

"Yes I'd say a lot of people would take into account of people would take into account their friends opinions because they don't want to seem weird or they don't want to seem unusual. They'd like their friends to think oh they're cool" (Joe, age 14)

“Well I don't want to be too extremely different yet I don't want to look like the same as everyone else." (Jamie, age 14)

Children discussed the meanings of products in terms of who they are, what others would think and what the product would reflect about them.

Children were clear about what type of people would buy products

"Children who really like Star Wars a lot probably."

“And what type of children would they be?"

“James, Matthew, Tim and other boys." 


\section{"Right. So would they mostly be the boys in your class?"}

"Yep there's a boy called James, he loves Star Wars so he'll probably get this."

Children also considered other's impressions of products they purchased and if positive this provided additional value. This was only mentioned by eight children across all ages. If others like the product or are impressed this reflects on the owner. The following quotes illustrate the value of impressing others as mentioned by an eight year old boy and a ten year old girl.

"Because well yeah I like having, I like having toys that they think are pretty good, yes."

(Miles, age 8)

"Well like other people and if it, it feels good to like have it sort of and like use it and like if I have clothes that are like colourful I know that other people might think that I look good in the clothes. Yep." (Annie, age 10)

Twelve children discussed the influence of the product on others impressions of them or the type of people who would buy certain products. This association was mentioned by children ten and older and was considered more by older children.

"Well I think it's about growing up and also some of the clothes I wore I got made fun of and I think all my friends wore cool stuff and all that stuff and I think that gave me a little bit of influence."(Grace, age 10)

"It's more about how they look and feel than what brand it is. I'm not kind of that person that goes for the really expensive brands just because they're that label."(Clare, age 14)

\subsubsection{Curiosity/ Novelty Value}

The concept of epistemic value was introduced by Sheth, Newman and Gross (1991b) to account for the value provided by new or different alternatives over ones that consumers have used or tried before with the underlying motivation for this type of value being curiosity. Children again mentioned value associated with novelty, curiosity or knowledge and once again it was not a relevant value dimension for all purchases but was part of value for some purchases for most children of all ages. This is not unexpected as it has been linked to play and other activities of children 
(Reio, Petrosko, Wiswell, \& Thongsukmag, 2006) and was identified from the children's shopping diaries in the first study.

While children tended to largely rely on products they knew already, sometimes they were curious to try something new or valued having a new or unique product.

The literature in psychology refers to "need for knowledge" as the underlying motive behind curiosity. Table 5-10 details the curiosity/ novelty value of products for children.

Table 5-10 The Curiosity/ Novelty Value of Products for Children

\begin{tabular}{|c|c|c|}
\hline $\begin{array}{l}\text { Second } \\
\text { Order } \\
\text { Concept }\end{array}$ & Description of Concept & First Order Concepts \\
\hline $\begin{array}{l}\text { Curiosity/ } \\
\text { Novelty } \\
\text { Value }\end{array}$ & $\begin{array}{l}\text { Utility derived from } \\
\text { alternative's capacity to } \\
\text { provide novelty or satisfy a } \\
\text { desire for knowledge }\end{array}$ & $\begin{array}{l}\text { - New /different/unique } \\
\text { - Curious to try product } \\
\text { - Interesting }\end{array}$ \\
\hline
\end{tabular}

Curiosity was not mentioned a lot in the study as providing value only twelve children mentioned it across all ages. It was only an occasionally relevant dimension in certain contexts. It was found to sometimes be relevant in the context of food products. Curiosity was sometimes related to emotional value the chance that the product would be loved or liked.

"Well yeah because it might be a new like taste so I could taste something new." (Megan, age 9)

“And it's just I see something really nice on TV I ask my Mum if we can like have it sometimes." (Mark, age 9)

"We do because sometimes I like to look at the packets like I like to see the advertising sort of thing like how it catches your eye. Like if it sounds really nice on the packet, I probably would buy it. So I sort of study it. So if it sounds really nice I would probably buy it other than just go for the usual. Like I sometimes try out the new sort of icecream to see if it is as the ad says." (Kate, age 12)

"Well I'd try it and see if it's good." (Fred, age 12) 
Around half of children spoke of valuing products which were different or unique at times. Older children were more likely to value products which were new or different than younger children. Three of the boys aged seven and eight referred to valuing rare Lego figures. This uniqueness was sometimes related to social value. The unique product would impress others.

"Oh I chose it because it came with really cool looking Lego figures."

"And why is that important?"

“Oh normally just because everyone's looking for sets that comes with rare people."

“Rare?"

"Yep. Because some quite a lot of the Star War figures you can't get any more."

“Right. So which figures did it come with can you remember?”

"Darth Vada, his apprentice and Juno Eclipse the pilot." (Stephen, age 8)

"Like I'd rather have one of these hyena droid instead, I mean the rocker battle droid instead of the normal battle droid"

Right

And

Why is that?

Because these ones look a bit cooler and they're rarer.

Right do you know how much it was?

Yes $\$ 50$.

\section{Okay right and what did you think about that price?}

I thought it was a good price because this is quite cool. And the guys are quite rare. (Toby, age 7)

"Like things that I haven't read or played before I might want to get that because I want to play something new" (Bella, age 9)

"It feels quite good but other people might get it too and then, and then you're not the only one who has it and then yeah so." (Annie, age 10)

Sometimes children overcame the risk associated with purchasing a new product by trying a small amount the first time.

"And then I might get something small to try and if I like that then next time I'll get it in a bigger sort of thing." (Siobhan, age 13) 
Mainly children preferred to know about choices through direct experience or at least have some knowledge of the product this enhanced their value perceptions.

"If it was like the same price as something I knew then I'd just get that one, yeah.

The one that I know. "(Max, age 13)

"It depends on it because sometimes I really like to try stuff that's really new but sometimes I just get kind of scared of it and just you know stick to the same stuff" (Lin, age 13).

\subsubsection{Perceived Price}

While products have objective prices, the way these prices are encoded by consumers has been described as the perceived price. The perceived price involves the categorisation of prices into existing classifications of familiar experience (Lichtenstein, et al., 1988). This in turn is related to the product offering and the functional value of the product in terms of the value for money perceived. The definition used for this functional value is similar to that found by Sweeney and Soutar (2001), but simpler in that children referred to short term costs rather than incorporating long term costs. In order to capture children's response to price as part of the value offered by products and changes with age the concepts identified were congruent with the concept of perceived price as found in the literature but the contributing first order concepts differed as children got older. Table 5-11 details the perceived price of products for children.

Table 5-11 The Perceived Price of Products for Children

\begin{tabular}{|l|l|l|}
\hline $\begin{array}{l}\text { Second Order } \\
\text { concept }\end{array}$ & $\begin{array}{l}\text { Description of } \\
\text { Concept }\end{array}$ & First Order Concepts \\
\hline Perceived Price & $\begin{array}{l}\text { Utility derived } \\
\text { from price as } \\
\text { encoded by the }\end{array}$ & - Affordability \\
& - Price high/low \\
& & - Price acceptability \\
& - Compargain price \\
& - Price importance \\
\hline
\end{tabular}


The price was found to be an important factor in all children's consumer decisions. For very young children with limited consumer experience and naive perceptions of what constitutes value (Fox \& Kehret-Ward, 1990) the price was mainly perceived only in terms of what children could afford. However, for most children they remembered the prices they had paid or were typical of the products they purchased as mentioned in terms of the 'price knowledge' but they simply accepted these prices if they could afford them. Sometimes they felt the price was high or low but the 'value for money' conceptualisation as related to the perceived price was not important.

Seven of the youngest children aged seven and eight years discussed checking the price of the items during value assessments. The children considered whether they could 'afford' the item. Price was mentioned by five out of six eight year olds and the two seven year olds. For the youngest consumers if you really want or like a product and you can afford it, you buy it.

"Well if I've got enough to buy like one of them and another set and but if I don't if I have just like an amount of money that I would, I just buy the set that's that much." (Toby, age 7)

"I just find yeah if I really like it and I have enough money I quite often buy it." (Miles, age 8)

“Actually Mum didn't actually want me to, Mum was thinking about me being a membership on Club Penguin and by then I had it's \$7 and I had more than \$7 so I probably could buy it and I started telling her." (Olive, age 8)

"Well I got the money from selling something on Trademe which I got \$100 for so that, that was about $\$ 80$ maybe a bit more. I just thought I would buy that because it looked really cool at the time." (Stephen, age 8)

Stephen who was eight years old, qualified his buying if he could afford it and wanted it bringing in the concept of 'how expensive it was' this was coded as high/ low price.

"If it's too expensive and I have enough money then I probably wouldn't buy it unless it was something that I really wanted but if it's just cheap then I would probably buy it." (Stephen, age 8) 
Five of the seven and eight year olds children felt price wasn't that important.

"I think about the cuteness - not the price." (Olive, age 8)

\section{"Right and did you think much about the price when you were buying it?"}

“Well no I didn't know how much because I had already $\$ 100$ and then I saw it and it was like $\$ 99$ so then I paid \$100.” (Tim, age 8)

By nine to ten years children were incorporating how low the price was, how acceptable the price was and the comparative price into their decisions. All nine and ten year olds considered the price to some extent. Most of the children in this age group considered the affordability of the price and all except one child also considered additional price related aspects. "Well I just have a look at what's there and if there's something I like and it's maybe \$3 or \$5 I might buy it if I have enough money for it. So I just see what's there because I mean if something's there that's like \$200 and all I've got is \$5 I can't buy that." (Mark, 9 years)

Children were beginning to consider the price in relation to perceived benefits by this age. Mark who was nine years old considered the acceptability of the price for the product

“Yes. I probably wouldn't buy it unless I knew more about it. When I knew more about it, it would be, it would be about the price because and if it's the price I might buy it and I'll have a look, I'll see how good, I'll play with that and I was like and then I was like wow this is cool I like think it's my favourite now for stuff to buy."

The eleven and twelve year olds considered whether they could afford the price they compared the price to similar offerings or other places of purchase and they thought about how acceptable the price was. They also discussed the relative size of the price in terms of how high/low it was.

"Probably because it's my first phone and it was the cheapest one there and I wanted it." (Charlie, age 12)

The concept of a bargain price was widely considered by this age.

"Also for the price. It was like two for, two pairs for $\$ 16$ or something so we just paid half each." (Molly, age 11) 
The thirteen and fourteen year olds discussed the price dimension in terms of these same concepts mentioned by the eleven and twelve year olds and again a bargain price influenced perceived value.

“Well like how much you get because you know like I don't really want to buy like a tiny thing for like ten bucks or whatever or you know get two for the price of one or something even if it's not like your favourite or something. Your favourite thing, if it's like cheaper, and you still like, I would probably buy it." (Max, age 13)

“When I'm going to town with my friends going to the movies or whatever if there's a deal you know two big packets of chips for \$5 and we wouldn't have been considering those chips or anything at all, suddenly there's a deal. Oh I'm saving money I may as well and I will get that deal." (Donald, age 14)

The idea that the 'price is not important' emerged again amongst the fourteen year olds in the context of products where the price was relatively standard such as movie tickets or in the context of low priced items such as confectionery.

\subsubsection{Perceived Risk}

Children discussed uncertainty about their decisions and related potential negative consequences. The marketing literature uses the term 'perceived risk' describe these considerations defining perceived risk as "the uncertainty that consumers face when they cannot foresee the consequences of their purchase decisions" (Schiffman, et al., 2005). Children spoke about risks associated with purchasing and relating to the product performance and losing or wasting their money and sometimes social risk.

Table 5-12 The Perceived Risk Involved for Children

\begin{tabular}{|l|l|l|}
\hline $\begin{array}{l}\text { Second Order } \\
\text { concept }\end{array}$ & $\begin{array}{l}\text { Description of } \\
\text { Concept }\end{array}$ & First Order Concepts \\
\hline Perceived Risk & $\begin{array}{l}\text { The expectation } \\
\text { and importance } \\
\text { of losses }\end{array}$ & $\bullet$ Performance risk \\
\hline
\end{tabular}

There was an increasing incidence of perceived risk mentioned as children got older. 
Table 5-13 Frequency of Perceived Risk in In-depth Interviews

\begin{tabular}{|l|l|}
\hline Age & Perceived Risk (No. of cases) \\
\hline $7-8$ & Low \\
\hline $9-10$ & Low \\
\hline $11-12$ & Moderate \\
\hline $13-14$ & High \\
\hline
\end{tabular}

For younger children (7-8 years) risk was not discussed however the following quote from a seven year old illustrates how previous experience influenced value positively and negatively influenced perceived risk.

"Because they could taste wrong to me, because even though I don't have allergies I just like the same ones." (Samantha, age 7)

Both performance and the related monetary risk is illustrated in the following quote

"Because if I buy something that doesn't taste good and I get it just a waste of money in the end, yeah." (Annie, age 10)

Sometimes children simply expressed their perceived risk as a factor which influences their final purchase decision. They acknowledged that the emotional and functional value they perceived may not be enduring.

"Well I feel a bit nervous because I mean you buy them you play with them and then after a while you get bored with them and then you throw them out or you give them to someone else. Yeah. I don't know how to say this one because yeah" (Mark, age 9)

"Because well I really liked it but every now and then I thought oh maybe I won't, maybe I won't end up liking it after a couple of days, so yeah. And then I eventually chose it because I thought oh it's quite cool so I might take it." (Oscar, age 9)

New or novel products with high novelty value were associated with higher perceived risk. 
"It depends on it because sometimes I really like to try stuff that's really new but sometimes I just get kind of scared of it and just you know stick to the same stuff." (Lin, age 13)

As children got older the perceived risk was more likely to be mentioned as a consideration in the final purchase decision. Products which were perceived to have high value were less likely to be associated with high risk.

"I've done that couple of times but there have been a couple of times I've done that and it's just been like I've just not used it and stuff. So it's ended up being like a waste of the money." (George, age 13)

Children did not discuss physical risks associated food such as health risks.

Children incorporated many dimensions into their value perception. Emotional value was a critical factor across all ages with children buying products they liked or loved and which would make them happy or provided pleasure. They also considered the functional value of products they purchased in terms of how products would perform. Aspects such as possession of salient attributes were considered by all whereas more abstract concepts relating to longer term use emerged as children grew older. While social influence was noted across all age studied the social value was changing as children got older. The perceived price was important as part of value for children but was only related to product benefits from nine to ten years of age. Perceived risk was an increasingly common consideration for older children.

"Not, not that much really when you've just going to the dairy to buy like something that costs two bucks or something, it's not really expensive, you're not sort of looking for top quality stuff but if you're going yeah to a movie or something and you're paying like fifteen bucks yeah then you sort of like want to know you're going to sit on a quite nice seat yeah or not like have to sit somewhere like right at the front or right to the side. So that's the sort of thing we think about if we're going to a movie and it's completely full and you get a ticket right to the side in the front or something then I'd rather not go I'd just wait till another time." (Max, age 13)

It was particularly so for high priced items versus lower priced items amongst this older age group as the quote illustrates. 


\subsubsection{Age Related Changes in Perceived Value}

The following Table 5-14 details a two-variable case ordered matrix of perceived value dimensions by age.

Table 5-14 A Two Variable Case Ordered Matrix of Perceived Value by Age

\section{$\underline{\text { Value Dimensions }}$}

\begin{tabular}{|l|l|l|l||l|}
\hline $\begin{array}{l}\text { Age } \\
\text { (years) }\end{array}$ & $\begin{array}{l}\text { Functional } \\
\text { Value }\end{array}$ & Social Value & Emotional Value & Price \\
\hline 7 (n=2) & $\begin{array}{l}\text { Quantity } \\
\text { Use value } \\
\text {-Product } \\
\text { lasts } \\
\text { Attributes }\end{array}$ & $\begin{array}{l}\text { (Social } \\
\text { influence) }\end{array}$ & $\begin{array}{l}\text { Liking/loving } \\
\text { product } \\
\text { Pleasure/Happiness }\end{array}$ & Afford \\
Not important \\
\end{tabular}




\begin{tabular}{|c|c|c|c|c|}
\hline & $\begin{array}{l}\text { lasts } \\
\text {-Amount of } \\
\text { use } \\
\text { Quantity }\end{array}$ & & $\begin{array}{l}\text { Sensory } \\
\text { performance }\end{array}$ & price \\
\hline $\begin{array}{l}10 \\
(n=7)\end{array}$ & $\begin{array}{l}\text { Attributes } \\
\text { Use value } \\
\text {-Product } \\
\text { lasts } \\
\text {-Amount of } \\
\text { use } \\
\text { Quantity } \\
\text { Quality }\end{array}$ & $\begin{array}{l}\text { (Social } \\
\text { influence) } \\
\text { Social self } \\
\text { image } \\
\text { Fitting in } \\
\text { Impress } \\
\text { friends } \\
\text { Share/ use } \\
\text { with friends }\end{array}$ & $\begin{array}{l}\text { Liking/loving } \\
\text { product } \\
\text { Cool product } \\
\text { Pleasure/Happiness } \\
\text { Fun product } \\
\text { Excited } \\
\text { Sensory } \\
\text { performance } \\
\text {-Look } \\
\text {-Taste }\end{array}$ & $\begin{array}{l}\text { Afford } \\
\text { Low/ high } \\
\text { price } \\
\text { Acceptability }\end{array}$ \\
\hline $\begin{array}{l}11 \\
(n=4)\end{array}$ & $\begin{array}{l}\text { Attributes } \\
\text { Quality } \\
\text {-Durability } \\
\text { Quantity } \\
\text { Use Value } \\
\text {-Amount of } \\
\text { use } \\
\text {-Utility } \\
\text { duration }\end{array}$ & $\begin{array}{l}\text { (Social } \\
\text { influence) } \\
\text { Tell friends } \\
\text { Fitting in }\end{array}$ & $\begin{array}{l}\text { Liking/loving } \\
\text { product } \\
\text { Excited } \\
\\
\text { Sensory } \\
\text { performance } \\
\text {-Look } \\
\text {-Taste }\end{array}$ & $\begin{array}{l}\text { Afford } \\
\text { Low/ high } \\
\text { price } \\
\text { Acceptability } \\
\text { Comparative } \\
\text { Price }\end{array}$ \\
\hline $\begin{array}{l}12 \\
(\mathrm{n}=8)\end{array}$ & $\begin{array}{l}\text { Attributes } \\
\text { Quantity } \\
\text { Quality } \\
\text {-Durability } \\
\text {-Fit } \\
\text { Use value } \\
\text {-Amount of } \\
\text { use } \\
\text {-Product } \\
\text { lasts }\end{array}$ & $\begin{array}{l}\text { (Social } \\
\text { influence) } \\
\text { Recommend } \\
\text { Fitting in } \\
\text { Tell friends }\end{array}$ & $\begin{array}{l}\text { Liking/loving } \\
\text { product } \\
\text { Pleasure/Happiness } \\
\text { Fun product } \\
\text { Excited } \\
\\
\text { Sensory } \\
\text { performance } \\
\text {-Taste } \\
\text {-Look }\end{array}$ & $\begin{array}{l}\text { Low/ high } \\
\text { price } \\
\text { Comparative } \\
\text { price } \\
\text { Acceptability } \\
\text { Afford } \\
\text { Bargain price }\end{array}$ \\
\hline
\end{tabular}




\begin{tabular}{|c|c|c|c|c|}
\hline $\begin{array}{l}13 \\
(\mathrm{n}=9)\end{array}$ & $\begin{array}{l}\text { Attributes } \\
\text { Quality } \\
\text {-Durability } \\
\text {-Fit } \\
\text {-Style } \\
\text { Quantity } \\
\text { Use value } \\
\text {-Amount of } \\
\text { use } \\
\text {-Utility } \\
\text { duration }\end{array}$ & $\begin{array}{l}\text { (Social } \\
\text { influence) } \\
\text { Fitting in } \\
\text { Show friends } \\
\text { Social self } \\
\text { image }\end{array}$ & $\begin{array}{l}\begin{array}{l}\text { Liking/loving } \\
\text { product }\end{array} \\
\text { Pleasure/Happiness } \\
\text { Cool product } \\
\text { Fun product } \\
\text { Excited } \\
\text { Sensory } \\
\text { performance } \\
\text {-Look } \\
\text {-Taste }\end{array}$ & $\begin{array}{l}\text { Low/ high } \\
\text { price } \\
\text { Acceptability } \\
\text { Bargain } \\
\text { Price } \\
\text { Comparative } \\
\text { price } \\
\text { Afford }\end{array}$ \\
\hline $\begin{array}{l}14 \\
(n=6)\end{array}$ & $\begin{array}{l}\text { Attributes } \\
\text { Quality } \\
\text {-Durability } \\
\text {-fit } \\
\text { Quantity } \\
\text { Use value } \\
\text {-Utility } \\
\text { duration } \\
\text {-Amount of } \\
\text { use }\end{array}$ & $\begin{array}{l}\text { (Social } \\
\text { influence) } \\
\text { Social self } \\
\text { image } \\
\text { Fitting in } \\
\text { Impress } \\
\text { friends }\end{array}$ & $\begin{array}{l}\text { Liking/loving } \\
\text { product } \\
\text { Pleasure/Happiness } \\
\text { Fun product } \\
\text { Cool product } \\
\text { Sensory } \\
\text { performance } \\
\text {-Look } \\
\text {-Taste }\end{array}$ & $\begin{array}{l}\text { Low/ high } \\
\text { price } \\
\text { Acceptability } \\
\text { Not important } \\
\text { Comparative } \\
\text { Price } \\
\text { Bargain } \\
\text { Price }\end{array}$ \\
\hline
\end{tabular}

Key:

\section{Majority $>60 \%$}

Around Half 41-60\%

Less than Half $20-40 \%$

( ) Not a value dimension, a condition

The specific details of how the dimensions of perceived value were perceived by children and changed with increasing age are summarised here and discussed in detail in Chapter 6, Sections 6.6 and 6.7. 
Seven to eight year old children's value perception was a simple consideration of product performance and quantity, and emotional value in combination with being able to afford products.

By nine years of age the concept of quality emerged and by ten years of age children considered their social self-image. There was also a change in the way the price was evaluated with children considering the acceptability of the price for the product they were purchasing. This supports the emergence of a trade-off concept of value.

By thirteen to fourteen years of age children had a well-established concept of value incorporating many dimensions. Price was considered in terms of worth and whether it was a bargain price or not. Social meanings associated with products were incorporated and quality was understood.

\section{7. Results: Consequences}

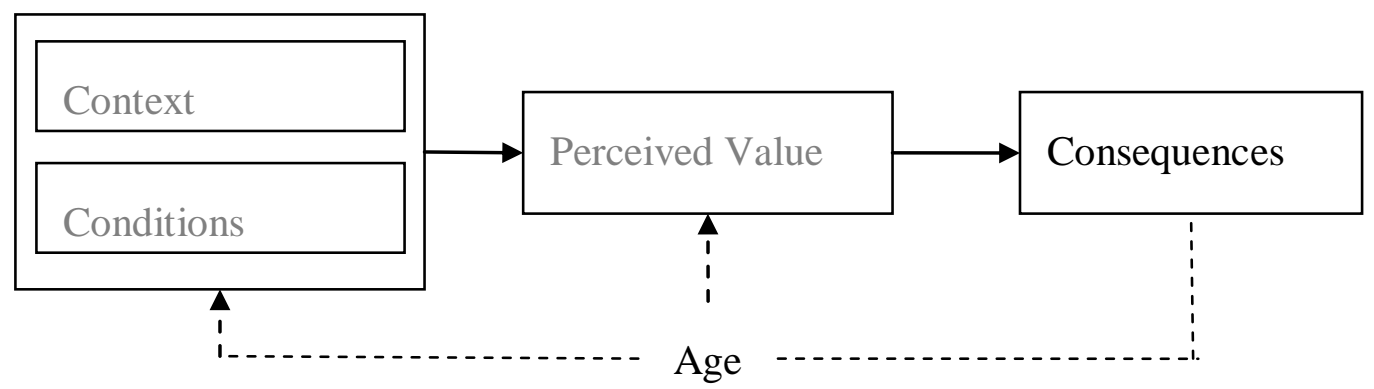

Consequences are the result of strategies children use to perceive value. The consequence of value perception was usually purchase but sometimes the result was a decision to delay the purchase or not to purchase at all. Sometimes this was because risk intervened and the decision not to purchase was made. However, due to the fact that this study required them to discuss items they had purchased, the decision to purchase was the usual outcome. A few children mentioned dissatisfaction with purchase termed 'post purchase dissonance'. Whether they are satisfied or not also impacts future value perceptions.

\subsubsection{Purchase}

Purchase was the usual outcome of high perceived value. Children were discussing the value of items for which they had made the decision to purchase. The decision to purchase or intention to purchase was related to the dimensions of value as illustrated in the following quotes. 
"Like friends they eat the brand of potato chips and say it was pretty good and it sounds good, like you what it's like and stuff if it sounds good and I like the flavour, I like the salt and vinegar is pretty good. It comes in salt and vinegar then I'll probably get it."(Lin, age 13)

"Also because I generally compare prices, how much you get for it because at one of our dairies you get 1.5 litre for $\$ 2.90$ and a $600 \mathrm{ml}$ for $\$ 3.40$ so you end up buying a 1.5 litre which my parents aren't happy, oh my Mum's not happy but my Dad understands that it's cheaper because it's fair enough." (Luke, age 13)

Children sometimes discussed decisions not to purchase or to delay purchases in the following case due to price.

"It was like should I buy this or this."

\section{“Right."}

“They're both the same price but I've only got $\$ 5$ and they both cost $\$ 5$ which one should I buy. Then I thought I'll buy this water gun and I'll buy these army, this army toy later because I'll just buy it next week instead of buying it this week." (Angus, age 9)

Older children (Mainly aged 11 and over) discussed not buying products that were too cheap due to risks associated with product performance or due to the price not being within their acceptable price range such product were considered not to provide sufficient value to purchase.

“Yes $\$ 4.50$ but like if it was 50cents I wouldn't have bought it because apparently like cheap stuff, like cheap earrings will get your ears infected and like cheap lip balm I don't know what it could do to your lips, yeah especially if it was secondhand. I wouldn't buy anything from the Mary Potter Hospice shop if it was like lip balm from the Mary Potter Hospice shop." (Grace, age10)

"If they were really expensive I wouldn't buy them or if they were out of my price range I wouldn't buy them. But otherwise yep because I do have some earrings that aren't actually proper silver and stuff because I like them, yep." (Ruby, age 11)

When children perceived products to offer value they were usually purchased, except in the case of younger shoppers where in situations of high parental control certain 
purchases were not allowed or in the situation where children could simply not afford the item.

\subsubsection{Post Purchase Assessment}

Consumers compare expectations of a purchase with the reality of the purchase as they perceive it and are either satisfied or dissatisfied (Gilly \& Gelb, 1982). If they are dissatisfied it is described as a form of cognitive dissonance termed post purchase cognitive dissonance. There were children, across all ages, who had experienced such feelings about their purchases.

"Like sometimes I feel that if I make a mistake and I want to change it but usually I feel good after it because I know that I'll be able to buy something else another time." (Sarah, age 8)

"But sometimes if they don't like them I don't really like to wear them around them because of embarrassment and stuff like that." (Molly, age 11)

"I actually stood there looking at it for five minutes thinking should I buy it or should I not buy it and then"

\section{"Why were you thinking that"?}

“Because I guess I'm kind of careful with my money because I don't want to spend something and regret it and like yeah." (Gina, age 12)

"And I looked at the bargaining table and I managed to see this book which is \$6 and I know Lemony Snickett he's in another series which I like and so this is his latest so I might as well buy it because it's only \$6. So I bought it and I was a bit annoyed later on because I found out that you could have bought it somewhere else for \$3.50.” (Josh, age 12)

"How did I feel? I don't know when I look back at it, now sometimes I think it was a stupid choice because the new system's far more expensive compared to the old one but it's not looking too bad now because it looks like the old systems' just going to completely, like they're going to get rid of it completely so if I've got an old phone I have to buy a new one." (George, age 13)

“Well kind of awkward like I don't know if I should have bought it maybe. Maybe I should have saved my money but it was so tempting and yes." (Belinda, age 14) 
Finally the knowledge gained through purchasing feeds back into the next decisions the child makes in terms of experience and knowledge about products, prices and money as well as future wants.

"Yeah well yeah because if I bought something like a couple of days ago that was really bad I probably wouldn't buy it again." (Max, age 13)

The post purchase cognitive dissonance felt has some positive implications as it can lead to learning for children. They will consider the reasons for their disappointment when making their next purchase decision and consider additional value dimensions determined to be important. 


\section{8. Conceptual Framework of Results}

Concepts used to perceive value in the alternatives children purchase have been analysed using grounded theory methods. In order to understand the changes which occur in value perception as children grow older the contexts of their purchasing, conditions influencing value perception and value perception itself have been investigated as well as outcomes of value. Figure 5-1 below represents a conceptual framework of antecedents and outcomes of perceived value among children aged eight to fourteen years.

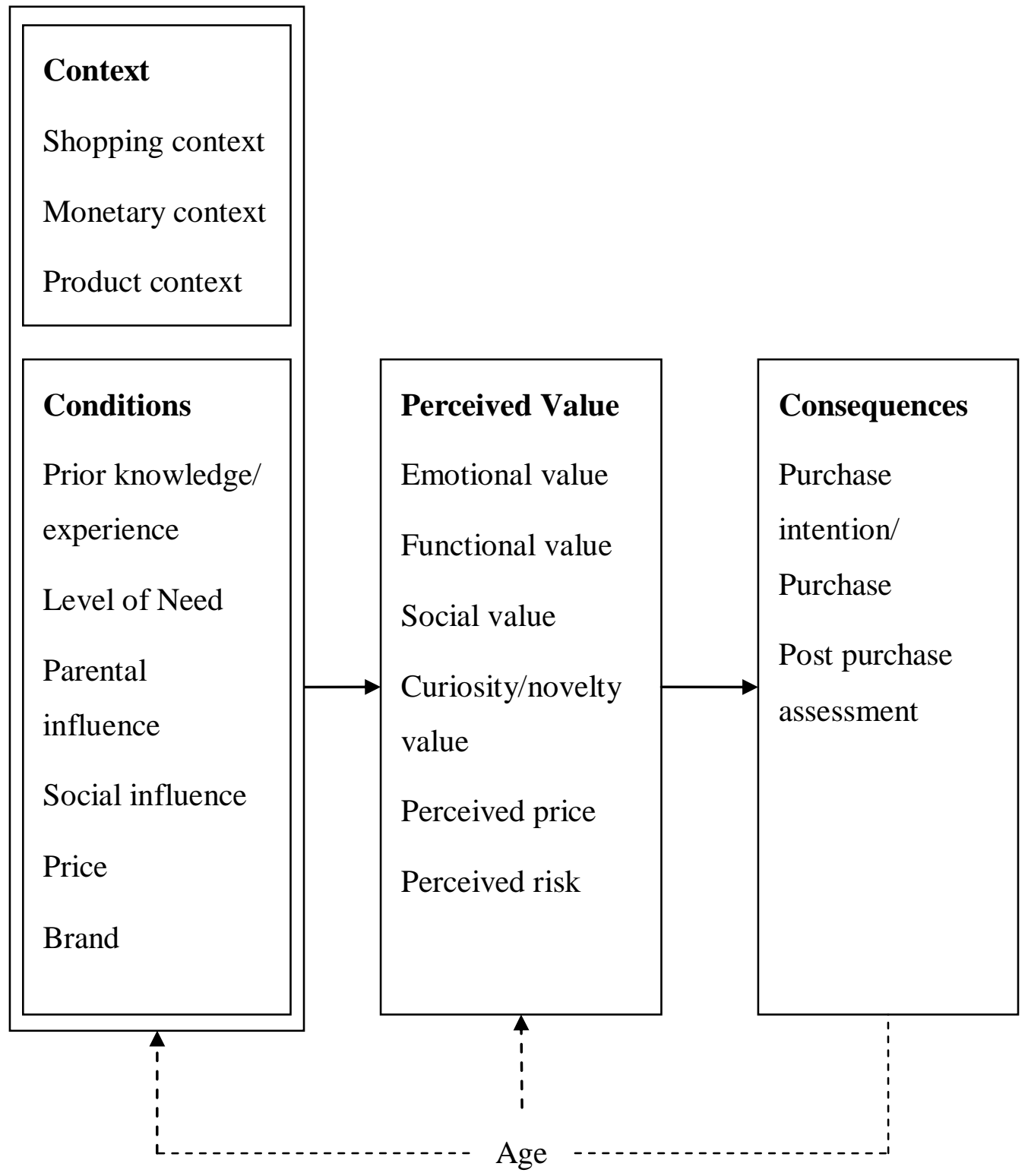


Age itself represents changes in cognitive ability as well as changes in experience. Changes in value perception cannot be solely attributed to either. As children grow older contextual factors such as the amount of money they have, where they can shop and what they can or want to shop for change. Knowledge about products, prices and brands increases and parental influence and social influence factors change. The importance of the dimensions of perceived value change as well and purchase experience influences children's subsequent purchasing.

\section{9. Conclusion}

The use of in-depth interviews and Grounded Theory methodology further elaborated upon concepts identified in study one and additional concepts were identified. This method also allowed the process involved, including the conditions leading to and consequences of value perception for children, to be determined. The limitations of the diary study with regard to compliance were overcome. Similar numbers of boys and girls participated in the interviews. The use of more flexible questioning and probing led to greater depth and understanding of meaning behind children's responses. It allowed understanding of the changing contexts, conditions and consequences involved in children's value perception. In addition as a result of probing for detail, children's consideration of some concepts emerged at an earlier age than was found in the diaries. So while some concepts were spontaneously mentioned as being important, additional concepts were identified using this method.

The study set out to define perceived value from a child's perspective and identify the relevant concepts comprising the perceived value construct in children's consumer decision-making and examine age related changes in children's perception of value. A number of concepts known to be associated with perceived value emerged but in sometimes surprising ways. There were clear age related effects in terms of the complexity of children's evaluations, the range of dimensions considered and also the interplay between benefits and costs. These findings were consistent with the diary research. The in-depth interviews confirmed the finding that even the youngest consumers studied had a concept of value. Again the dimensions of price and quality were found to vary most with age. Social influence on perceived value judgements was evident even for the youngest consumers and varied from 
informative to normative. Children were aware of the value of the opinions of others and that products could provide value by helping them to fit in.

Chapter 6 will discuss the results in greater depth, relating the findings to the literature and proposing theoretical relationships. 
Chapter 6. Discussion and Propositions 


\section{1. Introduction}

This research investigation comprised two parts. An event based diary research technique was used to explore the concept of value with children in the context of the products which they actually purchased, at the time or around the time of purchase and without researcher intervention. The purpose was to identify which concepts were important in terms of their contribution to value for children's purchases. This was followed by in-depth interviews analysed using grounded theory methods (Corbin \& Strauss, 2008) to look into value perception in more detail. This methodological approach allowed exploration of concepts and contexts and also the proposing of relationships between concepts influencing value perception for the children and age related changes again emerged. Themes identified in the first stage were refined and extended, and categories were filled out and developed in the second stage.

While the two stages were coded and analysed separately, in accordance with grounded theory methods, the emerging categories from the in-depth interview stage were considered in light of the literature and the concepts identified in the first stage of the investigation. In this way the objectives of the research could be met. Findings must be compared back to literature when naming concepts "This is to prevent the proliferation of the same or similar concepts with different names, basically referring to the same sets of behaviours, from cluttering the literature". (Morse, 2004, p. 1389).

The evidence was utilised to propose theoretical relationships. It has been noted that: "A well-established theory, which should be subjected to empirical testing, requires a substantial evidentiary warrant. When one is building theory, however, one must draw from everywhere - other theories, one's own and others' insights, and empirical evidence." (Graue \& Walsh, 1998, p. 28).

Results are related to previous conceptual research in terms of both the marketing concept of perceived value in purchase decisions and theories of cognitive development. Age related changes in the concepts and theories of child development are discussed as well as conditions and contexts related to value perception. For each conceptual area relationships are proposed which refer to the context of children's value perceptions. Following each related group of propositions, appropriate 
evidence available in the literature is detailed. The last section presents a completed conceptual model to describe children's developing perceptions of value.

\section{2. The Two Stages of the Research}

The two stages of the research identified many of the same concepts comprising children's value perception. The second stage was useful to overcome limitations of the first stage, enrich the insights obtained and expand the conceptual detail necessary to propose theoretical relationships.

In stage one, concepts were identified from children's descriptions but the source of value could not always be fully understood. For example, children might write colour or size in their diary but not discuss what it meant to them or why the attribute was important. In the second stage, using the constant comparative method described by Corbin and Strauss (2008) concepts were detailed and elaborated upon moving closer to theoretical saturation. The researcher could pursue interesting ideas and probe for meaning. Contexts and conditions were identified and described and consequences were found. Table 6-1 summarises the themes identified in the first stage of the research and the refinements made to these as they relate to the dimensions of children's value perceptions which resulted from the in-depth interview stage of the research. 


\begin{tabular}{|c|c|}
\hline Stage 1- Diary & Stage 2 In-Depth Interviews \\
\hline Functional Value - Performance & $\begin{array}{l}\text { Functional Value - Performance } \\
\begin{array}{c}\text { - } \\
\text { - }\end{array} \text { Qualitributes } \\
-\quad \text { Use value } \\
-\quad \text { Quantity } \\
\end{array}$ \\
\hline \multicolumn{2}{|l|}{ Functional Value - Quality } \\
\hline \multicolumn{2}{|l|}{ Affective Attitude } \\
\hline \multirow[t]{2}{*}{$\begin{array}{l}\text { Emotional Value } \\
\begin{array}{l}\text { - } \quad \text { Emotional value } \\
\text { - } \quad \text { Sensory response to product }\end{array}\end{array}$} & $\begin{array}{l}\text { Emotional Value } \\
\begin{aligned} \text { - } & \text { Emotional value } \\
\text { - } & \text { Affective response to product } \\
\text { - } & \text { Sensory response to product }\end{aligned}\end{array}$ \\
\hline & $\begin{array}{l}\text { Social Value } \\
\begin{aligned}- & \text { Social meaning } \\
- & \text { Social acceptance } \\
- & \text { Social self-concept }\end{aligned}\end{array}$ \\
\hline Curiosity/ Novelty Value & Curiosity/ Novelty Value \\
\hline \multirow[t]{2}{*}{ Perceived Price } & Perceived Price \\
\hline & Perceived Risk \\
\hline
\end{tabular}

The dimensions of the core concept of the study, perceived value, which were modified after gathering further information using in-depth interviews, were as follows.

Functional value was determined to be a multi-dimensional concept to which four types of functional value contributed. These were attributes or features of the product which lead to enhanced performance, the quantity, the use value of the product and the quality of the product. All these dimensions were found to fit within one definition of functional value. 'Reasoning for purchase based on the utility derived from the product attributes and expected practical, functional or physical performance.' This was modified from that of Sweeney and Soutar (2001) so as to 
encompass the naïve formulations of quality and performance which were used by children.

In the first stage perceived quality was initially viewed as a distinct dimension but was subsequently incorporated as a functional dimension on further investigation. While the meaning of the concept changed as children got older, perceived quality still fitted within the overall meaning of functional value. It had similarities but was distinct from the attributes category in that it was more abstract, and represented a combination of more enduring product performance and manufacturing input components relating to overall excellence or superiority. It was increasingly mentioned as children got older.

Affective attitude was explored further in the interviews and found to contribute to the emotional value of the product. The definition 'utility derived from the feelings associated with the choice', similar to that used by Sheth et al. (1991b) was determined to represent the same concept as identified in the study. How much a product was liked or loved was part of the emotional value of a product for children. Children's sensory responses to products were related to the arousal of feelings such as liking or loving, the sensation was providing pleasure rather than functional aspects, and hence sensory response was determined to be contributing emotional value to products.

Social value was not commonly mentioned in the first stage, only social influence on value perception. However, in the second stage it was found that social value was important for children and was related to some aspects of social influence. The definition used is an adaptation of that provided by Sweeney and Soutar (2001) but extended to incorporate the social meaning dimension. It is 'The utility derived from the social meaning of a product and a product's ability to enhance social selfconcept.'

The second stage identified in more detail the contexts of children's purchasing beyond demographic variables and identified additional conditions influencing perceived value for children. It also provided evidence on which propositions regarding these concepts could be based. 
These conditions included the influence of others, the motivation behind the purchase, the price and price knowledge the child held and the meaning of the brand to the child.

\section{3. The Perceived Value Concept}

The current study investigated the development of the concept of perceived value with children. The study of concepts lies at the heart of social research whether qualitative of quantitative methods are used.

"Concepts are generally thought to be what enable us to interpret situations in terms of previous situations that we judge as similar to the present." (Gabora, Rosch, \& Aerts, 2008, p. 85). These authors use the description of concepts as "bridges between mind and world that participate in the generation of meaning" (Gabora, et al., 2008, p. 84).

Conceptual meaning forms the basis of cognitive developmental psychology with notable researchers such as Piaget and Vygotsky (see Chapter 2) using the concept learning paradigm to detail children's development (Gabora, et al., 2008).

The traditional view of concepts viewed them as logical sets defined by certain attributes which constituted membership to a group and all members were regarded as equal. Membership to a group was described as categorisation. Recent theories take into account the graded nature of concepts, recognising that all members of a group are not equally representative of the concept. Additionally concepts are known to be influenced by the contexts in which they are used (Gabora, et al., 2008). Advances in thinking regarding marketing concepts have begun to incorporate these considerations. Rossiter's (2002) C-OAR-SE procedure specifies incorporation of the object to be rated $(\mathrm{O})$, the attribute or dimension of judgement $(\mathrm{A})$ and the rater entity (R) in addition to construct definition (C) as critical in the development of instruments which are content valid, (SE refers to scale formation, and enumeration).

The study of the meaning of concepts remains a useful way to investigate developmental change in children. Certainly when combinations of concepts are used, as occurs in value perception. By looking at similarities and differences in the way the value was perceived by children in the context of their purchase decisions, the changes in conceptual meaning could be detailed and research objectives met. 
Both stages of the research investigation found value for children to be multidimensional involving an array of benefits and costs of purchase. For children, value was found to incorporate the benefits and costs perceived when purchasing a product. This was consistent with the overall definition originally proposed by Zeithaml (1988, p.14) who defined perceived value for adults as "perceived value is the consumer's overall assessment of the utility of a product based on perceptions of what is received and what is given."

In this section the nature of perceived value for children as found in this study is detailed. Results are discussed and relationships based on these results are advanced in the form of specific propositions. These propositions are then considered relative to the relevant literature, looking both for consistency with earlier work and for how our knowledge of perceived value for children is extended. In relation to perceived value four propositions are advanced.

\subsubsection{Benefits and Costs}

Children considered the benefits they got from the products they purchased in terms of performing a function or meeting needs, they considered psychological benefits in terms of emotions associated with purchases as well as the social benefits. New products sometimes offered curiosity or novelty value to young consumers and for some products such as toys or books this was related to the product's function. Costs associated with purchase were usually related to monetary price for children, however the risks of the purchase were also considered.

Proposition 1: Value for children is perceived in terms of the benefits and costs associated with the purchase

\section{Evaluation}

Early conceptualisations of perceived value conceptualised a trade-off between perceived quality and perceived price. However, subsequent work has supported a conceptualisation involving additional benefits of the purchase. More recent studies have favoured the definition of value consistent with the definition of Zeithaml (1988) as the utility derived from perceptions of benefits and costs (Sheth et al., 1991; Sweeney \& Soutar, 2001; Petrick, 2002; Lin, et al., 2005; Tsai, 2005; Pura, 2005). 


\subsubsection{Multidimensionality of Value}

For children in the study, the costs associated with purchase may be considered separately to the benefits; they may be considered in relation to the child's income or savings, or they may be traded off against the benefits perceived.

Patterns of response emerged within age groups with children describing benefits in terms of product attributes in concrete as well as more abstract terms from combinations of attributes in relation to enhanced product performance. Younger children did not have a well-developed concept of value, and benefits and costs were likely to be considered separately. Children gradually incorporated more information and by ten years a trade-off reflected in the 'acceptability' of the price for the product, was representative of many children in the study's value perceptions.

Value to adults is considered to be a high level abstraction, a higher level concept than quality (Zeithaml, 1988). Essentially abstraction is the formation of higher level concepts or constructs from their concrete or observable properties. Zeithaml's (1988) definition refers to value being more abstract than quality, however in the present study children were found to have a concept of value based on less abstract concepts such as attributes of products and practical benefits as well as emotional value in terms of affective response to products. Price was considered in terms of affordability. Despite not having a developed concept of quality they still had a concept of value in terms of a number of benefits offered by products. This suggests that the concept is not more or less abstract than quality for children but is formed and the contributing benefits change with age.

Certainly the study found evidence that several dimensions were considered in children's value perceptions, even for the youngest children in the study. Using a single dimensional conceptualisation of value would not capture the meaning of the concept for children as the meaning of the concept varied with age in terms of the differing contribution of the dimensions to the overall value of alternatives. While young children considered some of the dimensions contributing to 'value' for adults the overall concept 'it is good value' was not commonly mentioned by young children.

Proposition 2: Value for children is a multidimensional concept 


\section{Evaluation}

This is supported by recent work in area of perceived value. Research in the areas of durable consumer goods, tourism and e-tail industries have all found multidimensional conceptualisations to be the most useful way of capturing shared meaning when measuring value perception (Lin, et al., 2005; Petrick, 2002; Sweeney \& Soutar, 2001). Lin et al. (2005) have criticised the measurement of perceived value using a uni-dimensional measure when the give and get concepts are measured as causal of perceived value. Because, according to the definition of perceived value, they comprise value and hence the hypotheses are not falsifiable.

\subsubsection{Scope of Evaluation}

The generalised abstract dimensions of functional, emotional, social, and curiosity/novelty value as well as the price, found to be important for adult consumers (Sheth, et al., 1991b; Sweeney \& Soutar, 2001) were found through comparative analysis to be represented in children's value perceptions across all ages. However, the importance and complexity of these concepts varied with age. This was a consistent finding across the two studies.

In the present study children discussed several important contributions to their perceived value and which was formed from various contributing factors.

Proposition 3: Value for children is formed through the evaluation of products on up to five dimensions

\section{Evaluation}

The work of Lin et al. (2005) supports a first order reflective, second order formative model as the most representative of the value concept in a nomological network. In Lin's work the concept was modelled as a multi-dimensional reflective construct, a multidimensional formative construct and a uni-dimensional construct and the fit of each model with the data estimated using Structural Equation Modelling. The conceptual definitions for perceived value (Zeithaml, 1988) incorporating benefits and costs also support a multi-dimensional formative conceptualisation unless value is simply being looked at as overall value perception or value perception at the component level. 


\subsubsection{Interrelatedness of Value Dimensions}

The dimensions were sometimes found to vary together. Products that had high social value and lead to a child fitting into their social group were liked or loved and made the child happy to own them or consume them hence contributing emotional value. A chocolate bar which tasted pleasant often resulted in pleasure and happy emotions and might also fill them up if they were hungry. Children felt toys which performed functions well would be used a lot and they liked such toys perceiving them to have more value. Evidence from the exploratory study supports the interrelated nature of the value dimensions.

Proposition 4: The dimensions of perceived value are partially interrelated

\section{Evaluation}

In Zeithaml's (1988) investigation the Grey Benefit Scheme (Young \& Feigin, 1975) is used to illustrate the idea of abstraction from concrete features of products to higher level benefits. This means- ends chain also illustrates the relationship between product attributes, functional benefits, practical and emotional benefits and hence supports the interrelated nature of benefits to consumers.

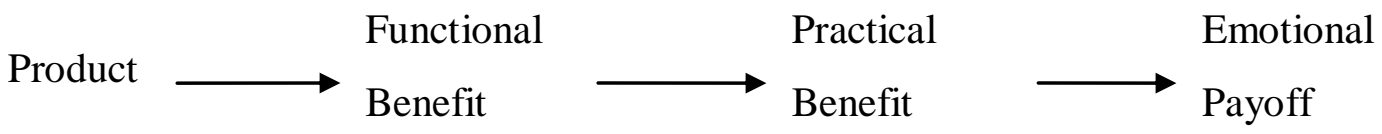

Figure 6-1 The Grey Benefit Scheme, (Young \& Feigin, 1975)

However, Sheth Newman and Gross (1991b) developed a scale to measure value at the product, brand or category level and specified the dimensions were independent. Since this work most researchers have agreed that the dimensions are unique but interrelated. Sweeney and Soutar (2001) developed the first multidimensional scale to measure perceived value for a durable good and found the dimensions to be interrelated. This was also found to be the case, at least to some extent, in subsequent work on measurement of the perceived value concept for adults (Petrick, 2002; Tsai, 2005). Varying sequences were also found in the current work and so it would not make sense to view the relationship in a linear fashion. 


\section{4. Age Related Changes in Value Perception}

Theories of consumer socialisation (John, 1999) and cognitive development (Hatano \& Inagaki, 2000a; Shaffer, 1999; Vygotsky, 1978) predicted that conceptual change would occur with increasing age. John (1999) reviewed a large body of research on children's consumer behaviour and described a stage like progression in thinking which comprised three qualitatively distinct, overlapping phases. This theory is largely Piagetian in nature and includes some information processing theory. Qualitative studies on the concepts of price (Fox \& Kehret-Ward, 1990) and economic concepts (Berti \& Bombi, 1988) have revealed patterns in thinking and understanding related to age. These findings differ in terms of what was found to be understood and how the information is actually used when perceiving value.

The results of the exploratory study found that the dimensions of perceived value identified for adults emerged from the children's diaries and in-depth interviews regarding their purchasing. Children had a concept of value from the time they started to purchase independently and considered similar generalised types of benefits related to their purchases as well as costs of the purchase. The concepts were less sophisticated and the way in which certain concepts were considered and combined, changed with age. Rather than weighing the benefits with the costs they were considered separately by the youngest children in the study yet as they grew older they incorporated additional concepts and considered them in combination. So, while children in the study had a concept of value it changed with age.

Current theories of cognitive development have built on the ideas of Piaget proposing two departures from his influential work. Piagetian thought regarding knowledge acquisition as constructed, through the interaction of a child with their environment and the restructuring of knowledge through assimilation and accommodation is retained, however, it is now acknowledged that conceptual development is domain specific (rather than domain general as proposed by Piaget) and is constrained by innate tendencies and acquired knowledge (Hatano \& Inagaki, 2000a, 2000b). It seems that the current study fits best within the Post Piagetian framework proposed by these theorists, the details of which are now discussed with regards to the four propositions which underlie it. 


\section{Knowledge is Constructed}

The idea of construction is supported by the current research this Piagetian idea proposes that humans interact with the environment and construct rules through regularities they observe as well as knowledge transmitted to them. They incorporate this into existing knowledge and connect it to prior knowledge. This results in the elaboration of conceptual knowledge. Young children incorporated the experiences they had with shopping into subsequent shopping decisions as evidenced by the influence of previous experience or knowledge about products on the perceived value of alternatives.

\section{$\underline{\text { Knowledge Acquisition Involves Restructuring }}$}

The very young children assessed value based on benefits and prices but discussed checking prices with parents or simply comparing prices to the money they had available. As they got advice and gained experience this was incorporated into subsequent value judgements. In addition their number knowledge was increasing as was their understanding of work and pay (Berti \& Bombi, 1988). As they worked more for money and their income increased their perceptions of the value of money changed. It became more complex and this understanding was incorporated into the value concept in terms of the acceptability of the price. This acquisition of knowledge resulted in a restructuring of the value concept which gradually became a trade-off between the costs and the benefits.

Acquisition of shopping knowledge involved restructuring. So the amount of knowledge increased but there was also restructuring of knowledge resulting in conceptual change.

Knowledge Acquisition is Domain specific

The term domain refers to a specific range of knowledge covered by a theory (Hatano \& Inagaki, 2000). Classification of domains is usually based on innate bases. Many researchers have rejected the idea of domain general competence and this study provides evidence for children's progression in thinking about perceived value. A single descriptive model has not been found to adequately explain children's conceptual understanding of all marketing and economic concepts. Concepts develop gradually and appear to differ depending which naïve theory is used, for example psychology in judgements requiring social perspective taking or 
biology regarding needs. John (1999) has proposed a consumer socialisation model to children's consumer knowledge; however it does not account for inconsistencies found in some studies.

\section{$\underline{\text { Knowledge is Constrained }}$}

Finally, this theory proposes that knowledge is constrained by innate constraints, acquired knowledge and socio-cultural constraints. Some people attend to certain types of information more than others and this is what is referred to as innate constraints. Also the environment in which children grow and importance attributed to different domains of knowledge influences children's knowledge. For example, if a culture bases transactions on barter rather than money, money related knowledge may be later developing. A spectrum of development was found in the current studies rather than all children acquiring a concept at a certain age.

Overall, the concept of value became more complex in the study in terms of the number of dimensions considered and the incorporation of abstract concepts such as quality into value and the concept of a trade-off between benefits and costs. The way the youngest ( 7 and 8 year old) children described the value they perceived in the alternatives they purchased was described as a combination of specific benefits and costs of the purchase. They considered the utility of specific attributes, the use value and the sensory performance of products, and their emotional response or feelings associated with alternatives. As children got older they incorporated the perceived quality of alternatives into value and the benefits were weighed up against the costs.

The incorporation of more information as children grew older and the level of abstraction from the combination of lower attributes led to changes in the meaning of the concepts. In the present study no children mentioned the benefits of the product in relation to price until they were nine or ten years old.

On this basis it is proposed that:

Proposition 5a: The conceptual meaning of the dimensions of perceived value will change with age

Proposition 5b: With increasing age perceived value will become increasingly abstract and the number of contributing dimensions will increase. 
Proposition 5c: As children get older and incorporate abstract thought in their evaluations, value will become a trade-off between the benefits and the costs

\section{Evaluation}

Many studies have identified change in children's conceptual meanings as they grow older. Of particular relevance to the current study are changes in children's thinking about thinking or naïve psychology and related to this children's self-perception.

Children between the ages of four and ten years have been shown to use more abstract concepts relative to perceptual attributes as they get older, in categorisation tasks (John \& Sujan, 1990b). Young children used mainly concrete observable attributes (also termed perceptual or visual) which were not inherent to the core concept of categories such as colour while older children increasingly used underlying attributes which related to the function the category served.

\section{5. Contexts and Conditions Influencing Perceived Value}

In stage one of the research several themes important for children's perception of value were identified. In stage two these ideas were explored and expanded and additional conditions which influenced value perception were identified. While contexts were recorded in the diaries the contexts in which children were purchasing were more fully explored in the in-depth interviews.

\subsubsection{Contexts}

The context of children's shopping experiences was found to change as they grew older. Theories of cognitive development emphasise the importance of environmental factors on children's cognitive development (Hatano \& Inagaki, 2000a; Shaffer, 1999; Vygotsky, 1978) and the construction and reconstruction of knowledge. As discussed previously the person interacts with the environment and constructs rules based on regularities and knowledge transmitted to them. Children shopped with others initially, parents influenced value perception and this experience shaped future experiences allowing them to gain competence and shop independently. They also changed in terms of their understanding of money as their knowledge of the link between work and payment increased. They had more money to spend and shopped for a greater variety of products as the parental influence was 
withdrawn gradually changing in nature from that of control to influence. They had freedom to shop at places which were convenient and hence choice was greater In the first study it was found that children had limited amounts of money to spend and children were beginning to purchase independently. It was found that they purchased from five main categories of product, these were food/drink (46/62), clothes (19/62), entertainment (12/62), books (11/62) and toys (8/62). From the indepth interview study the five main categories were identified; food/drink (45/51), clothes (35/51), toys (25/51), computer games (19/51), electronics/ phones (17/51), and books (13/51). Toys were more likely to be purchased by younger children and electronics and phones by older children. Food was more commonly purchased by older children than younger children as parents gave the older children more responsibility for food choice.

\subsubsection{Conditions}

Children's value perception was found to be influenced by many factors. These are now grouped in terms of their source. There were external influences of friends and parents, internal influences of needs or wants and previous experience and knowledge as well as the product related factors of brands and prices. The conditions which were found to have contributed to value perception are described in Figure 6-2 overleaf. 


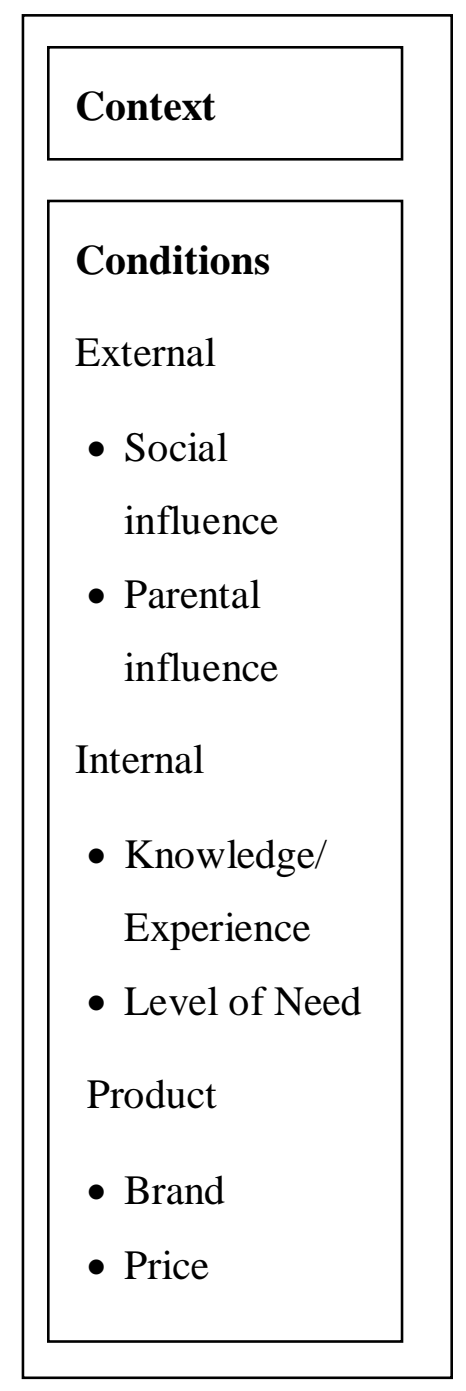

Figure 6-2 Conditions Influencing Perceived Value

\subsubsection{Social Influence}

Social influence is used to refer to the influence of other's on children's value perception. Social influence was most closely aligned with the concept of reference group influence (Bearden \& Etzel, 1982) identified in the literature. Park and Lessig (1977, p. 102) defined reference group as "an actual or imaginary individual or group conceived of having significant relevance upon an individual's evaluations, aspirations, or behavior". Influence was described in this research as informational, utilitarian (normative) or value expressive. Informational influence relates to the use of credible others to obtain information about a product, normative influence relates to a desire to comply with the views of others while value expressive represents a 
desire to be like a reference group or a liking of a reference without a desire to be part of it (Bearden \& Etzel, 1982).

Social influence was positively associated with purchase value and this was found in both studies. Products which children saw their friends with or liked or even talked about were more highly valued than those which were not owned or liked by friends. Consistently entire peer groups would bring the same items to the in-depth interviews and children would mention that all the boys or girls in their class liked a particular product. Social influence was important for children, and reference groups providing information or approving purchases, influenced the value of alternatives. These influences may be similar to normative and informational influences described by some researchers (Bearden, Netemeyer, \& Teel, 1989).

Proposition 6a: Being approved by peers will enhance the perceived benefits of an alternative

Proposition 6b: Being approved by peers will reduce the perceived costs of an alternative

Proposition 6c: Peer influence on children's perceived value will be mainly informational and normative

Proposition 6d: As children get older the influence of peers on perceived value will increase

\section{Evaluation}

Several studies support the influence of peers on children's purchasing and an increase in influence as they grow older (John, 1999; McNeal, 1987; Moschis \& Moore, 1979; Valkenburg \& Cantor, 2001). Moschis and Moore (1979) found that teenagers who indicated frequent communication about consumption with peers had a greater tendency to use peer preference when evaluating products. In a study of teenager's choices of footwear brands the informational factor was found to be of low relevance and the normative factor was found to be comprised of identity and compliance (Auty \& Elliot, 2001). More recently, research with tweens (aged 9-15 years) found that peers opinions in clothing choice only mattered for $12.8 \%$ of children in the study (Drake-Bridges \& Burgess, 2010). 


\subsubsection{Parental Influence}

Parents were regarded as important influences on children teaching them consumer skills and approving children's choices as well as introducing children to products. They also controlled younger children's decisions at times in terms of what to buy and how much to pay.

Parental influence was found to decline in mention in the diaries as children grew older, it was mentioned in only seven diaries and not at all for those over twelve years. In the in-depth interviews it was found that parents were influential in certain situations for 42 of the 51 children. The nature of parental influence changed. Parents did still influence the decisions of older children but for largely high cost, higher perceived risk products. Not so much low cost products as for younger children where the influence broadly covers all categories purchased from.

Parents also recognised increasing competence allowing children to decide with increasing independence as they considered the value they were getting in a more sophisticated manner.

Proposition 7a: Being approved by parents will enhance the perceived benefits of an alternative

Proposition 7b: Being approved by parents will reduce the perceived costs of an alternative

Proposition 7c: As children get older the influence of parents on perceived value will decrease

Proposition 7d: As children get older the influence of parent approval on perceived value will be higher for higher priced products

\section{Evaluation}

This finding was supported by the research regarding tweens clothing choice in which $88.2 \%$ of children indicated that parents were the reference group most often shopped with. In addition to this finding $50.5 \%$ of children indicated their parents helped them to make the purchase decision (Drake-Bridges \& Burgess, 2010). 


\subsubsection{Previous Knowledge/ Experience}

Both stages found consensus regarding the importance of previous experience. Children consistently relied on previous experience as a source of information to base their decisions upon. The diary study results suggested that children relied more on previous experience than prior knowledge with around half the children mentioned this and only thirteen mentioned prior knowledge; however the interviews found similar numbers utilising these sources of information. The results suggest that children relied on previous experience as it allowed them to accurately assess the benefits of purchase while at the same time reducing the perceived risks associated with it.

Proposition 8a: Previous experience or prior knowledge will enhance the perceived benefits of an alternative

Proposition 8b: Previous experience or prior knowledge will reduce the perceived costs of an alternative

\section{Evaluation}

This is supported by the model proposed by Zeithaml (1988) which showed that intrinsic attributes are used to infer quality. For young children they were used instead of quality. Prior experience with a product means that intrinsic attributes (attributes consumed as part of the product) are known and benefits can be accurately assessed. In this way risk is minimised and value enhanced. When children did not have prior experience with a product or service they tended to then rely on their knowledge of the product. If a product was not known information was sought from reference groups (as discussed) or alternative sources such as advertising or reviews. Perceived value of alternatives was enhanced by knowing something about the product.

This influence was identified in the diaries and was elaborated upon in the interviews. The products purchased over the two week period in the diaries were largely food/ drinks and for the majority of purchases the products found to provide the highest perceived value were not new. In the in-depth interviews children included more products and higher priced items which were not purchased regularly. It was found that children relied on previous experience across a broad range of categories that they purchased from but that if a product was new, they would 
usually value products they knew about over those which were totally new. When children encountered new products they preferred those they had heard of ahead of those they had no knowledge of. Young children aged seven and eight were influenced by the television shows and stories they knew.

Proposition 8c: Use of imagery relating products to known products/ characters will enhance children's value perception by increasing prior knowledge.

\subsubsection{Level of Need}

In the second stage of the study it was found that feelings, wants and needs influenced the value of alternatives.

Young children were motivated by wants reflecting higher levels in Maslow's hierarchy of needs, psychological needs rather than physiological needs (Schiffman, et al., 2005). Physiological needs were usually met. Sometimes products were purchased to fulfil needs at more than one level of the hierarchy such as sweets. The more they wanted a product the more attractive an offering was perceived. Children were sometimes unaware of what motivated them to want the product.

Proposition 9: As children get older they will increasingly purchase products which are needed as well as those that are wanted.

\section{Evaluation}

Belk, Ger and Askegaard (2003) have described three levels of underlying motives of consumption, needs, wants and desires. Distinguishing wants from needs in terms of wants being a higher level of need, a feeling involving the mind rather than the body and linked to personal preference (Belk, et al., 2003), see Table 6-2 overleaf. This is consistent with the distinction found for children's purchases and may influence the changes observed in terms of the heightened influence of emotional value and sensory response in children's perceived value of products as well as the increasing functional considerations. 


\begin{tabular}{lll}
\hline & Need & Want \\
\hline Initial state & Fixed & Open \\
Relation to object & Open & Open or fixed \\
Cartesian relation & Body & Mind \\
Mode of expression & Necessity & Wish \\
Root & Naturalization of social & Personal preferences \\
& institutions & \\
\hline
\end{tabular}

(Adapted from Belk, et al., 2003, p.329)

\subsubsection{Brand Meaning}

Extrinsic attributes refer to attributes which are related to the product but are not part of the product and include things like the price, brand and amount of advertising (Zeithaml, 1988). Consumers use such cues when intrinsic cues are difficult to evaluate. Brands were found to be an important cue for children. Brand positively influenced value perception for children of all ages and the extent of influence became greater as they developed understanding of brand meaning. Brand was used by young children in the first study to identify products and this was explored in stage two to determine whether brand influenced value perception. It was found that as children got older brands had a deeper meaning and became increasingly important. Evidence that brands were associated with deeper meaning was found for children from eleven years of age up. They associated brands with reputation and quality. A developing understanding that a brand encapsulates a set of benefits, rather than simply identifying a product, was evident.

Proposition 10a: Having a well-known brand will enhance the perceived benefits of an alternative

Proposition 10b: Having a well-known brand will reduce the perceived costs of an alternative

Proposition 10c: As children grow older the influence of brand on perceived value will increase

\section{Evaluation}

Numerous studies have looked at children and brands (Hite \& Hite, 1995; John, 1999; Moschis \& Moore, 1979; Otnes, et al., 1994). Children have been shown to recognise brands from a young age (Hite \& Hite, 1995) and include brands in letters 
to Santa. These findings are congruent with the observation of the current research that younger children used brands to identify products and older children associated them with deeper meaning. Achenreiner and John (2003) found that brands related to perceptual features of products for children at eight years but by twelve years they had abstract meanings which were not observable. These abstract meanings were functional (such as quality) as well as symbolic.

\subsubsection{Price/ Price Knowledge}

Children's value perception was influenced by the actual objective price and their price knowledge. The price knowledge the child possessed influenced the way they saw the price and this knowledge was found to increase with age. Most children of all ages remembered the prices of the products they purchased. The actual price influenced perceived value in the way it was perceived by the consumer. For young children actual price influenced the perceived costs in terms of whether they could afford the product. In addition they sometimes considered whether they would have any money left over. It was not found to influence their perception of benefits. As children got older the price influenced their value perceptions in two ways a higher price enhanced perceived benefits and perceived costs in terms of perceived price and monetary risk.

Proposition 11a: For young children price will be evaluated only in terms of affordability and not influence value perceptions in other ways

Proposition 11b: As children get older a high price will enhance perceived benefits

Proposition 11c: As children get older high price will positively influence perceived costs

Proposition 11d: As children get older price knowledge will increase for categories they purchase from this will be accompanied by a narrowing of the acceptable price range

\section{Evaluation}

This is supported by the work of McNeal and McDaniel (1981, cited in John, 1999) who found that children knew products have prices and that variability exists between prices and places of purchase. 
The finding that the relative importance of price was not high for younger children is supported by McNeal (1992) who found only 10\% of children's drawings about shopping included price information and that when other information was available such as brand and shop image that these cues were more important.

Moschis and Churchill $(1978,1979)$ found more favourable attitudes to prices for younger adolescents relative to older adolescents. While price recall accuracy has been found to be low for children (Erikson, 2003, Stephens \& Moore, 1975), explicit memory is unlikely and knowledge is likely to be greatest for personally relevant products. Broader measures using a categorisation procedure found accurate estimation for children aged 8-10 years (Pliner, et al., 1996). Price ranges were relatively broad and what the current study illustrates is that it is difficult to find products and prices which would be relevant to all children. On this basis price knowledge is difficult to quantify.

\section{6. Perceived Benefits}

The benefits associated with products have been widely acknowledged to incorporate more than utilitarian dimensions (Petrick, 2002; Pura, 2005; Sheth, et al., 1991b; Sweeney \& Soutar, 2001; Tsai, 2005). Children considered benefits of the products they purchased, benefits refer to the consumer's perception of what is received.

Concepts were related back to the literature as they emerged from the data. The work regarding hedonic consumption was identified as relevant to the current findings. Perceived value research had begun to incorporate this work particularly with regard to shopping value (Babin, Darden, \& Griffin, 1994) but more recently with regard to perceived value (Sánchez-Fernández, Iniesta-Bonillo, \& Holbrook, 2009). In line with this research emotional, social and functional benefits could be classified as hedonic, symbolic and utilitarian in nature as pictured in Figure 6-3. 


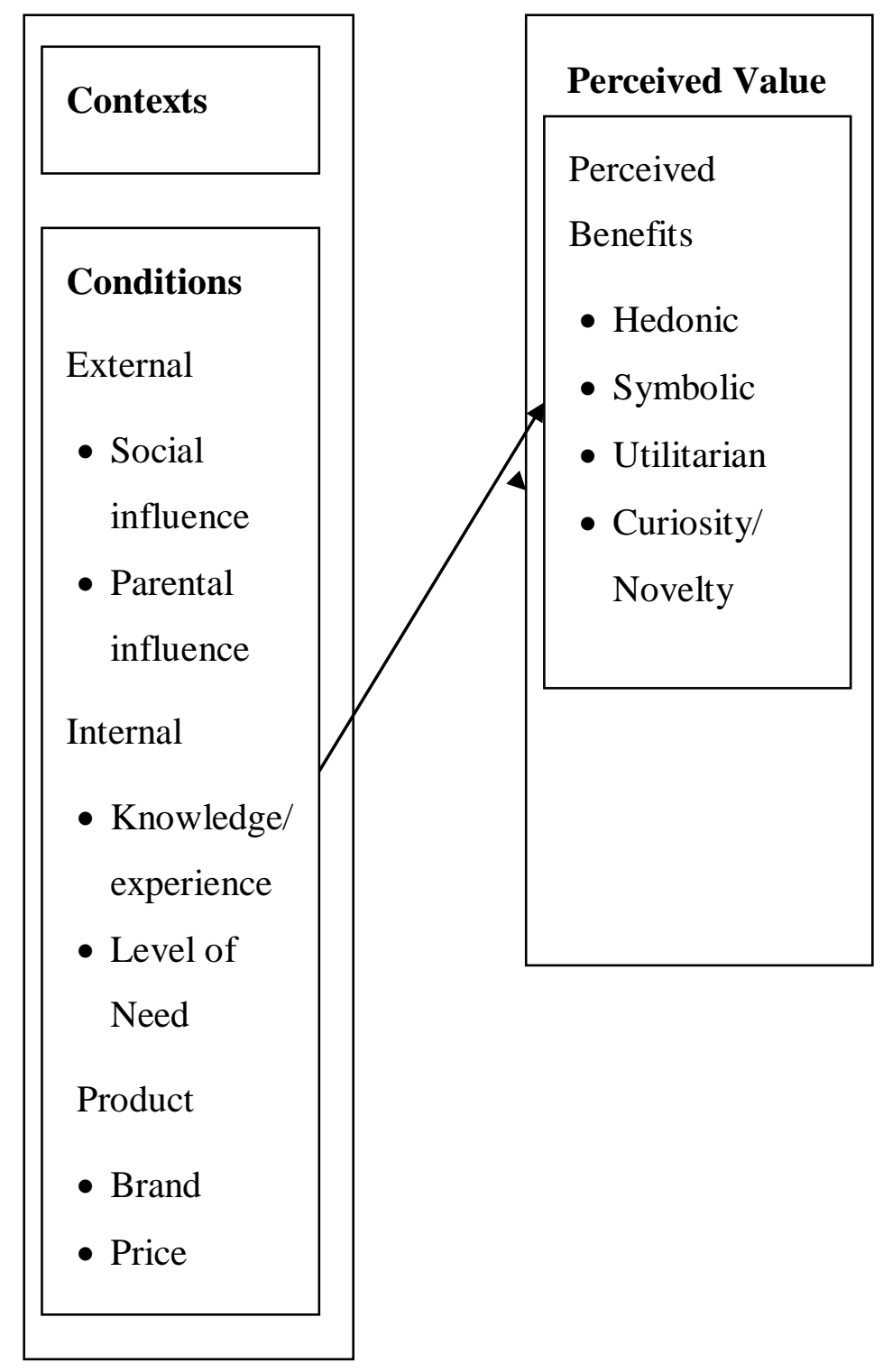

Figure 6-3 Conditions Influencing Perceived Value and Perceived Benefits

Hedonic consumption as a research area in consumer behaviour has its origins with the work of Holbrook and Hirshman (1982) who defined hedonic consumption as follows "Hedonic consumption designates those facets of consumer behaviour that relate to multisensory, fantasy and emotive aspects of one's experience with products" (Holbrook \& Hirshman, 1982, p.92). According to these authors multisensory refers to experience in multiple sensory modalities. Fantasy refers to imagery associated with the response which may be related to prior experiences but in the hedonic perspective are situated at the fantasy end of the spectrum relative to 
the reality end. The emotive aspects of consumption relate to emotional arousal beyond affect being both psychological and physiological in nature and termed by these authors as contrasting consumer research to this point, in that the efferent response is included rather than just afferent.

Babin, Darden and Griffin (1994) accept a dual nature of value benefits as

A general view of value recognizing both (1) a utilitarian outcome resulting from some type of conscious pursuit of an intended consequence and (2) an outcome related to more spontaneous hedonic responses captures a basic duality of rewards for much human behaviour (p. 645).

These authors suggest the former refers to extrinsic rewards while the latter refers to more intrinsic, personal and emotional rewards. These authors apply the concepts to the shopping experience rather than product acquisition. While the current study investigates product acquisition, these definitions more accurately reflect the distinction between hedonic and utilitarian dimensions identified in the results. This definition also more accurately reflects current advances in neuroscience which do not support the efferent/afferent distinction to sensation, in other words the criticism of consumer researchers by Holbrook and Hirschman (1982) regarding measurement of affect. They suggest that by measuring affect research does not adequately capture the hedonic response. However, evidence from psychology suggests that this distinction may not be possible in reality and that measuring affect may be adequate to capture hedonic response.

"Pleasure is never merely a sensation" (Fijda, 2007; Kringelbach \& Berridge, 2008; Ryle, 1954, cited in Berridge \& Kringelbach, 2008, p. 459).

Instead, it always requires the activity of the hedonic brain systems to paint an additional 'hedonic gloss' onto a sensation to make it liked. That is consistent with the role of pleasure in the valuation of sensory stimuli in decision making including most importantly their hedonic valence, in order to act as an interface between sensation and goal-directed action (Dickinson \& Balleine, 2008, cited in Berridge \& Kringelbach, 2008, p. 459).

On this basis, affect may capture part of hedonic response but other relevant pleasure dimensions would certainly add to the construct. The level of emotional response is likely to be indicative of hedonic response. 
This research has found that children's purchase value was characterised by both these types of value as well as social value related to social identity and group membership which have been described as hedonic aspects by some (Hartman, Shim, Barber and O’Brien, 2006) and symbolic by others (Sánchez-Fernández, et al., 2009). Children's consumer behaviour has been regarded by some researchers as motivated by hedonism, in benefit segmentation work this was found to be the case for the seemingly utilitarian product of toothpaste (Haley, 1968).

Children valued products providing hedonic benefits over those that did not provide such benefits.

\subsubsection{Hedonic Benefits}

Hedonic benefits have been defined as the "aesthetic/experiential and enjoyment related benefits" (Chitturi, Raghunathan, \& Mahajan, 2008, p. 49). On this basis the emotional value dimension found in the present study relates to such benefits.

\subsubsection{Emotional Value}

In the first study affective attitude to products was separated from emotional value. Affective attitude was defined as a positively valenced reaction to a product and emotional value to identification of the utility associated with such a response such as the pleasure or happiness the product would provide. However, recent research regarding the 'pleasure' of a reward define this concept as multi-level, motivated by wanting, and comprised of two levels: "1. core 'liking' reactions which need not necessarily be conscious 2 . conscious experiences of pleasure, in the ordinary sense of the word, which may be elaborated out of core 'liking' reactions by cognitive brain mechanisms of awareness." (Berridge \& Kringelbach, 2008, p. 458) On this basis it was decided that the two components should not be treated as separate and 'emotional' value should encompass both affective attitude to products as well as emotional arousal and anticipated feelings associated with the product. The emotional value incorporates both the attitude or reaction and the pay-off of this to the person in terms of pleasure. The concept varies in intensity for different products and it is imperative that this variation is captured by consumer researchers.

Viewing the benefit dimensions of perceived value as separate requires qualification due to functional and experiential nature of products. Some stimuli are more likely to 
elicit pleasure than others. Clearly different products would be differentially influenced by these dimensions. For a product such as a picture/painting hedonic value dimensions would be more important while the value a product such as a broom may be determined by largely utilitarian dimensions. However, while provision of the dominant dimension may provide sufficient value to the consumer, contribution from additional dimensions should enhance the overall perceived value of an alternative.

Evidence from the current study is provided with regard to the nature of products children purchase and their purchase motivation. The main category children purchased from overall was food and beverages; children purchased snack food and beverages, rather than grocery items. The food was not usually needed for survival as their primary needs were met by parents. The main products purchased by younger children were toys while older children predominantly purchased food and beverages but also clothing, phones and electronic equipment. Children mainly purchased products based on acquired needs (or wants) rather than primary needs and hence pleasure was a conscious or subconscious desired outcome. On relating this finding back to the literature it was found that such motives have been termed transformational or positively reinforcing purchase motives (Rossiter, Percy, \& Donovan, 1991). Such motives enhance the user's physical, sensory or mental state (discussed here with reference to brands but also applicable at product level). Informational motives are negatively reinforcing and refer to the utilitarian aspects of a purchase.

Proposition 12: For products motivated by wants, hedonic and symbolic benefits will be more important than utilitarian benefits

Emotional value was mentioned by children of all ages including affective reactions to products as well as anticipated feelings about the product such as happiness, excitement, coolness and fun. Children chose between products offering the same functional benefits but varying in terms of the pleasure response. Children perceived the greatest value on the basis of maximum pleasure. On this basis it is proposed:

Proposition 13a: Emotional value will incorporate affective reactions to products and anticipated feelings about owning or consuming the product 
Proposition 13b: Children's perception of the emotional value of an alternative will determine choice (once basic functional requirements are met)

\section{Evaluation}

Researchers have suggested children may be highly influenced by affective reactions to products (Pecheux \& Derbaix, 1999) and in their development of a scale to measure brand attitude these authors identified both a hedonic dimension based on affective responses to brands and a utilitarian dimension. The hedonic dimension was found to be the more important dimension for children aged eight to twelve years.

Emotional value has been used in the current study to describe what some researchers have termed a hedonic dimension. This contrasts some studies which describe hedonic dimensions of value in terms of play and aesthetics (this was for services and the context was adult consumers who clearly differentiate work and play) (Holbrook, Chestnut, Oliva, \& Greenleaf, 1984; Sánchez-Fernández, et al., 2009). Clearly the context of the current study was with children who did not purchase items for work. Hence to distinguish work from play was not relevant. Aspects such 'fun' and 'pleasure' were reflected in the dimensions of emotional value. And products were discussed in a utilitarian way regarding play as well as in an emotional way.

Proposition 13c: Emotional value will be sufficient to capture the hedonic component of value perception by children

\subsubsection{Sensory Response to Product}

The sensory pleasure of products has been regarded as both hedonic and utilitarian in the literature. Taste has been associated of food quality, a utilitarian concern, as well as pleasure within the hedonistic perspective in the literature. In the current study sensory performance was defined as an emotional benefit in terms of pleasure rather than functional in terms of quality based on the evidence. The choice of the maximum pleasure once functional needs are met was supported by the choice of treat options to satisfy feelings of hunger ahead of healthy choices unless the parents influenced or controlled choice for children. For clothes, toys, food or décor items the aesthetic beauty or attractiveness was a key benefit. The sensory performance of 
the product was important for almost all children in the study and was often the differentiating factor in terms of value provided.

Proposition 14a: Positive sensory response will enhance perceived value for children.

Proposition 14b: Positive sensory performance will contribute to perceived emotional value

\section{Evaluation}

In the early benefit segmentation study described by Haley (1968) children chose toothpaste using the benefit of flavour rather than function for this seemingly utilitarian purchase. Pliner et al. (1996) in their work on the price perceived quality relationship with children aged five to twelve years found that when prizes for games varying in colour and monetary value were offered, red was the clear favourite while the distribution in terms of monetary value was random.

\subsubsection{Symbolic Benefits}

The origins of the 'social value' concept are from symbolic consumption, Holbrook and Hirschman asserted that there was: “... much to be gained by -both pragmatically and conceptually- from inquiries into the esthetic, intangible and subjective aspects of consumption..." "These factors pertain to phenomena that we shall refer to as 'hedonic consumption."”(Holbrook \& Hirschman, 1982, p. 92). While social value is different to the hedonic dimension 'emotional value' it is not considered mutually exclusive (Solomon, 1983, p. 319) value has been asserted to refer to choice imagery (Sheth, et al., 1991b, p. 161) or social identity (Sweeney \& Soutar, 2001), and is an intangible aspect of products. In his most recent work Holbrook treats the social value dimension as distinct from hedonic value (SánchezFernández, et al., 2009) calling it symbolic value.

\subsubsection{Social Value}

In the present study 'social value' was regarded as a benefit of a product distinct from 'emotional value' in that it related to reference group perceptions. This perspective is supported by current theory conceptualising perceived value as multidimensional. Marketing academics have long recognised the importance of reference groups on the perceived value of products. Reference groups have been 
shown to influence consumer behavior in adults (Bearden \& Etzel, 1982) and children (Drake-Bridges \& Burgess, 2010; Valkenburg \& Cantor, 2001).

Social value was found to incorporate both the value derived social approval and that derived through enhancing one's social self-image. The definition: "The perceived utility derived from an alternative's association with one or more specific social groups. An alternative acquires social value through association with positively or negatively stereotyped demographic, socioeconomic, and cultural-ethnic groups. Social value is measured on a profile of choice imagery." (Sheth, Newman \& Gross, 1991), and that of Sweeney and Soutar (2001) "The utility derived from the product's ability to enhance social self-concept" define social value in terms of group association and self-concept respectively.

The concept of value derived from compliance to norms, is not specifically included in these definitions. While these definitions are similar to the social value found in the present study, they are not sufficient to completely capture the meaning of the concept found for children. Applying the three-fold susceptibility to interpersonal influence theory proposed by Bearden and Etzel (1982) helps provide an explanation of results.

These authors proposed that reference groups influence purchase decisions in terms of information-seeking, utilitarian (used to refer to compliance or normative influence) and value-expressive ways as discussed in Section 6.5. Information seeking refers to the influence of group members as sources of information, utilitarian refers to normative influence and conforming to group norms, while valueexpressive refers to the desire to reflect one's self-concept or desired self-concept (Park \& Lessig, 1977). The definition which captured the meaning of the concept for children in the present study was the utility derived from the social approval of a product (informational and compliance to norms) and a product's ability to enhance social self-concept (desired self-concept) related to these reference group influence factors.

Proposition 15a: Social value will include social meaning, social acceptance and a products ability to enhance social self-concept with reference groups

Children were more likely to spontaneously mention social value as they got older. In the diary study social values were not mentioned until after the age of nine while in the in-depth interviews a seven year old mentioned social value. In the in-depth 
interviews social value was mentioned by most children. It was found that the social value of products for children developed in two stages and began with children buying products that were valued or liked by others or recommended by others. The youngest children in this study obtained information from others and sought approval of their choices at seven years. By ten years the idea of products reflecting identity or 'social self-image' was incorporated. The value of social approval in terms of 'fitting in' was beginning to be acknowledged by age eight and remained a key value dimension for children of all ages studied. Social value became increasingly important with age.

For 7-8 year olds social value was largely related to informational and normative influence (social meaning and social acceptance). The emergence of valueexpressive influence on perceived value occurred around ten years of age. Children began to express a desire to impress others or reflect who they were with products. This increased markedly amongst the thirteen and fourteen year olds.

Proposition 15b: As children grow older the ability of products to enhance social self-concept will be increasingly important

\section{Evaluation}

The work of Kehret-Ward and Yalch (1984) showed that children took into consideration their own self-image and the congruency with product image once they were over eleven years of age. Achenreiner and John (2003) provided evidence that the symbolic meaning of brands was understood by children over the age of twelve years whereas for eight year olds brand was simply familiar or related to perceptual product features.

Children discussed the importance of social value dimensions for products they would consume with or around friends such as toys and books for younger children and for older children clothing, phones and electronic games. For some young children (aged 7-8) social values were more important than for other children of this age. The popularity of a product with friends was most important. The children wanted to fit in as reflected in their desire to seek information from others and for social approval. For older children social value was related to the product and the context of consumption. Both diaries and in-depth interviews revealed an increasing 
differentiation between socially consumed products and privately consumed products such as food as children got older.

Proposition 15c: As children grow older the importance of social value will increase for conspicuously consumed products and decrease for privately consumed products.

\section{Evaluation}

For adults the influence of reference groups on decisions about brands was found to be greatest for publicly consumed luxuries and publicly consumed necessities. Reference group influence on product decisions was greater for luxury products than necessities (Bearden \& Etzel, 1982). These finding are consistent with the findings for older children.

\subsubsection{Utilitarian Benefits}

'Utilitarian' has been used in consumer research to describe considerations of utility derived from the functionality of products. It represents an objective approach focussing on an object, its price, and the functional utility provided by that object (Babin, et al., 1994). The term 'utilitarian benefits' has been used to refer to "...the functional, instrumental, and practical benefits of consumption offerings..." (Chitturi, et al., 2008, p. 49). This rational idea of utility is useful for predicting purchase of certain products and explaining some of the benefits offered by products. While conceptually it is not necessarily the case, luxury items or wants have been described by marketing researchers as typically hedonic in nature and necessities as typically utilitarian. Luxuries are related to pleasure and necessities to functionality (Kivetz \& Simonson, 2002). Children in the study purchased mainly items which were wanted and as such would be more luxuries or non-essential items than necessities and as such may be regarded as hedonic shoppers.

The purchase motivation concepts described by Rossiter, Percy and Donovan, (1991) described an informational motive associated with problem removal and a transformational motive associated with sensory gratification or social approval. Similarly goals of prevention (those that ought to be met and which reduce the probability of a painful experience) have been shown to be met by utilitarian benefits and goals of promotion (those a person aspires to meet and increase the probability of a pleasurable experience) by hedonic benefits (Chitturi, et al., 2008). 
The current study identified many of the products children buy as experiential in nature and their purchase motivations were transformational, supporting the importance of such hedonic benefits. Such an assertion assumes that decisions do not proceed in a linear- rational fashion as per the utilitarian paradigm. However, there is increasing evidence that both utilitarian and hedonic value dimensions are important even for luxury items or wants. Indeed it is difficult to find products or services for which hedonic or utilitarian dimensions are mutually exclusive. The study found that children considered both utilitarian functional and hedonic dimensions of value for the products they purchased.

Children's goals included both prevention and promotion and in contradiction to the words of Srinivasan (1987, p. 99) who asserted that “...the 'fun' aspect of buying is exemplified in children, who are largely risk-oblivious." The current study provided evidence to suggest that children do perceive risk as indicated by their reliance on prior knowledge or experience across all ages.

The utilitarian benefits perceived by children in the study were grouped into functional values of product specific attributes, quality, use value, and quantity. These benefit categories allowed the progression in children's understanding of quality to be traced. The youngest children used product specific attributes relating to short term performance, the anticipated use value of the product and the quantity or size of the product as indicators of performance whereas older children incorporated the more abstract concept of quality relating to manufacturing inputs and longer term performance.

\subsubsection{Functional Value - Attributes}

Children had expectations of products to provide functional and practical benefits. They required products to possess certain attributes which enhanced performance or function. These attributes were product specific and usually related to short term function. Even the youngest children mentioned the possession of certain attributes as being important. Children incorporated more attributes to infer a superior product with age.

Proposition 16a: For children, the functional value of products will include the possession of salient attributes 
Proposition 16b: As children get older, the number of attributes evaluated to determine functional value will increase

\section{Evidence}

Capon and Kuhn (1980) found that children had increasing ability to incorporate judgement on more than one dimension as well as ability to focus only on relevant information with age. Bahn (1986) also found that the number of dimensions on which brand preference was based increased with age but only for cereals. He also found that the type of dimension used changed in terms of whether it was cognitive, effective or perceptual. For beverages the youngest children (4-5 years) used tasty /sweet while the older children (8-9 years) used adult or child focussed. A change from perceptual to cognitive was noted while relatively inconsistent and product dependent.

In their investigation of the information children would use to select a product Ward, Wackman and Wartella (1977) found the majority of children across all ages (four to twelve years) mentioned physical attributes, and that with increasing age there was a significant increase in the mention of price and functional attributes as well as the abstract concept of quality.

\subsubsection{Functional Value - Quality}

Children mentioned the quality of the products they purchased from the age of nine but only for clothes and only in terms of durability at this age. Quality was defined as the overall superiority of the product performance. Children judged the superiority of products in terms of single attributes of functional performance. They wanted 'good' products but the abstract concept of quality was later to develop than value itself. The abstract concept of quality developed with age. By ten years the quality of product performance was mentioned and this was elaborated to durability for toys as well as clothing. The concept of quality emerged for durable products first and other dimensions which adults mention such as the reliability or manufacturing inputs or for food nutritional considerations, were seldom mentioned. By age twelve a few children mentioned health for food choices but usually relating to parental approval. It was not actually related to the child's perception of quality and physical risks were not perceived. 
Quality was related to superior performance in terms of such aspects as a rubber actually rubbing out and toys not breaking the first time you used them.

Proposition 17a: Quality will be increasingly important as children get older Proposition 17b: Quality will emerge for durable products before non-durable products for children

\section{Evaluation}

While Pliner et al. (1996) found a price - perceived quality link for children in that they chose the most expensive prize in an experiment to investigate this relationship. Qualitative research revealed this to be related to the product which was worth a higher monetary price being perceived as better. This finding does not necessarily mean the concept of quality was understood in adult terms by children in the study. It does however indicate a perceived link between a higher price and a better product.

The concept of quality may not be as useful in measuring superiority or excellence of products children purchase, instead a more general 'superiority of performance' measure may be more useful and generalisable.

Research regarding the value reflected in prices also found that children related manufacturing inputs to prices at nine to ten years (Fox \& Kehret-Ward, 1985, 1990).

\subsubsection{Functional Value - Use Value}

Children also focussed on the use value of the products they purchased. The use value can be defined as the utility derived from the consumption of the product. Children mentioned consideration of the rate of consumption as well as the duration of consumption. They considered products which would take a long time to consume to be more valuable than those that would be quickly consumed or used up. They made these evaluations prior to purchasing.

As children get older they considered the amount of use and ease of use as well as how long they would use or enjoy the product for contingent on the durable versus non-durable nature of the product. How long the product would take to consume became less important with regard to non-durable items.

Proposition 18a: For children the functional value of products will include the use value 
Proposition 18b: How long a product takes to consume will decrease in importance with age

\section{Evaluation}

There was no evidence found in the literature regarding use value as defined here, for child consumers.

\subsubsection{Functional Value - Quantity}

Quantity of product or size was important to young consumers; they valued larger products ahead of smaller ones. This was an objective consideration related to the size amount or quantity of product received.

Proposition 19: Size will be related to higher perceived functional value for younger children, while for older children's size or quantity will be related to their needs/ wants

\section{Evaluation}

Fox and Kehret-Ward (1990) found that $85 \%$ of ten year olds cited the amount of materials used by the manufacturer as the source of value in a price. They related higher prices to greater material inputs alone. While this reflects the meaning of prices it is related to children perceiving more or larger products to be more valuable. Turner and Brandt (1978) found that with increasing age there was an increase in ability to compute and compare unit prices with age although by eight years of age only $16 \%$ of children possessed the three levels of consumer skills including this level.

\subsubsection{Curiosity/ Novelty Value}

When a product was new or the attribute of being novel was relevant children considered this benefit. Advertising, packaging or social influence was discussed as arousing curiosity. Curiosity or novelty value was found to influence the perceived value of products such as books which have novelty as part of their function or when encountering a new product such as chewing gum or a new flavour of product. However, they usually wanted to have at least heard something about the product before buying it. 
Proposition 20: Novelty/ curiosity value is relevant to children when familiarity is low.

\section{Evaluation}

Marketing which results in curiosity in the target market can lead to product trial (Smith \& Swinyard, 1988) and people will seek to satisfy their curiosity if they have an opportunity to do so (Berlyne, 1954). Arousing curiosity has long been a goal of advertising and marketing and one exposure to an advertisement can be enough to stimulate curiosity.

\section{7. Perceived Costs}

Children perceived value in terms of what they had to give up and this changed over time from simply a relative consideration in relation to their own money to include the comparative and trade off dimensions of the concept. Other costs found in studies with adult consumers relating to on-going monetary costs such as acquisition costs, maintenance costs, disposal costs and other such costs were not found to be relevant to these consumers and the types of products they purchased. The financial costs associated were not really important for younger consumers who considered the price in terms of affordability, although as they got older the cost of using up their money was considered. Monetary costs were not related to time and effort to shop in terms of being willing to pay more to save time or effort. 


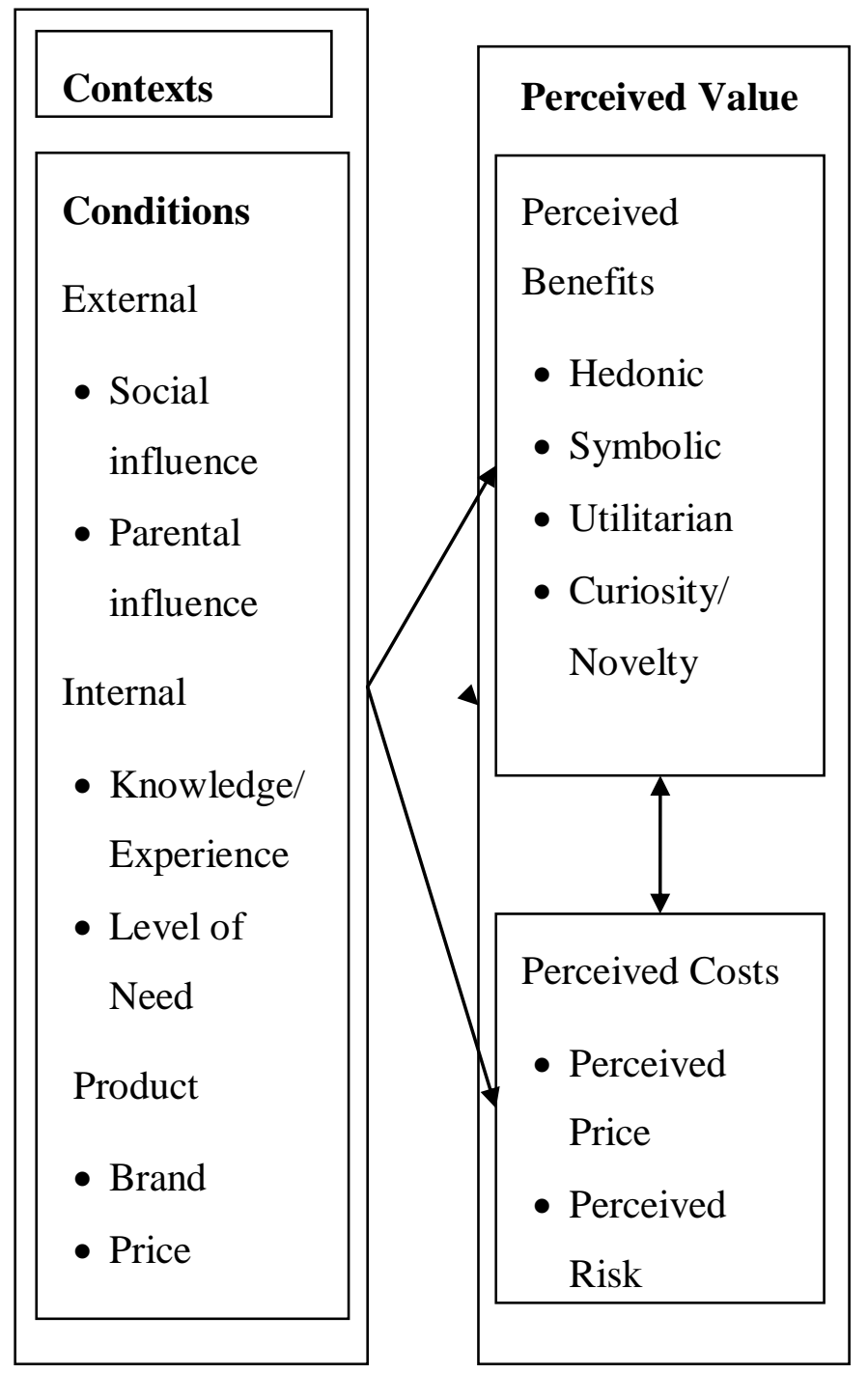

Figure 6-4 Conditions Influencing Perceived Value, Perceived Benefits and Costs

\subsubsection{Perceived Price}

Price perception is used to describe the way consumers translate objective prices in their mind (Lichtenstein, et al., 1988). Price was perceived in terms of affordability initially for the youngest children in the study and then in terms of financial costs. For many of the youngest children value was provided by benefits alone they considered the price separately and one did not impact the other. As children grew older the benefits were considered in terms of worth incorporating dimensions beyond affordability in the costs. They used their knowledge of prices previously paid. There was no evidence to suggest perceived price was a precursor to perceived value. 
The acceptability of the price emerged by eleven years in diaries and nine to ten in the in-depth interviews. Indicating while it was not a top of mind consideration it was definitely considered by nine and ten year olds. Children were aware of the relative size of the price at this stage comparing prices to other similar products. For young children a high or expensive perceived price lead to a decision not to purchase, often they did not have the money to purchase high priced goods. When motivation to purchase was extremely high the children spoke of saving for the item.

Proposition 21a: Perceived benefits will negatively influence perceived price, this influence will increase with age

Proposition 21b: Perceived price will positively influence perceived monetary risk and negatively influence perceived performance risk

\section{Evaluation}

The relationship between price and perceived quality for adult consumers was discussed in the literature review and the fact that researchers have found it difficult to prove a generalised price perceived quality relationship. However, the concept of a range of acceptable prices emerged from this study as a way of capturing an optimum price which is not too high or too low for consumers. This would also capture the change from younger consumers for whom there may not be a price which is too low. There was no evidence to suggest that price was a precursor to value as found for adults in the study by Sweeney, Soutar and Johnson (1999), findings are more aligned with those of Zeithaml (1988), who suggested price is part of the trade-off between benefits and costs.

\subsubsection{Perceived Risk}

Children in the study perceived monetary risks (financial) and product performance related risks. Children did not want to spend all their money and were concerned about wasting money. They also considered whether the product would provide the benefits they sought.

Some marketing academics have asserted that children do not perceive risks. According to Srinivasan (1987) in a discussion of consumer choice and fun aspects of consumption children do not perceive risks. 
It must be noted that this fun aspect of consumption is severely hampered by perceived risk which generates anxiety. Hence the 'fun' aspect of buying is exemplified most in children, who are largely risk-oblivious. Thus risk reduction is often a precondition for 'joy of buying' to operate (Srinivasan, 1987, p. 99).

On this basis the author argued that children would make choices at the affective stage of the Lavidge and Steiner model of cognitive-affective-conative decisions (Lavidge \& Steiner, 1961) with little need to reduce risk through cognitive channels (such as buying the product a friend has bought). However, the current research does not support this assertion, children perceived risks when purchasing and decisions were not usually made on impulse but incorporated consideration of both rational and emotional benefits. What children in the study did not mention were physical risks associated with products. Factors such as the health outcomes of eating unhealthy products were not considered important. They focussed on short term risks such as wasting their money and not enjoying products. This accounts for the lack consideration of the negative implications of consumption behaviours such as playing computer games and eating junk food. The quality of products such as food was not understood.

Most of the seven and eight year olds children did not perceive monetary risks, however one eight year old did discuss the risk of having no money and by nine years they were often mentioning the risk of wasting their money. Product performance risk was mentioned by one of the youngest children in the study and by nine years the monetary and product performance risk were well established concepts influencing children's perceptions of value.

The children reduced perceived risk or avoided risk by asking for information from others or relying on prior knowledge or experience. (This also provided information about utilitarian aspects of products as well as symbolic and hedonic aspects). No evidence emerged that risk was a precursor to value in the current investigation.

As children got older the price seemed to influence the extent to which risks were perceived and utilitarian aspects were considered. Older children had more money and hence the perceived price of products differed. For very young children their 
limited incomes influenced the perceived price and therefore the level of product involvement was usually high.

Proposition 22a: Perceived risk will be a cost influencing perceived value for children

Proposition 22b: Perceived risk will include monetary and performance dimensions

Proposition 22c: Perceived risk will increase in influence on perceived value as children get older

Proposition 22d: Perceived risk will be more important for high involvement decisions for children

Factors which positively influence perceived value also serve to reduce perceived risk.

\section{Evaluation}

No evidence in literature was found regarding perceived risk and children's consumer decision making. However, Sweeny, Soutar and Lester (1999) found that perceived value mediated the relationship between perceived risk and willingness to purchase. The current study supports a relationship between risk and value, however no evidence emerged to support risk as a precursor to value in the context of children's purchasing.

\section{8. Consequences of Perceived Value}

The outcomes related to value perception were purchase and post purchase assessment. The products which children purchased and their post purchase assessment were found to contribute to their experience and future value perception. Figure 6-5 details the overall model on which the propositions are based. 


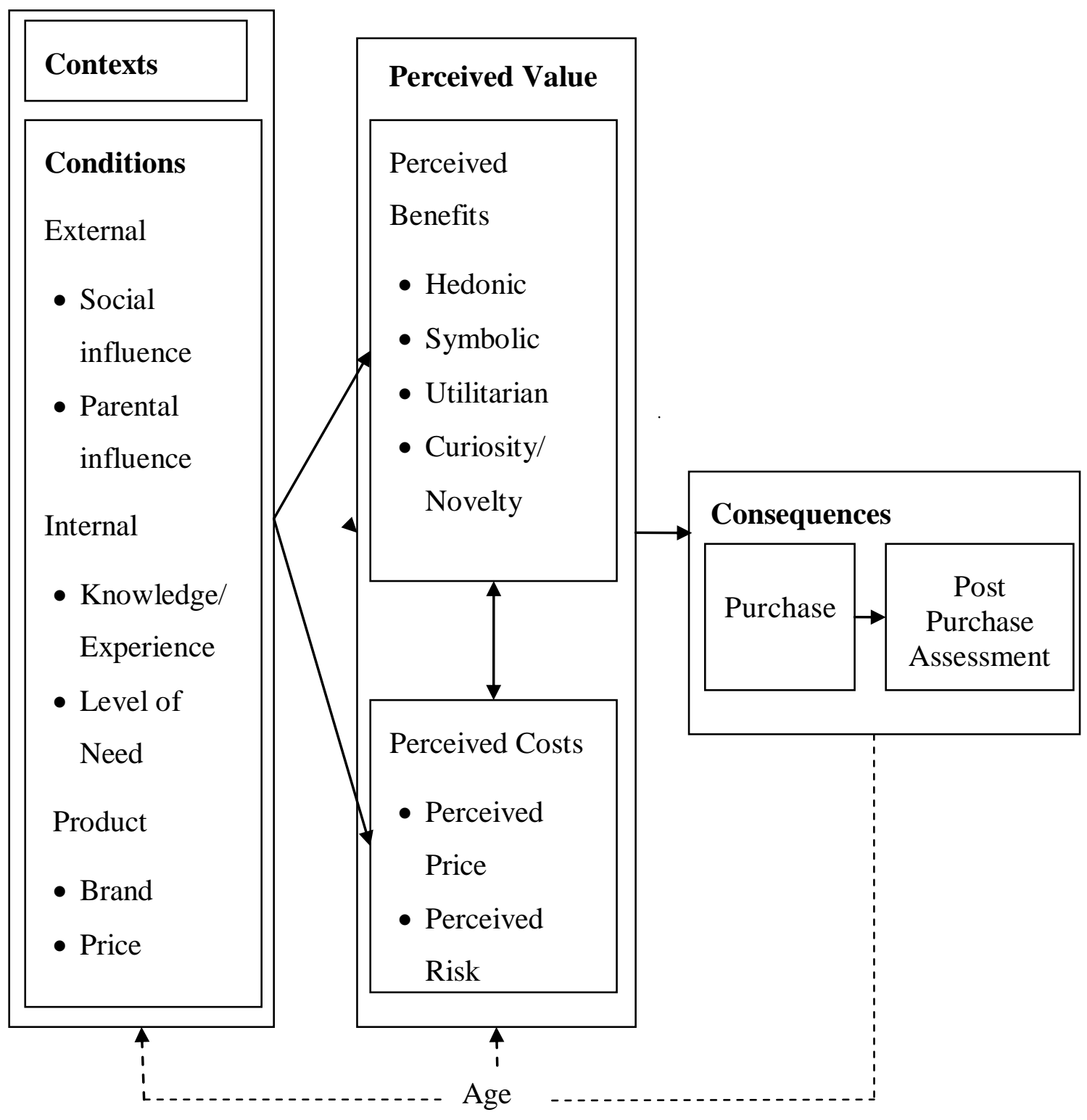

Figure 6-5 Conceptual Model of the Antecedents and Consequences of Perceived Value

\subsubsection{Purchase}

That perceived value leads to purchase has been well established and for children there is no exception. Children have limited money and are seeking to buy the best product for their money. Children chose the best product for the price and while the price changed from being one they could afford to be a trade-off between the perceived benefits and the perceived price, in both situations the perceived value resulted in purchase. Perceived benefits positively influenced purchase while perceived costs negatively influenced purchase behaviour. 
Proposition 23a: High perceived benefits will positively influence value perception and purchase behaviour

Proposition 23b: Acceptable perceived costs will positively influence value perception and purchase behaviour

\section{Evaluation}

This supports previous work in the context of adult consumers that has shown strong positive relationships between value dimensions and purchase intention (Lin et al., 2005) and purchase (Sheth, et al., 1991).

\subsubsection{Post Purchase Assessment}

How children felt after purchase influenced their future decisions. As they grew older they had greater knowledge of products and this was used in subsequent decisions. The extent of satisfaction/ dissatisfaction felt about the purchase also influenced future value perceptions. Children mentioned experience and knowledge impacting future value perception.

\section{Proposition 24: Post purchase assessment will influence future value perception}

\section{Evaluation}

Consumer socialisation theory (John, 1999) and theories of cognitive development (Hatano \& Inagaki, 2000a) acknowledge that the interaction of the child and the environment influences development.

\subsection{Summary}

The two stages of research have provided convergent findings regarding the concept of perceived value. The in-depth interview method revealed more complex value perception at a younger age than suggested by the diary study alone. The combination of qualitative methods allowed the concept to be more fully understood than either method in isolation and limitations associated with single methods were reduced.

The ideas and concepts emerging from the study have been discussed in relation to the existing literature and propositions made. These have been supported where possible with previous research with children. 
This research illustrates the importance of a model of perceived value which incorporates utilitarian as well as hedonic and symbolic benefits as well as curiosity/ novelty value as part of an integrated view of perceived value for children. Children's own purchase decisions were characterised by becoming increasingly complex, high on hedonic, symbolic and utilitarian aspects. When they were using their own money purchases tended not to be assessed on the basis of solely hedonic, symbolic or utilitarian dimensions of value but a combination. In cases of low familiarity, curiosity/ novelty value was important.

A series of propositions have been advanced on the basis of evidence presented in Chapters 5 and 6 and then these have been related to findings regarding children's consumer behaviour as well as cognitive development found in the literature. In this way the findings can be incorporated with those from the extant literature.

Chapter 7 summarises the investigation, the contributions of the research and the associated limitations. Finally directions for future research are identified and conclusions are drawn. 
Chapter 7. Implications and Conclusions 


\subsection{Introduction}

This thesis has presented the results and analysis of a two stage qualitative study utilised to investigate children's perceptions of purchase value. The study sought to define perceived value from a child's perspective and to identify the relevant concepts comprising the value construct in children's consumer decision making. In addition the study investigated age related changes in children's perception of the concept with the objective of developing a theory to describe how children perceive value.

Given these objectives a two stage qualitative research strategy was determined to be the optimal way to achieve this. Creative use of methods involving diaries and indepth interviews provided rich insight into children's thoughts about value in the context of products they were purchasing.

In reviewing the literature it was found that little agreement existed in terms of the nature of perceived value for adult consumers and while scales existed for adults they were unlikely to accurately reflect the concept amongst child consumers. Anecdotal evidence suggested that value was an important concept for children but little work had been carried out in the area. There had also been a call in the literature for research regarding children's value perception. The process of consumer socialisation of children involves a combination of maturation and learning which leads to change in the way they understand concepts and several theories have been advanced in order to explain and predict this change. As such it was necessary to study the concept of interest in an in-depth manner with children. Grounded theory methods provided the optimal method of analysis to use in order to develop theory regarding this concept for children.

To summarise the key findings from this investigation, the nature and meaning of perceived value for children was found. Six unique and generalisable dimensions contributing to the concept were identified. The contexts and conditions of children's shopping varied as they grew older, shaping their value perceptions in terms of the benefits they perceived and the meaning they applied to costs of purchase. Purchase value changed from being about benefits offered by a product and a price which children could afford to more adult-like perception involving trade-off between benefits and costs. 
Conditions influencing perceived value were found to be internal, product-related or external. They were internal to the child in terms of their perceived level of need, their experience with the product or prior knowledge of it, product-related in terms of objective price and brand, or external from parents and peers.

The current study showed that rather than being contradictory, hedonic, symbolic and utilitarian benefits of products are important contributing factors and can be complementary in their contribution to the perceived value of products by children. The ideas from the literature regarding utilitarian and hedonic consumption have been compared to the results of this study and it was concluded that all products had some degree of functional and emotional value contributing to their perceived value for children. Contrary to some views children did not purchase solely on the basis of pleasure without consideration of functional aspects of products.

Emotional and sensory benefits perceived by children remained a constant consideration across the ages investigated in the present study, while the dimensions of functional and social value as well as perceived price and perceived risk varied as children grew older. The functional value of products was evaluated in terms of specific attributes by younger children. This was still the case for older children but became more complex with age as it was related to the quality of the product. Use value was found to change from how long a product would take to consume to how long it would be useful for. Finally the way quantity was considered changed from being assessed solely on size or amount and was related to what you actually wanted or needed. Social value changed from the normative value of 'fitting in' to social groups and the 'approval of others' to incorporate reflection of who children were or 'social self-image'.

The way costs were perceived varied by age. The price was perceived as a cost which limited children's purchase choice in terms of affordability initially then in terms of acceptability and comparison to what other products cost as children got older. Risk was considered by a few younger children but the oldest children commonly discussed risk in monetary, product performance and social terms.

The age related conceptual development shown in the present study is consistent with recent theories of conceptual development and is follows related concepts such as social perspective taking, as well as understanding of economic concepts. 
Findings support Post Piagetian theory of cognitive development. Children's perceptions showed a gradual change with age, based on a combination of understanding, knowledge and experience as well as relevance.

\subsection{Research Contributions}

Contributions have been made on theoretical, empirical and methodological grounds. These will each be discussed and then the practical implications presented.

This study has made several theoretical contributions and built on current knowledge of perceived value and consumer socialisation in marketing in the following ways. The nature of perceived value as it is assessed by children has been revealed, age related changes in the concept have been identified, and key influencing factors as well as changes in the relative influence of these factors have been found. Empirical evidence has been provided to support theoretical assertions.

The concept of perceived value for children from age eight to fourteen years has been found to be most accurately reflected by a multidimensional construct comprised of costs and benefits. This extends the work of other researchers such as Zeithaml (1988), Sheth et al (1991b) and Sweeney and Soutar (2001), to child consumer behaviour. The current study found that within their changing frames of reference (which differ significantly from that of adults), children were quite 'canny' in their purchases from a young age. Certainly evidence was found of rational thought regarding costs and benefits of purchases, from the youngest consumers in the study. In this way the definition of perceived value proposed by Zeithaml (1988) has been extended to the context of children. The nature of benefits considered was found to include both hedonic and utilitarian dimensions and did not support the notion that children are purely hedonic shoppers.

This study has defined the concept of 'perceived value' of products and identified the generalisable dimensions which should be included when measuring this concept with children. These dimensions define the content domain for measurement scales for future quantitative work in this area. This is supported by the work of Rossiter (2002) who presented a critical discussion of current methods in marketing and described a new procedure for scale development. A fundamental part of this proposal was related to the conceptualisation of constructs. The method relies on 
"logical arguments, and the concurrence of experts, based usually on open-ended input from pre-interviews with raters" (Rossiter, 2002, p. 308). The emphasis of this procedure is on content validity which requires comprehensive definition of constructs. Comprehensive definition is also required in the method proposed by Churchill (1979). Of particular relevance here is the demonstrated importance of defining the concept with the rater entity doing the rating. This study provides a definition for the rater entity of 'children'. The dimension, functional value would require product specific attributes to be incorporated, however the study contributes the foundation definitions for future scale development.

The study identified six generalised dimensions of value important for children when purchasing independently which were consistent with adult value perceptions. These include emotional value, functional value, social value, curiosity/ novelty value, risk and price. The way in which these dimensions contributed to value perception was found to change and develop with age and as such the definition of these dimensions of perceived value were modified to incorporate this variation. By comparing existing theory (Sheth, et al., 1991b; Sweeney \& Soutar, 2001) to concepts identified in this study the knowledge in the area is advanced and the change in the conceptual definition of perceived value can be followed. This helps to avoid a proliferation of similar concepts in the area as suggested by Morse (2004) which can lead to confusion for future studies.

The way children considered the dimensions of perceived value was found to change rapidly and to vary markedly with age supporting consumer socialisation theory (John, 1999) and cognitive developmental theory (Hatano \& Inagaki, 2000b). The changes in the contexts in which children purchased and the conditions influencing their purchases influenced changes in the value dimensions considered. Findings support the use of grounded theory methodology in the study of consumer socialisation of children and their conceptual understanding. Specifically the dimensions of functional value, emotional value, social value and the way they considered brand and price showed the most variation.

While children were found to focus on shorter term outcomes when they started independent purchasing they incorporated longer term implications as they matured and gained experience as consumers. Sensory response had a heightened impact relative to more rational attributes of products for younger children. Functional 
dimensions were still important, they were however, less likely to relate to long term implications associated with purchases for the youngest consumers. Of particular importance in terms of functional value is the evidence regarding quality. Children changed from focusing on specific attributes at younger ages to combining these in terms of a more abstract conceptualisation of quality between eleven and thirteen years, for the majority of children.

Social factors were influential from a young age, particularly peers. Initially friends were important sources of information about products and products were valued that would enhance one's social acceptance, but as children grew older, social meaning and its relation to their self-concept was incorporated. Branding played a central role in children's perceptions of value even from the time of their first purchases. While they were largely unaware of the concept in terms of 'brand meaning', eight, nine and ten year olds used brands as product identifiers. Brands conferred deeper meanings about benefits for older children by eleven to twelve years which extends the work on brand meaning for children (Achenreiner \& John, 2003) into the area of their value perception.

This study contributes a grounded theory for children's value perception. This theory consists a set of empirically based propositions relating the contexts in which the children shopped, conditions impacting the value they perceived and consequences relating to perceived value and a conceptual model detailing perceived value for children incorporating age related influence.

This study contributes evidence to support an integrated approach to children's developing knowledge of marketing concepts incorporating cognitive developmental and external influences as important influencing factors on consumer concepts. The theoretical support may be important for other marketing concepts, clearly before adopting instruments and marketing theory to study children qualitative research is necessary to identify subtle changes and differences in conceptual meaning as children grow.

The methodological approach used in this study has not been found in the literature regarding consumer behaviour of children. This study utilised two methods of data collection, diaries and in-depth interviews and qualitative analysis following grounded theory methodology. The approach adopted also responds to the call for 
child centred research (Banister \& Booth, 2005) in which children are conceptualised as knowing and acting people (Cook, 2009). By combining the two methods problems associated with interviewing children by adults were reduced (Graue \& Walsh, 1998). The diary method was found to be useful for capturing top of mind thoughts, sensations and feelings with high temporal validity which could be elaborated upon using the in-depth interviews. The use of the diary in isolation would not have provided the depth of understanding obtained from using the combination of methods in the context of children's consumer behaviour.

\subsection{Implications for Practitioners}

Children represent an increasingly important market for companies and those that market products for this consumer group (Light, 2004).

The model advanced in the present study of children's perceived value provides a useful guideline to marketing practitioners in terms of the benefits that are relevant for children as well as the costs. They will be able to provide products which offer relevant benefits and highlight these benefits in their marketing to children.

The age related model can help practitioners provide market offerings which are successful for the children's market and which target their desired age within the market segment. Specifically the study found that both hedonic as well as utilitarian benefits of products were important to children of all ages. As mentioned earlier children were more capable of rational value consideration than previously thought. As such marketers should highlight not only the enjoyment or pleasure children get from their products but also the functional value that products provide. They should provide products with sufficient quality and performance so as to meet the children's approval. This study showed that by seven to eight years old children were aware of and considered the performance of products to be important. They have choice and will optimise the value they get for their small incomes. Marketers should produce products for children that possess relevant functional attributes (which marketers should research during product development) such as movable parts or containing figures for toys, or being collectable. Products targeted at this age group which are large or contain many items in the pack are more likely to be considered valuable. Food products which last a long time are considered to provide better value than those which are quickly consumed. The use value is also important to children and 
items with a one off use are not valued as highly as those which can be used for a longer time or many times.

Importantly for very young children in the study (7-8 years) the price only represented sacrifice and was not traded off against what they were getting. It was considered in absolute terms relative to the amount of money they had to spend. On this basis, marketers targeting consumers in this age group need to remain up to date on the amount of pocket money and other sources of money these children have so as to price their products within the child's budget. For these youngest consumers there was no evidence of a price which was too low. For older children however, the concept of an 'acceptable price' for the product was found with children considering perceived benefits in relation to perceived costs. This was emerging between nine and ten years of age. Marketers need to consider the price in combination with the product and comparative offerings in the market to ensure this is reflected in their offering.

Children of all ages in the study considered how much they liked products and the pleasurable response they would have to products they purchased. As such marketers must ensure that the consumption of the products they produce for this market, are superior in terms of emotional response. This can be achieved through aesthetics or sensory pleasure aroused which can be combined with superior functional performance.

This study also identifies important influence factors which can be taken into account by marketing practitioners. Parents influenced children's purchase decisions across all ages. Parental approval was found to be necessary to secure the sale, for younger children in particular. For older children products could be differentiated in terms of involvement and parents were found to be more influential for high involvement decisions for this age group. As such marketers should aim to provide value to the children but additionally consider parental approval.

Social value was critical and children were influenced by what their reference groups had or liked reflecting their desire to fit in or impress their friends. As they got older (13 -14 in the current study) the development of consideration of social self-image was emerging and the reflection of who they are related to products and brands. Brand extensions may be useful for new products in order to build on existing 
knowledge amongst children. Association with familiar and popular characters or figures is also likely to enhance both social value and emotional value of products.

Direct experience was found to be an important influence on value perception for children. As such marketing efforts which lead to trial of products will influence the value of those products for children. Products parents buy initially for the children were known, resulting in enhanced perceived value and reduced perceived risk. If children didn't have direct experience of a product then prior knowledge was highlighted as important to these children. Prior knowledge can be facilitated by marketers through the use of advertising, word of mouth strategies as well as by association with familiar and popular characters or figures.

\subsection{Implications for Policy}

Young children aged seven to eight years, did not perceive price in terms of a tradeoff between benefits and costs. They focussed on the benefits they perceived and the monetary cost in terms of whether they could afford the item. The benefits they considered related to product function in terms of specific attributes, use and quantity. They did not perceive quality in adult terms. Their emotional response to the product in terms of liking the product, pleasure associated with owning or using it and sensory performance was paramount. On this basis young children may be at risk of being sold low quality products. This is particularly important regarding food as young children will purchase unhealthy foods if they like them and associate them with sensory pleasure when shopping independently. It is also of concern regarding toys or games which may have health and safety implications. Regulations exist regarding food safety generally and product safety for children however, greater protection is advocated for child focussed products targeted at older children up to at least eight years. Warnings and age recommendations on packaging are useful measures in addition minimum quality standards would be useful. Regulation around pricing and the availability of unhealthy items in situations where parental influence is unavailable such as schools is also recommended.

Government regulation regarding food quality for products targeted at children would be beneficial. A health and or safety symbol specifically designed for children (similar to the healthy food tick) may assist them in identifying quality products. Also the association of products with familiar and popular characters will enhance 
young children's value perception and as such requirements for association could be regulated.

The research has highlighted the influence of previous experience or prior knowledge on children's value perception. Funding for educational programs to educate parents about healthy eating for children is recommended. In this way children would be exposed to 'good' products and healthy options by their parents leading to higher perceived value for such items over inferior alternatives.

Also the importance of parents in shaping children's consumer knowledge and teaching economic concepts will help them to develop a better understanding of value and help protect them from being sold low value items. In this way parents can gradually hand over the responsibility to the children as they understand and learn about acceptable prices and product quality both immediately and longer term. In addition opportunity exists for schools to help improve children's ability to understand some of the concepts which were not incorporated into value perception until later such as quality and risk. Investing money in consumer education both within the education system and through marketing campaigns to providing strategies for parents to use with their children is recommended.

\subsection{Limitations of the Study}

As with all research endeavours, there were limitations associated with the current study. There were some which applied to the overall study and some specific to each of the two stages.

The study used qualitative methods and as such focused on "naturally occurring, ordinary events in natural settings" (Miles \& Huberman, 1994, p. 10). Findings are detailed and descriptive, situated in contexts and as such may not be generalised to other contexts without further research. By limiting the study to schools in communities with higher socioeconomic status, the findings are limited to this group. By conducting further research on the proposed model and propositions, the applicability of the results to other socioeconomic groups could be tested.

Researching children carries with it a number of restrictions related to access and leading to limitations in terms of research design. Both studies required both school and parental consent for the child to participate and as such suffered low consent 
rates. Children participating were limited to those who were both willing to participate and those whose parents had consented. In addition to this restricted access to children meant strict adherence to grounded theory methods of data collection had to be adapted meet these requirements. Interviewing had to be carried out in small batches and only those for whom consent had be obtained could be interviewed.

Both studies were cross sectional providing a one off picture of the phenomena for each respondent. Longitudinal investigation of children's understanding over time would provide insight into the conceptual change within each child as they developed.

The requirement for written response in the diaries meant that children needed to be able to articulate and write responses to open-ended questions. Girls were more likely to complete the diaries using this response format than boys resulting in a gender biased sample for the diary study. Secondly diaries only access explicit knowledge and thoughts and it is accepted that children's knowledge is sometimes implicit. These limitations were overcome to some extent by following the initial diary investigation with an in-depth interview procedure which provided for verbal response and resulted in a gender balanced sample. This method allowed probing for detail and contradictory or confusing responses to be followed up. If knowledge is implicit it may however, not be accessible via either verbal or written formats.

There was no researcher intervention other than distributing and collecting the diaries reducing the chance of bias relating to the researcher in responses for the diary study. This bias was managed in the interviews by getting to know the respondents prior to the interviews reducing the children's perceptions of the researcher as a teacher and developing rapport with respondents. Additionally keeping questions open-ended and initially broad, the researcher tried to ensure children's responses were not lead.

\subsection{Future Research}

The proposed conceptual model and resulting propositions have several implications for future research. Clearly the most obvious direction for future research would be confirmation of the proposed theory and testing of the theoretical relationships. This 
could be done by replication, conducting studies with other demographic samples such as different socioeconomic groups and ethnicities to determine the influence of these factors on the development of the concept of value. Such work may lead to confirmation or extension of the grounded theory.

While grounded theory methods do not always require quantitative support (Corbin \& Strauss, 2008), for a broadly applicable concept such as perceived value, quantitative testing of some of the propositions would be desirable. Such research would increase the generalisability of the findings. The results suggest that the existing scales for measurement of perceived value with adults would not have been sensitive to the differences found in children's perceived value as they got older. In addition while the broadly defined dimensions were found to be relevant, the specific measures were not. Children's words and meanings should be used. This study has identified concepts, conceptual meanings and six conceptually important dimensions which could be utilised to develop a measurement instrument allowing quantitative measurement of perceived value with children. For example based on the findings of this work, for the rater entity of children using the following seven items would capture the content of social value for children.

- This is a product I would recommend to friends

- This is a product I would tell friends about

- This is a product I would use with friends

- This is a product I would share with friends

- This is a product that would help me fit in/ be liked

- This is a product my friends will like/think is cool

- This is a product which suits who I am

The development of a generalisable measure of children's perceptions of value based on these findings would be a worthy area of future research.

Propositions have been made about relationships between the variables identified in the study and these relationships could be empirically tested. Experimental procedures would offer a method of manipulating variables such as price, brand, 
social influence, knowledge and level of motivation on the perceived value of child focussed products.

\subsection{Concluding Remarks}

Children are an increasingly important consumer group. They are experiencing a changing world in terms of technological advances and have been characterised as the instant gratification generation. They have increasing incomes and autonomy to spend and as such they require skills to participate in the consumer environment. The marked and rapid change in conceptual understanding mean that marketers need knowledge of children's conceptual understanding at different ages so they can produce and market products to this group in an ethical and effective manner.

This research has enhanced our understanding of children as consumers by providing an in-depth description of their value perceptions when purchasing across the age range of eight to fourteen years. As such this research has addressed the gap identified by John (1999) in her extensive review of the literature regarding the consumer socialisation of children. At this time the lack of understanding of this concept in the area of child consumer behaviour was highlighted.

Clearly children's value perception can only be understood through the many dimensions of which it is comprised. Consideration of the changing contexts in which they purchase, as well as influencing factors involved and their understanding at different ages, will help marketing to children be more effective and ensure they are not exploited.

Many possibilities for exciting research into key influencing factors on children's perceived value have been highlighted. In the changing consumer environment in which our children are growing, this is likely to be an increasingly popular area. 


\section{References}

Achenreiner, G. B., \& John, D. R. (2003). The meaning of brand names to children: A developmental investigation. Journal of Consumer Psychology, 13(3), 205219.

Agarwal, S., \& Teas, R. K. (2001). Perceived value: Mediating role of perceived risk. Journal of Marketing Theory and Practice, 9(4), 1-14.

Agarwal, S., \& Teas, R. K. (2002). Cross-national applicability of a perceived quality model. The Journal of Product and Brand Management, 11(4/5), 213 226.

Agarwal, S., \& Teas, R. K. (2004). Cross-national applicability of a perceived riskvalue model. The Journal of Product and Brand Management, 13(4/5), 242256.

Alderson, P. (2001). Research by children: Rights and methods. International Journal of Social Research Methodology: Theory and Practice, 4(2), 139153.

AMA. (2011). Dictionary. Retrieved 06/26/2011, 2011, from http://www.marketingpower.com/_layouts/Dictionary.aspx?dLetter=B

Andronikidis, A. I., \& Lambrianidou, M. (2010). Children's understanding of television advertising: A grounded theory approach. Psychology \& Marketing, 27(4), 299-322.

Annells, M. (1996). Grounded theory method: Philosophical perspectives, paradigm of inquiry, and postmodernism. Qualitative Health Research, 6(3), 379-393.

Anonymous. (2005, Jul 21). Insight - child consumerism: First of the little big spenders. Marketing Week, 32.

Arnold, \& Reynolds. (2003). Hedonic shopping motivations. Journal of Retailing, 79(2), 77-95.

Auty, S., \& Elliot, R. (2001). Being like or being liked: Identity vs. social approval in a social context. Advances in Consumer Research, 28, 235-241.

Babin, B. J., Darden, W. R., \& Griffin, M. (1994). Work and/or fun: Measuring hedonic and utilitarian shopping. Journal of Consumer Research, 20(4), 644656. 
Bahn, K. D. (1986). How and when do brand perceptions and preferences first form? A cognitive developmental investigation. Journal of Consumer Research, 13(3), 382-393.

Bandura, A. (1977). Social learning theory. New Jersey: Englewood Cliffs.

Banister, E. N., \& Booth, G. J. (2005). Exploring innovative methodologies for child-centric consumer research. Qualitative Market Research, 8(2), 157-175.

Barenboim, C. (1981). The development of person perception in childhood and adolescence: From behavioral comparisons to psychological constructs to psychological comparisons. Child Development, 52(1), 129-144.

Bartholomew, A., \& O'Donohue, S. (2003). Everything under control: A child's eye view of advertising. Journal of Marketing Management, 19, 443-457.

Bauer, H. H., Sauer, N. E., \& Becker, C. (2005). Investigating the relationship between product involvement and consumer decision-making styles. Journal of Consumer Behaviour, 5(4), 342-354.

Bearden, W. O., \& Etzel, M. J. (1982). Reference group influence on product and brand purchase decisions. Journal of Consumer Research, 9(2), 183-194.

Bearden, W. O., Netemeyer, R. G., \& Teel, J. O. (1989). Measurement of consumer susceptibility to interpersonal influence. Journal of Consumer Research, 15(4), 473-481.

Belch, G., \& Belch, M. (2004). Advertising and promotion: An integrated marketing communications perspective. New York: McGraw Hill.

Belk, R., Ger, G., \& Askegaard, S. (2003). The fire of desire: A multisited inquiry into consumer passion. Journal of Consumer Research, 30(3), 326-351.

Belk, R., Mayer, R., \& Driscoll, A. (1984). Children's recognition of consumption symbolism in children's products. Journal of Consumer Research, 10(4), 386-397.

Berlyne, D. E. (1954). A theory of human curiosity. British Journal of Psychology, $45,180-191$.

Berridge, K. C., \& Kringelbach, M. L. (2008). Affective neuroscience of pleasure: Reward in humans and animals. Psychopharmacology, 199, 457-480.

Berti, A., \& Bombi, A. (1988). The child's construction of economics (G. Duveen, Trans.). New York: Cambridge University Press. 
Biswas, A., \& Sherrell, D. L. (1993). The influence of product knowledge and brand name on internal price standards and confidence. Psychology \& Marketing, 10(1), 31-46.

Bjorklund, D. F. (1995). Children's thinking: Developmental function and individual differences (2nd ed.). Pacific Grove, California: Brooks/Cole.

Bolger, N., Davis, A., \& Rafaeli, E. (2003). Diary methods: Capturing life as it is lived. Annual Review of Psychology, 54, 579-616.

Bradley, R., \& Corwyn, R. (2002). Socioeconomic status and child development. Annual Review of Psychology, 53(1), 371-399.

Brannen, J. (2005). Mixing methods: The entry of qualitative and quantitative approaches into the research process. International Journal of Social Research Methodology, 8(3), 173-184.

Briesch, R. A., Krishnamurthi, L., Mazumdar, T., \& Raj, S. P. (1997). A comparative analysis of reference price models. Journal of Consumer Research, 24(2), 202.

Brucks, M., Zeithaml, V. A., \& Naylor, G. (2000). Price and brand name as indicators of quality dimensions for consumer durables. Academy of Marketing Science. Journal, 28(3), 359-374.

Burris, V. (1983). Stages in the development of economic concepts. Human Relations, 36(9), 791-812.

Bush, A. J., Smith, R., \& Martin, C. (1999). The influence of consumer socialization variables on attitude toward advertising: A comparison of African-Americans and Caucasians. Journal of Advertising, 28(3), 13-24.

Cabanac, M. (1979). Sensory pleasure. The Quarterly Review of Biology, 54(1), 129.

Capon, N., \& Kuhn, D. (1980). A developmental study of consumer informationprocessing strategies. Journal of Consumer Research, 7(3), 225-233.

Capon, N., \& Kuhn, D. (1982). Can consumers calculate best buys? Journal of Consumer Research, 8(4), 449-453.

Carson, D., Gilmore, A., Perry, C., \& Gronhaug, K. (2001). Qualitative marketing research. London: Sage Publications Inc. 
Caruana, A., \& Vassallo, R. (2003). Children's perception of their influence over purchases: The role of parental communication patterns. The Journal of Consumer Marketing, 20(1), 55-66.

Case, R. (1992). The minds staircase: exploring the conceptual underpinnings of children's thought and knowledge. Hillsdale, New Jersey: Erlbaum.

Chang, T.-Z., \& Wildt, A. R. (1994). Price, product information, and purchase intention: An empirical study. Academy of Marketing Science. Journal, 22(1), 16-27.

Chaplin, L. N., \& John, D. R. (2005). The development of self-brand connections in children and adolescents. Journal of Consumer Research, 32(1), 119-129.

Chitturi, R., Raghunathan, R., \& Mahajan, V. (2008). Delight by design: The role of hedonic versus utilitarian benefits. Journal of Marketing, 72(3), 48-63.

Chung, J., Yu, J., \& Pysarchik, D. (2006). Cue utilization to assess food product quality: A comparison of consumers and retailers in India. The International Review of Retail, Distribution and Consumer Research, 16(2), 199-214.

Churchill, G. A., Jr. (1979). A paradigm for developing better measures of marketing constructs. Journal of Marketing Research, 16(1), 64-73.

Cook, D. T. (2009). Knowing the child consumer: historical and conceptual insights on qualitative children's consumer research. Young Consumers, 10(4), 269282.

Corbin, J., \& Strauss, A. (2008). Basics of qualitative research (3 ed.). Thousand Oaks, California: Sage Publications, Inc.

Crain, W. (2000). Theories of development: Concepts and applications (4th ed.). Upper Saddle River, New Jersey: Prentice Hall.

Creswell, J. W. (2003). Research design (2 ed.). Thousand Oaks, California: Sage Publications.

Darbyshire, P., MacDougall, C., \& Schiller, W. (2005). Multiple methods in qualitative research with children: more insight or just more? Qualitative Research, 5(4), 417-436.

Denzin, N. K., \& Lincoln, Y. S. (1998). Introduction: Entering the field of qualitative research. In N. K. Denzin \& Y. S. Lincoln (Eds.), Strategies of Qualitative Inquiry. Thousand Oaks, California: Sage Publications Inc. 
Denzin, N. K., \& Lincoln, Y. S. (2005a). Introduction: The discipline and practice of qualitative research. In N. K. Denzin \& Y. S. Lincoln (Eds.), The Sage handbook of qualitative research (3rd ed., pp. 1-32). Thousand Oaks, California: Sage Publications Inc.

Denzin, N. K., \& Lincoln, Y. S. (Eds.). (2005b). The Sage handbook of qualitative research (3 ed.). Thousand Oaks, California: Sage Publications Inc.

Deshpande, R. (1983). "Paradigms lost": On theory and method in research in marketing. The Journal of Marketing, 47(4), 101-110.

Dickson, P. R., \& Sawyer, A. G. (1990). The price knowledge and search of supermarket shoppers. Journal of Marketing, 54(3), 42-51.

Dodds, W. B. (2003). Managing customer value. Lanham: University Press of America.

Dodds, W. B., Monroe, K. B., \& Grewal, D. (1991). Effects of price, brand, and store information on buyers' product evaluations. Journal of Marketing Research, 28(3), 307-319.

Dotson, M. J., \& Hyatt, E. M. (2005). Major influence factors in children's consumer socialization. The Journal of Consumer Marketing, 22(1), 35-42.

Drake-Bridges, E., \& Burgess, B. (2010). Personal preferences of tween shoppers. Journal of Fashion Marketing and Management, 14(4), 624-633.

Erickson, L.-M. (2003). The development of price knowledge among young consumers: A socialization perspective. Unpublished Doctor of Philosophy, New York University, Graduate School of Business Administration, United States, New York.

Flavell, J., Miller, P. H., \& Miller, S. A. (1993). Cognitive development (3rd ed.). Englewood Cliffs: Prentice Hall.

Fox, K. F., \& Kehret-Ward, T. (1985). Theories of value and understanding of price: A developmental perspective. Advances in Consumer Research(12), 79-84.

Fox, K. F., \& Kehret-Ward, T. (1990). Naive theories of price: A developmental model. Psychology \& Marketing 7(4), 311-329.

French, S. A. (2003). Pricing effects on food choices. The Journal of Nutrition, 133(3), 841-843.

Gabor, A. (1977). Pricing: Principles and practice. London: Heinemann Educational Books. 
Gabora, L., Rosch, E., \& Aerts, D. (2008). Toward an ecological theory of concepts. Ecological Psychology, 20, 84-116.

Gardner, D. M. (1971). Is there a generalized price-quality relationship? Journal of Marketing Research, 8(2), 241-243.

Gelman, R., \& Baillargeon, R. (1983). A review of Piagetian concepts. In P. H. Mussen (Ed.), Handbook of child psychology. Cognitive development (Vol. 3). New York: Wiley.

Gerstner, E. (1985). Do higher prices signal higher quality? Journal of Marketing Research, 22(2), 209-215.

Gilbert, D. T., Fiske, S. T., \& Lindzey, G. (1998). The handbook of social psychology (4th ed. Vol. 1). New York: The McGraw-Hill Companies, Inc.

Gilly, M. C., \& Gelb, B. D. (1982). Post-purchase consumer processs and the complaining consumer. Journal of Consumer Research, 6, 305-308.

Glaser, B. (1978). Theoretical sensitivity. Mill Valley, California: Sociology Press.

Glaser, B., \& Strauss, A. (1967). The discovery of grounded theory: Strategies for qualitative research. Chicago: Aldine Publishing Company.

Gollop, M. M. (2000). Interviewing children: a research perspective. In A. B. Smith, N. J. Taylor \& M. M. Gollop (Eds.), Children's voices (pp. 18-36). Auckland: Pearson Education New Zealand Limited.

Graue, M. E., \& Walsh, D. J. (1998). Studying children in context: Theories methods and ethics. Thousand Oaks, California: Sage Publications.

Grover, S. (2004). Why won't they listen to us? On giving power and voice to children participating in social research. Childhood, 11(1), 81-93.

Guba, E. G., \& Lincoln, Y. S. (2005). Paradigmatic controversies, contradictions, and emerging confluences. In N. K. Denzin \& Y. S. Lincoln (Eds.), The Sage handbook of qualitative research (3rd ed., pp. 191-215). Thousand Oaks, California: Sage Publications Inc.

Haley, R. I. (1968). Benefit segmentation: A decision-oriented research tool. Journal of Marketing, 32(3), 30-35.

Hansen, T. (2005). Perspectives on consumer decision making: An integrated approach. Journal of Consumer Behaviour, 4(6), 420-437. 
Hatano, G., \& Inagaki, K. (2000a). Domain-specific constraints of conceptual development. International Journal of Behavioural Development, 24(3), 267275.

Hatano, G., \& Inagaki, K. (2000b). Knowledge acquisition and use in higher-order cognition. In K. Pawlik \& M. R. Rosenzweig (Eds.), The international handbook of psychology (pp. 167-190). London: Sage Publications Ltd.

Haynes, J. L., Burts, D. C., Dukes, A., \& Cloud, R. (1993). Consumer socialization of preschoolers and kindergartners as related to clothing consumption. Psychology \& Marketing, 10(2), 151-166.

Hite, C. F., \& Hite, R. E. (1995). Reliance on brand by young children. Journal of the Market Research Society, 37(2), 185-193.

Holbrook, M. B., Chestnut, R. W., Oliva, T. A., \& Greenleaf, E. A. (1984). Play as a consumption experience: The roles of emotions, performance, and personality in the enjoyment of games. Journal of Consumer Research, 11(2), 728-739.

Holbrook, M. B., \& Hirschman, E. C. (1982). The experiential aspects of consumption: Consumer fantasies, feelings, and fun. Journal of Consumer Research, 9(2), 132-140.

Howard, J. A., \& Sheth, J. N. (1969). The theory of buyer behaviour. New York: Wiley.

Hunleth, J. (2011). Beyond on or with: Questioning power dynamics and knowledge production in 'child-oriented' research methodology. Childhood, 18(1), 81-93.

Jarvis, C., MacKenzie, S., \& Podsakoff, P. (2003). A critical review of construct indicators and measurement model misspecification in marketing and consumer research. Journal of Consumer Research, 30(2), 199-218.

John, D. R. (1999). Consumer socialization of children: A retrospective look at twenty-five years of research. Journal of Consumer Research, 26(3), 183213.

John, D. R., \& Sujan, M. (1990a). Age differences in product categorization. Journal of Consumer Research, 16(4), 452-460.

John, D. R., \& Sujan, M. (1990b). Children's use of perceptual cues in product categorization. Psychology \& Marketing, 7(4), 277-294. 
John, D. R., \& Whitney, J. C. (1986). The development of consumer knowledge in children: A cognitive structure approach. Journal of Consumer Research 12(4), 406-417.

Johnson, E. J., \& Russo, J. E. (1984). Product familiarity and learning new information. Journal of Consumer Research 11(1), 542-550.

Kalyanaram, G., \& Little, J. D. C. (1994). An empirical analysis of latitude of price acceptance in consumer packaged goods. Journal of Consumer Research, $21(3), 408-418$.

Kehret-Ward, T., \& Yalch, R. (1984). To take or not to take the only one: Effects of changing the meaning of a product attribute on choice behavior. Journal of Consumer Research, 10(4), 410-416.

Keller, H. (2000). Developmental psychology I: Prenatal to adolescence. In K. Pawlik \& M. R. Rosenzweig (Eds.), The international handbook of psychology (pp. 235-261). London: Sage Publications Ltd.

Kivetz, R., \& Simonson, I. (2002). Earning the right to indulge: Effort as a determinant of customer preferences toward frequency program rewards. Journal of Marketing Research, 39(2), 155-170.

Kortesluoma, R. L., Hentinen, M., \& Nikkonen, M. (2003). Conducting a qualitative child interview: Methodological considerations. Journal of Advanced Nursing, 42(5), 434-441.

Lavidge, R. J., \& Steiner, G. A. (1961). A model for predictive measurements of advertising effectiveness. Journal of Marketing, 25, 59-62.

Lawson, R., \& Bhagat, P. S. (2002). The role of price knowledge in consumer product knowledge structures. Psychology \& Marketing, 19(6), 551-568.

Leavitt, H. J. (1954). A note on some experimental findings about the meanings of price. The Journal of Business (pre-1986), 27(3), 205-210.

Li, M., \& Green, R. (2011). A mediating influence on customer loyalty: The role of perceived value. Journal of Management and Marketing Research, 7, 1-12.

Lichtenstein, D. R., Bloch, P. H., \& Black, W. C. (1988). Correlates of price acceptability. Journal of Consumer Research, 15(2), 243-252.

Lichtenstein, D. R., Ridgway, N. M., \& Netemeyer, R. G. (1993). Price perceptions and consumer shopping behavior: A field study. Journal of Marketing Research, 30(2), 234-245. 
Light, E. (2004, April). Tween scene. New Zealand Retail, 28-31.

Lin, C., Sher, P. J., \& Shih, H. (2005). Past progress and future directions in conceptualizing customer perceived value. International Journal of Service Industry Management, 16(4), 318-336.

Lindstrom, M. (2003). Brandchild. London and Sterling: Kogan Page.

Lunt, P., \& Furnham, A. (1996). Economic socialization. Cheltenham: Edward Elgar Publishing Limited.

Mahon, A., Glendinning, C., Clarke, K., \& Craig, G. (1996). Researching children: Methods and ethics. Children and Society, 10(2), 145-154.

Marshall, C., \& Rossman, G. B. (2006). Designing qualitative research (4th ed.). Thousand Oaks: Sage Publications Inc.

Martensen, A., \& Tufte, B. (2002). Children - consumption, advertising and media. In F. Hansen, Rasmussen, J., Martensen, A., Tufte, B. (Ed.), Children consumption, advertising and media (pp. 9-23). Denmark: Copenhagen Business School Press.

Marx, M. H., \& Henderson, B. B. (1996). A fuzzy trace analysis of categorical inferences and instantial associations as a function of retention interval. Cognitive Development, 11, 551-569.

McConnell, D. J. (1970). The alphabet and price as independent variables: A note on the price: quality question. The Journal of Business, 43(4), 448-451.

McNeal, J. U. (1987). Children as consumers. Massachusetts Toronto: Lexington Books.

McNeal, J. U. (1992). Kids as customers. Massachusetts Toronto: Lexington Books.

McNeal, J. U. (1999). The kids market: Myths and realities. New York: Paramount Market Publishing Inc.

McNeal, J. U. (2007). On becoming a consumer: Development of consumer behaviour patterns of childhood. Burlington: Elsevier.

McNeal, J. U., \& Ji, M. F. (1999). Chinese children as consumers: an analysis of their new product information sources. The Journal of Consumer Marketing, 16(4), 345-364.

Miles, M. B., \& Huberman, A. M. (1994). Qualitative data analysis. An expanded sourcebook (2nd ed.). Thousand Oaks, California: Sage Publications Inc. 
Miller, P. H. (1993). Theories of developmental psychology (3rd ed.). New York: W. H. Freeman and Company.

Miyazaki, A. D., Grewal, D., \& Goodstein, R. C. (2005). The effect of multiple extrinsic cues on quality perceptions: A matter of consistency. Journal of Consumer Research, 32(1), 146-153.

Monroe, K. B. (1973). Buyers' subjective perceptions of price. Journal of Marketing Research, 10(1), 70-80.

Monroe, K. B. (1979). Pricing: Making profitable decisions. New York: McGrawHill.

Monroe, K. B. (2003). Pricing: Making profitable decisions (3rd ed.). New York: McGraw-Hill/Irwin.

Monroe, K. B., \& Krishnan, R. (1985). The effect of price on subjective product evaluations. In J. Jacoby \& J. Olson (Eds.), Perceived quality (pp. 209-232). Lexington: Lexington Books.

Monroe, K. B., \& Lee, A. Y. (1999). Remembering versus knowing: Issues in buyers' processing of price information. Academy of Marketing Science, 27(2), 207-225.

Moore, E. S., \& Lutz, R. J. (2000). Children, advertising, and product experiences: A multimethod inquiry. Journal of Consumer Research, 27(1), 31-48.

Moore, R. L., \& Stephens, L. F. (1975). Some communication and demographic determinants of adolescent consumer learning. Journal of Consumer Research, 2(2), 80-92.

Morris, C. G., \& Maisto, A. A. (2002). Psychology: An introduction (11th ed.). New Jersey: Prentice Hall.

Morse, J. M. (2004). Constructing qualitatively derived theory: Concept construction and concept typologies. Qualitative Health Research, 14(10), 1387-1395.

Moschis, G. P., \& Churchill, G. A., Jr. (1978). Consumer socialization: A theoretical and empirical analysis. Journal of Marketing Research, 15(4), 599-609.

Moschis, G. P., \& Churchill, G. A., Jr. (1979). An analysis of the adolescent consumer. Journal of Marketing, 43(3), 40-48.

Moschis, G. P., \& Moore, R. L. (1979). Decision making among the young: A socialization perspective. Journal of Consumer Research, 6(2), 101-112. 
Nguyen, L., T. (2003). Growing up in a material world: An investigation of the development of materialism in children and adolescents. Unpublished Doctor of Philosophy, University of Minnesota, Minnesota.

Otnes, C., Kim, Y. C., \& Kim, K. (1994). All I want for Christmas: An analysis of children's brand requests to Santa Claus. Journal of Popular Culture, 27(4), 183-194.

Park, W. C., \& Lessig, P. V. (1977). Students and housewives: Differences in susceptibility to reference group influence. Journal of Consumer Research 5(4), 102-110.

Patton, M. Q. (2002). Qualitative research and evaluation methods (3 ed.). Thousand Oaks, California: Sage Publications, Inc.

Pecheux, C., \& Derbaix, C. (1999). Children and attitude toward the brand: A new measurement scale. Journal of Advertising Research, 39(4), 19-27.

Peterson, R. A., \& Wilson, W. R. (1985). Perceived risk and price-reliance schema as price-perceived-quality mediators. In J. Jacoby \& J. Olson (Eds.), Perceived quality (pp. 247-267). Lexington: Lexington Books.

Petrick, J. F. (2002). Development of a multi-dimensional scale for measuring the perceived value of a service. Journal of Leisure Research, 34(2), 119-134.

Pliner, P., Freedman, J., Abramovitch, R., \& Darke, P. (1996). Children as consumers: In the laboratory and beyond. In P. Lunt \& A. Furnham (Eds.), Economic socialization: The economic beliefs and behaviours of young people (pp. 35-46). Cheltenham: Edward Elgar Publishing Company.

Poggenpoel, M., Myburgh, C. P. H., \& Van Der Linde, C. H. (2001). Qualitative research strategies as prerequisite for quantitative strategies. Education, 122(2), 408-413.

Pura, M. (2005). Linking perceived value and loyalty in location-based mobile services. Managing Service Quality, 15(6), 509-538.

Rao, A. R., \& Monroe, K. B. (1988). The moderating effect of prior knowledge on cue utilization in product evaluations. Journal of Consumer Research, 15(2), 253-264.

Rao, A. R., \& Monroe, K. B. (1989). The effect of price, brand name, and store name on buyers' perceptions of product quality: An integrative review. Journal of Marketing Research, 26(3), 351-357. 
Rao, A. R., \& Sieben, W. A. (1992). The effect of prior knowledge on price acceptability and the type of information examined. Journal of Consumer Research, 19(2), 256-270.

Reio, T., G. Jr., Petrosko, J., M., Wiswell, A., K., \& Thongsukmag, J. (2006). The measurement and conceptualization of curiosity. The Journal of Genetic Psychology, 167(2), 117-135.

Richards, L. (2005). Handling qualitative data (pp. 207). London: Sage Publications Ltd.

Richards, L., \& Morse, J. (2007). Read me first for a user's guide to qualitative methods (2nd ed.). Thousand Oaks: Sage Publications.

Richardson, P. S., Dick, A. S., \& Jain, A. K. (1994). Extrinsic and intrinsic cue effects on perceptions of store brand quality. Journal of Marketing, 58(4), 2836 .

Richins, M. L. (1997). Measuring emotions in the consumption experience. Journal of Consumer Research, 24(2), 127-146.

Roedder, D. L. (1981). Age differences in children's responses to television advertising: An information-processing approach. Journal of Consumer Research, 8(2), 144-153.

Rogers, A. (2005). Interviewing children using interpretive poetics. In S. Greene \& D. Hogan (Eds.), Researching children's experience. Approaches and methods. London: Sage Publications Ltd.

Roig, J. C. F., Garcia, J. S., Tena, M. A. M., \& Monzonis, J. L. (2006). Customer perceived value in banking services. The International Journal of Bank Marketing, 24(5), 266-283.

Rose, G. M., Boush, D., \& Shoham, A. (2002). Family communication and children's purchasing influence: a cross-national examination. Journal of Business Research, 55(11), 867-873.

Rossiter, J. R. (2002). The C-OAR-SE procedure for scale development in marketing. International Journal of Research in Marketing, 19(4), 305-335.

Rossiter, J. R. (2008). Qualitative research rules. International Journal of Advertising, 27(5), 915-919.

Rossiter, J. R., Percy, L., \& Donovan, R. J. (1991). A better advertising planning grid. Journal of Advertising Research, 31(5), 11-21. 
Sánchez-Fernández, R., Iniesta-Bonillo, M., \& Holbrook, M. (2009). The conceptualisation and measurement of consumer value in services. International Journal of Market Research, 51(1), 93-113.

Scally, R. (1999). The tweeners: 9 to 12 years. Discount Store News, 38(20), 33.

Schaffer, H. R. (2000). Social development. Oxford: Blackwell Publishers Ltd.

Schiffman, L., Bednall, D., Cowley, E., O'Cass, A., Watson, J., \& Kanuk, L. (2001). Consumer behaviour (2nd ed.). Sydney: Prentice Hall.

Schiffman, L., Bednall, D., O'Cass, A., Paladino, A., \& Kanuk, L. (2005). Consumer behaviour (3rd ed.). Frenchs Forest, NSW: Pearson Education Australia.

Shaffer, D. R. (1999). Developmental psychology: Childhood and adolescence (5th ed.). Pacific Grove, California: Brooks/Cole Publishing Company.

Shank, G. D. (2006). Qualitative research: A personal skills approach (2nd ed.). Upper Saddle River, New Jersey: Pearson Education, Inc.

Shapiro, B. P. (1973). Price reliance: Existence and sources. Journal of Marketing Research, 10(3), 286-294.

Sheth, J. N., Newman, B. I., \& Gross, B. L. (1991a). Consumption values and market choice. Cinncinati, Ohio: South Western Publishing Company.

Sheth, J. N., Newman, B. I., \& Gross, B. L. (1991b). Why we buy what we buy: A theory of consumption values. Journal of Business Research, 22(2), 159-170.

Shim, S. (1996). Adolescent consumer decision-making styles: The consumer socialization perspective. Psychology \& Marketing, 13(6), 547-569.

Siegler, R. S. (1991). Childrens thinking (2nd ed.). New Jersey: Prentice Hall.

Siegler, R. S. (1996). Emerging minds. The process of change in children's thinking. Oxford: Oxford University Press.

Sinha, I., \& DeSarbo, W. S. (1998). An integrated approach toward the spatial modeling of perceived customer value. Journal of Marketing Research, $35(2), 236-249$.

Smith, A. (1992). Understanding children's development (3rd ed.). Wellington: Bridget Williams Books Ltd. 
Smith, R. E., \& Swinyard, W. R. (1988). Cognitive response to advertising and trial: Belief strength, belief confidence and product curiosity. Journal of Advertising, 17(3), 3-14.

Snoj, B., Korda, A. P., \& Mumel, D. (2004). The relationships among perceived quality, perceived risk and perceived product value. The Journal of Product and Brand Management, 13(3), 156-167.

Solomon, M. R. (1983). The role of products as social stimuli: A symbolic interactionism perspective. Journal of Consumer Research, 10(3), 319-329.

Sproles, G. B., \& Kendall, E. L. (1986). A methodology for profiling consumers' decision-making styles. The Journal of Consumer Affairs, 20(2), 267.

Squire, L. (1986). Mechanisms of memory. Science, 232, 1612-1619.

Srinivasan, T. C. (1987). An integrative approach to consumer choice. Advances in Consumer Research, 14(1), 96-100.

Stephens, L. F., \& Moore, R. L. (1975). Price accuracy as a consumer skill. Journal of Advertising Research, 15(4), 27-34.

Strauss, A. (1952). The development and transformation of monetary meaning in the child. American Sociological Review, 17, 275-286.

Strauss, A. (1954). The development of conceptions of rules in children. Child Development, 25, 193-208.

Strauss, A., \& Corbin, J. (1998). Grounded theory methodology. In N. K. Denzin \& Y. S. Lincoln (Eds.), Strategies of qualitative inquiry (pp. 158-183). Thousand Oaks, California: Sage Publications, Inc.

Suri, R., \& Monroe, K. B. (2003). The effects of time constraints on consumers' judgments of prices and products. Journal of Consumer Research, 30(1), 92104.

Sweeney, J. C., \& Soutar, G. N. (2001). Consumer perceived value: The development of a multiple item scale. Journal of Retailing, 77(2), 203-220.

Sweeney, J. C., Soutar, G. N., \& Johnson, L. W. (1999). The role of perceived risk in the quality-value relationship: A study in a retail environment. Journal of Retailing, 75(1), 77-105.

Teas, R. K., \& Agarwal, S. (2000). The effects of extrinsic product cues on consumers' perceptions of quality, sacrifice, and value. Academy of Marketing Science. Journal, 28(2), 278-290. 
Tsai, S. (2005). Utility, cultural symbolism and emotion: A comprehensive model of brand purchase value. International Journal of Research in Marketing, 22(3), 277-291.

Turner, J., \& Brandt, J. (1978). Development and validation of a simulated market to test children for selected consumer skills. The Journal of Consumer Affairs, 12(2), 266-278.

Valkenburg, P. M., \& Cantor, J. (2001). The development of a child into a consumer. Applied Developmental Psychology, 22, 61-72.

Vanhuele, M., \& Dreze, X. (2002). Measuring the price knowledge shoppers bring to the store. Journal of Marketing, 66(4), 72-85.

Veale, A. (2005). Creative methodologies in participatory research with children. In S. Greene \& D. Hogan (Eds.), Researching children's experience. Approaches and methods (pp. 253-272). London: Sage Publications Ltd.

Viswanathan, M., Childers, T. L., \& Moore, E. S. (2000). The measurement of intergenerational communication and influence on consumption: Development, validation, and cross-cultural comparison of the IGEN scale. Academy of Marketing Science. Journal, 28(3), 406-424.

Vygotsky, L. S. (1978). Mind in society: The development of higher psychological processes (M. Cole, Trans.). Cambridge: Harvard University Press.

Wang, E. S.-T. (2010). Impact of multiple perceived value on consumers' brand preference and purchase intention: A case of snack foods. Journal of Foods Products Marketing, 16(4), 386-397.

Ward, S. (1974). Consumer socialization. Journal of Consumer Research, 1(2), 1-14.

Ward, S., Wackman, D., \& Wartella, E. (1977). How children learn to buy. Beverly Hills, California: Sage Publications

Woodall, T. (2003). Conceptualising 'value for the customer': An attributional, structural and dispositional perspective. Academy of Marketing Science Review(2003), 1-42.

Woodruff, R. B. (1997). Customer value: The next source for competitive advantage. Academy of Marketing Science. Journal, 25(2), 139-153.

Yin, R. K. (2009). Case study research: Design and methods. Los Angeles: Sage Publications Inc. 
Young, S., \& Feigin, B. (1975). Using the benefit chain for improved strategy fromulation Journal of Marketing, 39(3), 72-74.

Zambardino, A., \& Goodfellow, J. (2007). Doing 'affective' in branding? Journal of Marketing Management, 23(1/2), 27-37.

Zarantonello, L., \& Luomala, H. T. (2011). Dear Mr Chocolate: Constructing a typology of contextualized chocolate consumption experiences through qualitative diary research. Qualitative Market Research, 14(1), 55-82.

Zeithaml, V. A. (1988). Consumer perceptions of price, quality, and value: a meansend model and synthesis of evidence. Journal of Marketing, 52(3), 2-22. 
Appendix 1 Diary Materials 


\section{School Contact: Principal}

\section{Obtaining appointment with principal:}

Hello, my name is Janine Williams, I am a student at Victoria University of Wellington and I am working on a research project for my $\mathrm{PhD}$. The purpose of this research is to gain an understanding of what the concept of value means to children and young people. (The study involves two types of qualitative research: diaries and in-depth interviews.) As it is exploratory research relatively small numbers of participants are required.

Would it be possible to make an appointment to come and discuss my research with you? This would provide an opportunity for me to show you an information sheet regarding the research and answer any questions you may have. Thank you so much for your time.

School

Principal

Appointment 


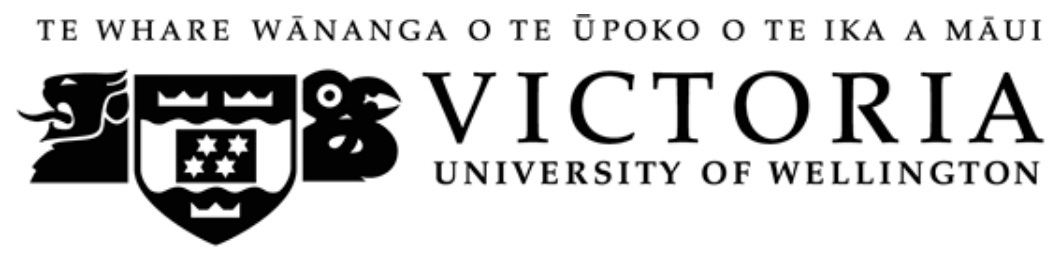

Victoria University of Wellington

Schools Information Regarding Research

Diary Study

A Study of Children's Understanding of Value

Researcher: Janine Williams, School of Marketing and International Business

I am a postgraduate student in marketing at Victoria University of Wellington. I am undertaking a $\mathrm{PhD}$ thesis and intend examining age differences in the way 8-14 year old children understand product value when making a purchase. I am well trained in research and have read extensively from the psychology literature in this area. A copy of a police check on me is included with this letter. The University requires approval for research involving children, and the study has been assessed and approved by the Victoria University of Wellington Human Ethics Committee.

The research involves a diary study requiring children to fill out a simple diary each time they purchase something over a two week period. They will be asked a few questions regarding the reasoning for their choice. I would like to visit the children on three occasions, once to explain the research and gain permission, once to give out the diaries and once to check on their progress. Each visit would take about ten minutes. For this phase of the research I will require ten children of each age group, (year 3, year 4, year 5 and year 6) from your school.

The child's teacher and I would need to explain to the children what the purpose of the diary will be and that they may withdraw from the research at any stage without explanation. Participation is entirely voluntary and parental consent will be obtained prior to conducting the research. It will be explained to parents that they have the right to change their mind at any stage and can withdraw their child from the research by contacting me.

The information collected will be confidential. No identifying information regarding the child or the school will be used in any publication resulting from the research, including the thesis itself or publication in scholarly journals. My supervisors and I will be the only people with access to the diaries and no material identifying the participants will be included. Two years after the completion of my research project all recordings and transcripts will be destroyed.

If you have any questions about my research, please do not hesitate to contact me or my supervisors. 


\author{
Researcher: Janine Williams $M S c$ \\ 144 Khandallah Rd \\ Khandallah \\ Wellington \\ Phone: (04) 4796116 or 0274901069 \\ Email: Janine.Williams@vuw.ac.nz \\ Supervisors Professor Peter Thirkell \\ School of Marketing and International Business \\ Phone: (04) 4635086 \\ Email: Peter.Thirkell@vuw.ac.nz \\ Dr Michel Rod \\ School of Marketing and International Business \\ Phone: (04) 4635152 \\ Email: Michel.Rod@vuw.ac.nz
}

If you consent to your school participating in the research project, please sign the attached consent form. If you would like a summary of the findings please indicate this by circling YES on the consent form and providing relevant details.

Thank you for your consideration,

Yours sincerely

Janine Williams $M S c$ 


\section{Victoria University of Wellington \\ School Consent Form}

\section{A Study of Children's Understanding of Value}

I have been given and understood the explanation of this research project.

Please circle: $\quad$ Yes

I have had an opportunity to ask questions and have had them answered to my satisfaction.

Please circle: $\quad$ Yes

I understand that I may withdraw my school, any class or child from this project before data collection is complete.

Please circle: Yes

I understand that any information participants provide will be confidential; no

information which identifies individuals will be used.

Please circle: Yes

I also understand the diaries will be stored securely for two years after the research is completed and then destroyed.

Please circle: $\quad$ Yes

I agree that (with parental consent) students from School may take part in this research.

Signed:.....

Date:

Name of Principal:

I would like to be sent a summary of the report. Please circle:

Yes/ No

If you would like to receive a summary of the results of this research please provide your postal address or email address. 


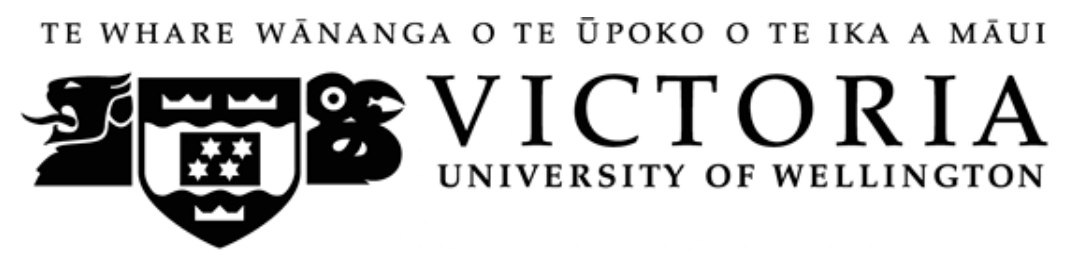

\author{
Victoria University of Wellington \\ Parents/ Guardians Information Regarding Research \\ Diary Study
}

\begin{abstract}
A Study of Children's Understanding of Value
Researcher: Janine Williams, School of Marketing and International Business

Dear Parent/ Guardian

I am a postgraduate student in marketing at Victoria University of Wellington. I am undertaking a $\mathrm{PhD}$ thesis and am examining age differences in the way children understand value when making a purchase. Before your child is involved in this research the University requires your prior approval.
\end{abstract}

The research involves children filling out diaries for a two week period where they will be required to answer questions about what influences their choice when purchasing products.

The child's teacher and I will explain to your child what the purpose of the research is and it will be explained that they may withdraw from the research at any stage without explanation. Parents have the right to change their mind at any stage and can withdraw their child from the research by contacting me.

The information collected will be confidential with no identifying information used in any publication resulting from the research, including the thesis itself or publication in scholarly journals. My supervisors and I will be the only people with access to the diaries and no material identifying the participants will be included. Two years after the completion of my research project all recordings and transcripts will be destroyed.

I have been given consent from the principal of School to approach you in order to gain consent for your child to participate in the research.

If you have any questions about my research, please do not hesitate to contact me or my supervisors.

Researcher: Janine Williams $M S c$

144 Khandallah Rd

Khandallah

Wellington

Phone: (04) 4796116 or 0274901069

Email: Janine.williams@vuw.ac.nz 
Supervisors Professor Peter Thirkell

School of Marketing and International Business

Phone: (04) 4635086

Email: Peter.thirkell@vuw.ac.nz

Dr Michel Rod

School of Marketing and International Business

Phone: (04) 4635152

Email: Michel.Rod@vuw.ac.nz

To participate in this research, you are required to complete a short questionnaire which will allow us to investigate whether differences in children's understanding of value are related to their monetary experience or the socioeconomic status of their family.

If you consent to your child participating in the research project, please return the attached consent form and questionnaire to your child's teacher. If you would like a summary of the findings please indicate this by circling YES on the consent form and providing relevant details.

Thank you for your consideration,

Yours sincerely

Janine Williams $M S c$ 
Victoria University of Wellington

Parental/ Guardian Consent Form

A Study of Children's Understanding of Value

I have been given and understood the explanation of this research project.

Please circle: $\quad$ Yes

I have had an opportunity to ask questions and have had them answered to my satisfaction.

Please circle: $\quad$ Yes

I understand that I may withdraw my child (or any information my child has provided) from this project before data collection is complete.

Please circle: $\quad$ Yes

I understand that any information my child provides will be confidential; no information which identifies them individually will be used.

Please circle: $\quad$ Yes

I understand that the diaries will be stored securely for two years after the research is completed and then destroyed.

Please circle: $\quad$ Yes

I agree that who is under my

guardianship, may take part in this research.

Signed:

Date:

Name of parent/guardian (please print clearly):

I would like to be sent a summary of the report. Please circle:

Yes/ No

If you would like to receive a summary of the results of this research please provide your postal address or email address. 


\section{Diary Study \\ What Do Children Think About Buying Things?}

Janine is doing a study for university to find out what kids think about when they buy things. She will give you a diary and when you buy something you will be asked to answer some questions. You don't have to do the research if you don't want to and you can stop at any time. There are no wrong or right answers and it doesn't matter if you don't know what to write.

Only Janine will read the diary and nothing will have your name on it. If you are happy to be part of this special project please tick the boxes you agree with.

I know about the project

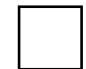

I know I can stop at any time

I know Janine will write a story about what the children tell her

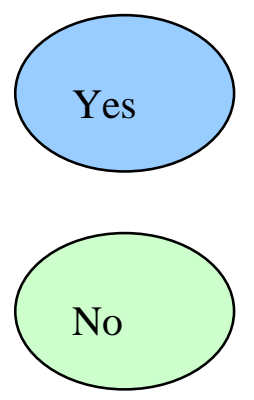

I would like to take part

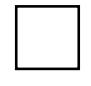

Name

Age

I would not like to take part
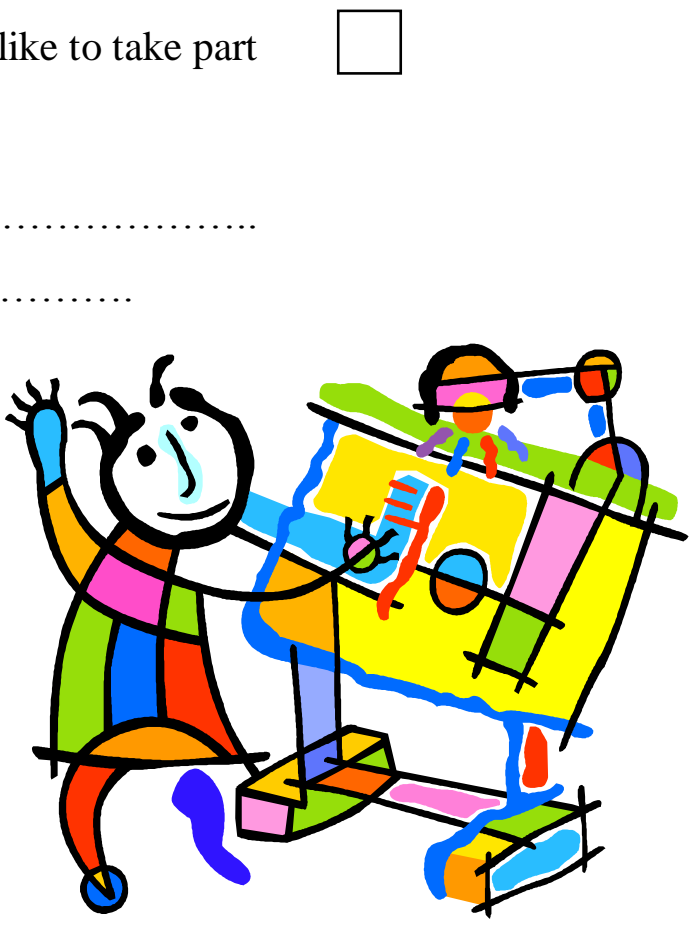


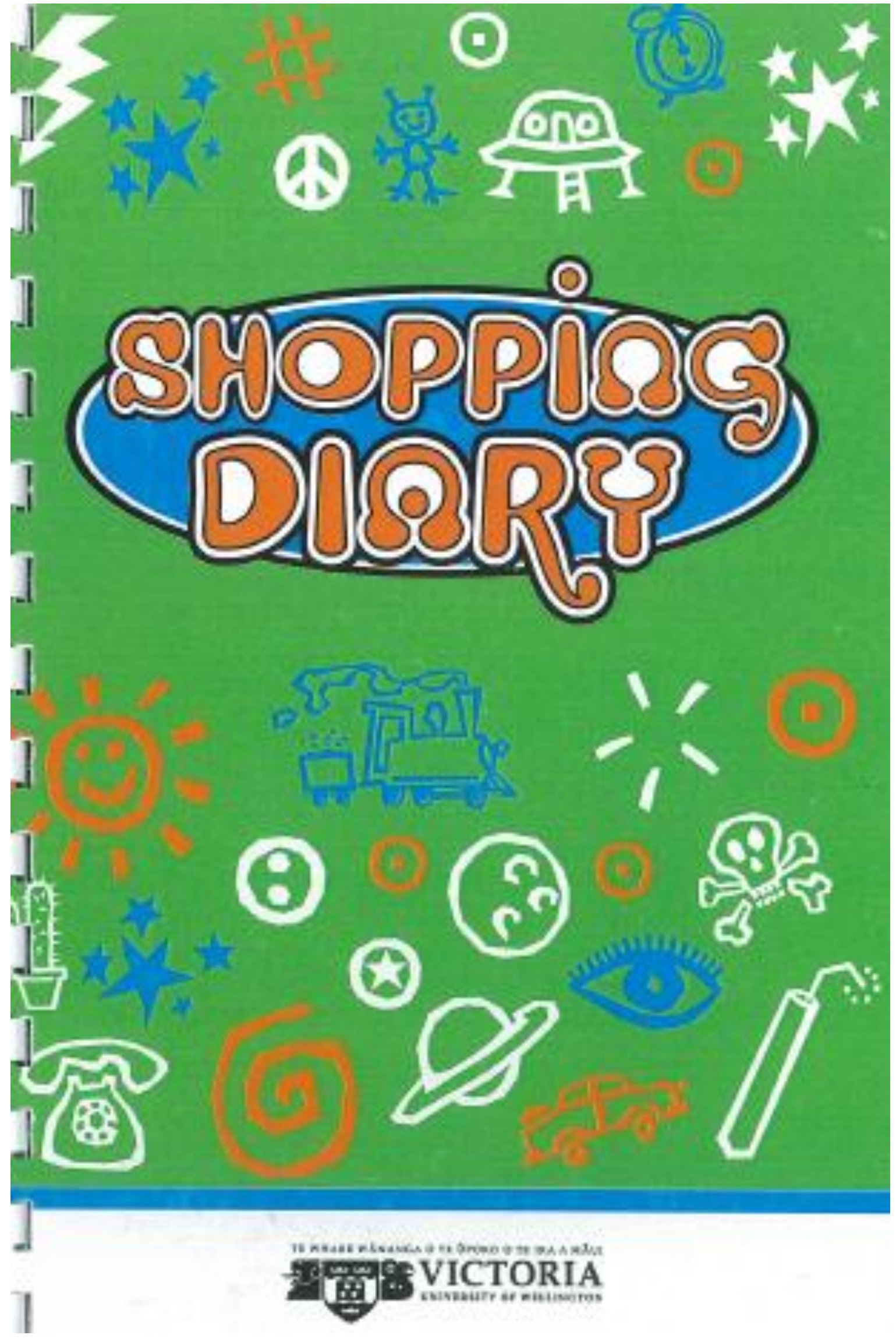


1]

I Shopping Diary

Thank you for agreeing to take part in this study. Before you start please fill in the first five questions by ticking the boxes which apply to you.

Q1. How old are you?

$\begin{array}{lllllll}\square_{11} & \square_{11} & \square_{12} & \square & \square & \square & \\ 1 & \square_{15} & \square_{16} & & \end{array}$

02. Are you a boy or a girl?

I Boy $\square$ Girl

03. How many children are in your family?

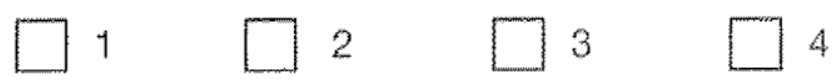

$\square 5$ or more

Q4. What position are you in the family?
$\square 1^{\text {st }}$ child
$\square 2^{\text {nd }}$ child
$\square 3^{\text {rd }}$ child
$\square 4^{\text {th }}$ child
$\square 5^{\text {th }}$ child

Other, please write which child you are

Q5. What school do you attend? 
Hi there,

Please write in this diary every time you buy something

yourself. You will have this diary for two weeks. Please take this diary with you and answer the questions as soon as you can after buying the itern.

Item one

1. What have you bought?

2. How did you choose what to buy?

(Please tell me everything you thought about)

3. How did you choose this EXACT one

rather than other similar items? 
4. Would you tell your friends about this item (tick yes or no)

$\square$ Yes $\square$ No

5. What would you tell them?

6. When you bought this product how excited did you feel?

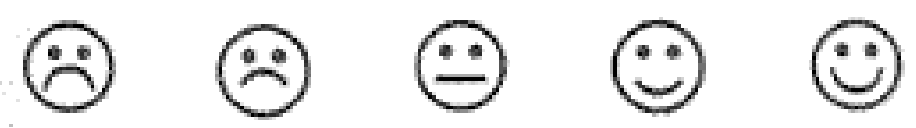

7. Why did you feel like this?

8. Did you use your own money to buy this ifem?

Yes, I used my own money.

No, someone else bought it for me.

9. If you used your own money, was it a glift, payment for jobs or pocket money? Please explain. 
Appendix 2 In-depth Interview Materials 


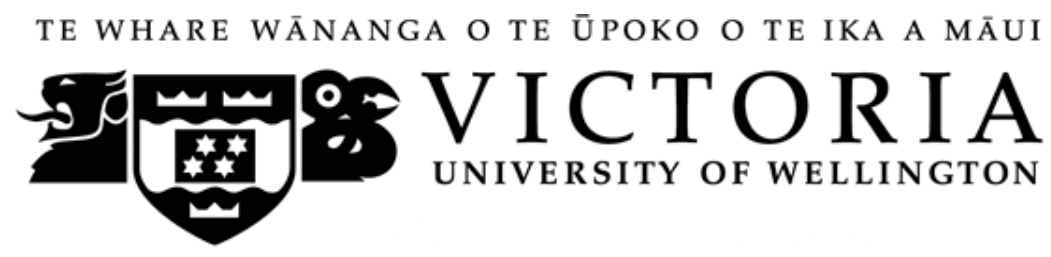

Victoria University of Wellington

Schools Information Regarding Research

In-depth Interviews

A Study of Children's Understanding of Value

Researcher: Janine Williams, School of Marketing and International Business

I am a postgraduate student in marketing at Victoria University of Wellington. I am undertaking a $\mathrm{PhD}$ thesis and intend examining age differences in the way 8-14 year old children understand product value when making a purchase. I am well trained in research and have read extensively from the psychology literature in this area. A copy of a police check on me is included with this letter. The University requires approval for research involving children, and the study has been assessed and approved by the Victoria University of Wellington Human Ethics Committee.

The research involves individual interviews with children where they will discuss what influences their perceptions of value when purchasing products such as confectionary, clothes or toys. Children will be asked to bring in products or product packaging of products they have bought themselves and will be asked to give their thoughts. They will then be provided with extra information which we know adults use to assess value. Examples include prices, brands and specific product information. The discussion should take about half an hour and will be audiorecorded. I would like to hold discussions at your school which would require the availability of a quiet space. For this phase of the research I will require up to ten children of each age, $8,9,10,11,12$, and 13 years.

The child's teacher and I would need to explain to the child what the purpose of the discussion will be and that they may withdraw from the research at any stage without explanation. Participation is entirely voluntary and parental consent will be obtained prior to conducting the research. It will be explained to parents that they have the right to change their mind at any stage and can withdraw their child from the research by contacting me.

The information collected will be confidential. No identifying information regarding the child or the school will be used in any publication resulting from the research, including the thesis itself or publication in scholarly journals. My supervisors, a university transcriber and I will be the only people with access to the recordings and transcripts of the discussions and no material identifying the participants will be included. Two years after the completion of my research project all recordings and transcripts will be destroyed. 
If you have any questions about my research, please do not hesitate to contact me or my supervisors.

\author{
Researcher: Janine Williams $M S c$ \\ 144 Khandallah Rd \\ Khandallah \\ Wellington \\ Phone: (04) 4796116 or 0274901069 \\ Email: Janine.williams@ vuw.ac.nz \\ Supervisors Professor Peter Thirkell \\ School of Marketing and International Business \\ Phone: (04) 4635086 \\ Email: Peter.thirkell@vuw.ac.nz \\ Dr Michel Rod \\ School of Marketing and International Business \\ Phone: (04) 4635152 \\ Email: Michel.Rod@vuw.ac.nz
}

If you consent to your school participating in the research project, please sign the attached consent form. If you would like a summary of the findings please indicate this by circling YES on the consent form and providing relevant details.

Thank you for your consideration,

Yours sincerely

Janine Williams $M S c$ 


\section{Victoria University of Wellington \\ School Consent Form}

A Study of Children's Understanding of Value

I have been given and understood the explanation of this research project.

Please circle: $\quad$ Yes

I have had an opportunity to ask questions and have had them answered to my satisfaction.

Please circle: $\quad$ Yes

I understand that I may withdraw my school, any class or child from this project before data collection is complete.

Please circle: Yes

I understand that any information participants provide will be confidential; no information which identifies individuals will be used.

Please circle: $\quad$ Yes

I also understand that the interviews will be audio-recorded. I understand that the recordings and transcripts of the discussion will be stored securely for two years after the research is completed and then destroyed.

Please circle: $\quad$ Yes

I agree that (with parental consent) students from School may take part in this research.

Signed:

Date:

Name of Principal:

I would like to be sent a summary of the report. Please circle:

Yes

\section{If you would like to receive a summary of the results of this research please provide your postal address or email address.}




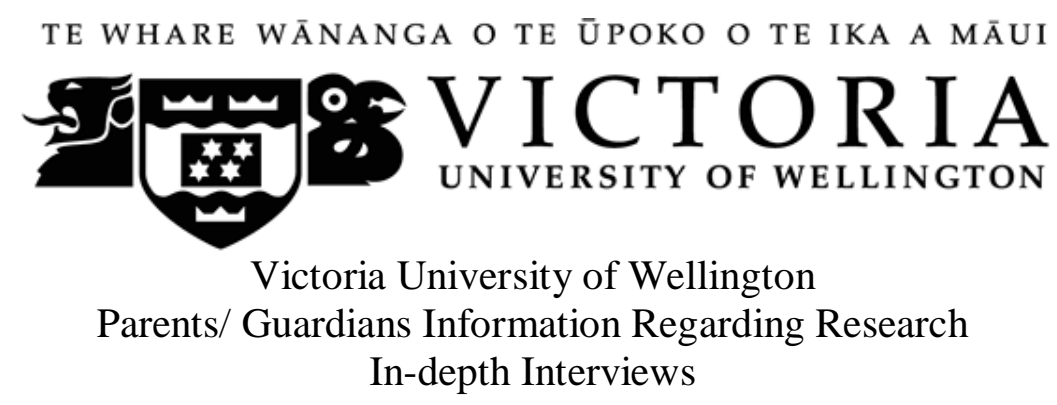

A Study of Children's Understanding of Value

Researcher: Janine Williams, School of Marketing and International Business

Dear Parent/ Guardian

I am a postgraduate student in marketing at Victoria University of Wellington. I am undertaking a $\mathrm{PhD}$ thesis and am examining age differences in the way children understand product value when making a purchase. I am married with three children of my own and am well used to talking to children. Before your child is involved in this research the University requires your prior approval.

The research involves discussions with children where they will discuss what influences their perceptions of value when purchasing products. Children will be asked to bring in products or product packaging of products they have bought themselves and will be asked to give their thoughts. They will then be provided with extra information which we know adults use to assess value. Examples include prices, brands and specific product information. The discussion should take about half an hour and will be audio-recorded Discussions will be held at your child's school.

The child's teacher and I will explain to your child what the purpose of the discussion is and it will be explained that they may withdraw from the research at any stage without explanation. Parents have the right to change their mind at any stage and can withdraw their child from the research by contacting me.

The information collected will be confidential with no identifying information used in any publication resulting from the research, including the thesis itself or publication in scholarly journals. My supervisors, a university transcriber and I will be the only people with access to the recordings and transcripts of the discussions and no material identifying the participants will be included. Two years after the completion of my research project all recordings and transcripts will be destroyed.

I have been given consent from the principal of School to approach you in order to gain consent for your child to participate in the research.

If you have any questions about my research, please do not hesitate to contact me or my supervisors. 


\author{
Researcher: Janine Williams $M S c$ \\ 144 Khandallah Rd \\ Khandallah \\ Wellington \\ Phone: (04) 4796116 or 0274901069 \\ Email: Janine.williams@ vuw.ac.nz \\ Supervisors Professor Peter Thirkell \\ School of Marketing and International Business \\ Phone: (04) 4635086 \\ Email: Peter.thrikell@vuw.ac.nz \\ Dr Michel Rod \\ School of Marketing and International Business \\ Phone: (04) 4635152 \\ Email: Michel.Rod@vuw.ac.nz
}

To participate in this research, you are required to complete a short questionnaire which will allow us to investigate whether differences in children's understanding of value are related to their monetary experience or the socioeconomic status of their family.

If you consent to your child participating in the research project, please return the attached consent form and questionnaire to your child's teacher. If you would like a summary of the findings please indicate this by circling YES on the consent form and providing relevant details.

Thank you for your consideration,

Yours sincerely

Janine Williams $M S c$ 
Victoria University of Wellington

Parental/ Guardian Consent Form

\section{A Study of Children's Understanding of Value}

I have been given and understood the explanation of this research project.

Please circle: $\quad$ Yes

I have had an opportunity to ask questions and have had them answered to my satisfaction.

Please circle: $\quad$ Yes

I understand that I may withdraw my child (or any information my child has provided) from this project before data collection is complete.

Please circle: Yes

I understand that any information my child provides will be confidential; no information which identifies them individually will be used.

Please circle: $\quad$ Yes

I also understand that the interviews will be audio-recorded. I understand that the recordings and transcripts of the discussion will be stored securely for two years after the research is completed and then destroyed.

Please circle: $\quad$ Yes

I agree that who is under my

guardianship, may take part in this research.

Signed:

Date:

Name of parent/guardian (please print clearly):

I would like to be sent a summary of the report. Please circle:

Yes

If you would like to receive a summary of the results of this research please provide your postal address or email address. 


\section{What Do Children Think About Buying Things?}

Janine is doing a study for university to find out what kids think about when they buy things. She will ask you to bring in something you have bought yourself and we will talk about your ideas. You don't have to talk if you don't want to and you can stop talking at any time. There are no wrong or right answers and it doesn't matter if you don't know what to say.

The talk will be recorded so Janine can write down what children tell her. Nothing will have your name on it. If you are happy to be part of this special project please tick the boxes you agree with.

I know about the project

I know I can leave at any time

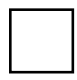

I know I will be recorded

I know Janine will write a story about what the children tell her

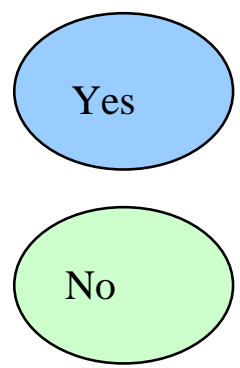

I would like to take part

I would not like to take part

Name.

Age

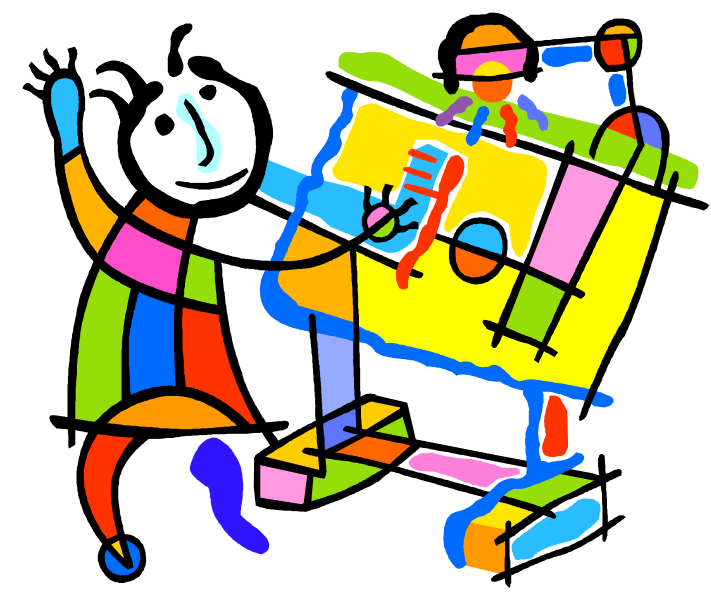




\section{Interview Guide: Children, Young people and Value}

Following is a set of semi-structured questions that will be asked in the interviews. The purpose of this interview is to gain an understanding of what the concept of value means to children and young people. Interview length is estimated to be approximately half an hour. Interview style and questions will be modified according to the age of participants.

\section{Obtaining verbal consent:}

As you know, I'm a PhD student at Victoria University in Wellington working on a project about what value means to children and young people. I am doing this research in order to understand how you choose things when you are shopping. In this interview I will ask you about the things you buy and how and why you choose them.

Participating in this project is entirely voluntary. If you don't want to have the interview you don't have to. If you don't mind talking to me I would like to record this interview to make sure I have an accurate record of what our conversation is like. Is it okay to go ahead with the questions? If you don't want to answer any of the questions, that's fine and if there is something that isn't clear please ask. This is not a test; there are no right or wrong answers. The main thing is that I want you to feel really comfortable. 


\begin{tabular}{|c|c|c|}
\hline \multicolumn{3}{|c|}{ Interview Protocol Children's Perceived Value } \\
\hline & Question & Related concept \\
\hline & $\begin{array}{l}\text { Age } \\
\text { Gender } \\
\text { No of children in family } \\
\text { and position in family } \\
\text { Decile of school } \\
\text { Mother's occupation } \\
\text { Father's occupation }\end{array}$ & \\
\hline & $\begin{array}{l}\text { Shopping behaviour } \\
\text { Do you have money of } \\
\text { your own? How much do } \\
\text { you have? } \\
\text { Do you shop for things } \\
\text { yourself? } \\
\text { What kinds of things do } \\
\text { you shop for? }\end{array}$ & \\
\hline Q1 & $\begin{array}{l}\text { a. Thinking about the } \\
\text { things you normally buy, } \\
\text { when you go shopping } \\
\text { how do you choose } \\
\text { something? } \\
\text { PROBE } \\
\text { b. Could you tell me } \\
\text { things you might think } \\
\text { about when choosing } \\
\text { something to buy? } \\
\text { PROBE }\end{array}$ & Perceived value/ consumption values \\
\hline Q2 & $\begin{array}{l}\text { a. Thinking about this } \\
\text { (product) that you have } \\
\text { brought into the } \\
\text { interview how did you } \\
\text { choose which one to buy? } \\
\text { b. What did you want to } \\
\text { know about it? } \\
\text { c. How did you know } \\
\text { which was the best } \\
\text { (product)? }\end{array}$ & Perceived value (product specific) \\
\hline
\end{tabular}




\begin{tabular}{|c|c|c|}
\hline & $\begin{array}{l}\text { d. What information } \\
\text { would you need to know } \\
\text { which was the best } \\
\text { value? }\end{array}$ & \\
\hline & & Dimensions of Value if Relevant/ Necessary \\
\hline Q3 & $\begin{array}{l}\text { a. What about the price } \\
\text { b. Would it influence } \\
\text { your decision? } \\
\text { c. What price would you } \\
\text { expect to pay for a } \\
\text { (Product brought in to } \\
\text { interview)? } \\
\text { d. What price would be } \\
\text { expensive for this? } \\
\text { e. What price would be } \\
\text { cheap? }\end{array}$ & Price \\
\hline Q4 & $\begin{array}{l}\text { What about what your } \\
\text { friends think? }\end{array}$ & Social \\
\hline Q5 & What about brands? & Brand related \\
\hline Q6 & $\begin{array}{l}\text { What about if you just } \\
\text { like something? }\end{array}$ & Feelings/ emotion \\
\hline Q7 & What about the amount? & Quantity \\
\hline
\end{tabular}


Appendix 3 Collages 


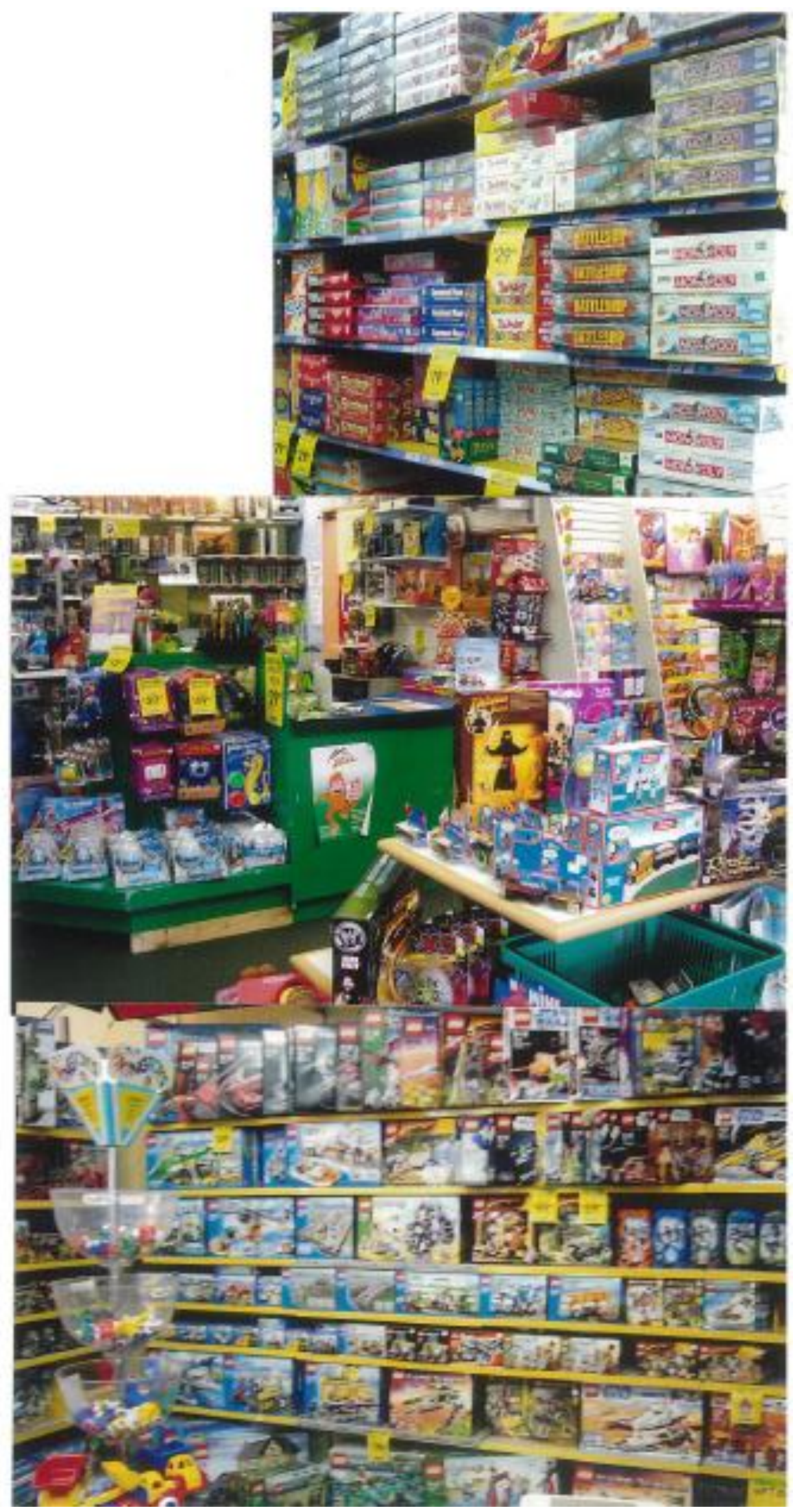




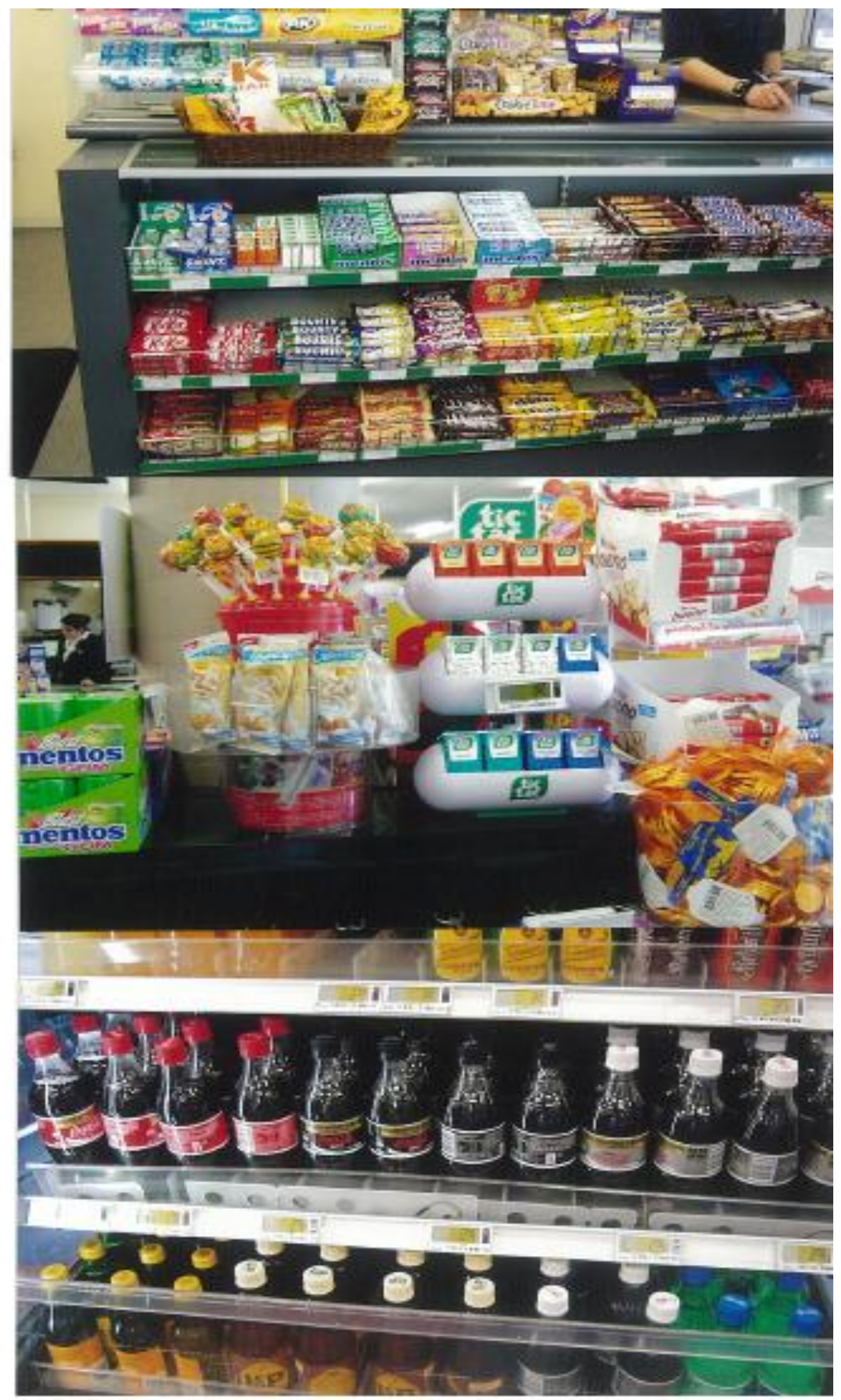




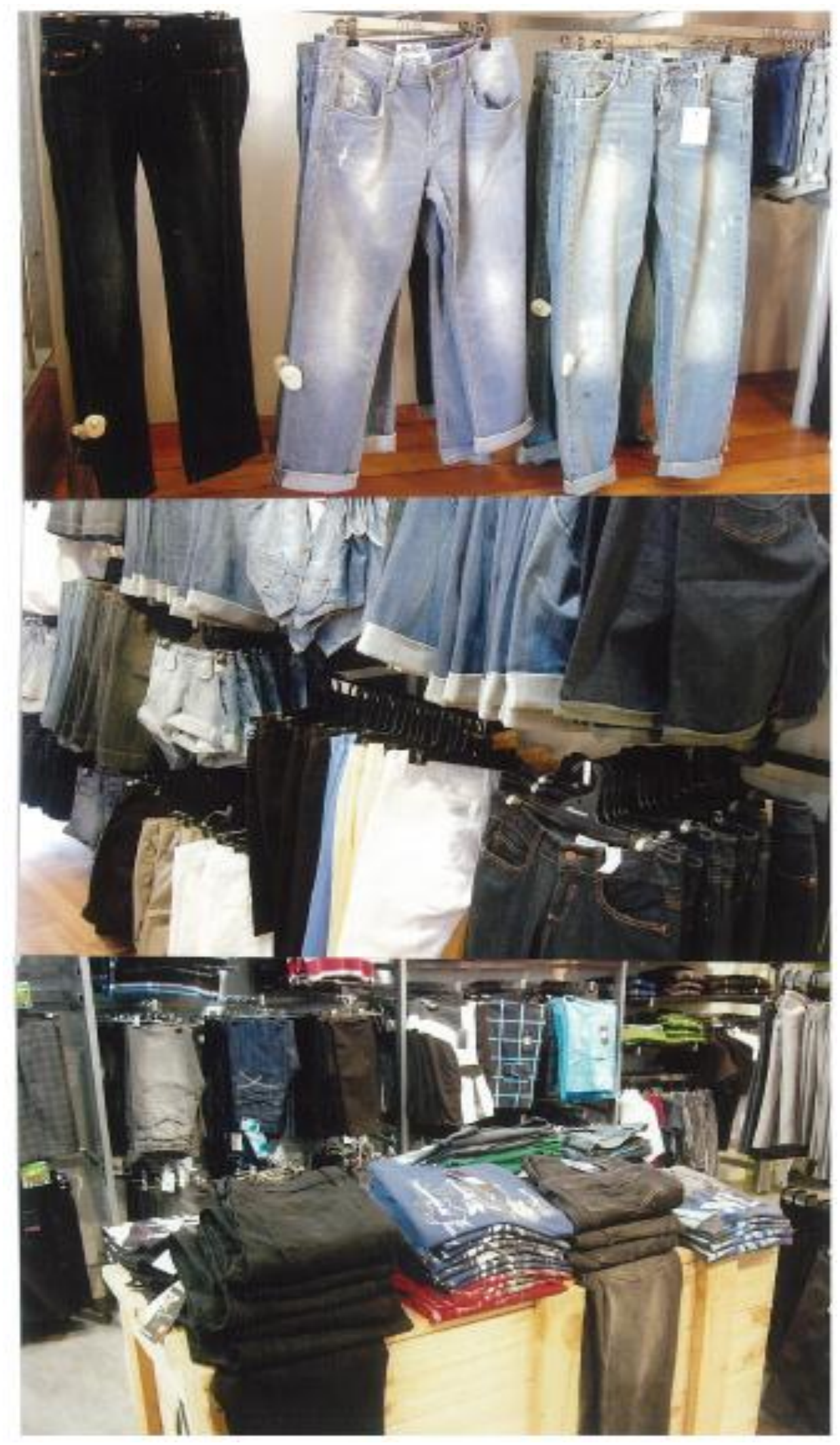


Appendix 4 Memos 


\section{Examples of Memos}

\section{Case Based Memo}

- This boy is 9 .

- He is highly influenced by friends and parents.

- He buys Pokemon cards as these are popular at school. He first got one given to him then his father bought him a set.

- His parents are trying to teach him consumer skills.

- He buys on popularity with friends and products he can use and share with friends, this is the utility they offer him.

- His place of purchase is limited by where his parents take him.

- He knows the prices and places he can purchase which he accepts and purchases what he can afford. His sense of value is limited to what he likes what is popular with his friends what he knows is good and whether he can afford it.

- He only shops with parents.

- He buys things he knows about through friends or TV.

- He only buys from the categories of toys or food and his parents control purchase from other categories such as clothes.

- Parents control the amount he spends.

- Value driven by pleasure and influence of friends and TV.

- Brands identify product therefore related to knowing or prior knowledge of product. 


\section{Concept based Memos}

\section{Perceived Value}

"Well I sort of look at it and if it's like, if I think it's like over-priced I will sort of, like leave and see if I can find a better bargain somewhere. And sometimes I have a good look at it, but sometimes - especially with food - I look at the used by dates and like if you go to fairs and such sometimes they put it on sale but it's like past used by date and you have to like, you have to see if it would be nice to eat and sort of like a wholesome decision to make".

\section{So how would you know if it would be nice to eat?}

'We' (kids) wouldn't really go and buy something like vegetables.

She talks about "looking at it" a couple of times but doesn't say what she looks for other than the "price" here. Under the concept of price come minor properties that help define how the concept of price is considered, whether it is acceptable to her, she mentions that if it is priced too high she will look elsewhere and if it is a comparatively "low price" she will be concerned about freshness.

Quality in terms of "freshness" is considered, particularly in the context of fairs. Fairs are possibly seen as somewhere people get rid of products and quality may be variable.

Whether it will "taste good" is an important concept. I'm not sure that this implies quality under the definition in the literature of superiority/excellence. It might be more about a pleasurable experience. Explore further

\section{Theoretical Memo}

\section{Summary memo Years 7 and 8}

The core concept of value comes through in all the interviews in children's consumer decision making. The conditions for value with these very young children include affordability which is influenced by how much money they get.

Another central concept is the knowledge or the experience with the product which reduces perceived risk (product related) and enhances the perceived value Parents influence considerations (functional value in particular) 
The fact that they are limited often in where they can purchase influences the value of products as they cannot shop around - convenience a factor

Emotional value is important

Sensory evaluation is very important - both food /non food

Brand influences choice for child relevant products

Brand identifies products

Price - reference prices known

They are influenced by not wanting to waste money

The functional utility of the products they purchase particularly for durable goods 